


\section{Activating inactive citizens through the organized sports setting: a hurdle race}

Linda Ooms 


\section{COLOFON}

Activating inactive citizens through the organized sports setting: a hurdle race Linda Ooms

ISBN/EAN: 978-90-393-7311-8

Copyright (c) 2020 Linda Ooms

All rights reserved. No part of this thesis may be reproduced, stored or transmitted in any way or by any means without the prior permission of the author, or when applicable, of the publishers of the scientific papers.

Layout and design by Dagmar van Schaik | persoonlijkproefschrift.nl Printed by Ipskamp Printing | proefschriften.net 
Activating inactive citizens through the organized sports setting:

a hurdle race

\section{Activeren van inactieve burgers in de georganiseerde sportomgeving: een weg met hindernissen \\ (met een samenvatting in het Nederlands)}

\section{Proefschrift}

ter verkrijging van de graad van doctor aan de Universiteit Utrecht

op gezag van de

rector magnificus, prof. dr. H.R.B.M. Kummeling, ingevolge het besluit van het college voor promoties

in het openbaar te verdedigen op

donderdag 10 september 2020 des ochtends te 11.00 uur

door

\section{Linda Ooms}

geboren op 5 april 1983

te Warnsveld 
PROMOTOREN

Prof. dr. C. Veenhof

Prof. dr. D.H. de Bakker ${ }^{\dagger}$

\section{COPROMOTOREN}

Dr. C.J. Leemrijse

Dr. D. Collard

The research presented in this thesis was performed at the Netherlands Institute for Health Services Research (NIVEL), Utrecht, and the Mulier Institute, Utrecht, The Netherlands.

This study was partly funded by the Netherlands Olympic Committee and Netherlands Sports Federation (NOC*NSF).

Financial support for publication of this thesis has been kindly provided by NOC*NSF, NIVEL and the Mulier Institute. 


\section{CONTENTS}

CHAPTER 1

General introduction and thesis outline

CHAPTER 2

Effectiveness of Start to Run, a 6-week training program for novice runners, on increasing health-enhancing physical activity: a controlled study

CHAPTER 3

The Start2Bike program is effective in increasing health-enhancing physical activity: a controlled study

\section{CHAPTER 4}

Characteristics of insufficiently active participants that benefit from health-enhancing physical activity (HEPA) promotion programs implemented in the sports club setting

CHAPTER 5

Sporting programs for inactive population groups: factors influencing implementation in the organized sports setting

CHAPTER 6

Sporting programs aimed at inactive population groups in the Netherlands: factors influencing their long-term sustainability in the organized sports setting

CHAPTER 7

General discussion

Summary

Samenvatting (summary in Dutch)

Dankwoord (acknowledgements)

Curriculum vitae

List of publications 


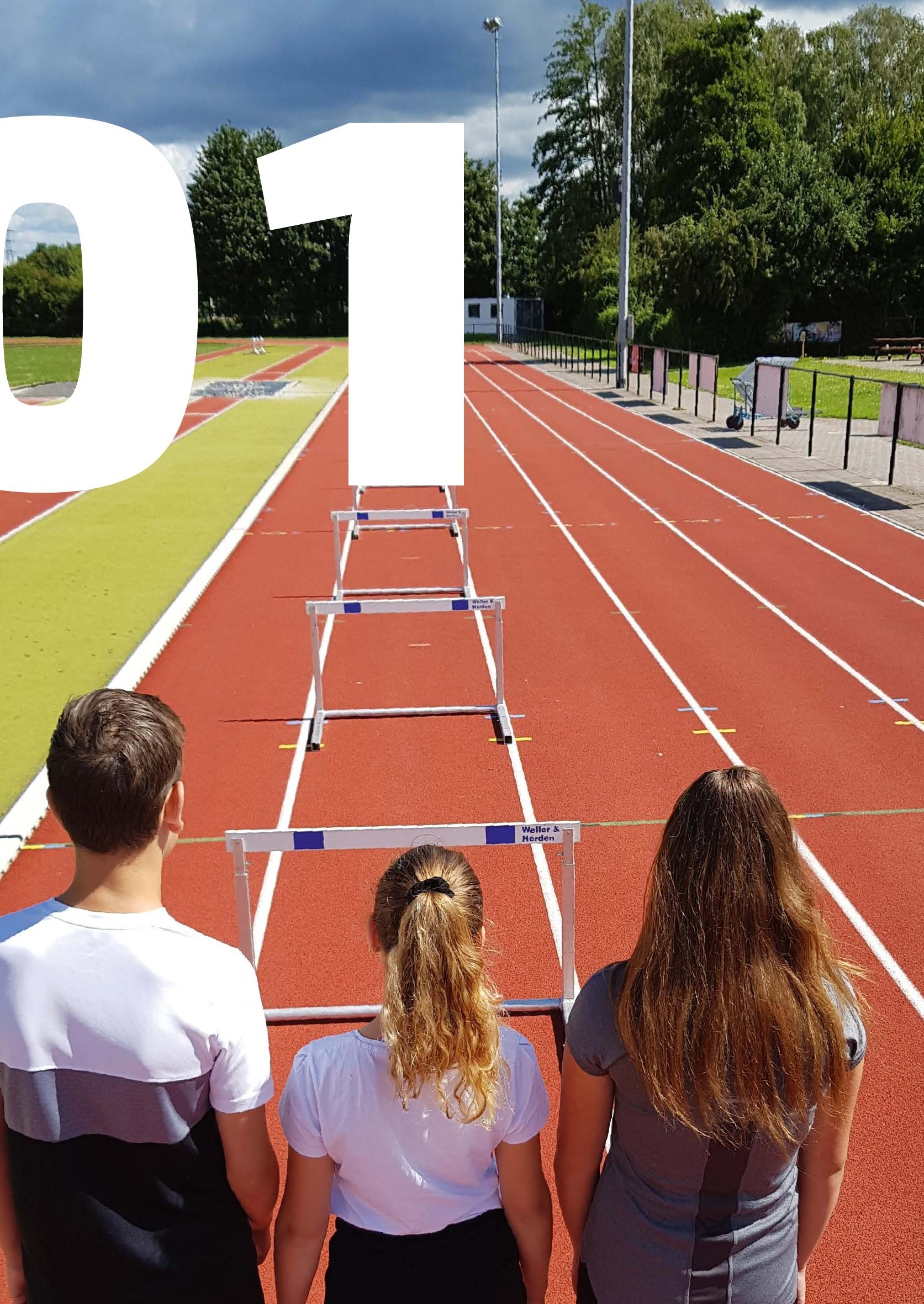




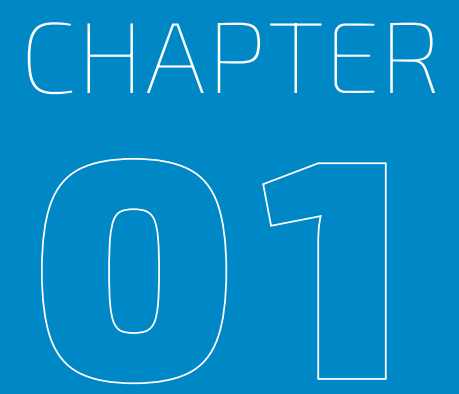

General introduction and thesis outline 


\section{Physical activity and health}

Regular physical activity plays an important role in the health and well-being of people of all ages [1]. The World Health Organization (WHO) defines physical activity as any bodily movement produced by skeletal muscles that requires energy expenditure [2]. It includes activities such as walking, cycling and sports, as well as other activities which require bodily movement and are done during play, active transportation, household chores, physical education, work and recreational activities. Regular physical activity decreases the risk of all-cause mortality, coronary heart disease, stroke, hypertension, type 2 diabetes, different kind of cancers (e.g. colon cancer, breast cancer), osteoporosis, dementia and (feelings of) anxiety and depression for adults of all ages [2-6]. It helps to maintain a healthy body weight and improves cognitive function, quality of life and sleep [2, 3]. In addition to the benefits listed above, being physically active is associated with improved physical function and a lower risk of falling and fall-related injuries in older adults $[2,3,6]$. Regular physical activity also provides many health benefits for children and adolescents, such as improved cardiorespiratory and muscular fitness, enhanced bone health, a healthier weight status, a more favorable cardiovascular risk factor status and reduced symptoms of depression $[2,3,7]$.

To support people in adopting or maintaining a physically active lifestyle, the WHO formulated the 'Global recommendations on physical activity for health' [2]. These physical activity guidelines describe the frequency, duration, intensity, type and total amount of physical activity needed to enhance health and prevent chronic diseases. This is also referred to as 'health-enhancing physical activity'. Recommendations are provided for children and adolescents, adults and older adults (see Tables 1.1 and 1.2). The Dutch physical activity guidelines were updated in 2017 [8] and are largely similar to these international guidelines and the previous Dutch physical activity norms [9]. The latter norms formed the basis for this research (see also Tables 1.1 and 1.2 for similarities and differences between guidelines). 


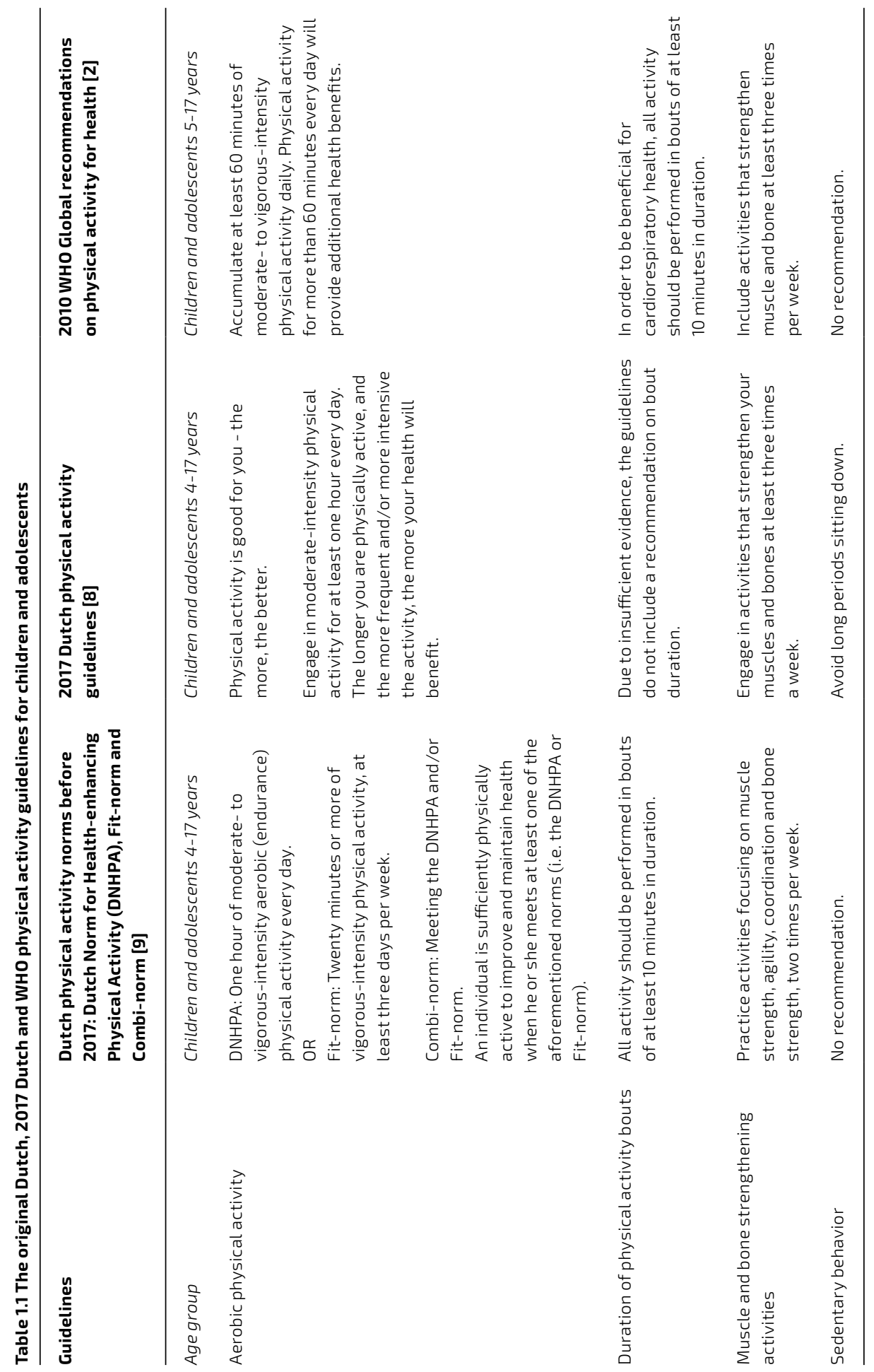




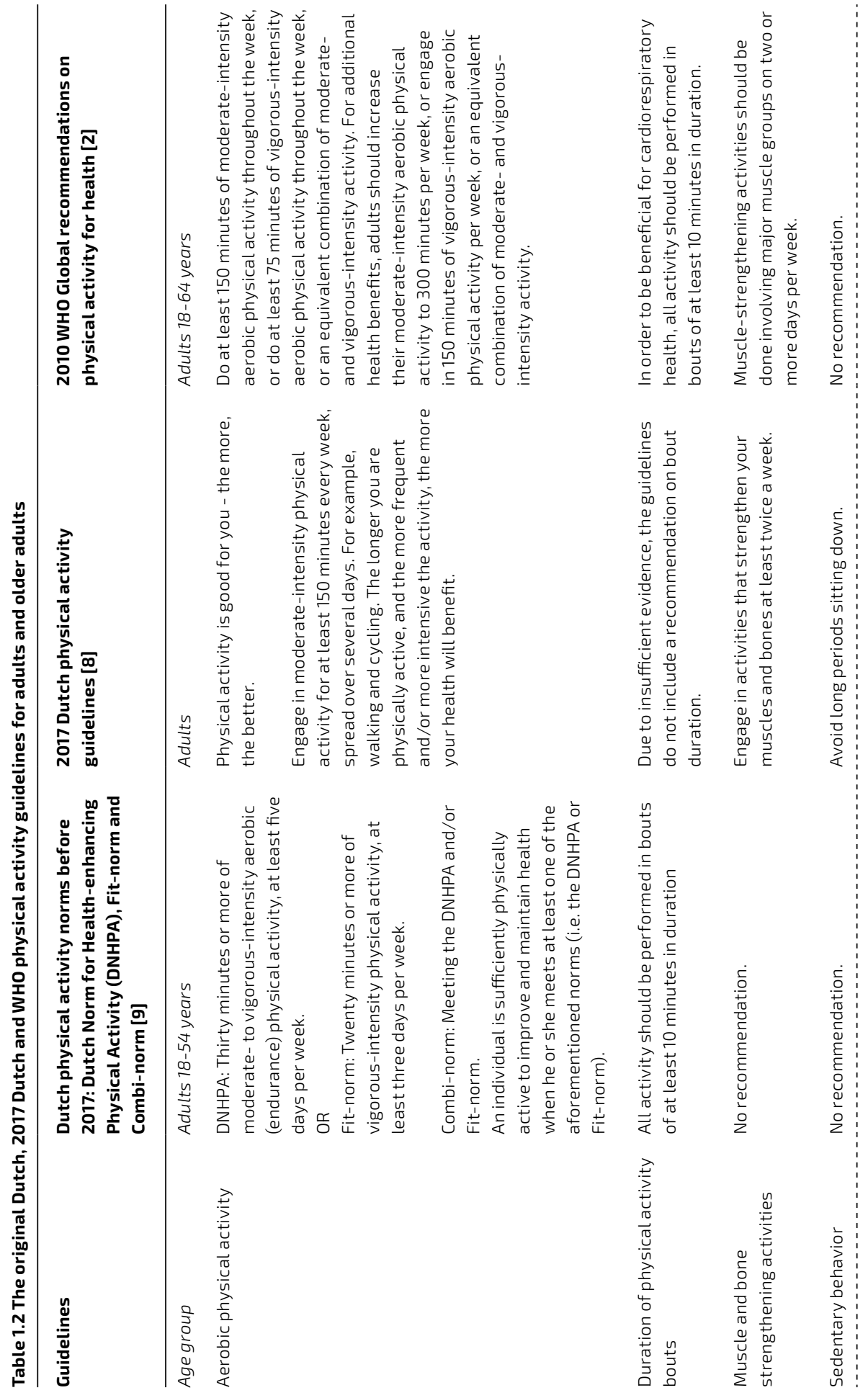




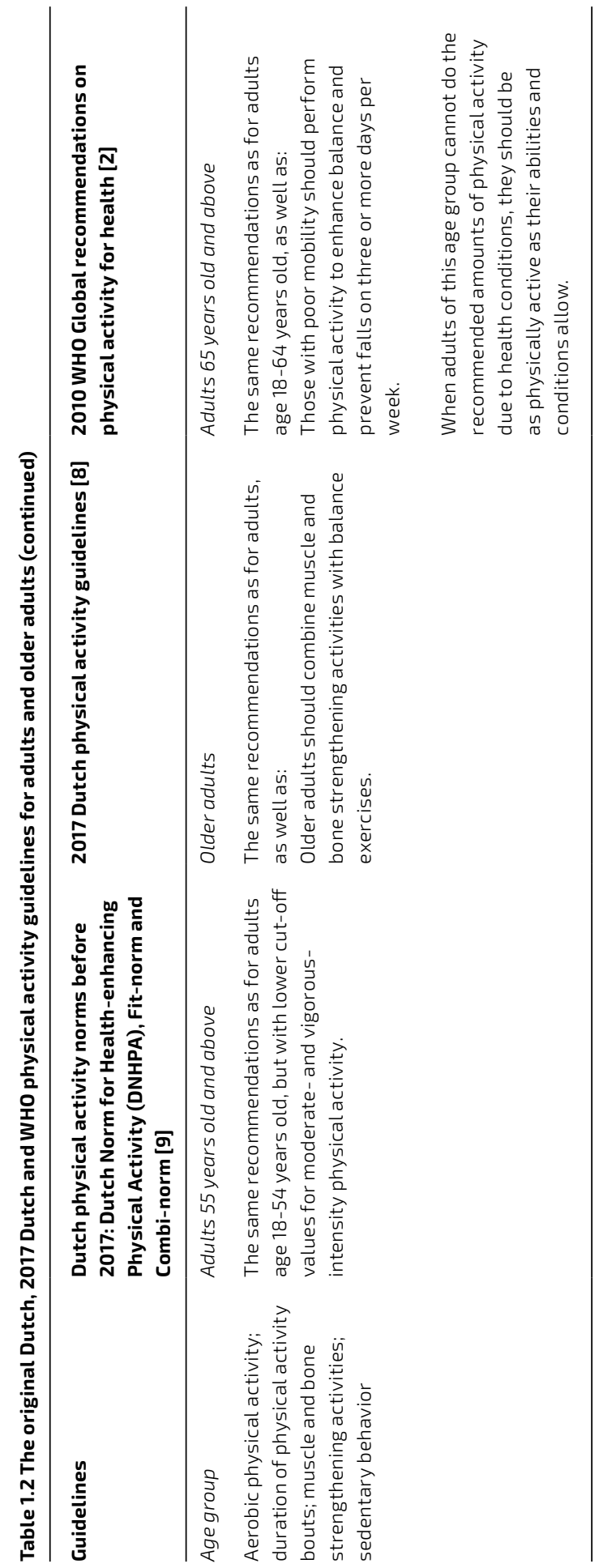




\section{Insufficient physical activity}

Despite the health benefits of regular physical activity and the existence of physical activity guidelines, a large part of the world population is insufficiently active. In 2016, 28\% of adults (18 years or older) worldwide, did not meet the WHO physical activity guidelines. Furthermore, the overall prevalence of insufficient physical activity remained stable between 2001 and 2016, but increased in high-income countries over time [10]. In the Netherlands, $54 \%$ of the Dutch population (12 years and older) did not meet the new Dutch physical activity guidelines in 2018. Adolescents, older adults, people with lower education levels, people who are unemployed, people with chronic conditions and/or physical disabilities and people with a non-Western migration background are examples of Dutch population subgroups that are more likely to be insufficiently active. In the Netherlands, the general prevalence of insufficient physical activity decreased only slightly (-6\%) between 2001 and 2018 [11]. This means that previous strategies aimed at increasing population physical activity levels have been largely ineffective. Different studies show that the greatest improvements in health are obtained by increasing the physical activity levels of the most inactive people, rather than getting those already active to do a little more $[3,5$, $6,8]$. Therefore, there is a need for initiatives to promote physical activity among inactive target groups. In this regard, a settings-based approach to health promotion has been advocated by the WHO $[12,13]$.

\section{Settings-based approach to health promotion}

A setting is the place or social context in which people engage in daily activities and in which policy, environmental, organizational, interpersonal and personal factors interact to affect health and well-being [14]. The settings-based approach to health promotion is based on the idea that changes in people's health and health behavior are easier to achieve if health promoters focus on settings instead of individuals [15]. It builds on the Ottawa Charter which stated that: "Health is created and lived by people within the settings of their everyday life; where they learn, work, play, and love." [12] The approach has an ecological perspective and acknowledges the multiple factors that influence behavior, i.e. personal, interpersonal, organizational, environmental and policy. Important key elements of the approach are: 1) creating supportive and healthy environments in order to make 'the healthy choice the easy choice', 2) integrating health promotion in the daily activities of the setting and 3 ) developing links with other settings and the wider community [15-20].

The settings-based approach has been applied to different settings such as universities, schools, workplaces and hospitals [15-18]. More recently, the organized sports setting, in particular sports clubs, has been recognized by policy makers and professionals working in the sports and health sectors, as an important setting to stimulate healthy behaviors [21-30]. Although sport promotion has a long history in many countries, the use of sports 
clubs as a setting to increase physical activity levels of inactive groups within a population, is relatively new.

\section{Organized sports setting and promotion of physical activity to inactive target groups}

Sports clubs have great potential to promote physical activity in the general population, given their wide reach in the community, their informal learning environment and the voluntary nature of participation [28,31]. Another positive aspect of participation in sport at a sports club, is the possibility to socially interact with other people. As social support has been identified as an important determinant of physical activity, participation in organized sports may lead to greater physical activity levels than other forms of physical activity [3234]. Sports club participants are more likely to be sufficiently active than non-participants $[11,35,36]$. Furthermore, at sports clubs, physical activity opportunities are provided on a regular and continuous basis (i.e. people can play sport on a weekly basis and during the whole year). This is in contrast with physical activity interventions, which are mostly of short or limited duration [37]. In this way, sports clubs can also play an important role in maintaining physical activity levels. Hence, increasing participation in sport in inactive population groups through sports clubs seems to be a promising strategy to enhance public health.

Different examples of general health promotion strategies and programs in sports clubs can be found in the literature, and research in this area is growing [e.g. 29, 38, 39]. However, only a few examples can be found that focus specifically on promoting physical activity among inactive target groups in sports clubs, and these are mainly in the Australian context. Here, State Sporting Associations were funded by the Victorian Health Promotion Foundation (VicHealth) to develop healthy (e.g. smoke-free settings) and welcoming environments in their associated clubs, to increase participation in sport among population subgroups that were more likely to be inactive (i.e. women and girls, Aboriginal Victorians and people from culturally diverse communities) $[23,26]$. Also, funding was provided to local sports clubs and recreation organizations to develop and implement cross-sectoral (including partnerships between health organizations, local governments and sports clubs) sporting programs for people who were not currently active and had low incomes [21, 22]. Sports Clubs for Health is a European expert-based approach that supports sports clubs in organizing health-enhancing sport activities, i.e. sport activities that help club members and non-club members (e.g. inactive people) meet the WHO physical activity guidelines [30]. In the Dutch context, the National Action Plan for Sport and Exercise (NAPSE) was initiated to stimulate physical activity among inactive target groups [25]. A description of this program and of the organized sports infrastructure in the Netherlands is provided in the next paragraph. 


\section{Organized sports in the Netherlands}

The infrastructure of organized sports is well established in the Netherlands. It comprises 76 National Sports Federations (NSFs), approximately 24,000 sports clubs and 5.2 million sports club members ( $67 \%$ adults $\geq 18$ years and $33 \%$ children and youth $0-17$ years) [ 40 ]. The Netherlands Olympic Committee and Netherlands Sports Federation (NOC*NSF) is the national sport umbrella organization for organized sports in the Netherlands and supports, coordinates and represents the interests of the affiliated NSFs and sports clubs. Given the ecological perspective of the settings-based approach [16-20], an ecological model is used to present the different levels at which sport is promoted in the Netherlands (see Figure 1.1). In the model, the different levels of the organized sports setting - national sport policy (NAPSE): Dutch Ministry of Health, Welfare and Sport and NOC*NSF (policy level), NSFs and sports clubs (environmental and organizational level) and participants (interpersonal and personal level) - are presented as layers, which will be described in more detail in the following subparagraphs. Also, the challenges that may be encountered when promoting physical activity among inactive groups, which mostly occur on the sports club level and the level of the (inactive) participant, are described.

Figure 1.1 Ecological model of sports promotion in the Netherlands

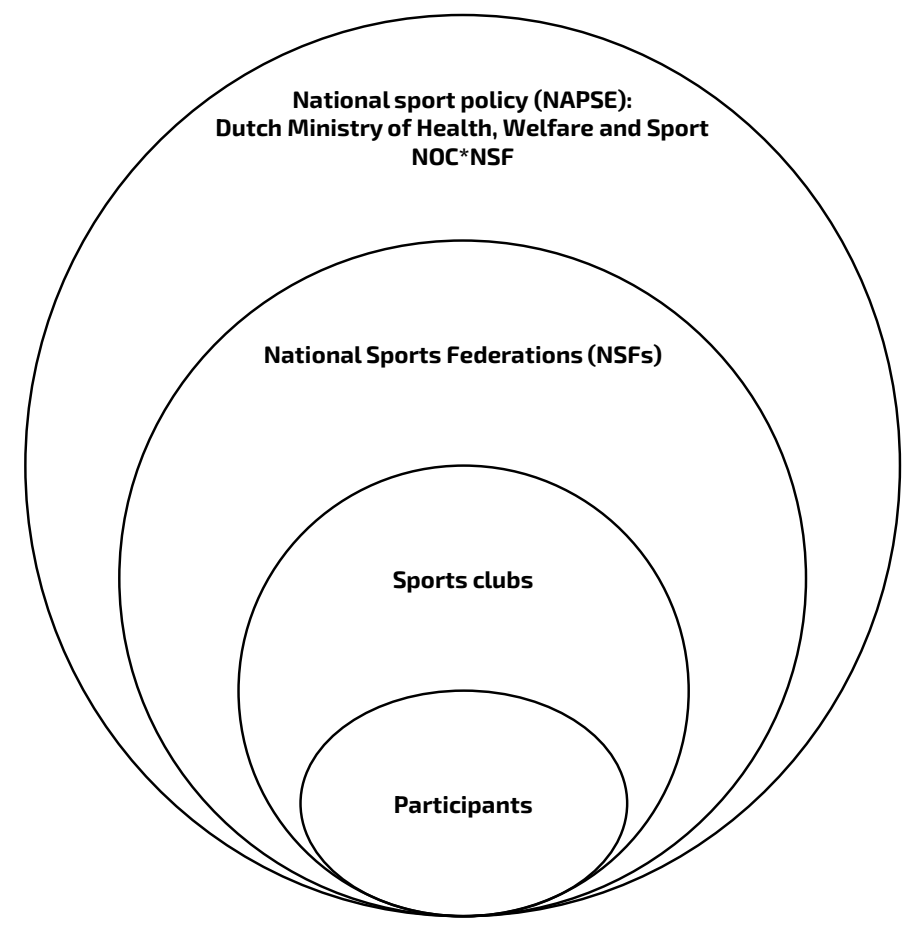




\section{National sport policy}

The outermost layer of the model comprises the sport policy level. National sport policy is developed by the Dutch Ministry of Health, Welfare and Sport. NOC*NSF is sparring partner for the Dutch government in sport policy development (both for elite and recreational sports) and implements central government's sport policy.

\section{National Action Plan for Sport and Exercise}

Considering the low levels of physical activity in the Dutch population, the Dutch Ministry of Health, Welfare and Sport initiated the National Action Plan for Sport and Exercise (NAPSE) [25]. This multiyear program was implemented from 2007 to 2014 and focused on people who were insufficiently active. Within the program, there was a specific focus on inactive people: "The range of sports and physical activities that are offered must be geared more towards encouraging inactive people and those who do not or rarely participate in sport or exercise." The main aim of the program was: "More people are sufficiently active and less people are inactive." The NAPSE consisted of policy development and strategy and intervention implementation in five important settings: the community, school, work, health care and organized sports setting.

Within the organized sports setting, seventeen NSFs received financial resources to develop sporting programs aimed at increasing sport participation in inactive population groups. A total of twenty-four programs were developed and piloted in a dozen local sports clubs during a one-year pilot period (2007). Process evaluations of all programs were conducted, and changes in physical activity levels and membership of participants were monitored (i.e. before and after finishing the program), during the pilot phase [41]. Based on the research results, fourteen programs from ten NSFs were seen as promising in reaching inactive people and increasing their physical activity levels. For these fourteen programs, additional funding was provided to implement them on a larger scale in the Netherlands over a three-year funded implementation period (from 2008-2011). The programs varied with regard to sport type, content, duration and target group. Most sporting programs were offered by sports clubs one or multiple times per year during a limited time period (e.g. weeks/months) and were aimed at teaching inactive people the basics of the sport in an easy and gradual manner. Afterwards, they were encouraged to continue the sport in a beginner group at the sports club. For example, in the six-week cycling program Start2Bike, adults learn the basics of mountain biking or road cycling. Other sporting programs were provided by sports clubs on a continuous basis (i.e. weekly during the whole year) and used simplified sport techniques and/or rules and easy to use (soft and non-threatening) sport materials to lower barriers for participation. An example is Fit Hockey, which is weekly hockey for older adults played on a small field with soft sticks and soft balls. See Table 1.3 for a description of all fourteen NAPSE sporting programs. After the funded implementation period, the activities had to be self-sustaining and continued by the sports clubs without government funding. In total, the Dutch government allocated 6.5 million euros to the organized sports setting to contribute to the aim of the NAPSE. The NOC*NSF coordinated the NAPSE program in the organized sports setting. 


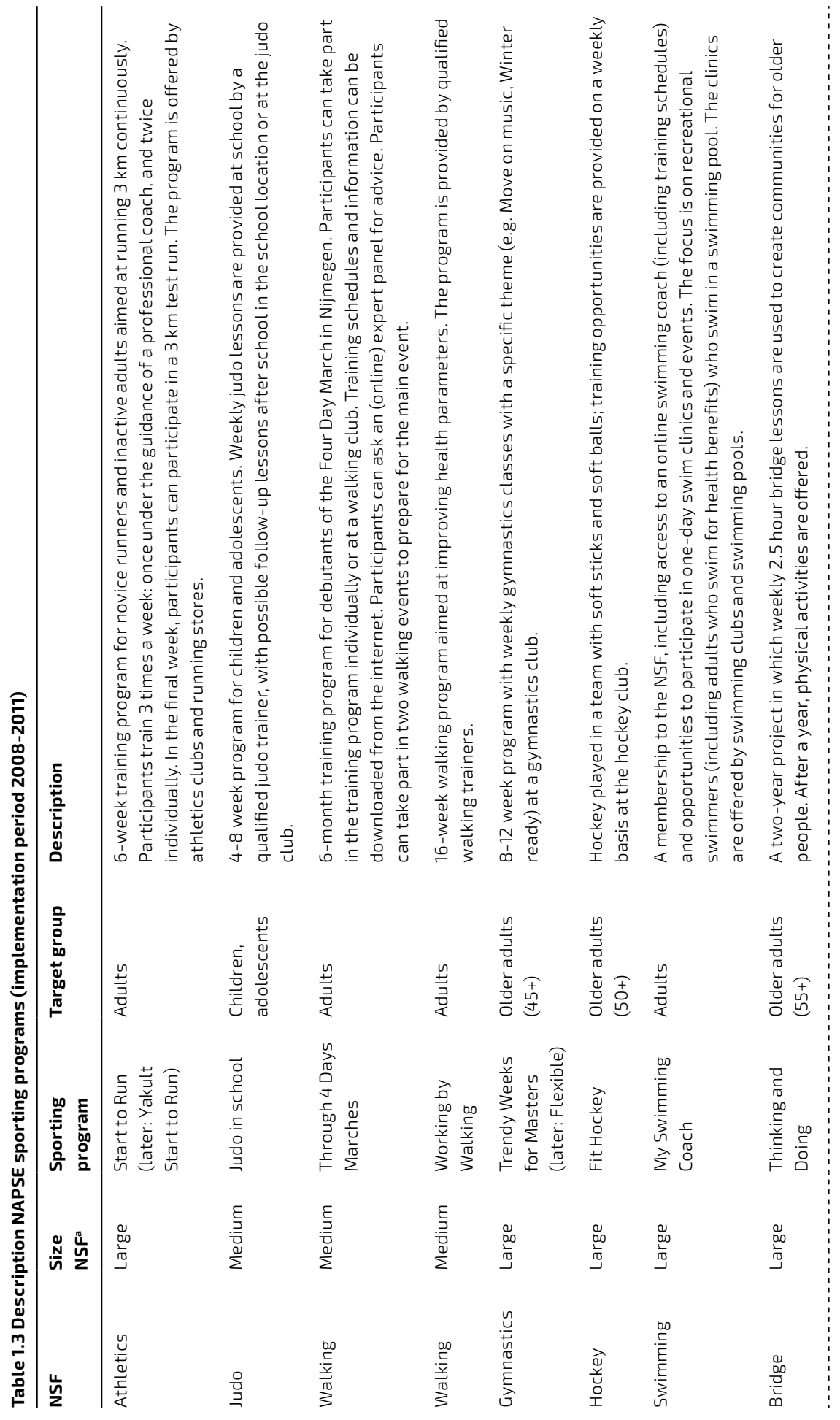




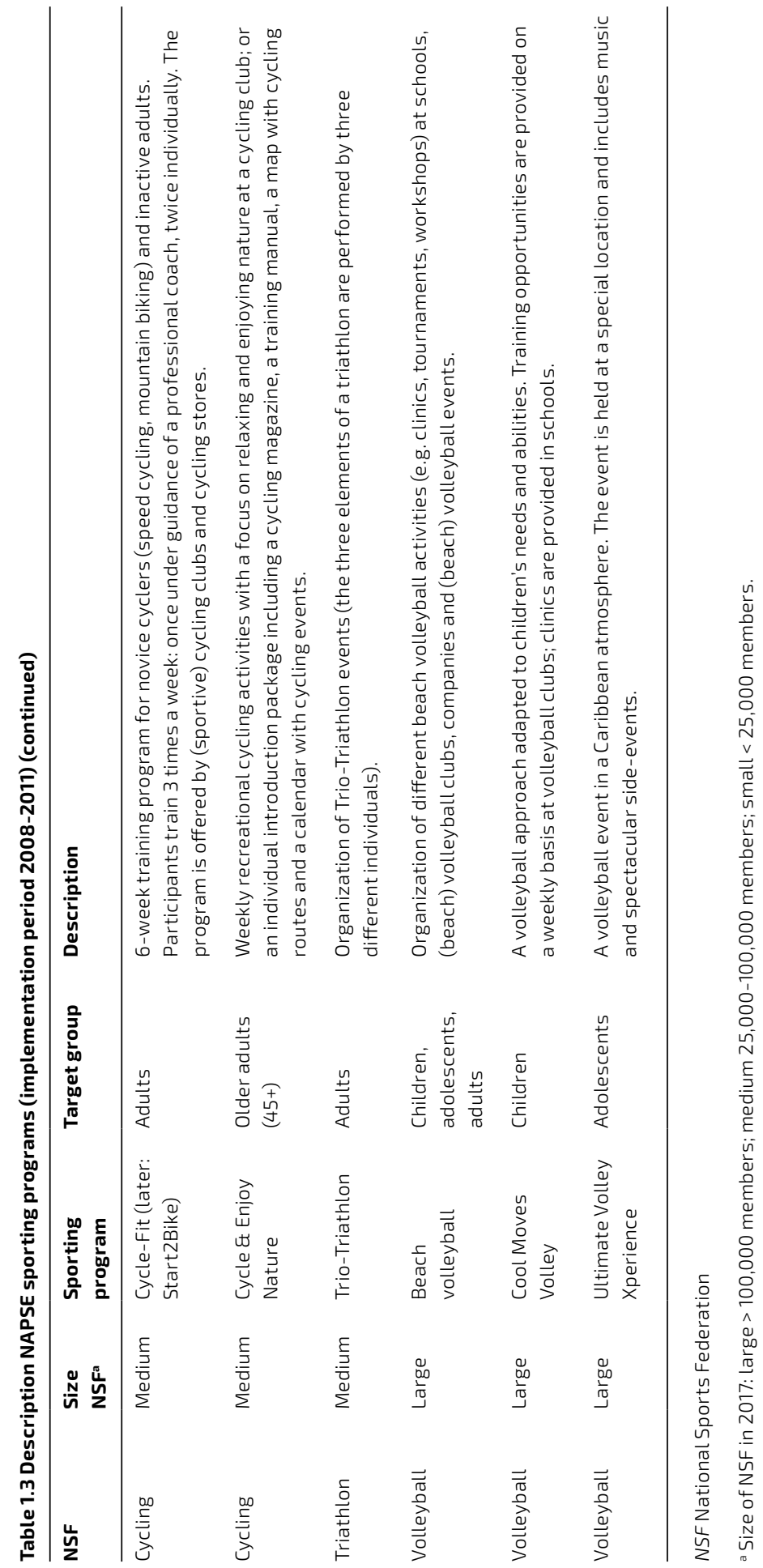




\section{NSFs and sports clubs}

The following two layers in the model include the environmental and organizational levels of the NSFs and sports clubs. NSFs govern their respective sport, organize national and regional competitions and provide support to local voluntary sports clubs. Within the NAPSE, NSFs coordinated the implementation of the programs at the national level. A NSF program coordinator was appointed, who was actively involved in recruiting sports clubs, national promotion of the sporting program and in supporting sports clubs (e.g. with materials, advice, education) with program implementation at the local level. Other NSF employees occasionally assisted the program coordinator

At the local sports club, volunteers manage and provide physical activity opportunities to people in the community. Sports clubs interpret and implement central sport policy, in this case the NAPSE, at the local level, in the local context. The dependence on volunteers also affects the way that the NAPSE policy and the NAPSE sporting programs are interpreted and implemented in this setting $[42,43]$. Four-fifths of the sports clubs in the Netherlands feel a sense of social responsibility and half think they should stimulate people to become more physically active [44]. However, a positive orientation towards health promotion does not lead to health promotion practice by sports clubs per se [29, 45-47]. The sports clubs' main focus is the provision of their 'regular' sport activities and competitions. Providing sporting programs for inactive people, which is beyond their core business, can be seen as an extra burden and lack of time, human resources and skills (e.g. to guide inactive people) can impede implementation of these kind of sporting programs [21-23, 26, 29, 43, 46, 47]. Only a quarter of Dutch sports clubs are satisfied with their volunteer base and are not searching for additional volunteers. Recruiting and maintaining volunteers is a challenge prevalent in many sports clubs in the Netherlands [48]. This has to be taken into account when organizing sporting programs for inactive people in sports clubs.

\section{Participants}

The innermost layer of the model constitutes the participants. In this case, the participants are inactive people, the target group of the NAPSE sporting programs. Inactive people are not yet part of the organized sports setting, and sports clubs need to attract inactive people to the NAPSE sporting programs. However, there are many factors (i.e. personal, interpersonal, environmental and policy) that influence sport and physical activity participation of inactive people. The NAPSE sporting programs may be able to overcome policy (e.g. lack of financial resources for the development of sporting programs for inactive people) and environmental (e.g. a lack of (suited) physical activities in the neighborhood) barriers [49, 50]. However, there are other, mainly personal and interpersonal factors, that can hinder inactive people in participating in these programs. Lack of time, other priorities, lack of financial resources, chronic conditions and/or physical disabilities and unfamiliarity with physical activity opportunities in the neighborhood are all possible barriers at the personal level [49-52]. Furthermore, negative or lack of past sport experiences, uncomfortable feelings of high exertion experienced in high-intensity physical activities, negative images people have of sport (i.e. being tough, too competitive and of high-intensity), anxiety and lack of 
confidence about engaging in sport activities and entering the unfamiliar sport setting, and lack of interest in sport at all, are other personal factors that can prevent inactive people from engaging in these programs [49-51, 53]. Other challenges are the high drop-out rate among novice sport participants and the increased risk of injuries with high-intensity and competitive sports [54-56]. Finally, as mentioned previously, social support is an important determinant of physical activity participation [32-34]. However, a lack of social support from family and friends to participate in sport, sometimes in combination with cultural norms and barriers (e.g. physical activity is unimportant, participation in sport by women and girls is inappropriate), are important interpersonal factors that can prevent inactive people from participating in sport [49-51]. It is important to take these factors into account when developing and implementing sporting programs for this target group. Sport activities should, for example, be tailored to the specific needs and abilities of inactive people, and proper recruitment strategies should be used to reach this target group.

\section{What is already known?}

For the NAPSE sporting programs to have public health impact, it is important that they are effective in enhancing the physical activity levels of inactive people. Furthermore, they have to be adopted, properly implemented and effective programs have to be continued as ongoing practice. In this regard, it is important to consider and evaluate the specific context in which the programs are implemented [57-59]. Despite the recent interest in the organized sports setting to promote physical activity among inactive target groups, little research has focused on how this can best be achieved in sports clubs. The research that has been performed in Australia, concerning the development of healthy and welcoming environments in sports clubs, provides some insight into factors influencing implementation, both at the level of State Sporting Associations and sports clubs [23, 26, $60,61]$. The research regarding the implementation of cross-sectoral sporting programs in Australia focused on the partnership and capacity-building strategies associated with successful implementation of these programs. In this regard, designing pragmatic programs that build on the core business of each participating organization, and using a phased approach to program development and implementation, were important [21, 22]. Only one study, also from Australia, examined factors influencing the sustainability of a funded health promotion program within sport and recreation organizations [62]. However, this research did not include sports clubs (but Regional Sports Assemblies), and was performed directly after the funding period ended. It is unknown if the health promotion program was sustained over time.

The Sports Club for Health (SCforH) approach provides seven general guiding principles (e.g. the SCforH initiatives take place in a 'healthy' environment), and four successive steps sports clubs have to go through to implement health-enhancing sport activities. Although practical recommendations are included with each step, these do not focus on inactive people per se [30]. 
In general, it is not known whether the results of the Australian studies and the SCforH approach are transferable to the NSFs and sports clubs in the Netherlands and to the specific inactive target groups. Moreover, evidence that these initiatives are actually effective in increasing physical activity levels of participants is lacking $[29,63,64]$. Therefore, it is important to gain more insight into the effectiveness, implementation and sustainability of sporting programs aimed at inactive target groups in the organized sports setting.

\section{Aim and outline of the thesis}

As demonstrated above, the potential for the organized sports sector in general, and sports clubs in particular, in promoting physical activity to inactive target groups, is recognized internationally. However, little research has focused on promoting physical activity among inactive target groups in this particular setting. Therefore, it is not known whether this setting is really suited for the inactive target group. Thus, the overarching aim of this research was to understand if and how the organized sports setting can successfully contribute to increasing physical activity levels of inactive people. Specifically, the fourteen Dutch NAPSE sporting programs, initiated by NSFs and implemented by sports clubs in the Netherlands, were studied during the three-year funded implementation period (research questions 1-3) and six and half years thereafter (research question 4).

In summary, the following research questions are examined in this doctoral thesis:

\section{Effectiveness (research was performed at the level of the participants)}

1. What is the short-term and long-term effectiveness of sporting programs aimed at inactive target groups in increasing health-enhancing physical activity levels?

The effectiveness of two NAPSE sporting programs in increasing health-enhancing physical activity levels was investigated in a controlled study design. Physical activity levels of program participants were assessed at three time-points: baseline, immediately after completing the program and six months after baseline. Changes in physical activity levels after six months were compared with a matched control group (chapters $\mathbf{2}$ and $\mathbf{3}$ ).

2. Which insufficiently active target groups benefit the most from these programs in terms of increasing health-enhancing physical activity?

The characteristics of insufficiently active participants that became sufficiently active after participation in three NAPSE sporting programs were examined in more detail. This was done by comparing the (baseline) characteristics of two groups: participants who were insufficiently active at baseline, but sufficiently active after six months (activated group) 
and participants who were insufficiently active both at baseline and after six months (nonactivated group) (chapter $\mathbf{4}$ ).

\section{Implementation (research was performed at the level of the NSFs)}

3. What are the main factors influencing the implementation of sporting programs aimed at inactive target groups in the organized sports setting?

A mixed methods study was conducted at the level of the NSF program coordinators. The integration of results from the qualitative and quantitative methods resulted in an overview with the most important factors facilitating and impeding implementation per implementation phase (chapter 5).

\section{Sustainability (research was performed at the levels of the NSFs and sports clubs)}

4. What are the main factors influencing the long-term sustainability of sporting programs aimed at inactive target groups in the organized sports setting?

Qualitative research methods were applied at the level of the NSFs (i.e. NSF program coordinators) and sports clubs (i.e. local program coordinators), six and a half years after the funded implementation period ended. A sustainability framework was used for data collection and analysis. The main factors influencing the long-term sustainability of the programs were summarized in an ecological model of the organized sports setting (chapter $\mathbf{6}$ ).

The final chapter, chapter $\mathbf{7}$, provides a general discussion of the research presented in this dissertation and considers suggestions for future studies and implications for practice. This dissertation ends with a summary in English and Dutch. 


\section{REFERENCES}

1. Bailey R, Hillman C, Arent S, Petitpas A. Physical activity: an underestimated investment in human capital? J Phys Act Health. 2013;10(3):289-308.

2. World Health Organization (WHO). Global recommendations on physical activity for health. Geneva: WHO; 2010.

3. 2018 Physical Activity Guidelines Advisory Committee. 2018 Physical Activity Guidelines Advisory Committee Scientific Report. Washington, DC: U.S. Department of Health and Human Services; 2018.

4. De Souto Barreto P, Cesari M, Andrieu S, Vellas B, Rolland Y. Physical activity and incident chronic diseases: a longitudinal oberservational study in 16 European countries. Am J Prev Med. 2017;52(3):373-378.

5. Kyu HH, Bachman VF, Alexander LT, Mumford JE, Afshin A, Estep K, Veerman JL, Delwiche K, Lannarone ML, Moyer ML, Cercy K, Vos T, Murray CJL, Forouzanfar MH. Physical activity and risk of breast cancer, colon cancer, diabetes, ischemic heart disease, and inschemic stroke events: systemic review and dose-response meta-analysis for the Global Burden of Disease Study 2013. BMJ. 2016;354:13857.

6. Warburton DER, Nicol CW, Bredin SSD. Health benefits of physical activity: the evidence. CMAJ. 2006;174(6):801-809.

7. Janssen I, Leblanc AG. Systematic review of the health benefits of physical activity and fitness in school-aged children and youth. Int J Behav Nutr Phys Act. 2010;7:40.

8. Weggemans RM, Backx FJG, Borghouts L, Chinapaw M, Hopman MTE, Koster A, Kremers S, van Loon LJC, May A, Mosterd A, van der Ploeg HP, Takken T, Visser M, Wendel-Vos GC, de Geus EJC, Committee Dutch Physical Activity Guidelines 2017. The 2017 Dutch physical activity guidelines. Int J Behav Nutr Phys Act. 2018;15:58.

9. Hildebrandt VH, Chorus AMJ, Stubbe JH. Trend report of physical activity and health 2008/2009 (report in Dutch). Leiden: TNO Quality of Life; 2010.

10. Guthold R, Stevens GA, Riley LM, Bull FC. Worldwide trends in insufficient physical activity from 2001 to 2016: a pooled analysis of 358 population-based surveys with 1.9 million participants. Lancet Glob Health. 2018;6(10):e1077-e1086.

11. National Institute for Public Health and the Environment (RIVM). Sport core indicators. 2018. https://www.sportenbewegenincijfers.nl/kernindicatoren/beweegrichtlijnen. Accessed 12 September 2019.

12. World Health Organization (WHO). Ottawa Charter for Health Promotion. Geneva: WHO; 1986.

13. World Health Organization (WHO). Global action plan on physical activity 2018-2030: more active people for a healthier world. Geneva: WHO; 2018.

14. World Health Organization (WHO). Health promotion glossary. Geneva: WHO; 1998.

15. Whitelaw S, Baxendale A, Bryce C, MacHardy L, Young I, Witney E. 'Settings' based health promotion: a review. Health Promot Int. 2001;16(4):339-353.

16. Dooris M. Joining up settings for health: a valuable instrument for strategic partnerships? Crit Public Health. 2004;14(1):49-61. 
17. Dooris M. Healthy settings: challenges to generating evidence of effectiveness. Health Promot Int. 2006;21(1):55-65.

18. Dooris M. Holistic and sustainable health improvement: the contribution of the settings-based approach to health promotion. Perspect Public Health. 2009;129(1):29-36.

19. McLeroy KR, Bibeau D, Steckler A, Glanz K. An ecological perspective on health promotion programs. Health Educ Q. 1988;15(4):351-377.

20. Sallis JF, Owen N, Fisher EB. Ecological models of health behavior. In: Glanz K, Rimer BK, Viswanath K, editors. Health behavior and health education: theory, research and practice. San Francisco: Jossey-Bass; 2008. p.465-485.

21. Casey MM, Payne WR, Brown SJ, Eime RM. Engaging community sport and recreation organisations in population health interventions: factors affecting the formation, implementation, and institutionalisation of partnership efforts. Ann Leis Res. 2009;12(2):129147.

22. Casey MM, Payne WR, Eime RM. Partnership and capacity-building strategies in community sports and recreation programs. Manag Leis. 2009;14(3):167-176.

23. Casey MM, Payne WR, Eime RM. Organisational readiness and capacity building strategies of sporting organisations to promote health. Sport Manag Rev. 2012;15:109-124.

24. Donaldson A, Finch CF. Sport as a setting for promoting health. Br J Sports Med. 2012;46(1):4-5.

25. Dutch Ministry of Health, Welfare and Sport. Time for sport: exercise, participate, perform. The Hague: Dutch Ministry of Health, Welfare and Sport; 2005.

26. Eime RM, Payne WR, Harvey JT. Making sporting clubs healthy and welcoming environments: a strategy to increase participation. J Sci Med Sport. 2008;11(2):146-154.

27. European Commission. Communication from the commission to the European parliament, the council, the European economic and social committee and the committee of the regions: developing the European Dimension in Sport. Brussels: European Commission; 2011.

28. Kokko S. Sports clubs as settings for health promotion: fundamentals and an overview to research. Scan J Public Health. 2014;42(Suppl.15):60-65.

29. Kokko S, Donaldson A, Geidne S, Seghers J, Scheerder J, Meganck J, Lane A, Kelly B, Casey M, Eime R, Villberg J, Kannas L. Piecing the puzzle together: case studies of international research in health-promoting sports clubs. Glob Health Promot. 2016;23(Supp. 1):75-84.

30. Koski P, Matarma T, Pedisic Z, Kokko S, Lane A, Hartmann H, Geidne S, Hämäläinen T, Nykänen U, Rakovac M, Livson M, Savola J. Sports Club for Health (SCforH): updated guidelines for healthenhancing sports activities in a club setting. Helsinki: Finnish Olympic Committee; 2017.

31. Kokko S, Kannas L, Villberg J. The health promoting sports club in Finland--a challenge for the settings-based approach. Health Promot Int. 2006;21(3):219-229.

32. Eyler AA. Correlates of physical activity: who's active and who's not? Arthritis Rheum. 2003;49(1):136-140.

33. Trost SG, Owen N, Bauman AE, Sallis JF, Brown W. Correlates of adults' participation in physical activity: review and update. Med Sci Sports Exerc. 2002;34(12):1996-2001.

34. Wendel-Vos W, Droomers M, Kremers S, Brug J, van Lenthe F. Potential environmental determinants of physical activity in adults: a systematic review. Obes Rev. 2007;8(5):425-440. 
35. Eime RM, Harvey JT, Charity MJ, Casey MM, van Uffelen JGZ, Payne WR. The contribution of sport participation to overall health enhancing physical activity levels in Australia: a populationbased study. BMC Public Health. 2015;15:806.

36. Kokko S, Martin L, Geidne S, van Hoye A, Lane A, Meganck J, Scheerder J, Seghers J, Villberg J, Kudlacek M, Badura P, Mononen K, Blomqvist M, de Clercq B, Koski P. Does sports club participation contribute to physical activity among children and adolescents? A comparison across six European countries. Scand J Public Health. 2018. DOI: 10.1177/1403494818786110.

37. Foster C, Hillsdon M, Thorogood M. Interventions for promoting physical activity. Cochrane Database Syst Rev. 2005(1). Art. No.: CD003180. DOI: 10.1002/14651858.CD003180.pub2.

38. Bennike S, Wikman JM, Ottesen LS. Football Fitness: a new version of football? A concept for adult players in Danish football clubs. Scand J Med Sci Sports. 2014;24(Suppl.1):138-146.

39. Kokko 5 . Guidelines for youth sports clubs to develop, implement, and assess health promotion within its activities. Health Promot Pract. 2014;15(3):373-382.

40. NOC*NSF. Membership and sport participation NOC*NSF 2017 (report in Dutch). Arnhem, NOC*NSF; 2017.

41. Pisters MF, Veenhof, C. Evaluation of the pilot phase of the National Action Plan for Sport and Exercise: the sports setting (report in Dutch). Utrecht: NIVEL; 2008.

42. Skille EA. Understanding sport clubs as sport policy implementers: a theoretical framework for the analysis of the implementation of central sport policy through local and voluntary sport organizations. Int Rev Sociol Sport. 2008;43(2):181-200.

43. Skille EA. Competitiveness and health: the work of sport clubs as seen by sport clubs representatives - a Norwegian case study. Int Rev Sociol Sport. 2010;45(1):73-85.

44. NOC*NSF. Sport participants monitor and sport providers monitor 2012 (report in Dutch). Arnhem: NOC*NSF; 2013.

45. Kokko S, Kannas S, Villberg J. Health promotion profile of youth sports clubs in Finland: club officials' and coaches' perceptions. Health Promot Int. 2009;24(1):26-35.

46. Meganck J, Scheerder J, Thibaut E, Seghers J. Youth sports clubs' potential as health-promoting setting: profiles, motives and barriers. Health Educ J. 2015;74(5):531-543.

47. Meganck J, Seghers J, Scheerder J. Exploring strategies to improve the health promotion orientation of Flemish sports clubs. Health Promot Int. 2017;32(4):681-690.

48. van Kalmthout J. Websheet sports clubs in the Netherlands. Development from 2000 until now (websheet in Dutch). Utrecht: Mulier Institute; 2019.

49. Deelen I, Özgül P, Lagendijk E. What moves vulnerable groups in neighborhoods in Utrecht? Qualitative research about the motives and barriers to participate in sport and physical activity (report in Dutch). Amsterdam: DSP-group; 2018.

50. Hoogendoorn MP, de Hollander EL. Barriers and motivators to sport and physical activity participation among underrepresented groups (report in Dutch). Bilthoven: National Institute for Public Health and the Environment (RIVM); 2016.

51. Allender S, Cowburn G, Foster C. Understanding participation in sport and physical activity among children and adults: a review of qualitative studies. Health Educ Res. 2006;21(6):826835. 
52. Hoare E, Stavreski B, Jennings GL, Kingwell BA. Exploring motivation and barriers to physical activity among active and inactive Australian adults. Sports. 2017;5(3):47.

53. Zwolinsky S, McKenna J, Pringle A. How can the health system benefit from increasing participation in sport, exercise and physical activty. In: Conrad D, White A, editors. Sports-based health interventions: case studies from around the world. New York: Springer; 2016. p.29-52.

54. Fokkema T, Hartgens F, Kluitenberg B, Verhagen E, Backx FJG, van der Worp H, Bierma-Zeinstra SMA, Koes BW, van Middelkoop M. Reasons and predictors of discontinuation of running after a running program for novice runners. J Sci Med Sport. 2018;22(1):106-111.

55. Khan KM, Thompson AM, Blair SN, Sallis JF, Powell KE, Bull FC, Bauman AE. Sport and exercise as contributors to the health of nations. Lancet. 2012;380:59-64.

56. Ristolainen L, Toivo K, Parkkari J, Kokko S, Alanko L, Heinonen OJ, Korpelainen R, Savonen K, Selänne H, Vasankari T, Kannas L, Villberg J, Kujala UM. Acute and overuse injuries among sports club members and non-members: the Finnish Health Promoting Sports Club (FHPSC) study. BMC Musculoskelet Disord. 2019;20:32.

57. Finch C. A new framework for research leading to sports injury prevention. J Sci Med Sport. 2006;9:3-9.

58. Finch CF. No longer lost in translation: the art and science of sports injury prevention implementation research. Br J Sports Med. 2011;45:1253-1257.

59. Finch CF, Donaldson A. A sports setting matrix for understanding the implementation context for community sport. Br J Sports Med. 2010;44:973-978.

60. Crisp BR, Swerissen H. Critical processes for creating health-promoting sporting environments in Australia. Health Promot Int. 2003;18(2):145-152.

61. Dobbinson SJ, Hayman JA, Livingston PM. Prevalence of health promotion policies in sports clubs in Victoria, Australia. Health Promot Int. 2006;21(2):121-129.

62. Casey MM, Payne WR, Eime RM, Brown SJ. Sustaining health promotion programs within sport and recreation organisations. J Sci Med Sport. 2009;12:113-118.

63. Priest N, Armstrong R, Doyle J, Waters E. Interventions implemented through sporting organisations for increasing participation in sport. Cochrane Database Syst Rev. 2008(3). Art. No.: CD004812. DOI: 10.1002/14651858.CD004812.pub3.

64. Priest N, Armstrong R, Doyle J, Waters E. Policy interventions implemented through sporting organisations for promoting healthy behaviour change. Cochrane Database Syst Rev. 2008(3). Art. No.: CD004809. DOI: 10.1002/14651858.CD004809.pub3. 


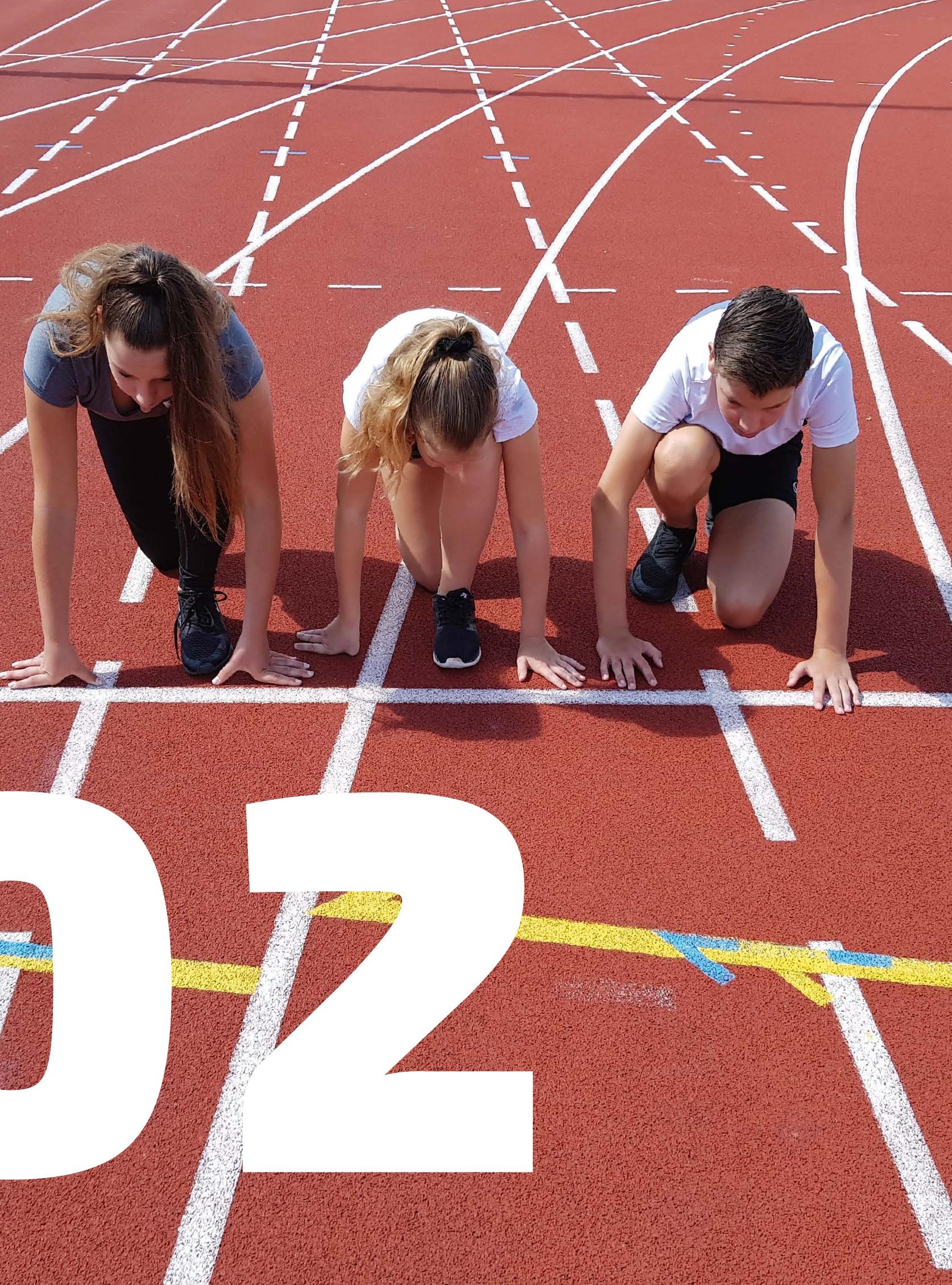




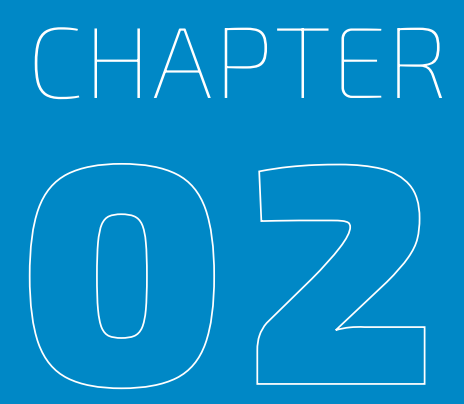

Effectiveness of Start to Run, a 6-week training program for novice runners, on increasing health-enhancing physical activity: a controlled study

Published as: Ooms L, Veenhof C, de Bakker DH. Effectiveness of Start to Run, a 6-week training program for novice runners, on increasing health-enhancing physical activity: a controlled study. BMC Public Health. 2013;13:697. 


\section{ABSTRACT}

Background: The use of the organized sports sector as a setting for health-promotion is a relatively new strategy. In the past few years, different countries have been investing resources in the organized sports sector for promoting health-enhancing physical activity. In the Netherlands, National Sports Federations were funded to develop and implement 'easily accessible' sporting programs, aimed at the least active population groups. Start to Run, a six-week training program for novice runners, developed by the Dutch Athletics Organization, is one of these programs. In this study, the effects of Start to Run on healthenhancing physical activity were investigated.

Methods: Physical activity levels of Start to Run participants were assessed by means of the Short QUestionnaire to ASsess Health-enhancing physical activity (SQUASH) at baseline, immediately after completing the program and six months after baseline. A control group, matched for age and sex, was assessed at baseline and after six months. Compliance with the Dutch physical activity guidelines was the primary outcome measure. Secondary outcome measures were the total time spent in physical activity and the time spent in each physical activity intensity category and domain. Changes in physical activity within groups were tested with paired t-tests and McNemar tests. Changes between groups were examined with multiple linear and logistic regression analyses.

Results: In the Start to Run group, the percentage of people who met the Dutch Norm for Health-enhancing Physical Activity, Fit-norm and Combi-norm increased significantly, both in the short- and longer-term. In the control group, no significant changes in physical activity were observed. When comparing results between groups, significantly more Start to Run participants compared with control group participants were meeting the Fit-norm and Combi-norm after six months. The differences in physical activity between groups in favor of the Start to Run group could be explained by an increase in the time spent in vigorousintensity activities and sports activities.

Conclusions: Start to Run positively influences levels of health-enhancing physical activity of participants, both in the short- and longer-term. Based on these results, the use of the organized sports sector as a setting to promote health-enhancing physical activity seems promising. 


\section{BACKGROUND}

The positive effects of physical activity on health and mortality have been well established. Participation in regular physical activity decreases the risk of coronary heart disease, stroke, type 2 diabetes mellitus, certain cancers (e.g. breast cancer, colon cancer), osteoporosis, obesity and falls [1-7]. Moreover, there is some evidence that physical activity is positively associated with mental health and quality of life $[8,9]$.

Given the numerous health benefits of physical activity participation, various guidelines have been published on the recommended volume and intensity of physical activity for healthy adults. Commonly used guidelines are those developed by the American College of Sports Medicine (ACSM) and the American Heart Association (AHA). To promote and maintain health, the ACSM and AHA recommend that: "All healthy adults aged 18 to 65 years need moderate-intensity aerobic (endurance) physical activity for a minimum of 30 minutes on at least five days each week or vigorous-intensity aerobic physical activity for a minimum of 20 minutes on at least three days each week. Also, combinations of moderateand vigorous-intensity activity can be performed to meet this recommendation." [10] Similar guidelines have been adopted in the Netherlands and are referred to as the Dutch Norm for Health-enhancing Physical Activity (DNHPA) and the Fit-norm. Someone who meets at least one of the two guidelines adheres to the so-called 'Combi-norm', the third norm used in the Netherlands (see Table 2.1) [11].

\section{Table 2.1 Dutch physical activity guidelines for adults}

\begin{tabular}{|c|c|}
\hline Norm & Description \\
\hline \multirow{5}{*}{$\begin{array}{l}\text { Dutch Norm for } \\
\text { Health-enhancing } \\
\text { Physical Activity } \\
\text { (DNHPA) }\end{array}$} & Adults (18-54 years): \\
\hline & Thirty minutes or more of at least moderate-intensity aerobic (endurance) physical \\
\hline & activity ( $\geq 4 \mathrm{MET}$; combined intensity score SQUASH $\geq 3$ ) on at least five days each week. \\
\hline & Adults (55 years and older): \\
\hline & $\begin{array}{l}\text { Thirty minutes or more of at least moderate-intensity aerobic (endurance) physical } \\
\text { activity ( } \geq 3 \mathrm{MET} \text {; combined intensity score SOUASH } \geq 3 \text { ) on at least five days each week. }\end{array}$ \\
\hline \multirow[t]{4}{*}{ Fit-norm } & Adults (18-54 years): \\
\hline & $\begin{array}{l}\text { Twenty minutes or more of vigorous-intensity physical activity ( } \geq 6.5 \mathrm{MET} \text {; combined } \\
\text { intensity score SQUASH } \geq 6 \text { ) on at least three days each week. }\end{array}$ \\
\hline & Adults (55 years and older): \\
\hline & $\begin{array}{l}\text { Twenty minutes or more of vigorous-intensity physical activity ( } \geq 5 \text { MET; combined } \\
\text { intensity score SQUASH } \geq 6 \text { ) on at least three days each week. }\end{array}$ \\
\hline Combi-norm & Meeting at least one of the previous mentioned norms (i.e. the DNHPA or Fit-norm). \\
\hline
\end{tabular}


Despite the existence of these guidelines, more than one third of the Dutch adult population does not engage in sufficient physical activity: in 2009, 58\% of the Dutch adult population met the DNHPA, 33\% met the Fit-norm, and 62\% met the Combi-norm [11].

One of the ways of being physically active is through organized sports. There is large potential for the organized sports sector as a setting in which to promote health-enhancing physical activity to the general population, given the large numbers of participants, the extent of community reach and the availability of many different sports and professional trainers. Moreover, physical activity opportunities are provided on a continuous basis (i.e. people can play sport on a weekly basis at a sports club). This is in contrast with physical activity interventions, which are mostly of short or limited duration. In this way, the organized sports sector can also play an important role in maintaining physical activity levels. Another positive aspect of the organized sports setting is the possibility to socially interact with other people. As social support has been identified as a determinant of physical activity [12-14], participation in organized sports may lead to greater physical activity benefits than other forms of physical activity. It is, for example, well known that people who are involved in (organized) sports are significantly more likely to meet physical activity guidelines than those people who are not [11].

However, there are still people who are doing sports activities below the recommend levels of physical activity (i.e. with regard to frequency, duration and/or intensity) and there are also people who never play sports at all. According to recent data, $56 \%$ of the Dutch population plays sports at least once a week. For the European Union countries combined this percentage is only $40 \%$ [15]. This shows the importance of further increasing participation rates in (organized) sports.

Sports promotion has a long history in many countries, but the use of the organized sports sector as a setting to gain control over health issues and unhealthy behaviors, like physical inactivity, is a relatively new strategy [16-19]. This settings-based health promotion approach is based on the idea that changes in people's health and health behavior are easier to achieve if health promoters focus on settings instead of individuals. It has also been applied to other settings, like schools and workplaces [20]. The approach builds on the Ottawa Charter of 1986 that stated: "Health is created and lived by people within the settings of their everyday life; where they learn, work, play and love." [21]

In the past few years, different countries have been investing resources in the organized sports sector for promoting health-enhancing physical activity: in Australia, for example, State Sporting Associations were funded to develop healthy (e.g. smoke-free settings) and welcoming environments in their associated clubs, to ultimately increase participation in sport for health benefits $[16,18]$. In the Netherlands, the Dutch Ministry of Health, Welfare and Sport initiated the National Action Plan for Sport and Exercise (NAPSE). This program was aimed at increasing the number of Dutch people meeting physical activity guidelines [17]. Within the NAPSE, National Sports Federations were funded to develop and implement sporting programs tailored to the needs and abilities of the least active population groups, i.e. making sports activities easily accessible and creating a welcoming sports environment for these target groups. A total of fourteen 'easily accessible' sporting programs were 
developed and implemented in different locations in the Netherlands. Start to Run, a sixweek training program for novice runners, developed by the Dutch Athletics Organization, is one of these programs. Participants are given the opportunity to become acquainted with the different aspects of running. Afterwards, they are stimulated to continue running as member of a local athletics club or the Dutch Athletics organization.

Running is a feasible form of a vigorous-intensity physical activity; it is not time consuming, it can be done anywhere and at any time, and only a pair of running shoes is needed. As a result, running is a popular way to become physically active, and there are many different training programs for novice runners available. There is strong literature on the health benefits of running in general and different studies have been published about (the prevention of) running related injuries [e.g. 22-26]. So far, no studies have been conducted, however, about the effectiveness of running programs on increasing healthenhancing physical activity levels. In general, there is a lack of research and evaluation of activities conducted in sports settings. Improvements in the research in this area are desirable. Particularly, there is a need for controlled study designs, incorporating both the short- and longer-term effects of sporting programs and activities, to move towards providing evidence-based programs $[27,28]$.

Therefore, the aim of this study was to assess the effectiveness of Start to Run on increasing health-enhancing physical activity, both in the short- and longer-term, and in comparison with a control group. The results of the current study will contribute to the knowledge base concerning the effectiveness of programs initiated in sports settings, and will, consequently, provide further insight into the role of the organized sports sector in promoting health-enhancing physical activity. The study findings may be of interest to policy makers in the areas of sports and health. Also, sporting organizations may use the results when developing and implementing similar sporting programs.

\section{METHODS}

\section{Study design}

To assess the effectiveness of Start to Run on increasing health-enhancing physical activity, a controlled study design was used. The study was performed according to Dutch legislation on privacy. The privacy regulations of the study were approved by the Dutch Data Protection Authority. According to Dutch legislation, approval by a medical ethics committee was not obligatory, as participants were not subjected to procedures, nor were they required to follow rules of behavior (i.e. participants were approached for the study after they had voluntarily registered for the Start to Run training program). 


\section{Study population}

\section{Start to Run participants}

Start to Run is aimed at adult novice runners who want to learn to run continuously for at least three kilometers. The program is offered two times a year (in March and September) by athletics clubs and running stores in more than hundred different locations in the Netherlands. Participants are recruited locally using different recruitment strategies (e.g. by advertisements in local media, posters, and flyers). For this study, the Dutch Athletics Organization provided data (i.e. name, email address, sex and age) of 513 individuals who had registered for the Start to Run program in March 2009. These individuals were sent an email with information about the study and a link to an online baseline questionnaire. By completing the baseline questionnaire, the Start to Run participants gave consent for participation in the study.

\section{Control group participants}

The control group consisted of members of the Dutch Health Care Consumer Panel of the Netherlands Institute for Health Services Research (NIVEL). This panel contains about three thousand individuals aged 18 years and older and is representative for the Dutch population with regard to age and sex. The panel members are questioned four times a year about health care, health insurance, and other related issues [29]. For the current study, 1328 panel members were approached. Control group participants did not receive any intervention. Moreover, they were asked if they had participated in the Start to Run program or any of the other NAPSE sporting programs before or during the study period, as this could influence results. Subsequently, control group members who had done so were excluded from the study. Compared with the Start to Run group, the control group members were significantly older, and were more likely to be male. As physical activity levels differ by age and sex [ 15 , 30], the control group was matched with the Start to Run group on age and sex.

\section{Start to Run program}

During the six-week training period, except for the last week, participants trained three times a week: one time in a group under guidance of one or more professional coaches (i.e. one coach per 15 participants), and two times individually. As a rule, training days were followed by rest days. In the last week, participants could test their running abilities in a three kilometers test run. Participation in this run, however, was not obligatory. A guided training session lasted approximately 90 minutes and consisted of a theoretical part (20-30 minutes), followed by a practical part (60-70 minutes). During the theoretical part one of the following theory items was discussed: health benefits of running and (prevention of) running-related injuries, running clothes and shoes, proper food and drinks (before, during and after training), physiological changes during running and training with a heart rate monitor. The practical part consisted of a warming-up, a run-walk part, and a cooling-down. 
Participants were instructed to walk and perform light (stretching) exercises to warm up and to cool down. During the warming-up also attention was paid to running technique (e.g. proper posture, stride, foot strike, breathing) and running technique exercises. The run-walk part consisted of a combination of running and walking, whereby running time and distance were gradually increased during the training period. On average there were 35 participants per group session, guided by two professional coaches. An individual training session lasted approximately 45 minutes and consisted, just as the practical part of the group sessions, of a warming-up, a run-walk part, and a cooling-down. Participants received instructions (e.g. training schedule, running tips) for the individual training sessions during the group sessions from their coach(es) and through weekly emails from the Dutch Athletics Organization. After completing the program, participants were stimulated to continue running. Participants were personally informed by their coach(es) about membership from this or other local athletics clubs. Additionally, participants received several emails from the Dutch Athletics Organization with information about local athletics clubs and an individual runner membership of the Dutch Athletics Organization.

\section{Outcome measures}

Demographic data were collected for each participant, including age and sex. The level of physical activity was assessed by the Short QUestionnaire to ASsess Health-enhancing physical activity (SQUASH). This instrument has proven to be fairly reliable and reasonably valid in ordering subjects according to their level of physical activity in an adult population [31]. The SQUASH measures the amount of physical activity for five domains: commuting activities, leisure-time activities, sports activities, household activities, and activities at work and school. It consists of three main queries, namely days per week, average time per day, and self-reported intensity (light, moderate or vigorous). An average week in the past month was taken as reference period. Using the Ainsworth Compendium of Physical Activities, a metabolic equivalent (MET) value, was assigned to all physical activities [32]. Based on age and assigned MET values, physical activities were subdivided into three intensity categories: light, moderate and vigorous. For adults aged $18-54$ years, the following cut-off values were used: < 4.0 MET (light), 4.0 to 6.5 MET (moderate), z 6.5 MET (vigorous). For adults aged $\geq 55$ years, the cut-off values were: $<3.0 \mathrm{MET}$ (light), 3.0 to 5.0 MET (moderate), $\geq 5.0 \mathrm{MET}$ (vigorous). This MET category was combined with self-reported intensity for each activity, resulting in a combined intensity score ranging from 1 to 9 , with 1 being light MET and light self-reported intensity to 9 being vigorous MET and vigorous self-reported intensity. The classification of physical activities according to the combined intensity score was as follows: < 3 (light), 3 to 6 (moderate), $\geq 6$ (vigorous). Subsequently, the following outcome measures were calculated: compliance with the Dutch physical activity guidelines (see Table 2.1); minutes per week spent in light-, moderate- and vigorousintensity activities; minutes per week spent in commuting activities, leisure-time activities, sports activities, household activities, and activities at work and school; and total minutes 
per week spent in physical activity. Compliance with the Dutch physical activity guidelines was seen as the primary outcome measure, as these guidelines specify the amount of physical activity necessary to obtain health benefits. The other physical activity outcome measures were used to explain possible changes in physical activity behavior in more detail.

Start to Run participants were assessed by means of an online questionnaire at baseline $(t=0)$, immediately after completing the program $(t=6$ weeks $)$ and six months after baseline ( $\mathrm{t}=6$ months: i.e. 4.5 months after cessation of the Start to Run training program). Control group participants were assessed at the start of the study $(t=0)$ by means of a postal questionnaire and six months later ( $\mathrm{t}=6$ months) by means of a postal or an online questionnaire. The assessments of the control group were performed in the same months as the assessments of the Start to Run group. To increase response rates, reminders were sent one week (for online questionnaires) or two weeks (for postal questionnaires) later.

\section{Sample size}

The sample size was based on detecting a difference in habitual physical activity according to the Fit-norm. As running is a vigorous-intensity activity, it was expected that the Start to Run program would mostly affect the percentage of people who met the Fit-norm. To detect a 20\% difference between the Start to Run group and the control group six months after baseline, with a two-sided $5 \%$ significance level and a power of $80 \%$, a sample size of 89 participants per group was necessary. Given the sample size of both the Start to Run group ( $n=513)$ and the control group $(n=1328)$, it was expected that sufficient participants were included in the study.

\section{Statistical analysis}

All statistical analyses were performed using Stata statistical software version 10.1 (Stata Corporation, College Station, Texas). Descriptive statistics were used to describe the main characteristics of each group and to explore baseline comparability. Means and standard deviations were calculated for continuous measures, while percentages were calculated for dichotomous measures. Differences between groups with regard to age and sex were tested with an independent t-test and chi-squared test, respectively. Changes in physical activity within groups were examined with paired t-tests for continuous physical activity measures and McNemar tests for dichotomous physical activity measures. To compare changes in physical activity between groups, multiple regression analyses (linear regression was used for continuous measures and logistic regression was used for dichotomous measures) were performed with physical activity level at six months as the dependent variable and group (Start to Run group versus control group, with the control group as the reference category) as the independent variable. Adjustments were made for baseline physical activity levels, by using this variable as a covariate in the regression model. To check if the results of the 
continuous physical activity outcome measures were influenced by outliers, also more robust regression techniques were applied: these techniques included the use of robust standard errors (i.e. Huber-White robust estimates of the standard errors and bootstrap estimates of the standard errors). As these robust regression techniques did not yield different results and conclusions, these results will not be presented here. P-values less than 0.05 were considered statistically significant.

\section{RESULTS}

\section{Study participants}

The flow of participants through the study is shown in Figure 2.1.

\section{Start to Run participants}

Of 513 persons approached, 244 completed the baseline assessment. Of these 244 persons, 125 completed the assessment at six weeks. Two persons were excluded from analysis, because compliance with the Dutch physical activity guidelines could not be calculated. Therefore, data of 123 persons were available to evaluate changes in physical activity after six weeks. All persons who completed the baseline assessment $(n=244)$ were also approached for the assessment at six months, irrespective if they had completed the assessment at six weeks. This was done to get an optimal response for comparisons with the control group. Of 244 persons approached, 104 completed the assessment at six months. Subsequently, four persons were excluded from analysis, because compliance with the Dutch physical activity guidelines could not be calculated. Consequently, data of 100 persons were available to evaluate changes in physical activity after six months and to make comparisons with the control group. There were 78 Start to Run participants who completed all three assessments (not shown in Figure 2.1). However, to optimally use data and maintain study power (i.e. for comparisons with the control group a sample size of 89 participants per group was necessary) all available cases were included in the analyses. This means that analyses were performed on 123 and 100 Start to Run participants for effects after six weeks and six months, respectively. Non-response analyses revealed that Start to Run participants who did not complete the assessment after six months were significantly younger ( $37 \pm 9$ years vs. $40 \pm 10$ years) and were more likely to be female ( $92.4 \%$ female vs. $70.0 \%$ female) compared with those who did complete this assessment. There were no significant differences in baseline physical activity levels between respondents and non-respondents. 


\section{Control group participants}

Of 1328 persons approached, 940 completed the baseline assessment. Of these 940 persons, 745 completed the assessment at six months. Subsequently, 46 persons were excluded from analysis due to participation in the Start to Run program $(n=2)$ or any of the other NAPSE sporting programs $(n=44)$. In addition, six other persons were excluded, because compliance with the Dutch physical activity guidelines could not be calculated. Of the remaining 693 persons, 100 were matched to the Start to Run group on age and sex.

\section{Figure 2.1 Flow of participants through the study}

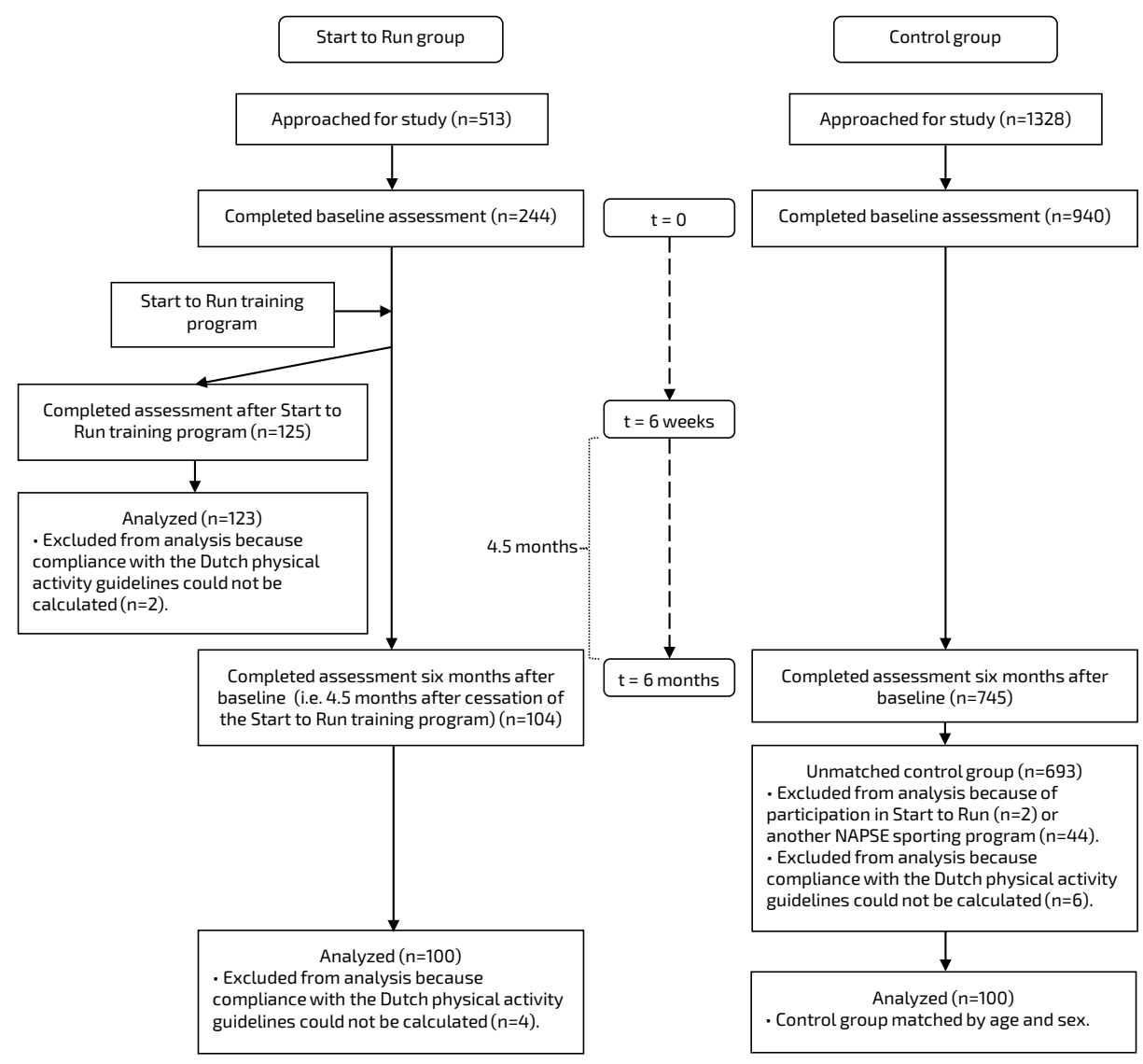




\section{Baseline characteristics of study participants}

The baseline characteristics of the Start to Run group (i.e. the participants who completed the six months assessment) and the control group are shown in Table 2.2. The Start to Run participants had a mean age of 40 years $(S D=10)$ and the control group participants had a mean age of 42 years ( $S D=9)$. The percentage of women was $70.0 \%$ in both groups. There were no significant differences in age and sex between groups. Matching was therefore successful. With regard to baseline physical activity levels, the Start to Run participants spent significantly less time in moderate-intensity physical activities ( $213 \pm 453 \mathrm{~min} /$ week vs. $406 \pm 596 \mathrm{~min} /$ week, $\mathrm{p}=0.01$ ) and household activities (552 $\pm 780 \mathrm{~min} /$ week vs. $919 \pm 968$ $\mathrm{min} /$ week, $\mathrm{p}=0.004$ ) compared with controls. For the remaining physical activity outcome measures, no significant differences were found between groups at baseline.

Table 2.2 Baseline characteristics of the Start to Run group and control group

\begin{tabular}{|c|c|c|c|}
\hline & $\begin{array}{l}\text { Start to Run } \\
\text { group }^{a}\end{array}$ & Control group & $\mathbf{P}$ \\
\hline Sample size (n) & 100 & 100 & \\
\hline \multicolumn{4}{|l|}{ Age (years) } \\
\hline Mean \pm SD & $40 \pm 10$ & $42 \pm 9$ & 0.12 \\
\hline Min-max & $21-71$ & $23-77$ & \\
\hline \multicolumn{4}{|l|}{ Sex (\%) } \\
\hline Male & 30.0 & 30.0 & 1.0 \\
\hline Female & 70.0 & 70.0 & \\
\hline \multicolumn{4}{|l|}{ Dutch physical activity guidelines (\%) } \\
\hline Compliance with DNHPA & 48.0 & 59.0 & 0.12 \\
\hline Compliance with Fit-norm & 56.0 & 55.0 & 0.89 \\
\hline Compliance with Combi-norm & 58.0 & 65.0 & 0.31 \\
\hline \multicolumn{4}{|l|}{ Physical activity by intensity, mean \pm SD $(\mathrm{min} /$ week $)$} \\
\hline Light-intensity activities & $1814 \pm 1224$ & $1958 \pm 1263$ & 0.42 \\
\hline Moderate-intensity activities & $213 \pm 453$ & $406 \pm 596$ & $0.01^{*}$ \\
\hline Vigorous-intensity activities & $238 \pm 250$ & $253 \pm 337$ & 0.73 \\
\hline \multicolumn{4}{|l|}{ Physical activity by domain, mean \pm SD $(\mathrm{min} /$ week $)$} \\
\hline Commuting activities & $88 \pm 137$ & $117 \pm 251$ & 0.30 \\
\hline Leisure-time activities & $257 \pm 296$ & $328 \pm 407$ & 0.16 \\
\hline Sports activities & $126 \pm 166$ & $107 \pm 147$ & 0.40 \\
\hline Household activities & $552 \pm 780$ & $919 \pm 968$ & $0.004^{*}$ \\
\hline Activities at work and school & $1309 \pm 935$ & $1182 \pm 951$ & 0.35 \\
\hline $\begin{array}{l}\text { Total time spent in physical activity, mean } \pm \text { SD } \\
\text { (min/week) }\end{array}$ & $2265 \pm 1251$ & $2616 \pm 1356$ & 0.06 \\
\hline
\end{tabular}

a Start to Run participants who completed the six months assessment.

* Significant $(p<0.05)$ difference between groups. 


\section{Changes in physical activity}

\section{Changes in physical activity after six weeks}

In Table 2.3, physical activity outcome measures are presented for the Start to Run group at baseline and after six weeks. At baseline, $43.9 \%$ of the Start to Run participants met the DNHPA, 53.7\% met the Fit-norm, and 57.7\% met the Combi-norm. After six weeks, these percentages increased significantly $(p<0.0001)$ to $74.8 \%, 87.0 \%$, and $91.1 \%$ for the DNHPA, Fit-norm, and Combi-norm, respectively. Although more Start to Run participants met physical activity guidelines after six weeks, the total time spent in physical activity did not change significantly (2237 \pm 1183 min/week vs. $1996 \pm 1451$ min/week, p=0.08). However, there were significant changes in physical activity behavior within physical activity intensity categories and domains, i.e. after six weeks, the Start to Run participants spent more time in vigorous-intensity activities (200 $\pm 205 \mathrm{~min} /$ week vs. $410 \pm 298 \mathrm{~min} /$ week, $p<0.0001)$, commuting activities (70 $\pm 110 \mathrm{~min} /$ week vs. $98 \pm 155 \mathrm{~min} /$ week, $\mathrm{p}=0.01$ ), leisure-time activities ( $240 \pm 268 \mathrm{~min} /$ week vs. $301 \pm 343 \mathrm{~min} /$ week, $\mathrm{p}=0.02)$ and sports activities (101 \pm $143 \mathrm{~min} /$ week vs. $243 \pm 173 \mathrm{~min} /$ week, $\mathrm{p}<0.0001$ ), while less time was spent in light-intensity activities (1827 $\pm 1192 \mathrm{~min} /$ week vs. $1423 \pm 1296 \mathrm{~min} /$ week, $\mathrm{p}=0.002$ ) and activities at work and school (1293 $\pm 940 \mathrm{~min} /$ week vs. $792 \pm 794 \mathrm{~min} /$ week, $\mathrm{p}<0.0001)$.

Table 2.3 Start to Run group: changes in physical activity after six weeks

\begin{tabular}{|c|c|c|c|}
\hline \multirow[t]{2}{*}{ Outcome measures } & \multicolumn{3}{|c|}{ Start to Run group ( $n=123)$} \\
\hline & Baseline & After six weeks & $\mathrm{Pa}$ \\
\hline \multicolumn{4}{|l|}{ Dutch physical activity guidelines (\%) } \\
\hline Compliance with DNHPA & 43.9 & 74.8 & $<0.0001^{*}$ \\
\hline Compliance with Fit-norm & 53.7 & 87.0 & $<0.0001^{*}$ \\
\hline Compliance with Combi-norm & 57.7 & 91.1 & $<0.0001^{*}$ \\
\hline \multicolumn{4}{|l|}{ Physical activity by intensity, mean \pm SD $(\mathrm{min} /$ week $)$} \\
\hline Light-intensity activities & $1827 \pm 1192$ & $1423 \pm 1296$ & $0.002^{*}$ \\
\hline Moderate-intensity activities & $209 \pm 462$ & $163 \pm 253$ & 0.21 \\
\hline Vigorous-intensity activities & $200 \pm 205$ & $410 \pm 298$ & $<0.0001^{*}$ \\
\hline \multicolumn{4}{|l|}{ Physical activity by domain, mean \pm SD (min/week) } \\
\hline Commuting activities & $70 \pm 110$ & $98 \pm 155$ & $0.01^{*}$ \\
\hline Leisure-time activities & $240 \pm 268$ & $301 \pm 343$ & $0.02^{*}$ \\
\hline Sports activities & $101 \pm 143$ & $243 \pm 173$ & $<0.0001^{*}$ \\
\hline Household activities & $563 \pm 759$ & $614 \pm 887$ & 0.43 \\
\hline Activities at work and school & $1293 \pm 940$ & $792 \pm 794$ & $<0.0001^{*}$ \\
\hline Total time spent in physical activity, mean \pm SD $(\mathrm{min} /$ week $)$ & $2237 \pm 1183$ & $1996 \pm 1451$ & 0.08 \\
\hline
\end{tabular}

\footnotetext{
a P-value for difference in physical activity within the Start to Run group.

* Significant $(p<0.05)$ change in physical activity after six weeks within the Start to Run group.
} 


\section{Changes in physical activity after six months: comparisons within groups}

In Table 2.4, physical activity outcome measures are presented for both the Start to Run group and control group at baseline and after six months. In the Start to Run group, the percentage of people who met the DNHPA (48.0\% vs. 64.0\%, p=0.004), Fit-norm (56.0\% vs. $82.0 \%, p<0.0001)$, and Combi-norm ( $58.0 \%$ vs. $84.0 \%, p<0.0001)$ increased significantly between baseline and six months. These changes were accompanied by a significant increase in the total time spent in physical activity (2265 $\pm 1251 \mathrm{~min} /$ week vs. $2536 \pm 1210$ $\mathrm{min} /$ week, $\mathrm{p}=0.04$ ). Also, significant changes in physical activity behavior were observed within physical activity intensity categories and domains, i.e. after six months, the Start to Run participants spent more time in vigorous-intensity activities ( $238 \pm 250 \mathrm{~min} /$ week vs. $382 \pm 306 \mathrm{~min} /$ week, $p<0.0001$ ), commuting activities ( $88 \pm 137 \mathrm{~min} /$ week vs. $132 \pm 181 \mathrm{~min} /$ week, $p=0.006)$ and sports activities ( $126 \pm 166 \mathrm{~min} /$ week vs. $225 \pm 182 \mathrm{~min} /$ week, $p<0.0001)$. In contrast, the control group participants did not significantly change their physical activity behavior between baseline and six months.

Table 2.4 Changes in physical activity after six months: comparisons within groups

\begin{tabular}{|c|c|c|c|c|c|c|}
\hline \multirow[t]{2}{*}{ Outcome measures } & \multicolumn{3}{|c|}{ Start to Run group ( $n=100)$} & \multicolumn{3}{|c|}{ Control group $(n=100)$} \\
\hline & Baseline & $\begin{array}{l}\text { After six } \\
\text { months }\end{array}$ & $\mathrm{Pa}^{\mathrm{a}}$ & Baseline & $\begin{array}{l}\text { After six } \\
\text { months }\end{array}$ & $\mathrm{P}^{\mathrm{b}}$ \\
\hline \multicolumn{7}{|l|}{ Dutch physical activity guidelines (\%) } \\
\hline Compliance with DNHPA & 48.0 & 64.0 & $0.004^{*}$ & 59.0 & 62.0 & 0.68 \\
\hline Compliance with Fit-norm & 56.0 & 82.0 & $<0.0001^{\star}$ & 55.0 & 57.0 & 0.83 \\
\hline Compliance with Combi-norm & 58.0 & 84.0 & $<0.0001^{*}$ & 65.0 & 73.0 & 0.10 \\
\hline \multicolumn{7}{|l|}{$\begin{array}{l}\text { Physical activity by intensity, mean } \\
\text { × SD (min/week) }\end{array}$} \\
\hline Light-intensity activities & $1814 \pm 1224$ & $1947 \pm 1043$ & 0.31 & $1958 \pm 1263$ & $1972 \pm 1181$ & 0.90 \\
\hline Moderate-intensity activities & $213 \pm 453$ & $206 \pm 369$ & 0.88 & $406 \pm 596$ & $450 \pm 740$ & 0.47 \\
\hline Vigorous-intensity activities & $238 \pm 250$ & $382 \pm 306$ & $<0.0001^{\star}$ & $253 \pm 337$ & $238 \pm 286$ & 0.60 \\
\hline \multicolumn{7}{|l|}{$\begin{array}{l}\text { Physical activity by domain, mean } \pm \\
\text { SD (min/week) }\end{array}$} \\
\hline Commuting activities & $88 \pm 137$ & $132 \pm 181$ & $0.006^{*}$ & $117 \pm 251$ & $124 \pm 215$ & 0.80 \\
\hline Leisure-time activities & $257 \pm 296$ & $276 \pm 358$ & 0.48 & $328 \pm 407$ & $325 \pm 515$ & 0.91 \\
\hline Sports activities & $126 \pm 166$ & $225 \pm 182$ & $<0.0001^{*}$ & $107 \pm 147$ & $108 \pm 142$ & 0.96 \\
\hline Household activities & $552 \pm 780$ & $585 \pm 597$ & 0.66 & $919 \pm 968$ & $807 \pm 856$ & 0.15 \\
\hline Activities at work and school & $1309 \pm 935$ & $1381 \pm 864$ & 0.49 & $1182 \pm 951$ & $1322 \pm 887$ & 0.11 \\
\hline $\begin{array}{l}\text { Total time spent in physical } \\
\text { activity, mean } \pm \text { SD (min/week) }\end{array}$ & $2265 \pm 1251$ & $2536 \pm 1210$ & $0.04^{*}$ & $2616 \pm 1356$ & $2660 \pm 1126$ & 0.73 \\
\hline
\end{tabular}

\footnotetext{
a P-value for difference in physical activity within the Start to Run group.

${ }^{\mathrm{b}} \mathrm{P}$-value for difference in physical activity within the control group.

* Significant $(p<0.05)$ change in physical activity after six months within the Start to Run group.
} 


\section{Changes in physical activity after six months: comparisons between groups}

The results of the multiple linear and logistic regression analyses are presented in Table 2.5. After six months, significantly more Start to Run participants compared with control group participants were meeting the Fit-norm (OR=5.1; 95\% Cl: 2.3-11.1, $p<0.001)$ and Combinorm ( $\mathrm{OR}=3.3 ; 95 \% \mathrm{Cl}: 1.4-7.7, \mathrm{p}=0.006)$. In addition, significant effects were found in favor of the Start to Run group concerning physical activity intensity categories and domains: after six months, the Start to Run participants were spending more time in vigorous-intensity activities (an average of $152 \mathrm{~min} /$ week more: $b=152 ; 95 \% \mathrm{Cl}: 80-223, \mathrm{p}<0.001$ ) and sports activities (an average of $107 \mathrm{~min} /$ week more: $b=107 ; 95 \% \mathrm{Cl}: 69-145, p<0.001$ ) compared with controls. For the remaining physical activity outcome measures, no significant differences were found between groups.

Table 2.5 Changes in physical activity after six months: comparisons between groups

\begin{tabular}{llll}
\hline Dichotomous outcome measures & OR (group variable) & 95\% Cl & P (group variable) \\
\hline $\begin{array}{l}\text { Dutch physical activity guidelines } \\
\quad \text { Compliance with DNHPA }\end{array}$ & 1.5 & $0.8-3.0$ & 0.22 \\
$\quad$ Compliance with Fit-norm & 5.1 & $2.3-11.1$ & $<0.001^{*}$ \\
$\quad$ Compliance with Combi-norm & 3.3 & $1.4-7.7$ & $0.006^{*}$ \\
\hline Continuous outcome measures & b-coefficient & $\mathbf{9 5 \%} \mathbf{C l}$ & $\mathbf{P}$ (group variable) \\
& (group variable) & & \\
\hline Physical activity by intensity & & & \\
$\quad$ Light-intensity activities & 38 & $-234-311$ & 0.78 \\
$\quad$ Moderate-intensity activities & -126 & $-265-12$ & 0.07 \\
$\quad$ Vigorous-intensity activities & 152 & $80-223$ & $<0.001^{*}$ \\
Physical activity by domain & & & \\
$\quad$ Commuting activities & 22 & $-27-71$ & 0.37 \\
Leisure-time activities & 19 & $-63-101$ & 0.65 \\
Sports activities & 107 & $69-145$ & $<0.001^{*}$ \\
Household activities & -45 & $-220-131$ & 0.62 \\
Activities at work and school & 5 & $-216-226$ & 0.96 \\
Total time spent in physical activity & 20 & $-274-313$ & 0.90 \\
\hline
\end{tabular}

\footnotetext{
a Multiple (linear or logistic) regression analyses were conducted with physical activity level at six months as the dependent variable, and group (Start to Run group versus control group, with the control group as the reference category) as the independent variable. Adjustments were made for baseline physical activity levels.

b Unstandardized regression coefficient.

* Significant $(p<0.05)$ difference in physical activity between groups.
} 


\section{DISCUSSION}

The aim of this study was to assess the effectiveness of Start to Run, a six-week training program for novice runners, on increasing health-enhancing physical activity, both in the short- and longer-term. In the Start to Run group, short- and longer-term beneficial within group effects were observed. In the control group, however, there were no significant changes in physical activity behavior within a period of six months. When comparing results between groups, the Start to Run program produced significant positive changes in health-enhancing physical activity levels: after six months, significantly more Start to Run participants compared with control group participants were meeting the Fit-norm and Combi-norm. The differences in the amount of physical activity between groups in favor of the Start to Run group could be explained by an increase in the time spent in vigorousintensity activities (physical activity intensity category) and sports activities (physical activity domain).

As running is a vigorous-intensity sports activity, these results are not surprising. This is especially true for the assessment after six weeks. More interesting is the fact that these outcome measures were also positively affected at the six months assessment. Considering the higher levels of vigorous-intensity physical activity and sports activity, the results suggest that most Start to Run participants were still running even 4.5 months after cessation of the Start to Run training program. Some additional results, not presented in the results section, confirm that this was indeed the case: at the six months assessment, running behavior was also directly assessed by a single question: "Are you (still) running at this moment?" The results of this question showed that $69.0 \%$ of the Start to Run participants was still performing running activities (see Appendix 2.1: Additional results evaluation Start to Run program). Based on these findings, it seems that Start to Run can recruit people that are insufficiently active; motivate them to take up running; and also frequently and long enough to meet levels of health-enhancing physical activity (as measured by the Fit-norm and Combi-norm). Consequently, Start to Run can positively contribute to improving health of participants.

To sustain health benefits, however, it is important that this running behavior is maintained, i.e. that the Start to Run participants continue to run on a regular basis. Often maintenance is defined as implementing behavior change for at least six months after cessation of intervention [33]. Since the last assessment of physical activity was 4.5 months after cessation of the Start to Run training program, it is difficult to ascertain whether sustained changes in physical activity behavior have been reached according to this definition of maintenance. Others, however, do not define maintenance as sustaining behavior change over a specified period of time. Rothman (2000), for example, rather looks at the processes that govern behavioral maintenance and he argues that people will maintain a change in behavior only if they are satisfied with the new behavior [34]. The Start to Run participants gave the overall training program a rating of 8.2 (scale $0-10$; 0 being 
very poor and 10 being excellent) (see Appendix 2.1: Additional results evaluation Start to Run program). Moreover, the fact that most Start to Run participants were still running 4.5 months after cessation of the Start to Run training program, may on its own indicate that they were satisfied with their new running behavior and thus will continue running. Nonetheless, definite conclusions cannot be drawn and follow-up assessments over longer periods of time are necessary to establish if the Start to Run participants continue their newly acquired physical activity behavior.

With regard to maintaining physical activity levels, the organized sports sector itself may play an important role. In this sector, physical activity opportunities are provided on a continuous basis (i.e. people can play sports on a weekly basis at a sports club). When first providing an easily accessible sporting program, like Start to Run, the next step, i.e. participation in organized sports on a continuous basis, may be facilitated. After completing the program, the Start to Run participants were stimulated to continue running as a member of a local athletics club or the Dutch Athletics Organization. At the six months assessment, $41.0 \%$ of the Start to Run participants reported that they became (and still were) a member of a local athletics club or the Dutch Athletics Organization, as a result of participation in the Start to Run training program (see Appendix 2.1: Additional results evaluation Start to Run program). These data suggest that an easily accessible sporting program, like Start to Run, may indeed facilitate participation in organized sports. The role of the organized sports sector in both increasing and maintaining health-enhancing physical activity levels should therefore be further explored.

Next to significant increases in vigorous-intensity physical activity and sports activity, the study had some other interesting findings: after six weeks, the Start to Run participants were spending significantly more time in commuting activities and leisure-time activities. These results suggest that Start to Run may have led to increases in physical activity in these domains. However, in the same period, there was also a significant decrease in the time spent in work and school activities and, consequently, light-intensity activities. These results indicate that, at six weeks, physical activity levels may have been influenced by other factors, like weather conditions, season and/or holidays. The influence of these factors on commuting activities, leisure-time activities and activities at work and school seems plausible, since no effects were found on these outcome measures at the six months assessment when compared with the control group. Yet, without an assessment of the control group at six weeks, some uncertainty remains.

Another interesting finding is that Start to Run did not directly affect the total time spent in physical activity. Despite no significant increases in the total time spent in physical activity, additional health benefits are obtained due to participation in Start to Run: as mentioned before, the increases in sports activity/vigorous-intensity physical activity were substantial, and resulted in more Start to Run participants meeting minimum recommended amounts of vigorous-intensity physical activity for health benefits. Also, there is evidence that vigorous-intensity physical activities, like running, lead to even greater improvements in aerobic fitness and greater reductions in cardiovascular disease and mortality risk than 
moderate- or light-intensity physical activities, which is independent of their contribution to energy expenditure [35-37].

To our knowledge, this is the first study evaluating the effectiveness of a training program aimed at novice runners on increasing health-enhancing physical activity. In general, there is a lack of research and evaluation of activities conducted in sports settings, especially of controlled study designs incorporating both the short- and longer-term effects $[27,28]$. Therefore, it is difficult to compare these results with those of previous studies. Most comparable studies would be physical activity intervention studies, and a lot of research has been done in this area [e.g. 38, 39]: some physical activity interventions that prescribed running positively affected physical activity behavior of participants. However, comparability is still limited, as these physical activity interventions did not focus on running per se, were often multi-component, took place in non-sports settings and used different outcome measures.

There are some limitations to this study that should be mentioned. First of all, the design of the study does not allow drawing any conclusions on which specific aspect of the Start to Run program (e.g. group sessions, individual sessions, test run) is most important for increasing (and continuing) physical activity. Moreover, participants' compliance with the different program components was not measured, making it even more difficult to disentangle the most effective program parts. Second, in this study, a self-report measure of physical activity was used. Despite their common use, there are several limitations of self-report tools, including inaccurate recall of the frequency, duration and intensity of physical activity, problems with question comprehension and interpretation, and social desirability bias which can lead to over-reporting of physical activity [40]. However, any inaccuracies are assumed to be random and among both groups. It is therefore unlikely that these potential sources of bias explain the differences in physical activity between the Start to Run group and control group. Self-report measures have the advantage that they are able to collect data from a large number of people at low costs. The SQUASH questionnaire itself has some distinct advantages compared with other physical activity questionnaires: it is short, quick to fill in (3-5 minutes), it measures the amount of physical activity (separately) for five different domains and provides the opportunity to estimate compliance with physical activity guidelines. An alternative to self-report measures is to use more objective instruments to measure physical activity, like accelerometers and heart rate monitors. Compared with self-report measures, objective instruments are more expensive and logistically more difficult to administer on a large scale. For these reasons, it was decided to use a self-report measure. Nonetheless, it would be interesting to see if the results of this study could be replicated with such an objective measure. Third, due to the voluntary nature of participation in the Start to Run training program, the possibility of selection bias cannot be entirely excluded. It could be that people who registered for Start to Run were already highly motivated to increase physical activity levels. Therefore, the findings of this study may not pertain to inactive individuals, i.e. the ones who are often less motivated to increase physical activity levels. On the other hand, also a large group of people who did not meet physical activity guidelines was attracted by the Start to Run 
training program (i.e. almost half of the Start to Run participants), which may indicate that the program is also suited for this population group. Although this voluntary participation into Start to Run might have caused selection bias, it is a strength of the study as well. First of all, behavior was not forced. Next to that, the study population of Start to Run was a sample of the actual Start to Run population. The Start to Run participants in this study had a mean age of 40 years and the percentage of women was 70.0\%. Demographic data collected by the Dutch Athletics Organization of the entire Start to Run population in March 2009 ( $n=4230)$ show that the study sample is representative for the entire Start to Run population with regard to age and sex: the average age of the entire Start to Run population was also 40 years and $77.8 \%$ of participants was female. Thus, the study was performed in a generalizable group. Moreover, since the study was performed in a real-world setting, namely the sports setting, results are directly transferable into practice. Finally, in this study, it was not possible to ascertain why more than half of the Start to Run participants dropped out of the study between the baseline and six months assessment. It is very difficult to determine why participants did not fill in this questionnaire, because no followup data were available of these persons. There could be cases that did not respond to the invitation to fill in this questionnaire because they stopped running (e.g. due to an injury or a bad running experience). Given the very low drop-out rate of the Start to Run training program (according to the Dutch Athletics Organization, only $2.2 \%$ of the participants dropped out of the Start to Run training program) and the (already) relatively high dropout in this the study after six weeks, this seems not a plausible explanation. With regard to baseline characteristics, non-respondents were somewhat younger and more likely to be female. There were, however, no significant differences in baseline physical activity levels between respondents and non-respondents. Therefore, the most likely explanation for the non-response is that participants were not motivated to participate in a scientific study and filling in a questionnaire. Furthermore, since no differences in baseline physical activity levels were found between respondents and non-respondents, it is unlikely that these losses to follow-up influenced study results substantially.

\section{CONCLUSIONS}

Considering the above-mentioned limitations, this study does add to the knowledge base concerning the effectiveness of programs initiated in sports settings. The results indicate that an easily accessible program, like Start to Run, organized by a sporting organization, can positively influence levels of health-enhancing physical activity of participants, both in the short- and longer-term. Consequently, Start to Run can lead to tangible health benefits among its participants. Based on these results, the use of the organized sports sector as a setting to promote health-enhancing physical activity seems promising. However, further research is needed to establish maintenance of physical activity behavior and 
generalizability of these results to other (easily accessible) sporting programs. Moreover, the role of the organized sports sector in maintaining health-enhancing physical activity levels should be further explored. In future studies, it is also recommended to include more in-depth analyses. It is, for example, important to investigate which population groups benefit most from a program like Start to Run (e.g. men vs. women, young adults vs. older adults, obese vs. non-obese people) and to establish the relative effectiveness of program parts. Research in the area of effectiveness of sporting programs in increasing health-enhancing physical activity is still lacking. These data will hopefully encourage policy makers and sporting organizations to both develop and rigorously evaluate easily accessible sporting programs. In this way, more knowledge about the role of the organized sports sector in both promoting and maintaining health-enhancing physical activity can be acquired. 


\section{REFERENCES}

1. Gill JM, Cooper AR. Physical activity and prevention of type 2 diabetes mellitus. Sports Med. 2008;38:807-824.

2. Jakicic JM. The effect of physical activity on body weight. Obesity (Silver Spring). 2009;17(Suppl.3):S34-S38.

3. Schmitt NM, Schmitt J, Doren M. The role of physical activity in the prevention of osteoporosis in postmenopausal women-An update. Maturitas. 2009;63:34-38.

4. Sherrington C, Whitney JC, Lord SR, Herbert RD, Cumming RG, Close JC. Effective exercise for the prevention of falls: a systematic review and meta-analysis. J Am Geriatr Soc. 2008;56:22342243.

5. Sofi F, Capalbo A, Cesari F, Abbate R, Gensini GF. Physical activity during leisure time and primary prevention of coronary heart disease: an updated meta-analysis of cohort studies. Eur J Cardiovasc Prev Rehabil. 2008;15:247-257.

6. Thune I, Furberg AS. Physical activity and cancer risk: dose-response and cancer, all sites and site-specific. Med Sci Sports Exerc. 2001;33:S530-5550.

7. Wendel-Vos GC, Schuit AJ, Feskens EJ, Boshuizen HC, Verschuren WM, Saris WH, Kromhout D. Physical activity and stroke. A meta-analysis of observational data. Int J Epidemiol. 2004;33:787798.

8. Bize R, Johnson JA, Plotnikoff RC. Physical activity level and health-related quality of life in the general adult population: a systematic review. Prev Med. 2007:45:401-415.

9. Ströhle A. Physical activity, exercise, depression and anxiety disorders. J Neural Transm. 2009;116:777-784.

10. Haskell WL, Lee IM, Pate RR, Powell KE, Blair SN, Franklin BA, Macera CA, Heath GW, Thompson PD, Bauman A. Physical activity and public health: updated recommendation for adults from the American College of Sports Medicine and the American Heart Association. Med Sci Sports Exerc. 2007;39:1423-1434.

11. Hildebrandt VH, Chorus AMJ, Stubbe JH. Trend report of physical activity and health 2008/2009 (report in Dutch). Leiden: TNO Quality of Life; 2010.

12. Eyler AA, Brownson RC, Donatelle RJ, King AC, Brown D, Sallis JF. Physical activity social support and middle- and older-aged minority women: results from a US survey. Soc Sci Med. 1999:49:781-789.

13. Sallis JF, Hovell MF, Hofstetter CR. Predictors of adoption and maintenance of vigorous physical activity in men and women. Prev Med. 1992;21:237-251.

14. Wendel-Vos W, Droomers M, Kremers S, Brug J, van Lenthe F. Potential environmental determinants of physical activity in adults: a systematic review. Obes Rev. 2007;8(5):425-440.

15. European Commission. Sport and physical activity. Special Eurobarometer 334/Wave 72.3. Brussels: TNS Opinion \& Social; 2010.

16. Dobbinson SJ, Hayman JA, Livingston PM. Prevalence of health promotion policies in sports clubs in Victoria, Australia. Health Promot Int. 2006;21(2):121-129. 
17. Dutch Ministry of Health, Welfare and Sport. Time for sport: exercise, participate, perform. The Hague: Dutch Ministry of Health, Welfare and Sport; 2005.

18. Eime RM, Payne WR, Harvey JT. Making sporting clubs healthy and welcoming environments: a strategy to increase participation. J Sci Med Sport. 2008;11(2):146-154.

19. Kokko S, Kannas L, Villberg J. The health promoting sports club in Finland--a challenge for the settings-based approach. Health Promot Int. 2006;21(3):219-229.

20. Whitelaw S, Baxendale A, Bryce C, MacHardy L, Young I, Witney E. 'Settings' based health promotion: a review. Health Promot Int. 2001;16(4):339-353.

21. World Health Organization (WHO): Ottawa Charter for Health Promotion. Geneva: WHO; 1986.

22. Buist I, Bredeweg SW, van Mechelen W, Lemmink KA, Pepping GJ, Diercks RL. No effect of a graded training program on the number of running-related injuries in novice runners: a randomized controlled trial. Am J Sports Med. 2008;36:33-39.

23. Chakravarty EF, Hubert HB, Lingala VB, Fries JF. Reduced disability and mortality among aging runners: a 21-year longitudinal study. Arch Intern Med. 2008;168:1638-1646.

24. Koplan JP, Powell KE, Sikes RK, Shirley RW, Campbell CC. An epidemiologic study of the benefits and risks of running. JAMA. 1982;248:3118-3121.

25. Taunton JE, Ryan MB, Clement DB, McKenzie DC, Lloyd-Smith DR, Zumbo BD. A prospective study of running injuries: the Vancouver Sun Run "In Training" clinics. Br J Sports Med. 2003;37:239244.

26. Williams PT. A cohort study of incident hypertension in relation to changes in vigorous physical activity in men and women. J Hypertens. 2008;26:1085-1093.

27. Priest N, Armstrong R, Doyle J, Waters E. Interventions implemented through sporting organisations for increasing participation in sport. Cochrane Database Syst Rev. 2008(3). Art. No.: CD004812. DOI: 10.1002/14651858.CD004812.pub3.

28. Priest N, Armstrong R, Doyle J, Waters E. Policy interventions implemented through sporting organisations for promoting healthy behaviour change. Cochrane Database Syst Rev. 2008(3). Art. No.: CD004809. DOI: 10.1002/14651858.CD004809.pub3.

29. Reitsma-van Rooijen M, de Jong JD. Health Care Consumer Panel: basic report with information about the panel, 2009 (report in Dutch). Utrecht: Netherlands Institute for Health Services Research (NIVEL); 2009.

30. Bauman A, Bull F, Chey T, Craig CL, Ainsworth BE, Sallis JF, Bowles HR, Hagstromer M, Sjostrom $M$, Pratt $M$. The international prevalence study on physical activity: results from 20 countries. Int J Behav Nutr Phys Act. 2009;6:21.

31. Wendel-Vos GC, Schuit AJ, Saris WH, Kromhout D. Reproducibility and relative validity of the short questionnaire to assess health-enhancing physical activity. J Clin Epidemiol. 2003;56:11631169.

32. Ainsworth BE, Haskell WL, Whitt MC, Irwin ML, Swartz AM, Strath SJ, O'Brien WL, Bassett DR Jr, Schmitz KH, Emplaincourt PO, Jacobs DR Jr, Leon AS. Compendium of physical activities: an update of activity codes and MET intensities. Med Sci Sports Exerc. 2000;32:5498-S504.

33. Marcus BH, Dubbert PM, Forsyth LH, McKenzie TL, Stone EJ, Dunn AL, Blair SN. Physical activity behavior change: issues in adoption and maintenance. Health Psychol. 2000;19:32-41. 
34. Rothman AJ. Toward a theory-based analysis of behavioral maintenance. Health Psychol. 2000;19:64-69.

35. Lee IM, Paffenbarger RS Jr. Associations of light, moderate, and vigorous intensity physical activity with longevity. The Harvard Alumni Health Study. Am J Epidemiol. 2000;151:293-299.

36. Swain DP. Moderate or vigorous intensity exercise: which is better for improving aerobic fitness? Prev Cardiol. 2005;8:55-58.

37. Swain DP, Franklin BA. Comparison of cardioprotective benefits of vigorous versus moderate intensity aerobic exercise. Am J Cardiol. 2006;97:141-147.

38. Foster C, Hillsdon M, Thorogood M. Interventions for promoting physical activity. Cochrane Database Syst Rev. 2005(1). Art. No.: CD003180. DOI: 10.1002/14651858.CD003180.pub2.

39. Marcus BH, Williams DM, Dubbert PM, Sallis JF, King AC, Yancey AK, Franklin BA, Buchner D, Daniels SR, Claytor RP. Physical activity intervention studies: what we know and what we need to know: a scientific statement from the American Heart Association Council on Nutrition, Physical Activity, and Metabolism (Subcommittee on Physical Activity); Council on Cardiovascular Disease in the Young; and the Interdisciplinary Working Group on Quality of Care and Outcomes Research. Circulation. 2006;114:2739-2752.

40. Sallis JF, Saelens BE. Assessment of physical activity by self-report: status, limitations, and future directions. Res Q Exerc Sport. 2000;71:51-14. 


\section{APPENDIX 2.1}

\section{Additional results evaluation Start to Run program}

Table A2.1.1 Start to Run group: running behavior and membership at the six months assessment

Start to Run group $(n=100)$

Percentage of participants that is (still) running $69.0 \%$

Percentage of participants that became (and still is) a member

$41.0 \%$ of a local athletics club or the Dutch Athletics Organization due to participation in Start to Run

Table A2.1.2 Overall rating Start to Run training program

Start to Run group $(n=123)$

Rating (scale $0-10$; 0 being very poor and 10 being excellent), mean \pm SD

$8.2 \pm 1.2$ 



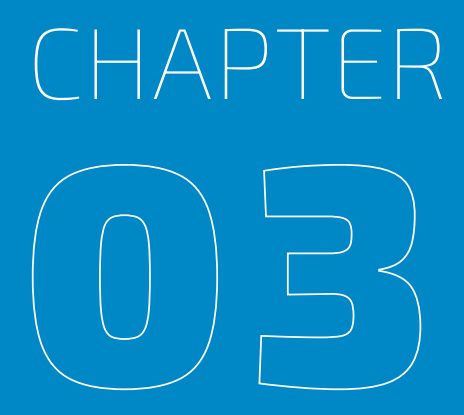

\section{The Start2Bike program is effective in increasing health-enhancing physical activity: a controlled study}

Published as: Ooms L, Veenhof C, de Bakker DH. The Start2Bike program is effective in increasing health-enhancing physical activity: a controlled study. BMC Public Health. 2017;17:606. 


\section{ABSTRACT}

Background: The sports club is seen as a new relevant setting to promote health-enhancing physical activity (HEPA) among inactive population groups. Little is known about the effectiveness of strategies and activities implemented in the sports club setting on increasing HEPA levels. This study investigated the effects of Start2Bike, a six-week training program for inactive adults and adult novice cyclers, on HEPA levels of participants in the Netherlands.

Methods: To measure physical activity, the Short QUestionnaire to ASsess Health-enhancing physical activity was used (SQUASH). Start2Bike participants were measured at baseline, six weeks and six months. A matched control group was measured at baseline and six months. The main outcome measure was whether participants met the Dutch Norm for Healthenhancing Physical Activity (DNHPA: 30 minutes of moderate-intensity activity on five days a week); Fit-norm (20 minutes of vigorous-intensity activity on three days a week); and Combi-norm (meeting the DNHPA and/or Fit-norm). Other outcome measures included: total minutes of physical activity per week; and minutes of physical activity per week per domain and intensity category. Statistical analyses consisted of McNemar tests and paired t-tests (within-group changes); and multiple logistic and linear regression analyses (betweengroup changes).

Results: In the Start2Bike group, compliance with Dutch physical activity norms increased significantly, both after six weeks and six months. Control group members did not alter their physical activity behavior. Between-group analyses showed that participants in the Start2Bike group were more likely to meet the Fit-norm at the six-month measurement compared to the control group (odds ratio $=2.5 ; 95 \%$ confidence interval $(C I)=1.1-5.8, p=0.03$ ). This was due to the Start2Bike participants spending on average $193 \mathrm{~min} /$ week more in vigorous-intensity activities ( $b=193 ; 95 \% \mathrm{Cl}=94-293, p<0.001)$ and $130 \mathrm{~min} /$ week more in sports activities $(b=130 ; 95 \% \mathrm{Cl}=82-178, p<0.001)$ than control group members.

Conclusions: Start2Bike positively influences HEPA levels of participants by increasing participation in sport. A relatively short sporting program, offered by a sports club, can be used to encourage less active people to engage in and continue sport at HEPA levels. Overall, sport can contribute to health through increased HEPA and the sports club can serve as a setting to stimulate this. 


\section{BACKGROUND}

Participation in regular physical activity can bring a wide range of health benefits that impact upon the population. These benefits go beyond physical health to include other benefits, such as improved cognitive function, quality of life, personal wellbeing and social functioning [1-7]. To receive these health benefits, adults should undertake a minimum of 30 minutes of moderate-intensity physical activity on five days per week or 20 minutes of vigorous-intensity physical activity on three days per week. Also, an equivalent combination of both moderate- and vigorous-intensity physical activity is possible [5, 8]. However, research suggests that 31\% of adults worldwide and 34\% of Dutch adults do not meet these levels of health-enhancing physical activity (HEPA) [7, 9]. These people are at higher risk of developing chronic diseases and premature death [1-7].

Participation in sports activities at a sports club can contribute considerably to HEPA levels of individuals [10]. In Europe, $12 \%$ of the population is a sports club member. This percentage is even higher in the Netherlands (27\%) [11]. Due to their wide reach, social and informal educational nature, sports clubs have great potential to promote a healthy and active lifestyle in the population $[12,13]$. Indeed, health professionals and policy makers see the sports club as a new relevant setting for programs and strategies to increase HEPA among inactive population groups [14-18].

More traditional institutional settings, like universities and workplaces, have already been used for health promotion. Settings-based health promotion is based on the idea that health behaviors of individuals are influenced by the places in which they live, work and play and the factors interacting in those places (i.e. environmental, organizational and personal factors). Important aims of this approach are among others: 1) creating supportive and healthy environments in order to make 'the healthy choice, the easy choice' and 2) integrating health promotion in the daily strategies and activities of the setting [19-22]. However, health promotion in general, and the promotion of HEPA among inactive groups in particular, is still a relatively new concept for sports clubs. Their focus is mainly on providing training, competition and elite sports $[14,16]$.

Nonetheless, a few examples of HEPA promotion strategies and activities in sports clubs can be found in the literature. In Australia, for instance, they focused on the development of healthy (e.g. healthy eating, responsible serving of alcohol) and welcoming sports club environments as a means to increase sport participation by less active population groups. Also, the implementation of sporting programs that involved cross-sectoral partnerships (i.e. between sports clubs and other sectors, like health, education and recreation) was advocated [14-16]. In the Dutch context, National Sports Federations received funding within the National Action Plan for Sport and Exercise (NAPSE) to develop sporting programs adapted to the needs and abilities of inactive people [23]. These programs had to be integrated in the daily activities of their affiliated clubs. In this regard, the Netherlands Tour Cycling Union (NTFU) initiated Start2Bike, a six-week training program for inactive 
adults and adult novice cyclers. Participants are learned the basic skills of mountain biking or road cycling. Subsequently, they are encouraged to continue cycling in a beginner's group at the club or as a member of the NTFU.

To date, research concerning HEPA strategies and activities in the sports club setting focused predominantly on implementation matters, like organizational readiness, partnership and capacity-building strategies and factors influencing implementation [1416, 23]. However, still little is known about the effectiveness of these initiatives on increasing HEPA levels [24]. There is a request for an evaluation of activities in controlled studies, assessing both short- and longer-term effects $[25,26]$. Until now, the only answer to this request was the evaluation of the Start to Run program, a six-week training program for novice runners, initiated by the Dutch Athletics Organization and implemented by local athletics clubs [27]. It proved to be effective in increasing HEPA levels of participants, with $69.0 \%$ of participants still engaged in running 4.5 months after they finished the program. However, it was stated that further research was needed to determine whether these results could be generalized to other sports and sporting programs. Therefore, this study aimed to investigate the short- and longer-term effects of the Start2Bike program on HEPA levels of participants in a controlled study design.

\section{METHODS}

\section{Study design}

To determine the effects of Start2Bike on HEPA levels of participants, a controlled study design was used. For comparability purposes, this study used the same data collection and analyses methods as those applied in the Start to Run study [27]. Start2Bike participants subscribed for the program on a voluntary basis. Subsequently, they were asked to participate in this study. They were not subjected to procedures, nor were they obligated to follow certain behavioral rules. Therefore, consistent with Dutch legislation, medical ethics committee approval was not required [28]. This study was performed according to ethical guidelines (i.e. with regard to principles like informed consent, enabling participation, avoiding adverse consequences, avoiding undue intrusion, confidentiality and data protection) [29]. Privacy procedures were conform Dutch Data Protection Authority regulations. For reporting of results, the Transparent Reporting of Evaluations with Nonrandomized Designs (TREND) group reporting standards were used as a guidance [30]. 


\section{Study population}

\section{Start2Bike participants}

Start2Bike is aimed at inactive adults and adult novice cyclers (i.e. mountain biking or road cycling). Dutch sportive cycling clubs offer the program twice a year (in spring and autumn) at 83 different locations. Recruitment of participants is done by the clubs in different ways, namely by the distribution of leaflets and posters, advertisements in local newspapers and word of mouth. This study included 260 adults (from the different Start2Bike locations) who had subscribed for the Start2Bike program in spring 2009, with email addresses provided by the NTFU. These persons received an email with study information and a link to an online baseline questionnaire. The Start2Bike participants provided consent for participation in this research by completing this questionnaire.

\section{Control group}

To control for possible changes in physical activity behavior in the Dutch adult population (i.e. physical activity changes caused by other factors than the Start2Bike program, like seasonal influences), members of the Dutch Health Care Consumer Panel served as control group. This panel consists of approximately 3000 adults ( $\geq 18$ years) and forms a representative sample of the Dutch adult population. The panel is used to record views about and experiences with health care and other related topics [31]. In this study, initially 1328 panel members were included. Control group participants did not receive any intervention. Furthermore, it was questioned whether they had participated in the Start2Bike program or any of the other NAPSE sporting programs before or during the research period, because this could bias the results. Consequently, panel members who had done so were excluded from this study. In addition, the mean age and percentage of females was higher among questioned panel members compared with Start2Bike participants. Age and gender are known to influence physical activity levels [11]. Therefore, an age and gender matched control group was formed.

\section{Start2Bike program}

The program was aimed at riding a mountain bike tour of $30 \mathrm{~km}$ or a road cycling tour of $70 \mathrm{~km}$. In Table 3.1, a description of the training program can be found. The program lasted for six weeks. Each week consisted of a group session led by professional coaches and two individual cycling sessions, whereby rest days were scheduled after training days. For individual training sessions, it was advised to cycle at least with one other person. A group session ( \pm 2 hours) included an introductory part ( \pm 30 minutes), core 1 (30 minutes), core 2 (45 minutes) and closure part (15 minutes). The introductory part consisted of a welcoming and explanation of the training, an equipment check (e.g. cycle, helmet) and warming-up (30 minutes). The warming-up was a combination of cycling, stretching and repeating of technical skills of the previous training. In core 1 , a new technical skill was practiced and, in 


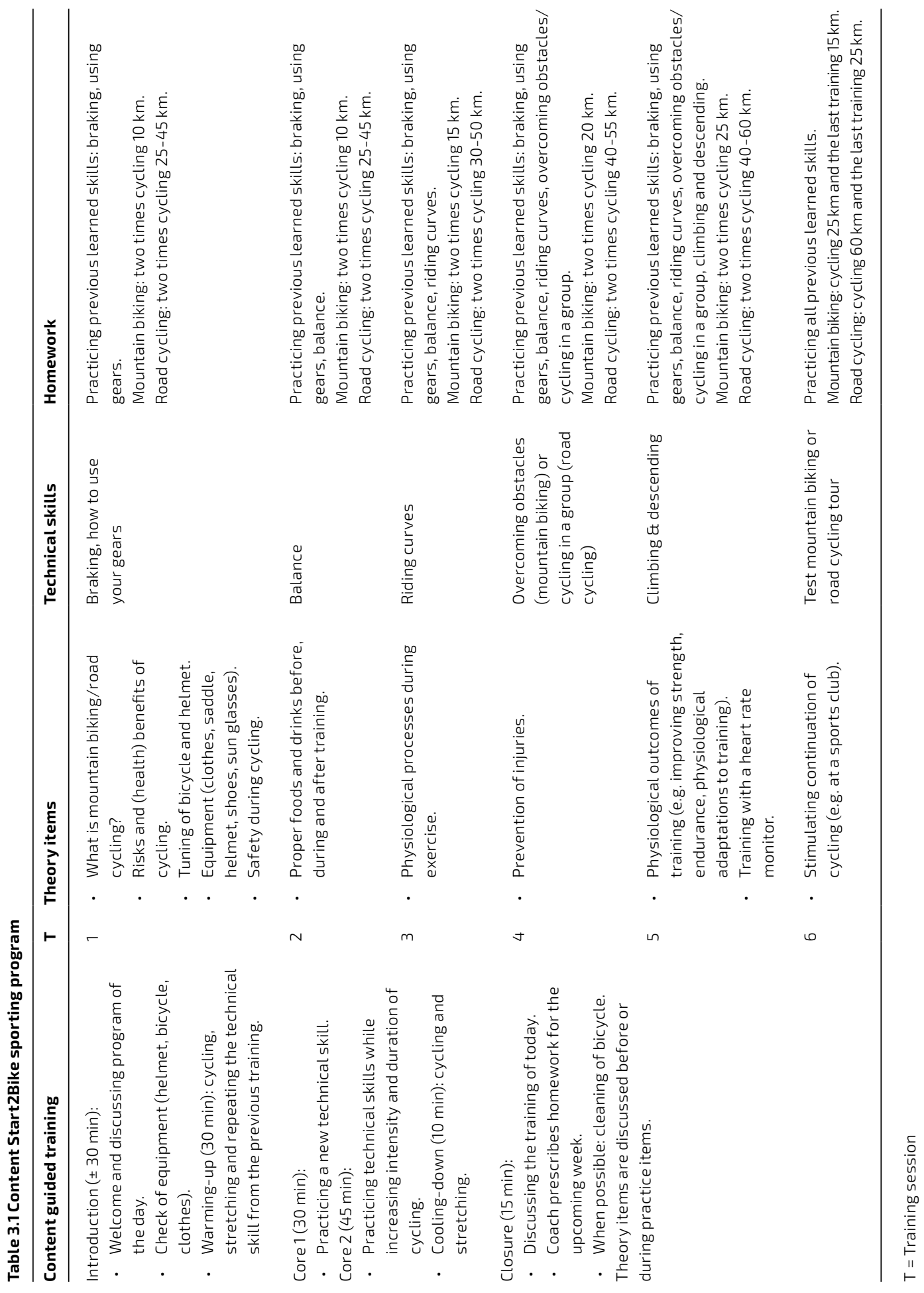


core 2, this was done with increasing cycling intensity and duration. Practice was ended with a cooling-down (10 minutes), which consisted of cycling at a slow speed and stretching. At the closure part, the training was discussed, the bicycle was cleaned (when possible) and the coach(es) provided instructions for the individual training sessions to the participants. Theory items, like the risks and (health) benefits of cycling, prevention of injuries and physiological outcomes of training, were discussed before or during practice items. During individual training sessions, participants had to practice previous learned technical skills, whereby cycling distance was gradually increased during the training period. At the sixth guided training session, participants could practice and test their cycling skills in a test tour, before participating in a real NTFU mountain biking $(30 \mathrm{~km})$ or road cycling tour (70 $\mathrm{km}$ ) (one week thereafter). Participants trained in a group of maximum twelve people. When there were more than twelve participants, the group was split. There were at least two professional coaches per guided training session and one coach per group of twelve people. The NTFU provided trainer courses, especially for the Start2Bike program. At the end of the program, participants were encouraged by their coach(es) (both verbally and through email) to continue mountain biking or road cycling in a beginner's group at the club through club membership. They were also informed about the option to continue cycling through an individual membership of the NTFU. Participants brought their own bicycle and equipment. In some locations, it was possible to lend materials.

\section{Outcome measures}

Demographic data (i.e. age and gender) were collected from all study participants. To measure physical activity, the Short QUestionnaire to ASsess Health-enhancing physical activity (SQUASH) was used. This tool is considered to be sufficiently reliable and valid to measure physical activity levels in an adult population [32]. The applied SQUASH procedure has been described in more detail elsewhere [27]. In short, the SQUASH contains questions about five domains of physical activity: 1) commuting activities, 2) leisure-time activities, 3) sports activities, 4) household activities, and 5) activities at work and school. The amount of time participants spent in each of the domain-specific activities was measured for an average week in the past month, using three main queries: days per week, average time per day and intensity (light, moderate, vigorous). Whether participants met Dutch physical activity norms was the main outcome measure derived from the SQUASH (i.e. meeting HEPA levels). According to these norms, adults should undertake a minimum of 30 minutes of moderate-intensity physical activity on five days per week (Dutch Norm for Health-enhancing Physical Activity: DNHPA) or 20 minutes of vigorous-intensity physical activity on three days per week (Fit-norm) for health benefits. Someone who meets at least one of the two norms adheres to the so-called 'Combi-norm', the third norm used in the Netherlands (see also Table 3.2). Dutch physical activity norms are based on international physical activity guidelines $[5,9]$. Secondary outcome measures calculated included: total 
minutes of physical activity per week; and minutes of physical activity per week per domain and intensity category.

Physical activity measurements of Start2Bike participants were performed at baseline $(t=0)$, six weeks ( $t=6$ weeks: i.e. directly after they finished the program) and six months after baseline ( $\mathrm{t}=6$ months: i.e. 4.5 months after they finished the program) using an online questionnaire. To enhance response for comparisons with the control group, all Start2Bike participants who returned the baseline questionnaire were invited to fill in the questionnaire at six months, irrespective if they had returned the questionnaire at six weeks. Physical activity measurements of control group participants were performed simultaneously at baseline ( $\mathrm{t}=0$ ) using a postal questionnaire and six months ( $\mathrm{t}=6$ months) using a postal or an online questionnaire. When necessary, a reminder was sent after a week (online forms) or two weeks (postal forms).

Table 3.2 Dutch physical activity norms for adults

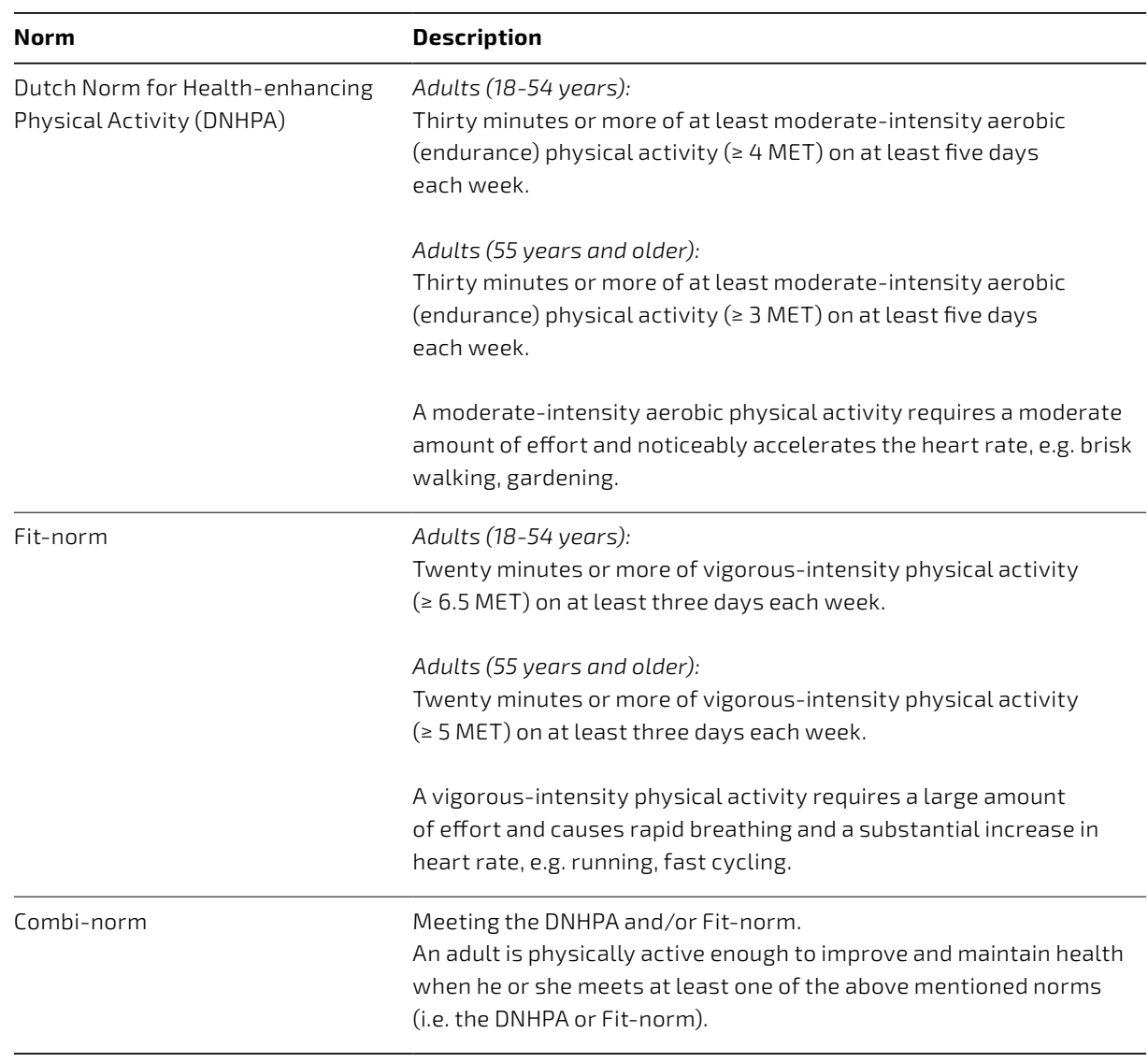

MET Metabolic equivalent 


\section{Sample size}

The sample size in this study was based on finding a change in HEPA. Mountain biking and road cycling are vigorous-intensity physical activities. Therefore, the Dutch Fit-norm (see Table 3.2) was used as reference. A sample size of 74 participants per group was needed to find a $20 \%$ difference between the Start2Bike group and the control group at the sixmonth measurement, assuming an alpha of 0.05 (two-sided) and a power of 0.80 . With 260 and 1328 participants included in the study for the Start2Bike group and control group, respectively, it was assumed that an adequate number of participants was approached.

\section{Statistical analysis}

The software program Stata (version 10.1, Stata Corporation, College Station, Texas) was used to perform statistical analyses. The main features of each group were described using descriptive statistics. A chi-squared test and an independent t-test were used to test between-group differences with regard to gender and age, respectively. McNemar tests (dichotomous measures) and paired t-tests (continuous measures) were performed to examine within-group changes in physical activity. Multiple logistic (dichotomous measures) and linear (continuous measures) regression analyses were used to test between-group changes in physical activity. In the regression analyses, physical activity level at six months was the dependent variable and group (Start2Bike group vs. control group, with the control group serving as reference category) the independent variable. To adjust for baseline physical activity, this variable was also added to the regression model as an independent variable. For instance, to test changes in meeting the Fit-norm between groups, the following variables were added to the logistic regression analyses: meeting the Fit-norm at six months (yes/no, dependent variable); group (Start2Bike vs. control group, independent variable); meeting the Fit-norm at baseline (yes/no, independent variable). In addition, more robust regression procedures were performed to examine whether the results (continuous measures) were influenced by outliers: this included the use of robust standard errors (i.e. bootstrap and Huber-White robust estimates of the standard errors). These latter procedures did not alter results and conclusions of this study significantly. Therefore, these results are not described in this article. The significance level for all analyses was set at $p<0.05$. 


\section{RESULTS}

Figure 3.1 presents a diagram of participant flow through the study. All three questionnaires were filled in by 72 Start2Bike participants (not presented in Figure 3.1). However, to preserve study power and use data optimally, all available cases were used in the analyses, i.e. 101 (changes after six weeks) and 79 (changes after six months) Start2Bike participants, respectively. Non-response analyses showed that there were no baseline differences in demographic factors and physical activity behavior between Start2Bike participants who did and did not fill in the six-month questionnaire.

\section{Figure 3.1 Participant flow through the study}

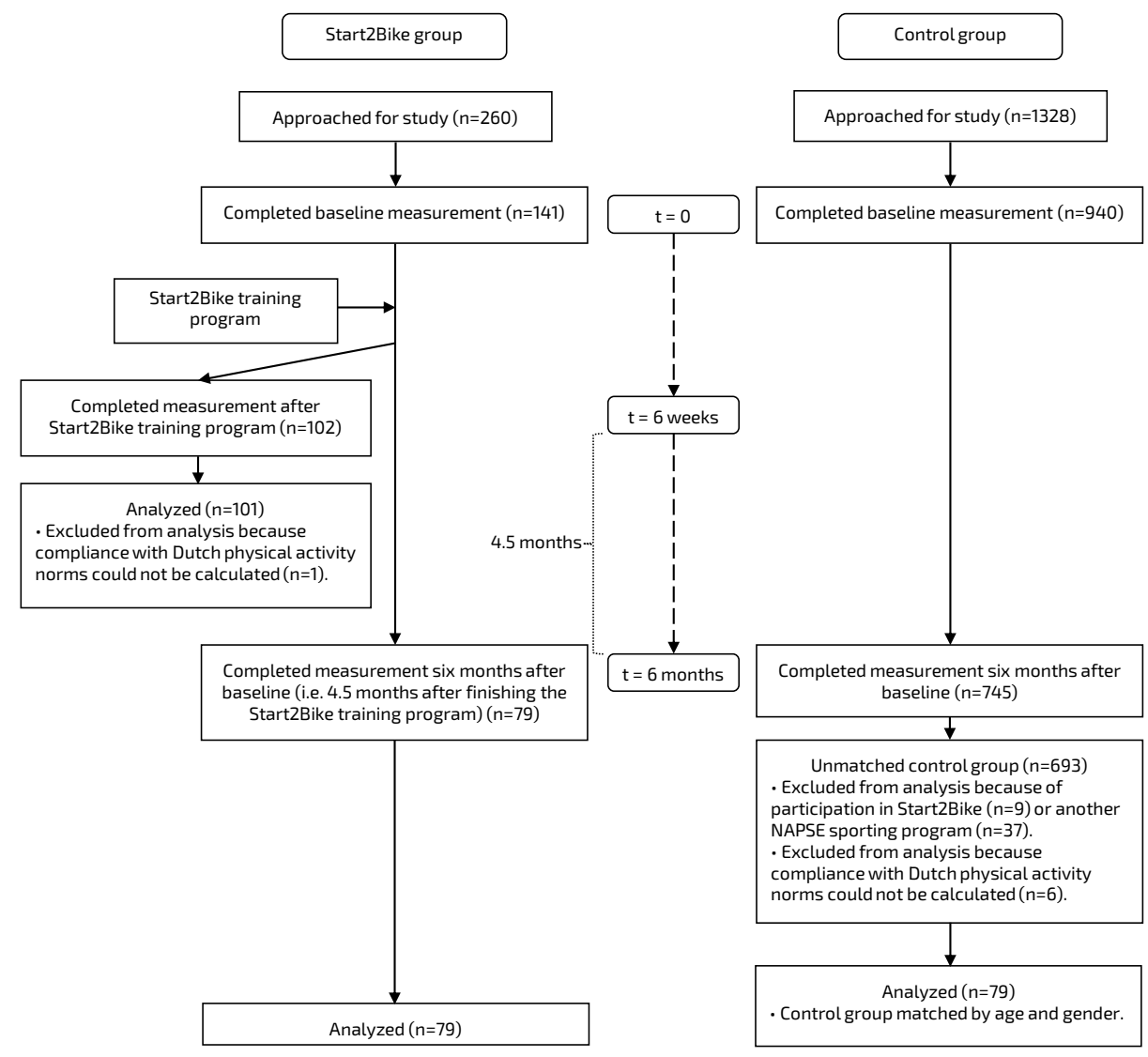




\section{Characteristics at baseline}

Table 3.3 presents baseline characteristics of Start2Bike and control group participants. Two thirds of Start2Bike participants was male and the average age was 45 years (SD=9). Gender and age characteristics, as well as baseline physical activity levels were comparable between the Start2Bike group and control group.

Table 3.3 Characteristics at baseline

\begin{tabular}{|c|c|c|c|}
\hline & $\begin{array}{l}\text { Start2Bike } \\
\text { group }^{b}\end{array}$ & Control group & $\mathbf{P}$ \\
\hline Sample size (n) & 79 & 79 & \\
\hline \multicolumn{4}{|l|}{ Age (years) } \\
\hline Mean \pm SD & $45 \pm 9$ & $46 \pm 9$ & 0.55 \\
\hline Min-max & $25-69$ & $24-64$ & \\
\hline \multicolumn{4}{|l|}{ Sex (\%) } \\
\hline Male & 67.1 & 67.1 & 1.0 \\
\hline Female & 32.9 & 32.9 & \\
\hline \multicolumn{4}{|l|}{ Dutch physical activity norms ${ }^{a}(\%)$} \\
\hline Compliance with DNHPA & 55.7 & 62.0 & 0.42 \\
\hline Compliance with Fit-norm & 63.3 & 53.2 & 0.20 \\
\hline Compliance with Combi-norm & 69.6 & 68.4 & 0.86 \\
\hline \multicolumn{4}{|l|}{ Physical activity by intensity, mean \pm SD $(\mathrm{min} /$ week $)$} \\
\hline Light-intensity activities & $1940 \pm 1313$ & $1909 \pm 1375$ & 0.89 \\
\hline Moderate-intensity activities & $329 \pm 586$ & $424 \pm 613$ & 0.32 \\
\hline Vigorous-intensity activities & $358 \pm 368$ & $288 \pm 420$ & 0.27 \\
\hline \multicolumn{4}{|l|}{ Physical activity by domain, mean \pm SD $(\mathrm{min} /$ week $)$} \\
\hline Commuting activities & $102 \pm 226$ & $130 \pm 220$ & 0.44 \\
\hline Leisure-time activities & $346 \pm 359$ & $433 \pm 495$ & 0.22 \\
\hline Sports activities & $173 \pm 203$ & $127 \pm 248$ & 0.21 \\
\hline Household activities & $465 \pm 769$ & $732 \pm 972$ & 0.06 \\
\hline Activities at work and school & $1581 \pm 1038$ & $1254 \pm 1041$ & 0.05 \\
\hline $\begin{array}{l}\text { Total time spent in physical activity, mean } \pm \text { SD }(\mathrm{min} / \\
\text { week) }\end{array}$ & $2626 \pm 1372$ & $2622 \pm 1490$ & 0.99 \\
\hline
\end{tabular}

SD Standard deviation

a Dutch physical activity norms:

- DNHPA Dutch Norm for Health-enhancing Physical Activity: Thirty minutes or more of at least moderateintensity aerobic (endurance) physical activity on at least five days each week.

- Fit-norm: Twenty minutes or more of vigorous-intensity physical activity on at least three days each week.

- Combi-norm: Meeting the DNHPA and/or Fit-norm.

${ }^{\mathrm{b}}$ Start2Bike participants who completed the six-month measurement. 


\section{Physical activity changes}

\section{Physical activity changes after six weeks: Start2Bike participants}

Physical activity levels of Start2Bike participants at the baseline and six-week measurement are shown in Table 3.4. Compliance with Dutch physical activity norms increased significantly ( $p<0.001$ ) from baseline to six weeks (DNHPA: 56.4\% vs. 77.2\%; Fit-norm: 66.3\% vs. 86.1\%; Combi-norm: $72.3 \%$ vs. 90.1\%). Despite this increase, the total minutes per week of physical activity decreased ( $2678 \pm 1322 \mathrm{~min} /$ week vs. $2137 \pm 1037 \mathrm{~min} /$ week, $p<0.001)$. Furthermore, significant $(p<0.001)$ changes were observed within intensity categories: a decrease in lightintensity activities (2006 $\pm 1302 \mathrm{~min} /$ week vs. $1360 \pm 912 \mathrm{~min} /$ week) and an increase in vigorous-intensity activities ( $359 \pm 341 \mathrm{~min} /$ week vs. $532 \pm 347 \mathrm{~min} /$ week). Within physical activity domains significant $(p<0.001)$ changes occurred for sports activities (increase: 189 $\pm 208 \mathrm{~min} /$ week vs. $337 \pm 246 \mathrm{~min} /$ week) and activities at work and school (decrease: 1642 $\pm 981 \mathrm{~min} /$ week vs. $971 \pm 651 \mathrm{~min} /$ week).

\section{Physical activity changes after six months: within-group comparisons}

Table 3.5 presents physical activity levels at the baseline and six-month measurement for both the Start2Bike group and control group. In the Start2Bike group, compliance with Dutch physical activity norms increased significantly from baseline to six months (DNHPA: $55.7 \%$ vs. $70.9 \%, p=0.02$; Fit-norm: $63.3 \%$ vs. $74.7 \%, p=0.04$; Combi-norm: $69.6 \%$ vs. $81.0 \%$, $\mathrm{p}=0.04)$. This was due to the Start2Bike participants spending significantly more minutes in vigorous-intensity activities (358 $\pm 368 \mathrm{~min} /$ week vs. $475 \pm 405 \mathrm{~min} /$ week, $\mathrm{p}=0.01$ ) and sports activities (173 $\pm 203 \mathrm{~min} /$ week vs. $255 \pm 208 \mathrm{~min} /$ week, $\mathrm{p}<0.001)$. There were, however, no changes in the total minutes per week of physical activity (2626 $\pm 1372 \mathrm{~min} /$ week vs. $2535 \pm 1372 \mathrm{~min} /$ week, $\mathrm{p}=0.57$ ). Physical activity levels of control group members did not change significantly within the six-month study period. 
Table 3.4 Physical activity changes after six weeks: Start2Bike participants

Outcome measures

Outcome measures

Dutch physical activity norms ${ }^{a}(\%)$

Compliance with DNHPA

Compliance with Fit-norm

Compliance with Combi-norm

Physical activity by intensity, mean \pm SD ( $\mathrm{min} /$ week)

Light-intensity activities

Moderate-intensity activities

Vigorous-intensity activities

Physical activity by domain, mean \pm SD (min/week)

Commuting activities

Leisure-time activities

Sports activities

Household activities

Activities at work and school

Total time spent in physical activity, mean \pm SD (min/week)

\section{Start2Bike group $(n=101)$}

Baseline After sixweeks $P$

$\begin{array}{lll}56.4 & 77.2 & <0.001^{*} \\ 66.3 & 86.1 & <0.001^{*} \\ 72.3 & 90.1 & <0.001^{*}\end{array}$

$\begin{array}{lll}2006 \pm 1302 & 1360 \pm 912 & <0.001^{*} \\ 314 \pm 566 & 245 \pm 393 & 0.10 \\ 359 \pm 341 & 532 \pm 347 & <0.001^{*}\end{array}$

$108 \pm 210 \quad 102 \pm 145 \quad 0.70$

$311 \pm 310 \quad 355 \pm 341 \quad 0.15$

$189 \pm 208 \quad 337 \pm 246 \quad<0.001^{*}$

$495 \pm 788 \quad 426 \pm 575 \quad 0.39$

$1642 \pm 981 \quad 971 \pm 651<0.001^{*}$

$2678 \pm 1322 \quad 2137 \pm 1037<0.001^{*}$

SD Standard deviation

${ }^{a}$ Dutch physical activity norms:

- DNHPA Dutch Norm for Health-enhancing Physical Activity: Thirty minutes or more of at least moderateintensity aerobic (endurance) physical activity on at least five days each week.

- Fit-norm: Twenty minutes or more of vigorous-intensity physical activity on at least three days each week.

- Combi-norm: Meeting the DNHPA and/or Fit-norm.

${ }^{b} \mathrm{P}$-value for change in physical activity within the Start2Bike group.

* Significant $(p<0.05)$ change in physical activity after six weeks within the Start2Bike group. 
Table 3.5 Physical activity changes after six months: within-group comparisons

\begin{tabular}{|c|c|c|c|c|c|c|}
\hline \multirow[t]{2}{*}{ Outcome measures } & \multicolumn{3}{|c|}{ Start2Bike group ( $n=79)$} & \multicolumn{3}{|c|}{ Control group $(n=79)$} \\
\hline & Baseline & $\begin{array}{l}\text { After six } \\
\text { months }\end{array}$ & $\mathrm{P}^{\mathrm{b}}$ & Baseline & $\begin{array}{l}\text { After six } \\
\text { months }\end{array}$ & $P^{c}$ \\
\hline \multicolumn{7}{|l|}{$\begin{array}{l}\text { Dutch physical activity norms } \\
\text { (\%) }\end{array}$} \\
\hline Compliance with DNHPA & 55.7 & 70.9 & $0.02^{*}$ & 62.0 & 62.0 & 1.0 \\
\hline Compliance with Fit-norm & 63.3 & 74.7 & $0.04^{*}$ & 53.2 & 55.7 & 0.79 \\
\hline Compliance with Combi-norm & 69.6 & 81.0 & $0.04^{*}$ & 68.4 & 73.4 & 0.45 \\
\hline \multicolumn{7}{|l|}{$\begin{array}{l}\text { Physical activity by intensity, } \\
\text { mean } \pm \text { SD (min/week) }\end{array}$} \\
\hline Light-intensity activities & $1940 \pm 1313$ & $1760 \pm 1350$ & 0.22 & $1909 \pm 1375$ & $1902 \pm 1148$ & 0.96 \\
\hline Moderate-intensity activities & $329 \pm 586$ & $300 \pm 507$ & 0.56 & $424 \pm 613$ & $355 \pm 558$ & 0.32 \\
\hline Vigorous-intensity activities & $358 \pm 368$ & $475 \pm 405$ & $0.01^{*}$ & $288 \pm 420$ & $255 \pm 287$ & 0.44 \\
\hline \multicolumn{7}{|l|}{$\begin{array}{l}\text { Physical activity by domain, } \\
\text { mean } \pm \text { SD (min/week) }\end{array}$} \\
\hline Commuting activities & $102 \pm 226$ & $99 \pm 142$ & 0.87 & $130 \pm 220$ & $101 \pm 182$ & 0.24 \\
\hline Leisure-time activities & $346 \pm 359$ & $335 \pm 433$ & 0.78 & $433 \pm 495$ & $359 \pm 330$ & 0.15 \\
\hline Sports activities & $173 \pm 203$ & $255 \pm 208$ & $<0.001^{*}$ & $127 \pm 248$ & $105 \pm 148$ & 0.32 \\
\hline Household activities & $465 \pm 769$ & $444 \pm 659$ & 0.70 & $732 \pm 972$ & $580 \pm 805$ & 0.10 \\
\hline Activities at work and school & $1581 \pm 1038$ & $1449 \pm 999$ & 0.36 & $1254 \pm 1041$ & $1397 \pm 995$ & 0.27 \\
\hline $\begin{array}{l}\text { Total time spent in physical } \\
\text { activity, mean } \pm \text { SD (min/week) }\end{array}$ & $2626 \pm 1372$ & $2535 \pm 1372$ & 0.57 & $2622 \pm 1490$ & $2512 \pm 1115$ & 0.49 \\
\hline
\end{tabular}

SD Standard deviation

a Dutch physical activity norms:

- DNHPA Dutch Norm for Health-enhancing Physical Activity: Thirty minutes or more of at least moderateintensity aerobic (endurance) physical activity on at least five days each week.

- Fit-norm: Twenty minutes or more of vigorous-intensity physical activity on at least three days each week.

- Combi-norm: Meeting the DNHPA and/or Fit-norm.

b P-value for change in physical activity within the Start2Bike group.

c $P$-value for change in physical activity within the control group.

* Significant $(p<0.05)$ change in physical activity after six months within the Start2Bike group. 


\section{Physical activity changes after six months: between-group comparisons}

Table 3.6 presents the results of the between-group analyses. These analyses showed that participants in the Start2Bike group were more likely to meet the Fit-norm at the six-month measurement compared to the control group (odds ratio $=2.5 ; 95 \%$ confidence interval $(C l)=1.1-5.8, p=0.03$ ). This was due to the Start2Bike participants spending on average 193 $\mathrm{min} /$ week more in vigorous-intensity activities ( $b=193 ; 95 \% \mathrm{Cl}=94-293, p<0.001)$ and 130 $\mathrm{min} /$ week more in sports activities $(b=130 ; 95 \% \mathrm{Cl}=82-178, \mathrm{p}<0.001)$ than control group members. Both groups were comparable for the other physical activity measures.

Table 3.6 Physical activity changes after six months: between-group comparisons

\begin{tabular}{|c|c|c|c|}
\hline Dichotomous outcome measures & $\begin{array}{l}\text { OR } \\
\text { (group variable) }^{\mathrm{b}}\end{array}$ & $95 \% \mathrm{Cl}$ & P (group variable) \\
\hline \multicolumn{4}{|l|}{ Dutch physical activity norms ${ }^{a}$} \\
\hline Compliance with DNHPA & 2.0 & $0.9-4.3$ & 0.08 \\
\hline Compliance with Fit-norm & 2.5 & $1.1-5.8$ & $0.03^{*}$ \\
\hline Compliance with Combi-norm & 1.7 & $0.7-4.0$ & 0.23 \\
\hline Continuous outcome measures & $\begin{array}{l}\text { b-coefficient } \\
\text { (group variable) }^{b, c}\end{array}$ & $95 \% \mathrm{Cl}$ & P (group variable) \\
\hline \multicolumn{4}{|l|}{ Physical activity by intensity } \\
\hline Light-intensity activities & -157 & $-494-180$ & 0.36 \\
\hline Moderate-intensity activities & -6 & $-145-132$ & 0.93 \\
\hline Vigorous-intensity activities & 193 & $94-293$ & $<0.001^{*}$ \\
\hline \multicolumn{4}{|l|}{ Physical activity by domain } \\
\hline Commuting activities & 8 & $-37-54$ & 0.72 \\
\hline Leisure-time activities & 17 & $-87-121$ & 0.75 \\
\hline Sports activities & 130 & $82-178$ & $<0.001^{*}$ \\
\hline Household activities & 14 & $-160-189$ & 0.87 \\
\hline Activities at work and school & -44 & $-351-263$ & 0.78 \\
\hline Total time spent in physical activity & 22 & $-329-373$ & 0.90 \\
\hline
\end{tabular}

CI Confidence interval, OR Odds ratio

a Dutch physical activity norms:

- DNHPA Dutch Norm for Health-enhancing Physical Activity: Thirty minutes or more of at least moderateintensity aerobic (endurance) physical activity on at least five days each week.

- Fit-norm: Twenty minutes or more of vigorous-intensity physical activity on at least three days each week.

- Combi-norm: Meeting the DNHPA and/or Fit-norm.

b To test between-group changes in physical activity, multiple (logistic or linear) regression analyses were performed. Physical activity level at six months was the dependent variable and group (the control group served as reference category) was the independent variable. Corrections were made for baseline physical activity levels.

c Unstandardized regression coefficient.

* Significant $(p<0.05)$ difference in physical activity between groups. 


\section{DISCUSSION}

\section{General findings}

This study examined the effects of participation in the six-week Start2Bike program on HEPA levels of participants. Start2Bike participants increased HEPA levels, both at the six-week and six-month measurement. Physical activity levels of control group members did not change significantly within the six-month study period. Between-group analyses showed that the Start2Bike program resulted in higher HEPA levels of participants according to the Fit-norm. This was due to the Start2Bike participants spending more minutes per week in vigorous-intensity activities (intensity category) and sports activities (domain).

\section{Explanation of findings}

Mountain biking and road cycling are vigorous-intensity sports activities. Therefore, the findings suggest that at least a part of the participants was still cycling 4.5 months after the last training session. In the six-month questionnaire, participants were also directly asked whether they were still cycling. Indeed, 75.9\% of participants was still practicing the sport and 32.9\% did this at a sportive cycling club (see Appendix 3.1: Additional study results Start2Bike). It should be noted, however, that these results do not reveal how much time was actually spent on cycling and it is possible that Start2Bike promoted participation in other sports activities as well. Nevertheless, participation in Start2Bike results in sport participation at HEPA levels and thus additional health benefits [5-8]. Moreover, considering the intensity of the practiced sports activities, there is evidence that high-intensity activities have more benefit for reducing cardiovascular disease and premature mortality than lowerintensity activities [33-35].

\section{Comparison with other studies}

Mountain biking and road cycling are non-load bearing sports (i.e. less pressure is placed on joints and tendons as compared to, for example, running) which can be easily incorporated into daily routines (e.g. cycling from home to work). Consequently, they are also suitable activities for less active people. On the other hand, the sports require particular cycling skills and have the image of being fast, exciting and adventurous [36]. A 'tough' image of the sport can impede the recruitment of inactive people [23]. This may explain why these sports have not been widely used as physical activities in HEPA promotion strategies [e.g. 37]. Nevertheless, the positive health effects of cycling in general have been well documented in the literature $[38,39]$. Therefore, there are a lot of cycling interventions aimed at promoting 
regular cycling (as opposed to sportive cycling), like town-wide media campaigns, cycle skills training and improvements in cycling infrastructure [40]. However, a recent systematic review about cycling interventions concluded that it is unclear whether these interventions result in an increase in physical activity [40].

On the other hand, the study findings are in support with the results of the evaluation of the Start to Run training program [27]. Furthermore, the study findings extent those results from running to sportive cycling. Consequently, it appears that a relatively short sporting program, implemented by sports clubs, can attract less active people, encourage them to participate in sport, and continue to practice sport at HEPA levels. However, there were also differences with regard to the participant population: The Start2Bike participants were more likely to be male (67.1\% vs. 30.0\%) and somewhat older (average age: 45 years vs. 40 years) compared with Start to Run participants. This may be inherent to the practiced sports. Nonetheless, this may have implications for the effectiveness of these sporting programs on increasing HEPA of different population subgroups. Therefore, in future research, it should be further studied which less active population subgroups (e.g. older adults vs. young adults, women vs. men, people with or without chronic disease) benefit most in terms of increasing HEPA levels. This will provide further insight into the usefulness of these sporting programs for particular subgroups.

\section{Practical implications and future directions}

Sports clubs are seen as new relevant settings to increase HEPA among inactive population groups [14-18]. The discussed results show that sport can contribute to health through increased HEPA and the sports club can serve as a setting to stimulate this. However, for actual health benefits, continued participation in sport at HEPA levels is necessary. Therefore, also efforts should be placed to maintain participation. At the end of the programs, Start2Bike and Start to Run participants were personally encouraged by their coaches to continue practicing the sport in a beginner's group at the sports club through club membership. At the six-month measurement, 32.9\% of the Start2Bike participants was (still) member of the sports club who offered the Start2Bike program (see Appendix 3.1: Additional study results Start2Bike). For the Start to Run program, this percentage was somewhat higher (41.0\%) [27]. Both running and sportive cycling are feasible sports that can be done anywhere and at any time. This may explain why a part of the participants was continuing the sport in non-organized forms. This can be different, however, for less feasible sports, like sports for which special facilities or equipment are needed (e.g. indoor (team) sports). Nevertheless, the sports club offers a social sporting context. Social support through interaction with other people at the club can be beneficial in maintaining sport behavior $[12,13,41]$. However, the actual amount of support that participants received as a club member was not measured. Therefore, it should be studied if and under what conditions participation in club sport can contribute to maintaining HEPA levels. Maintenance of behavior occurs when changes are sustained for a period of at least six months after 
cessation of an intervention [42]. Consequently, future research should also include multiple physical activity measurements over longer time periods to determine whether this sport behavior is continued.

\section{Strengths and limitations of the study}

The Start2Bike program was developed by a sporting organization and implemented by local sports clubs, with participants voluntary participating. Consequently, this research reflects activities implemented in the real-world sports setting and research results are directly applicable to practice. These are strengths of this study. On the other hand, this non-intrusive study design precluded the use of more objective physical activity measures (e.g. accelerometers) and the analyses of independent program parts (e.g. individual sessions, group sessions, sport event) [27]. Furthermore, selection bias may have occurred because participation in the Start2Bike program was on a voluntary basis. It is possible that people who chose to participate were more motivated to increase HEPA than those who did not (choose to) participate. Therefore, the results may not be generalizable to lessmotivated people, i.e. often the least-active ones. On the other hand, also adults who did not meet HEPA levels participated in the program, indicating that the program is appropriate for less active population groups. In addition, the voluntary character of participation is also a strength of the study. Behavior of participants was not forced and the Start2Bike study population was a sample of the actual Start2Bike population. This was confirmed by demographic data (i.e. gender and age) of the NTFU of the whole Start2Bike population in spring 2009 ( $n$ =422). Consequently, the research was performed in a generalizable group. Not all participants contacted responded to all questionnaires. The percentage of participants dropping out of the study was, however, comparable to the drop-out of the Start to Run study [27]. In addition, non-response analyses showed that respondents did not differ from non-respondents with regard to baseline demographic factors and physical activity behavior. Thus, it is improbable that study results were influenced markedly by these losses to follow-up. Finally, although participation in vigorous-intensity sports is associated with many health benefits, some undesirable effects, like sports-related injuries, may also occur. Most cycling injuries can be prevented, however, by training well, ride safely and using protective gear (e.g. a helmet) [36]. Nonetheless, it is important to consider these possible adverse effects in future research. 


\section{CONCLUSIONS}

The study results show that the six-week Start2Bike program positively influences HEPA levels of participants by increasing participation in sport. In addition, the results support previous research that a relatively short sporting program, offered by sports clubs, can encourage less active people to engage in and continue sport at HEPA levels. Overall, sport can contribute to health through increased HEPA and the sports club can serve as a setting to stimulate this. Consequently, these results are of value to policymakers and sports practitioners who acknowledge the possibilities of sports clubs in health promotion. Future research should investigate whether sport behavior is maintained and if and under what conditions participation in club sport can support this. Also, the suitability of sporting programs for different less active population subgroups should be examined. In this way, policy makers and sports practitioners can make well-informed choices regarding the contribution of this setting to a healthy and active lifestyle. 


\section{REFERENCES}

1. Bize R, Johnson JA, Plotnikoff RC. Physical activity level and health-related quality of life in the general adult population: a systematic review. Prev Med. 2007;45:401-415.

2. Bouaziz W, Lang PO, Schmitt E, Kaltenbach G, Geny B, Vogel T. Health benefits of multicomponent training programs in seniors: a systematic review. Int J Clin Pract. 2016;70(7):520-536. DOI: 10.1111/ijcp.12822.

3. Bouaziz W, Vogel T, Schmitt E, Kaltenbach G, Geny B, Lang PO. Health benefits of aerobic training programs in adults aged 70 and over: a systematic review. Arch Gerontol Geriatr. 2016;69:110127. DOI:10.1016/j.archger.2016.10.012.

4. Eime RM, Young JA, Harvey JT, Charity MJ, Payne WR. A systematic review of the psychological and social benefits of participation in sport for adults: informing development of a conceptual model of health through sport. Int J Behav Nutr Phys Act. 2013;10:135.

5. Haskell WL, Lee IM, Pate RR, Powell KE, Blair SN, Franklin BA, Macera CA, Heath GW, Thompson PD, Bauman A. Physical activity and public health: updated recommendation for adults from the American College of Sports Medicine and the American Heart Association. Med Sci Sports Exerc. 2007;39:1423-1434.

6. Warburton DER, Nicol CW, Bredin SSD. Health benefits of physical activity: the evidence. CMAJ. 2006;174(6):801-809.

7. World Health Organization (WHO). Global status report on noncommunicable diseases 2010. Geneva: WHO; 2011.

8. Cress ME, Buchner DM, Prohaska T, Rimmer J, Brown M, Macera C, DePietro L, Chodzko-Zajko W. Physical activity programs and behavior counseling in older adult populations. Med Sci Sports Exerc. 2004;36:1997-2003.

9. Bernaards C. TNO monitor physical activity and health: physical activity in the Netherlands 2000-2010 (report in Dutch). Leiden: TNO Healthy Living; 2011.

10. Eime RM, Harvey JT, Charity MJ, Casey MM, van Uffelen JGZ, Payne WR. The contribution of sport participation to overall health enhancing physical activity levels in Australia: a populationbased study. BMC Public Health. 2015;15:806.

11. European Commission. Sport and physical activity. Special Eurobarometer 412/Wave EB80.2. Brussels: TNS Opinion \& Social; 2014

12. Kokko S. Sports clubs as settings for health promotion: fundamentals and an overview to research. Scan J Public Health. 2014;42(Suppl.15):60-65.

13. Kokko S, Kannas L, Villberg J. The health promoting sports club in Finland--a challenge for the settings-based approach. Health Promot Int. 2006;21(3):219-229.

14. Casey MM, Payne WR, Brown SJ, Eime RM. Engaging community sport and recreation organisations in population health interventions: factors affecting the formation, implementation, and institutionalisation of partnership efforts. Ann Leis Res. 2009;12(2):129147.

15. Casey MM, Payne WR, Eime RM. Partnership and capacity-building strategies in community sports and recreation programs. Manag Leis. 2009;14(3):167-176. 
16. Casey MM, Payne WR, Eime RM. Organisational readiness and capacity building strategies of sporting organisations to promote health. Sport Manag Rev. 2012;15:109-124.

17. Dutch Ministry of Health, Welfare and Sport. Time for sport: exercise, participate, perform. The Hague: Dutch Ministry of Health, Welfare and Sport; 2005.

18. European Commission. Communication from the commission to the European parliament, the council, the European economic and social committee and the committee of the regions: developing the European Dimension in Sport. Brussels: European Commission; 2011.

19. Dooris M. Healthy settings: challenges to generating evidence of effectiveness. Health Promot Int. 2006;21(1):55-65.

20. Dooris M. Holistic and sustainable health improvement: the contribution of the settings-based approach to health promotion. Perspect Public Health. 2009;129(1):29-36.

21. Whitelaw S, Baxendale A, Bryce C, MacHardy L, Young I, Witney E. 'Settings' based health promotion: a review. Health Promot Int. 2001;16(4):339-353.

22. World Health Organization (WHO). Ottawa Charter for Health Promotion. Geneva: WHO; 1986.

23. Ooms L, Veenhof C, Schipper-van Veldhoven N, de Bakker DH. Sporting programs for inactive population groups: factors influencing implementation in the organized sports setting. BMC Sports Sci Med Rehabil. 2015;7:12.

24. Kokko S, Donaldson A, Geidne S, Seghers J, Scheerder J, Meganck J, Lane A, Kelly B, Casey M, Eime R, Villberg J, Kannas L. Piecing the puzzle together: case studies of international research in health-promoting sports clubs. Global Health Promot. 2016;23(S1):75-84.

25. Priest N, Armstrong R, Doyle J, Waters E. Interventions implemented through sporting organisations for increasing participation in sport. Cochrane Database Syst Rev. 2008(3). Art. No.: CD004812. DOI: 10.1002/14651858.CD004812.pub3.

26. Priest N, Armstrong R, Doyle J, Waters E. Policy interventions implemented through sporting organisations for promoting healthy behaviour change. Cochrane Database Syst Rev. 2008(3). Art. No.: CD004809. DOI: 10.1002/14651858.CD004809.pub3.

27. Ooms L, Veenhof C, de Bakker DH. Effectiveness of Start to Run, a 6-week training program for novice runners, on increasing health-enhancing physical activity: a controlled study. BMC Public Health. 2013;13:697.

28. Dutch government. Dutch law on medical scientific research with humans (WMO). http:// wetten.overheid.nl/BWBR0009408/2015-12-17. Accessed 26 April 2016.

29. Webster S, Lewis J, Brown A. Ethical considerations in qualitative research. In: Ritchie J, Lewis J, McNaughton Nicholls C, Ormston R, editors. Qualitative research practice: a guide for social science students and researchers. London: SAGE Publications, Ltd; 2014. p.77-110.

30. Des Jarlais DC, Lyles C, Crepaz N, Trend Group. Improving the reporting quality of nonrandomized evaluations of behavioral and public health interventions: The TREND statement. Am J Public Health. 2004;94: 361-366.

31. Reitsma-van Rooijen M, de Jong JD. Health Care Consumer Panel: basic report with information about the panel, 2009 (report in Dutch). Utrecht: Netherlands Institute for Health Services Research (NIVEL); 2009. 
32. Wendel-Vos GC, Schuit AJ, Saris WH, Kromhout D. Reproducibility and relative validity of the short questionnaire to assess health-enhancing physical activity. J Clin Epidemiol. 2003;56:11631169.

33. Lee IM, Paffenbarger RS Jr. Associations of light, moderate, and vigorous intensity physical activity with longevity. The Harvard Alumni Health Study. Am J Epidemiol. 2000;151:293-299.

34. Swain DP. Moderate or vigorous intensity exercise: which is better for improving aerobic fitness? Prev Cardiol. 2005;8:55-58.

35. Swain DP, Franklin BA. Comparison of cardioprotective benefits of vigorous versus moderate intensity aerobic exercise. Am J Cardiol. 2006;97:141-147.

36. Carmont MR. Mountain biking injuries: a review. Br Med Bull. 2008;85:101-112.

37. Foster $C$, Hillsdon M, Thorogood M. Interventions for promoting physical activity. Cochrane Database Syst Rev. 2005(1). Art. No.: CD003180. DOI: 10.1002/14651858.CD003180.pub2.

38. Oja P, Titze S, Bauman A, de Geus B, Krenn P, Reger-Nash B, Kohlberger T. Health benefits of cycling: a systematic review. Scan J Med Sci Sports. 2011;21:496-509.

39. Pretty J, Peacock J, Hine R, Sellens M, South N, Griffin M. Green exercise in the UK countryside: effects on health and psychological well-being, and implications for policy and planning. J Environ Plan Manag. 2007;50:211-231.

40. Yang L, Sahlqvist S, McMinn A, Griffin SJ, Ogilvie D. Interventions to promote cycling: systematic review. BMJ. 2010;341:c5293.

41. Eime RM, Harvey JT, Brown WJ, Payne WR. Does sports club participation contribute to healthrelated quality of life? Med Sci Sports Exerc. 2010;42:1022-1028.

42. Marcus BH, Dubbert PM, Forsyth LH, McKenzie TL, Stone EJ, Dunn AL, Blair SN. Physical activity behavior change: issues in adoption and maintenance. Health Psychol. 2000;19: 32-41. 


\section{APPENDIX 3.1}

\section{Additional study results Start2Bike}

Table A3.1.1 Start2Bike group: cycling behavior and membership at the six-month measurement

Start2Bike group $(n=79)$

Percentage of participants that is (still) mountain biking or road cycling

$75.9 \%$

Percentage of participants that is a member of the cycling club that

$32.9 \%$

offered Start2Bike 


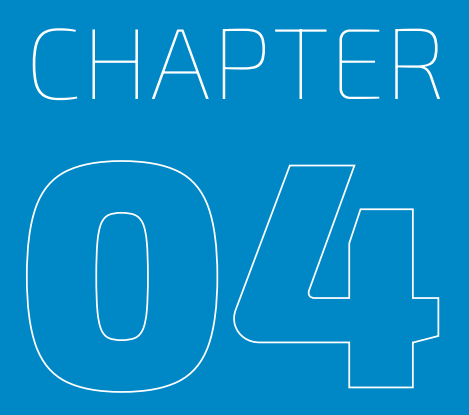

\section{Characteristics of insufficiently active participants that benefit from health-enhancing physical activity (HEPA) promotion programs implemented in the sports club setting}

Published as: Ooms L, Leemrijse C, Collard D, Schipper-van Veldhoven N, Veenhof C. Characteristics of insufficiently active participants that benefit from health-enhancing physical activity (HEPA) promotion programs implemented in the sports club setting. BMC Public Health. 2018;18:685. 


\section{ABSTRACT}

Background: Health-enhancing physical activity (HEPA) promotion programs are implemented in sports clubs. The purpose of this study was to examine the characteristics of the insufficiently active participants that benefit from these programs.

Methods: Data of three sporting programs, developed for insufficiently active adults, were used for this study. These sporting programs were implemented in different sports clubs in the Netherlands. Participants completed an online questionnaire at baseline and after six months ( $n=458)$. Of this sample, $35.1 \%(n=161)$ was insufficiently active (i.e. not meeting HEPA levels) at baseline. Accordingly, two groups were compared: participants who were insufficiently active at baseline, but increased their physical activity to HEPA levels after six months (activated group, $n=86$ ) versus participants who were insufficiently active both at baseline and after six months (non-activated group, $n=75$ ). Potential associated characteristics (demographic, social, sport history, physical activity) were included as independent variables in bivariate and multivariate logistic regression analyses.

Results: The percentage of active participants increased significantly from baseline to six months (from $64.9 \%$ to $76.9 \%, p<0.05$ ). The bivariate logistic regression analyses showed that participants in the activated group were more likely to receive support from family members with regard to their sport participation ( $62.8 \%$ vs. $42.7 \%, p=0.02)$ and spent more time in moderate-intensity physical activity (128 $\pm 191 \mathrm{~min} /$ week vs. $70 \pm 106 \mathrm{~min} /$ week, $\mathrm{p}=0.02$ ) at baseline compared with participants in the non-activated group. These results were confirmed in the multivariate logistic regression analyses: when receiving support from most family members, there is a $216 \%$ increase in the odds of being in the activated group (OR=2.155; 95\% Cl: 1.118-4.154, p=0.02) and for each additional $1 \mathrm{~min} /$ week spent in moderate-intensity physical activity, the odds increases with $0.3 \%(\mathrm{OR}=1.003 ; 95 \% \mathrm{Cl}: 1.001$ 1.006, $p=0.02$ ).

Conclusions: The results suggest that HEPA sporting programs can be used to increase HEPA levels of insufficiently active people, but it seems a challenge to reach the least active ones. It is important that promotional strategies and channels are tailored to the target group. Furthermore, strategies that promote family support may enhance the impact of the programs. 


\section{BACKGROUND}

Globally, insufficient physical activity is a major risk factor for mortality and noncommunicable diseases, such as cardiovascular diseases, cancer and diabetes [1]. According to international physical activity guidelines, adults should do at least 150 minutes of moderate-intensity aerobic physical activity throughout the week or do at least 75 minutes of vigorous-intensity aerobic physical activity throughout the week [2]. The guidelines can also be met by a comparable amount of both moderate- and vigorous-intensity physical activity. However, research indicates that a third of the world's population is not meeting these levels of health-enhancing physical activity (HEPA) [3]. Considering the importance of regular physical activity in the prevention of mortality and non-communicable diseases, these findings are alarming $[1,4,5]$.

Consequently, HEPA promotion is a priority aim of the World Health Organization (WHO), other health professionals and policy makers in different countries [1, 6-10]. According to the WHO, health should be promoted in the places where people live, learn, work and play [11]. Therefore, HEPA should also be stimulated in different settings. The involvement of the organized sports sector, and in particular the sports club, as a setting for HEPA promotion is a new strategy implemented by health professionals and policy makers [6, 7 , $9,10]$. Due to their wide reach, their informal learning environment and the voluntary nature of participation, sports clubs have great potential in promoting HEPA in the population $[12,13]$. Nonetheless, sport participation is characterized by considerable inequalities. Participation rates are lower among women, decline with age and are reduced in people with chronic diseases, low levels of education and people from culturally diverse backgrounds [14-16]. Concurrently, the people in these population subgroups are also more likely to be insufficiently active and at higher risk for developing non-communicable diseases [1, 3, 4, 17]. Thus, increasing these target groups' HEPA levels through participation in sport at a sports club may be challenging.

In the research literature, some examples of HEPA promotion strategies in the sports club setting can be found $[6,7,10,18]$. There is some evidence that relatively short sporting programs, implemented by sports clubs, can be used to encourage insufficiently active people to engage in and continue sport at HEPA levels [19, 20]. However, these studies considered the participant population as a whole. Therefore, the purpose of this study was to examine the characteristics of the insufficiently active participants that benefit from these programs in terms of increasing HEPA. The study results can contribute to developing effective and tailored sporting programs aimed at insufficiently active people. In addition, the findings will guide health professionals, policy makers and sport practitioners in their choices for HEPA promotion strategies regarding this target group. 


\section{METHODS}

\section{Study population}

Data from participants of three sporting programs, aimed at insufficiently active adults, were used, namely Start to Run, Start2Bike and Through 4 Days Marches (see Table 4.1). These data were collected in light of a larger study in which both a process and effectiveness evaluation of the programs were conducted $[10,19,20]$. In this study, more in-depth analyses of the data were performed. The data of the individual sporting programs were combined into one dataset to increase statistical power of the study (i.e. the number of insufficiently active people per sporting program was relatively low). The datasets could be combined because the programs were all adapted to insufficiently active adults, using feasible sports (i.e. running, sportive cycling and walking can be done anywhere and at any time), similar training principles and similar strategies to retain participants. Dutch National Sports Federations (NSFs) started the programs within the National Action Plan for Sport and Exercise which was aimed at increasing the number of people meeting HEPA levels [10]. Different sports clubs implemented the programs in the period 2008-2011. Online questionnaires were sent to participants at the start of the programs (spring 2009) and after six months. The NSFs provided email addresses of participants who had subscribed for the programs in spring 2009 ( $n=1314)$. The baseline questionnaire contained detailed information about the background and aims of the study. In addition, participants were informed that participation was voluntary, all collected information would be kept strictly confidential and only anonymized data would be published. In case of questions about the research, they could contact the researcher by email or telephone. By completing the baseline questionnaire, participants gave consent for participation in the study $(n=834)$. In total, 458 participants finished both questionnaires and formed the initial sample of this study (see Figure 4.1 for the flow of participants through the study). Non-response analyses showed that program participants who did not complete the six-month measurement were more likely to be female (71.0\% female vs. 57.0\% female) and significantly younger ( $41 \pm 11$ years vs. $45 \pm 11$ years) compared with participants that did complete this measurement. Furthermore, demographic data collected by the NSFs confirmed that the participants of this study were representative for the entire participant population of the individual sporting programs with regard to age and sex.

This study followed ethical principles (i.e. with regard to enabling participation, informed consent, confidentiality, avoiding undue intrusion, avoiding adverse consequences and data protection) [21]. Participants were not exposed to procedures, nor were they obligated to follow certain behavioral rules (i.e. participants were approached for the study after they had voluntarily registered for participation in the sporting programs). Therefore, in accordance with Dutch law, medical ethics committee's approval was not mandatory for conducting this study [22]. Study privacy procedures followed Dutch Data Protection 


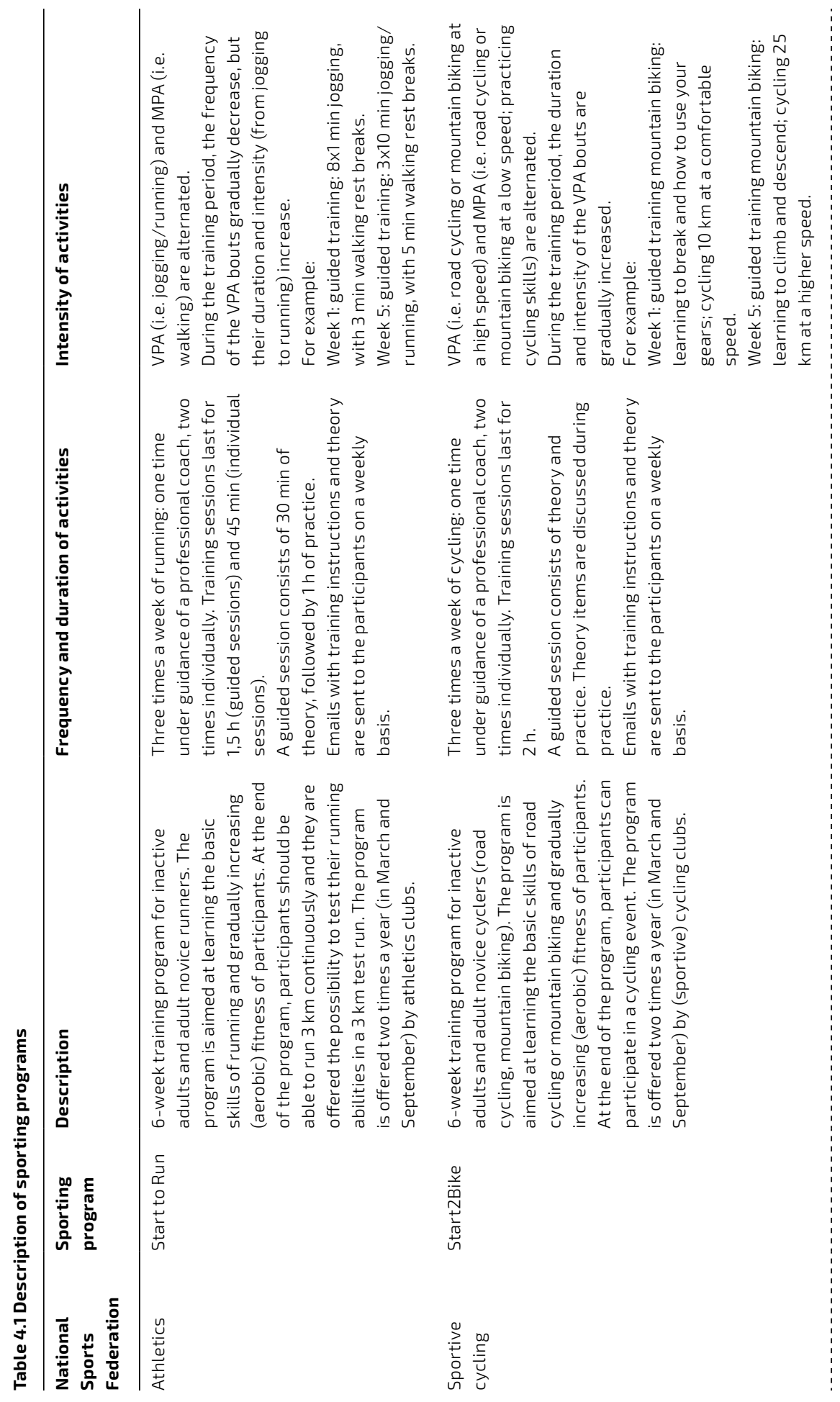




$$
\text { 潩 }
$$


Authority regulations. The Transparent Reporting of Evaluations with Nonrandomized Designs (TREND) group reporting standards were used as guidance for reporting of results [23].

\section{Figure 4.1 Participant flow through the study}
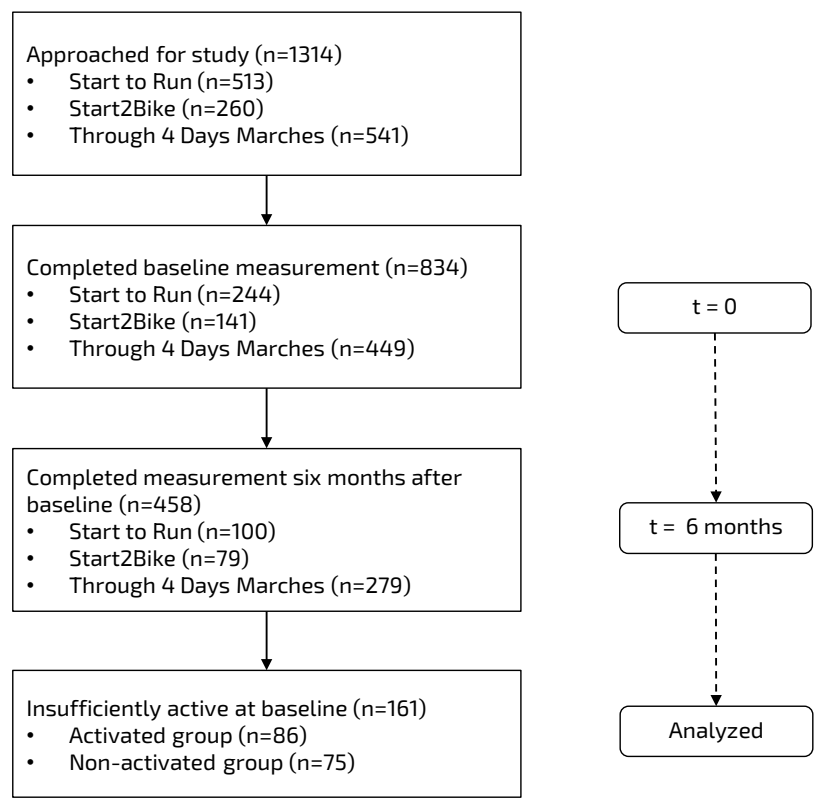

Active: participants who met the Combi-norm; Insufficiently active: participants who did not meet the Combi-norm; Activated group: participants who were insufficiently active at baseline, but active after six months; Non-activated group: participants who were insufficiently active both at baseline and after six months.

\section{Sporting programs}

A description of the sporting programs can be found in Table 4.1. The three sporting programs were developed for insufficiently active adults. The threshold for participation was very low so that adults with no previous training experiences or specific sport skills could participate. In this regard, graded training programs were applied, starting with (very) small amounts of moderate- and/or vigorous-intensity physical activity and gradually increasing intensity and duration of physical activity over time. The physical activities were always adapted to the (physical) abilities of the participants. At the sports club level, sometimes multiple groups were formed with each group providing to a different level of beginner. At the end of the programs, participants could test their sporting abilities by participating in a (test) sporting event (e.g. a $3 \mathrm{~km}$ test run). All programs consisted of practice and theory. The 
practical part consisted of a warming-up, practicing of specific sport skills and coolingdown. There was one group training session each week guided by one or more professional coaches, two or more training sessions were performed individually. Participants received instructions for the individual training sessions from their coaches (face-to-face and through email). Theory items, such as the health benefits of sport participation, healthy food and drinks and prevention of injuries, were discussed with the group before, during or after practice. At the final training session, participants received information about club membership and were encouraged by their coaches (both verbally and through email) to continue participating in the particular sport. Continuation was possible at the club (at reduced costs) in an appropriate beginners' group. Participation in the programs was at low costs and, for the Start2Bike program, some sports clubs provided cycles to participants during the training program. The NSFs provided trainer courses, especially for the sporting programs, to educate trainers about how to guide the insufficiently active target group. At a national level, the programs were promoted to (potential) participants via national press, websites of the NSFs and social media. Sports clubs recruited participants using different recruitment strategies, like the placement of advertisements in local media and the distribution of posters and flyers in the neighborhood.

\section{Possible associated characteristics}

The following characteristics were measured in the baseline questionnaire and included in analyses: demographic characteristics, sport history and physical activity. Social factors were also measured in the baseline questionnaire. Since social factors, like social support from family and friends, are related to physical activity behavior in a number of studies [2428], these factors were also included in the analyses. The characteristics will be described in more detail below.

\section{Demographic characteristics}

Participants were asked to report their sex, age, educational attainment (highest level completed) and the presence of chronic diseases (yes/no). Education was categorized into low-average (high school or lower) and high (higher professional education and university). Due to the low number of participants with low education levels, it was not possible to present this as a separate category in the analysis. Body Mass Index (BMI), defined as weight $(\mathrm{kg})$ divided by height squared $\left(\mathrm{m}^{2}\right)$, was calculated from participants' self-reported height and weight. According to WHO standards, participants with a BMI $\geq 25$ were classified as overweight [29]. Ethnicity was determined by country of birth of participant's parents. Based on the standard definition of ethnicity of Statistics Netherlands [30], participants were divided in people with a Dutch background (i.e. both parents are born in the Netherlands) and people with a foreign background (i.e. at least one parent is born abroad). 


\section{Social factors}

Social factors consisted of frequency of sport participation of most family members and friends. This was questioned as follows: Most of my family members/friends participate in sport: 'never', 'one time a week', 'a few times a week' or 'every day'. Sport participation was defined as regularly if most members of the group participated in sport at least once a week. In addition, it was questioned whether most family members/friends supported the respondent participating in sport: Most of my family members/friends support me participating in sport: 'yes' or 'no'.

\section{Sport history}

Participants' sport history was assessed by measuring sport participation (yes/no) and membership of a sports club (yes/no) before involvement in the program.

\section{Physical activity}

The Short QUestionnaire to ASsess Health-enhancing physical activity (SQUASH) was used to measure physical activity levels of participants at baseline and after six months. This questionnaire is seen as sufficiently reliable and valid to measure adults' physical activity levels [31]. More details of the SQUASH-procedure can be found in a previous research article [19]. In short, the SQUASH measures physical activity levels for a regular week in the past month. It includes five physical activity domains (commuting activities, leisure-time activities, sport activities, household activities and activities at work and school) and three main queries (days per week, average time per day, self-reported intensity: light, moderate, vigorous). Accordingly, total minutes of physical activity per week and the minutes per week spent in each intensity category were calculated. To measure HEPA levels, the Dutch physical activity norms were used [17]. These norms are based on the international physical activity guidelines and recommend that adults should undertake a minimum of 30 minutes of moderate-intensity physical activity on five days per week (Dutch Norm for Healthenhancing Physical Activity: DNHPA) or 20 minutes of vigorous-intensity physical activity on three days per week (Fit-norm) for health benefits. Someone who meets at least one of the two norms adheres to the so-called 'Combi-norm', the third norm used in the Netherlands (see also Table 4.2) $[2,17]$. A participant was classified as 'active' when he or she met the Combi-norm, because this norm combines both the DNHPA and Fit-norm and indicates whether someone is sufficiently active. Participants not meeting this norm were categorized as 'insufficiently active'. 
Table 4.2 Dutch physical activity norms for adults ( $\geq 18$ years)

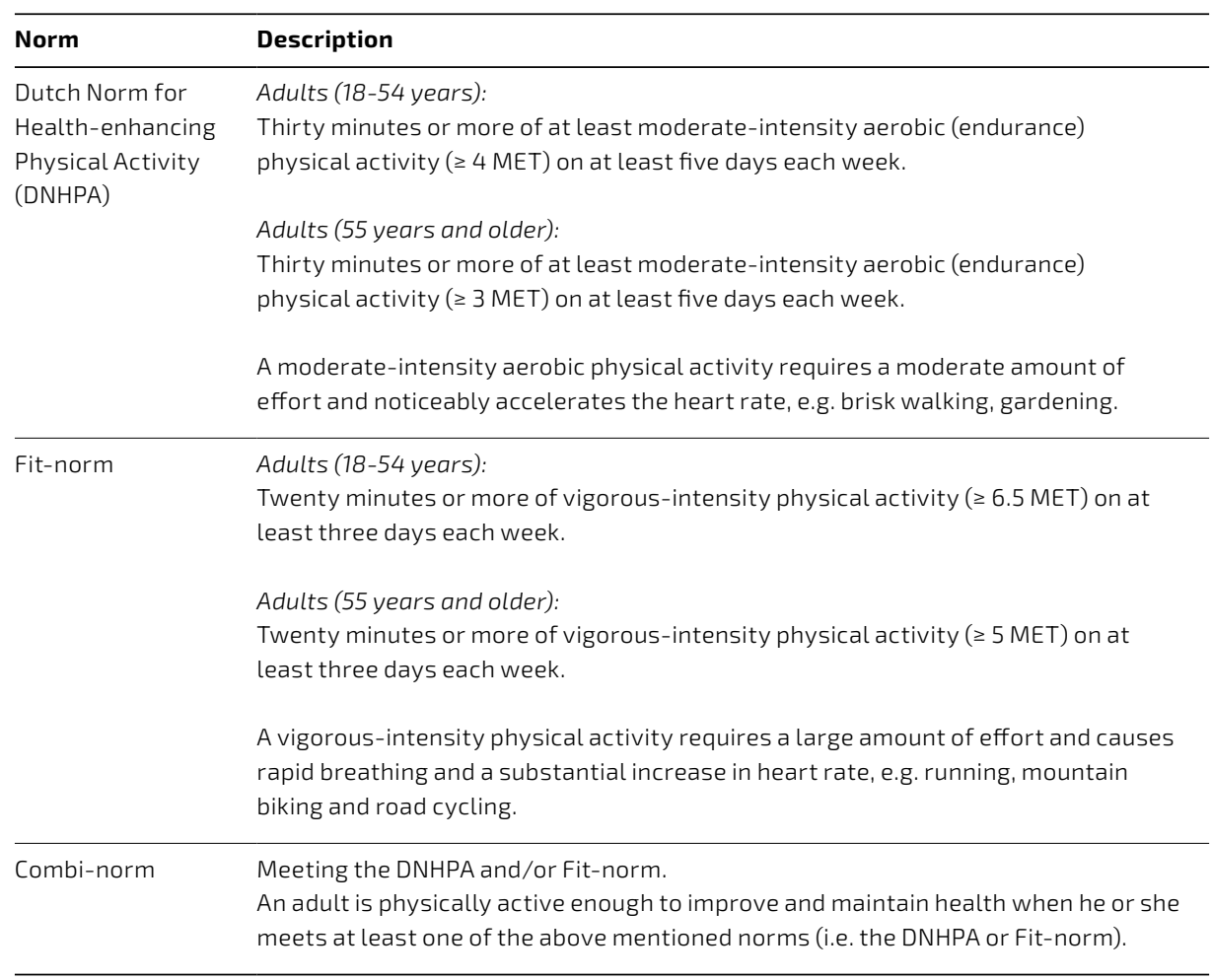

MET Metabolic equivalent

\section{Statistical analyses}

Stata statistical software (version 10.1, Stata Corporation, College Station, Texas) was used for statistical analyses. The main characteristics of study participants were described using descriptive statistics. Of the 458 participants included in this study, 35.1\% ( $n=161)$ were insufficiently active at baseline. These participants were selected to examine baseline characteristics associated with meeting HEPA levels after six months. For this purpose, two groups were compared: participants who were insufficiently active at baseline, but active after six months (activated group) versus participants who were insufficiently active both at baseline and after six months (non-activated group). First, bivariate logistic regression analyses were used with potential associated characteristics as independent variables and group (activated group vs. non-activated group, with the latter as reference category) as dependent variable. Subsequently, all variables with a P-value $<0.15$ were entered into a multivariate model, after which backwards elimination of variables was performed, removing the variable with the least significant $P$-value ( $P$ to remove $\geq 0.10$ ). This was done 
until only variables with a P-value $<0.05$ remained. The type of sporting program (Start to Run, Start2Bike, Through 4 Days Marches) was included as independent variable in all logistic regression analyses to control for possible differences between sporting programs. Dummy variables were created for this purpose, with the Start to Run program serving as reference category. Statistical significance was set at a $\mathrm{P}$-value $<0.05$.

\section{RESULTS}

\section{Baseline characteristics of participants and changes in physical activity}

Baseline characteristics of the participants are presented in Table 4.3. Of the 458 participants included in this study, 35.1\% ( $n=161)$ were insufficiently active. The percentage of active participants increased significantly from baseline to six months (from $64.9 \%$ to 76.9\%, p<0.05) (see also Table 4.3).

Table 4.3 Baseline characteristics of participants and changes in physical activity

\begin{tabular}{|c|c|c|c|c|}
\hline & $\begin{array}{l}\text { All sporting } \\
\text { programs } \\
\text { combined }\end{array}$ & Start to Run & Start2Bike & $\begin{array}{l}\text { Through } \\
4 \text { Days } \\
\text { Marches }\end{array}$ \\
\hline Sample size (n) & 458 & 100 & 79 & 279 \\
\hline \multicolumn{5}{|c|}{ Demographic characteristics } \\
\hline \multicolumn{5}{|l|}{ Gender n, (\%) } \\
\hline Female & $261(57.0)$ & $70(70.0)$ & $26(32.9)$ & $165(59.1)$ \\
\hline Male & $197(43.0)$ & $30(30.0)$ & $53(67.1)$ & $114(40.9)$ \\
\hline Age, mean \pm SD (years) & $45 \pm 11$ & $40 \pm 10$ & $45 \pm 9$ & $46 \pm 11$ \\
\hline \multicolumn{5}{|c|}{ Overweight (BMI $\geq 25)$ n, (\%)a } \\
\hline Yes & $201(44.0)$ & $40(40.4)$ & $33(41.8)$ & $128(45.9)$ \\
\hline No & $256(56.0)$ & $59(59.6)$ & $46(58.2)$ & $151(54.1)$ \\
\hline \multicolumn{5}{|l|}{ Ethnicity $n,(\%)^{b}$} \\
\hline Dutch & $357(93.7)$ & $70(88.6)$ & $68(95.8)$ & $219(94.8)$ \\
\hline Foreign & $24(6.3)$ & $9(11.4)$ & $3(4.2)$ & $12(5.2)$ \\
\hline \multicolumn{5}{|l|}{ Chronic diseases n, (\%) ${ }^{\mathrm{b}}$} \\
\hline Yes & $52(13.6)$ & $9(11.4)$ & $9(12.5)$ & $34(14.7)$ \\
\hline No & $331(86.4)$ & 70 (88.6) & $63(87.5)$ & $198(85.3)$ \\
\hline \multicolumn{5}{|l|}{ Education $\mathrm{n},(\%)^{\mathrm{b}}$} \\
\hline Low-average & $224(58.6)$ & $42(53.2)$ & $36(50.0)$ & $146(63.2)$ \\
\hline High & $158(41.4)$ & $37(46.8)$ & $36(50.0)$ & 85 (36.8) \\
\hline
\end{tabular}


Table 4.3 Baseline characteristics of participants and changes in physical activity (continued)

\begin{tabular}{lllll}
\hline & $\begin{array}{l}\text { All sporting } \\
\text { programs } \\
\text { combined }\end{array}$ & Start to Run & Start2Bike & $\begin{array}{l}\text { Through } \\
\text { 4 Days } \\
\text { Marches }\end{array}$ \\
\hline Sample size $(\mathrm{n})$ & 458 & 100 & 79 & 279 \\
\hline
\end{tabular}

\section{Social factors}

Regular sports participation of most... n, (\%)

Family members

$\begin{array}{lllll}\text { Yes } & 335(73.1) & 76(76.0) & 53(67.1) & 206(73.8) \\ \text { No } & 123(26.9) & 24(24.0) & 26(32.9) & 73(26.2)\end{array}$

Friends

$$
\begin{gathered}
\text { Yes } \\
\text { No }
\end{gathered}
$$

$354(77.3) \quad 78(78.0) \quad 54(68.4) \quad 222(79.6)$

$104(22.7) \quad 22(22.0) \quad 25(31.7) \quad 57(20.4)$

Supporting participant's sport participation by most... n, (\%)

Family members

Yes

No

Friends

$$
\text { Yes }
$$

No

\section{Sport history}

Participation in sport before program n, (\%)

$$
\text { Yes }
$$

Member of a sports club n, (\%)

$$
\text { Nes }
$$

\section{Physical activity}

Light-intensity PA, mean \pm SD (min/week)

$$
\begin{aligned}
& \text { Baseline } \\
& \text { After six months }
\end{aligned}
$$

Moderate-intensity PA, mean \pm SD (min/week)

$$
\begin{aligned}
& \text { Baseline } \\
& \text { After six months }
\end{aligned}
$$

325 (71.0)

$$
55 \text { (55.0) }
$$

$133(29.0)$

$45(45.0)$

$26(32.9)$

$62(22.2)$

$\begin{array}{llll}229(50.0) & 47(47.0) & 37(46.8) & 145(52.0) \\ 229(50.0) & 53(53.0) & 42(53.2) & 134(48.0)\end{array}$

Vigorous-intensity PA, mean \pm SD (min/week)

Baseline

After six months

$$
\begin{array}{llll}
1939 \pm 1348 & 1814 \pm 1224 & 1940 \pm 1313 & 1983 \pm 1402 \\
1950 \pm 1297 & 1947 \pm 1043 & 1760 \pm 1350 & 2004 \pm 1362
\end{array}
$$

$$
370 \pm 615 \quad 213 \pm 453 \quad 329 \pm 586 \quad 438 \pm 662
$$$$
445 \pm 638^{*} \quad 206 \pm 369 \quad 300 \pm 507 \quad 571 \pm 712^{*}
$$

$275 \pm 320 \quad 238 \pm 250 \quad 358 \pm 368 \quad 264 \pm 325$


Table 4.3 Baseline characteristics of participants and changes in physical activity (continued)

\begin{tabular}{|c|c|c|c|c|}
\hline & $\begin{array}{l}\text { All sporting } \\
\text { programs } \\
\text { combined }\end{array}$ & Start to Run & Start2Bike & $\begin{array}{l}\text { Through } \\
4 \text { Days } \\
\text { Marches }\end{array}$ \\
\hline Sample size (n) & 458 & 100 & 79 & 279 \\
\hline \multicolumn{5}{|c|}{ Physical activity (continued) } \\
\hline \multicolumn{5}{|c|}{ Total time spent in PA, mean \pm SD ( $\mathrm{min} /$ week $)$} \\
\hline Baseline & $2583 \pm 1432$ & $2265 \pm 1251$ & $2626 \pm 1372$ & $2685 \pm 1497$ \\
\hline After six months & $2734 \pm 1400^{*}$ & $2536 \pm 1210 *$ & $2535 \pm 1372$ & $2862 \pm 1459$ \\
\hline \multicolumn{5}{|l|}{ Active n, (\%) } \\
\hline Baseline & $297(64.9)$ & $58(58.0)$ & $55(69.6)$ & $184(66.0)$ \\
\hline After six months & $352(76.9)^{*}$ & $84(84.0)^{*}$ & $64(81.0)^{*}$ & $204(73.1)^{*}$ \\
\hline
\end{tabular}

BMI Body Mass Index, PA Physical activity, SD Standard deviation

${ }^{a}$ BMI could not be calculated for one respondent.

${ }^{\mathrm{b}} \mathrm{n}<$ sample $\mathrm{n}$, because questions were not mandatory. Consequently, not all participants completed these questions.

* Significant $(p<0.05)$ difference: after six months vs. baseline.

\section{Baseline characteristics of insufficiently active participants in comparison with active participants}

Baseline characteristics of insufficiently active participants in comparison with active participants are presented in Table 4.4. There were significant differences between these two groups: insufficiently active participants were more likely to be overweight (50.9\% vs. $40.2 \%, p=0.02)$, had less friends that participated in sport regularly $(71.4 \%$ vs. $80.5 \%$, $\mathrm{p}=0.02$ ) and were less likely to be participating in sport before involvement in the sporting program (54.0\% vs. $80.1 \%, p<0.001)$. In addition, they spent less of their time in physical activity (2128 $\pm 1378 \mathrm{~min} /$ week vs. $2829 \pm 1403 \mathrm{~min} /$ week, $\mathrm{p}<0.001)$, in this case moderate(101 $\pm 159 \mathrm{~min} /$ week vs. $516 \pm 714 \mathrm{~min} /$ week, $p<0.001)$ and vigorous-intensity (60 $\pm 79 \mathrm{~min} /$ week vs. $391 \pm 341 \mathrm{~min} /$ week, $p<0.001)$ physical activity. 
Table 4.4 Baseline characteristics: insufficiently active participants vs. active participants

\begin{tabular}{|c|c|c|c|}
\hline & $\begin{array}{l}\text { Insufficiently } \\
\text { active } \\
\text { participants }\end{array}$ & $\begin{array}{l}\text { Active } \\
\text { participants }\end{array}$ & P-value $^{a}$ \\
\hline Sample size (n) & 161 & 297 & \\
\hline \multicolumn{4}{|c|}{ Demographic characteristics } \\
\hline \multicolumn{4}{|l|}{ Gender n, (\%) } \\
\hline Female & $85(52.8)$ & $176(59.3)$ & 0.08 \\
\hline Male & $76(47.2)$ & $121(40.7)$ & \\
\hline Age, mean \pm SD (years) & $43 \pm 10$ & $46 \pm 12$ & 0.08 \\
\hline \multicolumn{4}{|c|}{ Overweight (BMI $\geq 25) \mathrm{n},(\%)^{\mathrm{b}}$} \\
\hline Yes & $82(50.9)$ & $119(40.2)$ & $0.02^{*}$ \\
\hline No & $79(49.1)$ & $177(59.8)$ & \\
\hline \multicolumn{4}{|l|}{ Ethnicity n, (\%) } \\
\hline Dutch & $133(93.0)$ & $224(94.1)$ & 0.79 \\
\hline Foreign & $10(7.0)$ & $14(5.9)$ & \\
\hline \multicolumn{4}{|l|}{ Chronic diseases n, (\%) } \\
\hline Yes & $23(16.0)$ & $29(12.1)$ & 0.28 \\
\hline No & $121(84.0)$ & $210(87.9)$ & \\
\hline \multicolumn{4}{|l|}{ Education n, (\%) } \\
\hline Low-average & $77(53.9)$ & 147 (61.5) & 0.14 \\
\hline High & $66(46.2)$ & $92(38.5)$ & \\
\hline \multicolumn{4}{|l|}{ Social factors } \\
\hline \multicolumn{4}{|c|}{ Regular sports participation of most... n, (\%) } \\
\hline \multicolumn{4}{|l|}{ Family members } \\
\hline Yes & $111(68.9)$ & $224(75.4)$ & 0.11 \\
\hline No & $50(31.1)$ & $73(24.6)$ & \\
\hline \multicolumn{4}{|l|}{ Friends } \\
\hline Yes & $115(71.4)$ & $239(80.5)$ & $0.02^{*}$ \\
\hline No & $46(28.6)$ & $58(19.5)$ & \\
\hline \multicolumn{4}{|c|}{$\begin{array}{l}\text { Supporting participant's sport participation } \\
\text { by most... n, (\%) }\end{array}$} \\
\hline \multicolumn{4}{|l|}{ Family members } \\
\hline Yes & $86(53.4)$ & $150(50.5)$ & 0.61 \\
\hline No & $75(46.6)$ & $147(49.5)$ & \\
\hline \multicolumn{4}{|l|}{ Friends } \\
\hline Yes & $92(57.1)$ & $146(49.2)$ & 0.11 \\
\hline No & $69(42.9)$ & $151(50.8)$ & \\
\hline
\end{tabular}


Table 4.4 Baseline characteristics: insufficiently active participants vs. active participants (continued)

\begin{tabular}{|c|c|c|c|}
\hline & $\begin{array}{l}\text { Insufficiently } \\
\text { active } \\
\text { participants }\end{array}$ & $\begin{array}{l}\text { Active } \\
\text { participants }\end{array}$ & P-value ${ }^{a}$ \\
\hline Sample size (n) & 161 & 297 & \\
\hline \multicolumn{4}{|l|}{ Sport history } \\
\hline \multicolumn{4}{|l|}{ Participation in sport before program n, (\%) } \\
\hline Yes & $87(54.0)$ & $238(80.1)$ & $<0.001^{\star}$ \\
\hline No & $74(46.0)$ & 59 (19.9) & \\
\hline \multicolumn{4}{|l|}{ Member of a sports club n, (\%) } \\
\hline Yes & $71(44.1)$ & $158(53.2)$ & 0.07 \\
\hline No & $90(55.9)$ & $139(46.8)$ & \\
\hline \multicolumn{4}{|l|}{ Physical activity } \\
\hline Light-intensity PA, mean \pm SD (min/week) & $1967 \pm 1361$ & $1923 \pm 1343$ & 0.68 \\
\hline Moderate-intensity PA, mean \pm SD $(\mathrm{min} /$ week $)$ & $101 \pm 159$ & $516 \pm 714$ & $<0.001^{*}$ \\
\hline Vigorous-intensity PA, mean \pm SD (min/week) & $60 \pm 79$ & $391 \pm 341$ & $<0.001^{*}$ \\
\hline Total time spent in PA, mean \pm SD (min/week) & $2128 \pm 1378$ & $2829 \pm 1403$ & $<0.001^{*}$ \\
\hline
\end{tabular}

BMI Body Mass Index, PA Physical activity, SD Standard deviation.

a P-value adjusted for sporting program.

${ }^{\mathrm{b}} \mathrm{BMI}$ could not be calculated for one respondent.

' $\mathrm{n}<$ sample $\mathrm{n}$, because questions were not mandatory. Consequently, not all participants completed these questions.

* Significant $(p<0.05)$ difference between insufficiently active participants and active participants.

\section{Comparison of activated group vs. non-activated group: results bivariate logistic regression analyses}

Table 4.5 compares the activated group (participants who were insufficiently active at baseline, but active after six months) with the non-activated group (participants who were insufficiently active both at baseline and after six months) on baseline characteristics. Based on the bivariate logistic regression analyses, significant differences between these groups were found: participants in the activated group were more likely to receive support from family members with regard to their sport participation (62.8\% vs. 42.7\%, $p=0.02)$ and spent more time in moderate-intensity physical activity (128 $\pm 191 \mathrm{~min} /$ week vs. $70 \pm$ $106 \mathrm{~min} /$ week, $\mathrm{p}=0.02$ ) at baseline compared with participants in the non-activated group. 
Table 4.5 Baseline characteristics: activated group vs. non-activated group, results bivariate logistic regression analyses

\begin{tabular}{|c|c|c|c|}
\hline & $\begin{array}{l}\text { Activated } \\
\text { group }\end{array}$ & $\begin{array}{l}\text { Non- } \\
\text { activated } \\
\text { group }\end{array}$ & P-value ${ }^{a}$ \\
\hline Sample size (n) & 86 & 75 & \\
\hline \multicolumn{4}{|c|}{ Demographic characteristics } \\
\hline \multicolumn{4}{|l|}{ Gender n, (\%) } \\
\hline Female & $43(50.0)$ & $42(56.0)$ & 0.40 \\
\hline Male & $43(50.0)$ & $33(44.0)$ & \\
\hline Age, mean \pm SD (years) & $44 \pm 10$ & $43 \pm 9$ & 0.42 \\
\hline \multicolumn{4}{|c|}{ Overweight (BMI $\geq 25) \mathrm{n},(\%)^{\mathrm{b}}$} \\
\hline Yes & $47(54.7)$ & $35(46.7)$ & 0.30 \\
\hline No & $39(45.4)$ & $40(53.3)$ & \\
\hline \multicolumn{4}{|l|}{ Ethnicity n, (\%) ${ }^{c}$} \\
\hline Dutch & $70(94.6)$ & $63(91.3)$ & 0.32 \\
\hline Foreign & $4(5.4)$ & $6(8.7)$ & \\
\hline \multicolumn{4}{|l|}{ Chronic diseases n, (\%) ${ }^{c}$} \\
\hline Yes & $12(16.2)$ & $11(15.7)$ & 0.85 \\
\hline No & $62(83.8)$ & $59(84.3)$ & \\
\hline \multicolumn{4}{|l|}{ Education $n,(\%)^{c}$} \\
\hline Low-average & $41(56.2)$ & $36(51.4)$ & 0.47 \\
\hline High & $32(43.8)$ & $34(48.6)$ & \\
\hline \multicolumn{4}{|l|}{ Social factors } \\
\hline \multicolumn{4}{|c|}{ Regular sports participation of most... n, (\%) } \\
\hline \multicolumn{4}{|l|}{ Family members } \\
\hline Yes & $55(64.0)$ & $56(74.7)$ & 0.14 \\
\hline No & $31(36.1)$ & $19(25.3)$ & \\
\hline \multicolumn{4}{|l|}{ Friends } \\
\hline Yes & $59(68.6)$ & $56(74.7)$ & 0.43 \\
\hline No & $27(31.4)$ & $19(25.3)$ & \\
\hline \multicolumn{4}{|c|}{ Supporting participant's sport participation by most... n, (\%) } \\
\hline \multicolumn{4}{|l|}{ Family members } \\
\hline Yes & $54(62.8)$ & $32(42.7)$ & $0.02^{*}$ \\
\hline No & $32(37.2)$ & $43(57.3)$ & \\
\hline \multicolumn{4}{|l|}{ Friends } \\
\hline Yes & $55(64.0)$ & $37(49.3)$ & 0.07 \\
\hline No & $31(36.1)$ & $38(50.7)$ & \\
\hline
\end{tabular}


Table 4.5 Baseline characteristics: activated group vs. non-activated group, results bivariate logistic regression analyses (continued)

\begin{tabular}{|c|c|c|c|}
\hline & $\begin{array}{l}\text { Activated } \\
\text { group }\end{array}$ & $\begin{array}{l}\text { Non- } \\
\text { activated } \\
\text { group }\end{array}$ & P-value ${ }^{a}$ \\
\hline Sample size (n) & 86 & 75 & \\
\hline \multicolumn{4}{|l|}{ Sport history } \\
\hline \multicolumn{4}{|l|}{ Participation in sport before program n, (\%) } \\
\hline Yes & $45(52.3)$ & $42(56.0)$ & 0.83 \\
\hline No & $41(47.7)$ & $33(44.0)$ & \\
\hline \multicolumn{4}{|l|}{ Member of a sports club n, (\%) } \\
\hline Yes & $40(46.5)$ & $31(41.3)$ & 0.49 \\
\hline No & $46(53.5)$ & $44(58.7)$ & \\
\hline \multicolumn{4}{|l|}{ Physical activity } \\
\hline Light-intensity PA, mean \pm SD (min/week) & $1940 \pm 1601$ & $1998 \pm 1030$ & 1.0 \\
\hline Moderate-intensity PA, mean \pm SD (min/week) & $128 \pm 191$ & $70 \pm 106$ & $0.02^{*}$ \\
\hline Vigorous-intensity PA, mean \pm SD (min/week) & $68 \pm 87$ & $51 \pm 68$ & 0.14 \\
\hline Total time spent in PA, mean \pm SD (min/week) & $2136 \pm 1610$ & $2119 \pm 1061$ & 0.70 \\
\hline
\end{tabular}

BMI Body Mass Index, PA Physical activity, SD Standard deviation.

a $\mathrm{P}$-value for difference between activated group and non-activated group based on bivariate logistic regression analyses. The potential associated characteristic was included as independent variable and group (activated group vs. non-activated group, with the latter as reference category) as dependent variable. Corrections were made for type of sporting program.

${ }^{\mathrm{b}} \mathrm{BMI}$ could not be calculated for one respondent.

c $\mathrm{n}<$ sample $\mathrm{n}$, because questions were not mandatory. Consequently, not all participants completed these questions.

* Significant $(p<0.05)$ difference between activated group and non-activated group.

\section{Comparison of activated group vs. non-activated group: results multivariate (backwards) logistic regression analyses}

Table 4.6 presents the results of the multivariate (backwards) logistic regression analyses. These analyses confirmed the bivariate logistic regression analyses: participants in the activated group were more likely to receive support from family members with regard to their sport participation and spent on average more minutes in moderate-intensity physical activity at baseline compared with participants in the non-activated group. More specifically, when receiving support from most family members there is a $216 \%$ increase in the odds of being in the activated group $(\mathrm{OR}=2.155 ; 95 \% \mathrm{Cl}: 1.118-4.154, \mathrm{p}=0.02)$ and for each additional $1 \mathrm{~min} /$ week spent in moderate-intensity physical activity, the odds increases with $0.3 \%(\mathrm{OR}=1.003 ; 95 \% \mathrm{Cl}$ : 1.001-1.006, $\mathrm{p}=0.02)$ (see Table 4.6). 
Table 4.6 Baseline characteristics: activated group vs. non-activated group, results multivariate (backwards) logistic regression analyses

\begin{tabular}{lll}
\hline & OR $\mathbf{( 9 5 \% ~ C l )}$ & P-value $^{\mathbf{a}}$ \\
\hline $\begin{array}{l}\text { Social factors } \\
\text { Supporting participant's sport participation by most... }\end{array}$ & & \\
$\quad$ Family members & $2.155(1.118-4.154)$ & $0.02^{*}$ \\
$\begin{array}{l}\text { Physical activity } \\
\text { Moderate-intensity PA }\end{array}$ & $1.003(1.001-1.006)$ & $0.02^{*}$ \\
\hline
\end{tabular}

CI Confidence interval, OR Odds ratio, PA Physical activity.

a OR activated group vs. non-activated group, with the latter group as the reference category.

b P-value for difference between activated group and non-activated group based on multivariate (backwards) logistic regression analyses. The potential associated characteristics were included as independent variables, using backwards elimination of variables, and group (activated group vs. nonactivated group, with the latter as reference category) as dependent variable. Corrections were made for type of sporting program.

*Significant $(p<0.05)$ difference between activated group and non-activated group.

\section{DISCUSSION}

\section{General findings}

To our knowledge, this is the first study examining the characteristics of the insufficiently active participants that benefit from HEPA promotion programs implemented in the sports club setting. Results showed that a third of the participants was insufficiently active at baseline. The percentage of participants meeting HEPA levels increased significantly during the six-month study period. Insufficiently active participants were more likely to meet HEPA levels after six months when they received support from family members with regard to their sport participation and spent more time in moderate-intensity physical activity at baseline.

\section{Explanation of findings and practical implications}

Social support from family to be physically active has been associated with regular physical activity participation and initiation of this behavior [24-28]. For instance, family members can influence sport behavior positively by providing social norms that enable this behavior or by providing positive feedback about (the benefits of) the participant's sport participation [26]. Therefore, promoting social support from family as a component in HEPA strategies 
may be advantageous. The examined sporting programs did not use particular social support strategies. Nonetheless, the sports club itself can be an ideal setting to involve other family members as passive or active participants. Introducing family members to the activity at an introductory session, using them as (sporting) buddies or involving them in other club activities (social activities, volunteering), may create the necessary support for the insufficiently active participant to participate in sport. Indeed, sports club activities can include multiple family members [12]. However, from the literature it is not known how much and what kind of support is necessary to initiate sport behavior [25]. Furthermore, the relationship between physical activity and social support is a dynamic process in which the amount and type of support may change over time and through the phases of adoption and maintenance of this behavior [24, 32]. Therefore, research should examine which family support strategies at which stages of behavioral change are most beneficial to increase participant's sport behavior.

The results suggest that the sporting programs can be used to increase HEPA levels of insufficiently active people, especially of those who already engage in a modest amount of moderate-intensity physical activity. Nonetheless, a majority of the participants was already sufficiently active at baseline and specific insufficiently active population subgroups (e.g. older adults, people with chronic diseases, people with a foreign background, lower educated people) were hardly reached. Barriers and preferences for sport and physical participation vary across different population subgroups [33]. For insufficiently active people, unfamiliarity with the sport setting or the 'tough' image of sport may prevent them from participating [10,33]. Moreover, there is evidence that the target group is less aware of sport and physical activity opportunities in their neighborhood [34]. Therefore, an explanation for not reaching large numbers of insufficiently active people, might be the use of inappropriate recruitment strategies. For these sporting programs, participants were recruited by sports clubs using different recruitment strategies (e.g. the placement of advertisements in local media and the distribution of posters and flyers in the neighborhood). Not knowing the right people or channels to reach insufficiently active people was indeed a barrier for recruitment of this target group by the sports clubs [10].

To increase the population prevalence of HEPA it is important to attract more insufficiently active people to these HEPA sporting programs. Therefore, sports clubs should promote the sport activities in a non-threatening and fun manner, using promotion channels that are appropriate to the target group. In this regard, they may consider engaging in partnerships with primary health care, community health or other relevant organizations to get closer to this target group [18]. For instance, physicians and other health professionals can refer patients who need to be more physically active for their health to the sporting programs [35].

Furthermore, for people who are completely inactive, it is not inconceivable that more comprehensive strategies may be necessary to increase their physical activity levels. The threshold for sport participation can be too high for these people. Combining the sporting programs with broader physical activity programs, for instance, could both help in attracting inactive people and increasing their physical activity levels before engaging 
them into organized sports. For people who are inactive due to medical reasons, initial guidance by a physiotherapist could be helpful in decreasing fear of movement and physical limitations before participating in sport activities.

In general, it is important to know people's reasons for inactivity and tailor HEPA promotion programs to the inactive target group [10]. This can be achieved by actively involving these people in the development of such programs using different formative research strategies (e.g. interviews, observations, focus groups) [36, 37]. The three sporting programs in the current study were pilot tested before advancing to broader implementation, with also inactive people participating in the pilot phase (4\% to $14 \%$ of participants) [38]. However, it is not known to what extend their opinions were included in program design (as opposed to the opinions of insufficiently active people in general).

Finally, there might be some inactive people who cannot be persuaded to become physically active at all.

\section{Strengths and limitations of the study}

This study was performed in the real-world sport setting, namely sports clubs, with participants voluntarily participating in the sporting programs. Therefore, results are directly transferable into practice. Furthermore, although data were collected in 2009, all three programs are still running (in the same way) in many different sports clubs in the Netherlands with on average 1.500 (Through 4 Days Marches) to 3.500 (Start to Run) participants each year. Thus, considering the recent interest for HEPA promotion in sports clubs, the findings are still relevant today (in 2018). These are strengths of this study. However, there are some limitations to this study which may have implications for interpretation of the results. First, it was not possible to determine why almost half of the participants dropped out of the study between the baseline and six-month measurement. Non-respondents were more likely to be female and somewhat younger, but there were no significant differences between respondents and non-respondents in baseline sport and physical activity behavior. The sporting programs themselves had a very low dropout rate (i.e. between 2\%-3\% of participants stopped with the programs). Furthermore, participants of this study were representative for the entire participant population of the individual sporting programs with regard to age and sex. Thus, it is unlikely that the study findings were influenced markedly by these losses to follow-up. Second, the use of selfreport measures may have introduced social desirability biases, for instance, the overreporting of physical activity. In this case, the percentage of active participants may be overestimated. Third, this study combined data of three sporting programs. This could be done, because the programs were very comparable with regard to their content, i.e. they used feasible sports, graded training programs and similar retention strategies. It is not known, however, to what extent these results are generalizable to other HEPA sporting programs, like programs that use less feasible sports (e.g. indoor sports for which special facilities or equipment are needed) or other training/retention strategies. Fourth, the 
baseline questionnaire contained a limited number of characteristics (individual, social) of participants. It is possible that other factors that were not measured in this questionnaire may also influence sport participation of insufficiently active people, such as factors in the physical (e.g. proximity to recreational facilities/sports club) or economic (e.g. costs for physical activity) environment [25, 27-28]. Therefore, in future research, a larger number of factors should be taken into account. Finally, the number of insufficiently active participants was too low to perform more thorough analyses, for instance, to examine characteristics for different levels of baseline physical activity or to perform the analyses separately for males and females.

\section{CONCLUSIONS}

Considering these limitations, this study does add to the knowledge base about who are the insufficiently active participants that benefit from HEPA promotion programs implemented in the sports club setting. The results suggest that HEPA sporting programs can be used to increase HEPA levels of insufficiently active people, especially of those who receive social support from family members with regard to their sport participation and already participate in a modest amount of moderate-intensity activity. The results may have implications for designing and implementing HEPA promotion programs in the sports clubs setting. For instance, it is important that promotional strategies and channels are tailored to the target group. Furthermore, strategies that promote family support may enhance the impact of the programs. Clearly further research is needed to understand the factors that influence sport and physical activity behavior of insufficiently active people and to develop effective strategies to improve HEPA-levels of this target group. 


\section{REFERENCES}

1. World Health Organization (WHO). Global status report on noncommunicable diseases 2010. Geneva: WHO; 2011.

2. World Health Organization (WHO). Global recommendations on physical activity for health. Geneva: WHO; 2010.

3. Hallal PC, Andersen LB, Bull FC, Guthold R, Haskell W, Ekelund U. Global physical activity levels: surveillance progress, pitfalls, and prospects. Lancet. 2012;380:247-257.

4. Kyu HH, Bachman VF, Alexander LT, Mumford JE, Afshin A, Estep K, Veerman JL, Delwiche K, Lannarone ML, Moyer ML, Cercy K, Vos T, Murray CJL, Forouzanfar MH. Physical activity and risk of breast cancer, colon cancer, diabetes, ischemic heart disease, and inschemic stroke events: systemic review and dose-response meta-analysis for the Global Burden of Disease Study 2013. BMJ. 2016;354:i3857.

5. Warburton DER, Nicol CW, Bredin SSD. Health benefits of physical activity: the evidence. CMAJ. 2006;174(6):801-809.

6. Casey MM, Payne WR, Eime RM. Partnership and capacity-building strategies in community sports and recreation programs. Manag Leis. 2009;14(3):167-176.

7. Eime RM, Payne WR, Harvey JT. Making sporting clubs healthy and welcoming environments: a strategy to increase participation. J Sci Med Sport. 2008;11(2):146-154.

8. European Commission. Communication from the commission to the European parliament, the council, the European economic and social committee and the committee of the regions: developing the European Dimension in Sport. Brussels: European Commission; 2011.

9. Kokko S, Donaldson A, Geidne S, Seghers J, Scheerder J, Meganck J, Lane A, Kelly B, Casey M, Eime R, Villberg J, Kannas L. Piecing the puzzle together: case studies of international research in health promoting sports clubs. Glob Health Promot. 2015;23(1):75-84.

10. Ooms L, Veenhof C, Schipper-van Veldhoven N, de Bakker DH. Sporting programs for inactive population groups: factors influencing implementation in the organized sports setting. BMC Sports Sci Med Rehabil. 2015;7:12.

11. World Health Organization (WHO). Ottawa Charter for Health Promotion. Geneva: WHO; 1986.

12. Kokko S, Kannas L, Villberg J. The health promoting sports club in Finland--a challenge for the settings-based approach. Health Promot Int. 2006;21(3):219-229.

13. Kokko S. Sports clubs as settings for health promotion: fundamentals and an overview to research. Scan J Public Health. 2014;42(Suppl.15):60-65.

14. Downward P, Rasciute S. Exploring the covariates of sport participation for health: an analysis of males and females in England. J Sports Sci. 2014. DOI: 10.1080/02640414.2014.924056.

15. European Commission. Sport and physical activity. Special Eurobarometer 412/Wave EB80.2 Brussels: TNS Opinion \& Social; 2014.

16. Heron N, Kee F, Cupples ME, Tully MA. Correlates of sport participation in adults with longstanding illness or disability. BMJ Open Sport Exerc Med. 2015;1:e000003. DOI: 10.1136/bmjsem2015-000003. 
17. Bernaards CM. TNO monitor physical activity and health: physical activity in the Netherlands 2000-2013 (report in Dutch). Leiden: TNO Healthy Living; 2014.

18. Casey MM, Payne WR, Brown SJ, Eime RM. Engaging community sport and recreation organisations in population health interventions: factors affecting the formation, implementation, and institutionalisation of partnership efforts. Ann Leis Res. 2009;12(2):129147.

19. Ooms L, Veenhof C, de Bakker DH. Effectiveness of Start to Run, a 6-week training program for novice runners, on increasing health-enhancing physical activity: a controlled study. BMC Public Health. 2013;13:697.

20. Ooms L, Veenhof $C$, de Bakker DH. The Start2Bike program is effective in increasing healthenhancing physical activity: a controlled study. BMC Public Health. 2017;17:606.

21. Webster S, Lewis J, Brown A. Ethical considerations in qualitative research. In: Ritchie J, Lewis J, McNaughton Nicholls C, Ormston R, editors. Qualitative research practice: a guide for social science students and researchers. London: SAGE Publications, Ltd; 2014. p.77-110.

22. Dutch government. Dutch law on medical scientific research with humans (WMO). http:// wetten.overheid.nL/BWBR0009408/2015-12-17. Accessed 31 Augustus 2017.

23. Des Jarlais DC, Lyles C, Crepaz N, Trend Group. Improving the reporting quality of nonrandomized evaluations of behavioral and public health interventions: the TREND statement. Am J Public Health. 2004;94(3): 361-366.

24. Boutelle KN, Jeffery RW, French SA. Predictors of vigorous exercise adoption and maintenance over four years in a community sample. Int J Behav Nutr Phys Act. 2004;1(1):13.

25. Eyler AA. Correlates of physical activity: who's active and who's not? Arthritis Rheum. 2003:49(1):136-140.

26. McNeill LH, Kreuter MW, Subramanian SV. Social environment and physical activity: a review of concepts and evidence. Soc Sci Med. 2006;63(4):1011-1022.

27. Trost SG, Owen N, Bauman AE, Sallis JF, Brown W. Correlates of adults' participation in physical activity: review and update. Med Sci Sports Exerc. 2002;34(12):1996-2001.

28. Wendel-Vos W, Droomers M, Kremers S, Brug J, van Lenthe F. Potential environmental determinants of physical activity in adults: a systematic review. Obes Rev. 2007;8(5):425-440.

29. World Health Organization (WHO). Obesity: preventing and managing the global epidemic. Geneva: WHO; 2000.

30. Statistics Netherlands. Year report integration 2012 (report in Dutch). The Hague: Statistics Netherlands; 2012.

31. Wendel-Vos GC, Schuit AJ, Saris WH, Kromhout D. Reproducibility and relative validity of the short questionnaire to assess health-enhancing physical activity. J Clin Epidemiol. 2003;56:11631169.

32. Oka RK, King AC, Young DR. Sources of social support as predictors of exercise adherence in women and men ages 50 to 65 years. Women Health. 1995;1(2):161-175.

33. Allender S, Cowburn G, Foster C. Understanding participation in sport and physical activity among children and adults: a review of qualitative studies. Health Educ Res. 2006;21(6):826835. 
34. Ståhl T, Rütten A, Nutbeam D, Bauman A, Kannas L, Abel T, Lüschen G, Diaz JA, Rodriquez DJA, Vinck J, van der Zee J. The importance of the social environment for physically active lifestyle: results from an international study. Soc Sci Med. 2001;52:1-10.

35. Khan KM, Thompson AM, Blair SN, Sallis JF, Powell KE, Bull FC, Bauman AE. Sport and exercise as contributors to the health of nations. Lancet. 2012;380:59-64.

36. Donaldson A, Finch CF. Planning for implementation and translation: seek first to understand the end-users' perspectives. Br J Sports Med. 2012;46(5):306-307.

37. Gittelsohn J, Steckler A, Johnson CC, Pratt C, Grieser M, Pickrel J, Stone EJ, Conway T, Coombs D, Staten LK. Formative research in school and community-based health programs and studies: "state of the art" and the TAAG approach. Health Educ Behav. 2006;33:25-39.

38. Pisters MF, Veenhof, C. Evaluation of the pilot phase of the National Action Plan for Sport and Exercise: the sport setting (report in Dutch). Utrecht: NIVEL; 2008. 


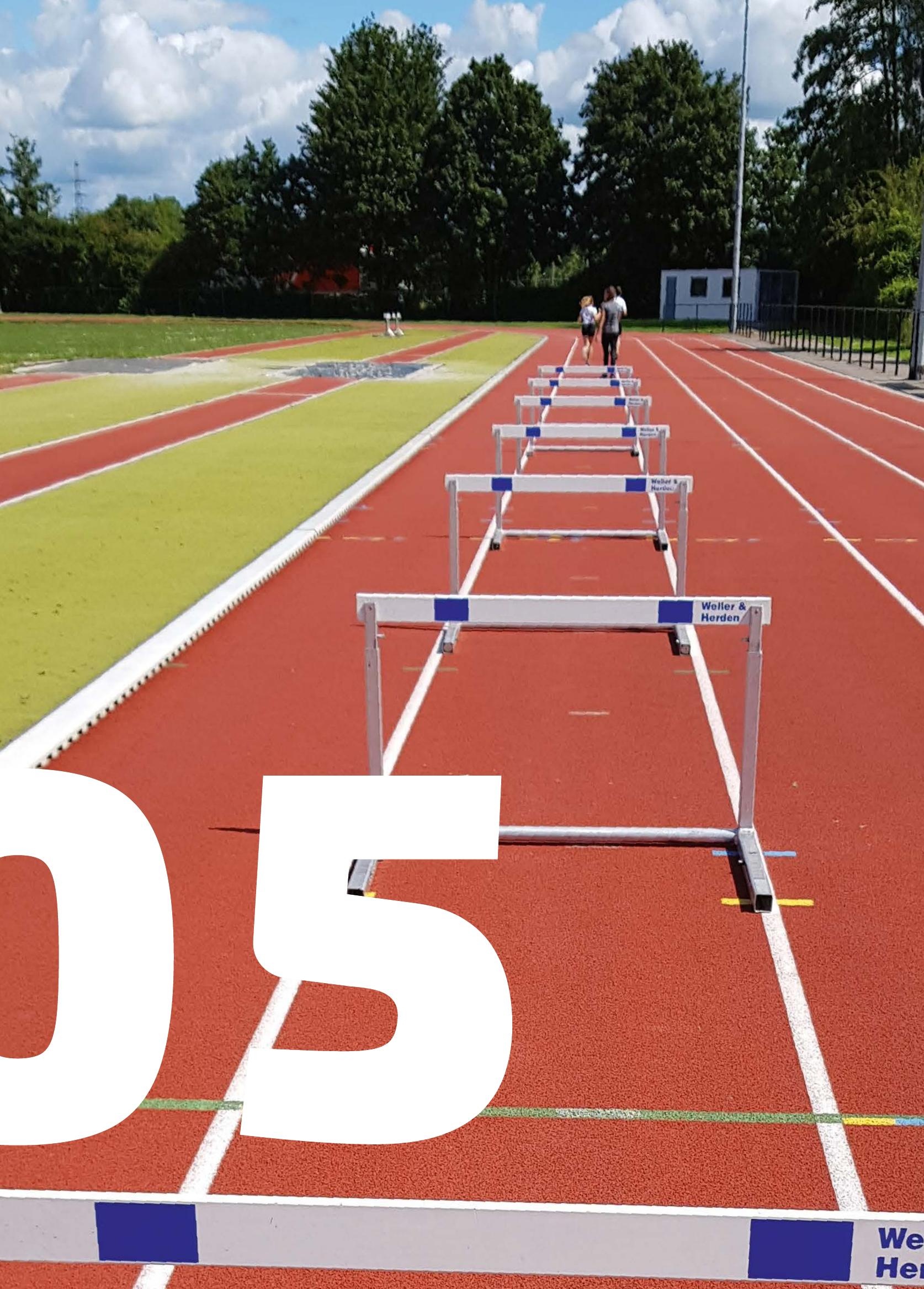




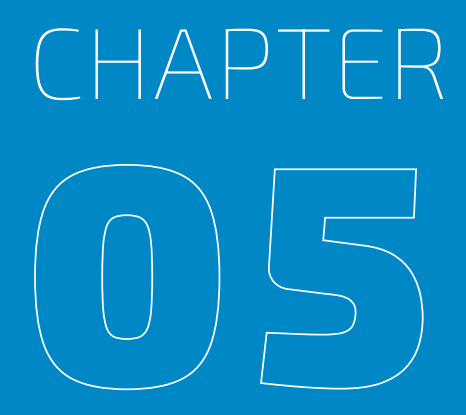

\section{Sporting programs for inactive population groups: factors influencing implementation in the organized sports setting}

Published as: Ooms L, Veenhof C, Schipper-van Veldhoven N, de Bakker DH. Sporting programs for inactive population groups: factors influencing implementation in the organized sports setting. BMC Sports Science, Medicine and Rehabilitation. 2015;7:12. 


\section{ABSTRACT}

Background: The organized sports sector has received increased attention as a setting to promote health-enhancing physical activity (HEPA) to the general population. For significant public health impact, it is important that successful HEPA programs are widely adopted, implemented and continued as ongoing practice. The importance of evaluating the context in which programs are implemented has been identified as critical. However, little research has focused on understanding the organized sports implementation context, including factors facilitating and impeding implementation. In this study, the main factors influencing implementation of HEPA programs in the organized sports setting were studied.

Methods: Fourteen sporting programs in the Netherlands aimed at increasing participation in sports by inactive population groups and funded within the National Action Plan for Sport and Exercise (NAPSE) were investigated. The programs were developed by ten Dutch National Sports Federation (NSFs) and implemented by different sports clubs in the Netherlands over a three-year implementation period (June 2008-June 2011). The qualitative research component involved yearly face-to-face interviews (i.e. fourteen interviews each year, $n=12$ program coordinators) and a group meeting with the program coordinators of the NSFs $(n=8)$. Cross-case comparisons and thematic analyses were performed to identify and categorize important facilitating and impeding factors respectively. The quantitative research component, used to identify the most important facilitating and impeding factors across all sporting programs, consisted of ranking of factors according to importance by the program coordinators ( $n=12)$.

Results: Different factors act during six identified (implementation) phases. When comparing factors across phases, several key learnings were evident. Successful implementation relied, for example, on program design and enthusiastic individuals within sporting organizations. On the other hand, inactive people were hard to reach and participation of sports clubs was not self-evident. The findings were discussed in a broader context.

Conclusions: This study adds to the knowledge base concerning the implementation of sporting programs, aimed at inactive people, in the organized sports setting. The main factors facilitating and impeding implementation were identified. The results of this study can be used by sports practitioners and policy makers when developing and implementing HEPA programs in this setting. 


\section{BACKGROUND}

Participation in regular physical activity impacts positively on physical and mental health [1-3]. However, an alarming number of people are not sufficiently active to receive these benefits. In the Netherlands, this comprises $34 \%$ of adults and $51 \%$ of children and youth [4]. Worldwide, 31\% of adults do not engage in enough physical activity. According to the World Health Organization, insufficient physical activity is the fourth leading risk factor for mortality causing an estimated 3.2 million deaths globally each year [5]. The greatest improvements in health are obtained by increasing physical activity levels of the most inactive people, rather than getting those already active to do a little more [3].

Given the low levels of physical activity, many countries are investing resources in strategies to increase population-wide levels of health-enhancing physical activity (HEPA) [6]. Recognizing the complexity of physical activity behavior and the multiple factors influencing this behavior, more attention is paid to holistic and multi-disciplinary approaches to physical activity promotion. One such approach commonly used in health promotion is the settings-based approach, which is based on the idea that changes in people's health and health behavior are easier to achieve if health promoters focus on settings instead of individuals [7]. This approach builds on the Ottawa Charter of 1986 that stated: "Health is created and lived by people within the settings of their everyday life; where they learn, work, play and love [8]." The settings-based approach has an ecological perspective and acknowledges the multiple levels of influence on behavior, i.e. personal, organizational, environmental and policy. It, therefore, takes into account the complexity of systems and societies in which people make their health choices [9-12]. The settings-based approach has been applied to different settings, like schools and workplaces [7, 9, 10]. A setting that has received increased attention in promoting health, including HEPA, is the organized sports sector [13-23].

There is large potential for the organized sports sector as a setting in which to promote HEPA to the general population, given the large numbers of participants, the extent of community reach and the availability of many different sports. The Dutch sports system, for example, consists of 76 National Sports Federations, approximately 25,000 sports clubs and 4.8 million sports club members [24]. Another positive aspect of participation in organized sports is that those people who are involved in organized sports are significantly more likely to meet levels of HEPA than those who are not [4]. Moreover, it has been suggested that participation in sports clubs is associated with improved psychosocial health in addition to improvements (in health) attributable to participation in physical activity [25]. Also, the social and informal nature of the sports setting has been argued to be advantageous for promoting HEPA $[22,26]$. Therefore, further increasing physical activity levels of sports participants who do not meet levels of HEPA and increasing participation in sports by inactive population groups seems to be a promising strategy to enhance public health. 
Different countries have already been investing resources in the organized sports sector for promoting health. Good examples of strategies can be derived from Australia. Early Australian efforts, for example, focused on delivering health promotion messages at sponsored sporting events [21]. More recently, the focus is on the creation of healthy (e.g. smoke-free settings, healthy food choices) and welcoming sporting environments as a means to increase participation in sport for health benefits [14-16, 19]. In Finland, guidelines have been developed for youth sports clubs to develop, implement and assess health promotion within their activities [23]. Another example is the ' 11 for Health' program, a football-based health education program, which was developed by the Fédération Internationale de Football Association (FIFA) Medical Assessment and Research Centre for children in Africa. The program combined learning football skills with health education messages and was implemented in different countries in Africa [27]. Furthermore, in the Netherlands, the Dutch Ministry of Health, Welfare and Sport initiated the National Action Plan for Sport and Exercise (NAPSE). This program was aimed at increasing the number of Dutch people meeting levels of HEPA [18]. Within the NAPSE, National Sports Federations (NSFs) were asked to develop sporting programs aimed at increasing participation in sports by inactive population groups. Seventeen NSFs developed twenty-four programs which were pilot tested by a dozen local sports clubs. Based on results of a process evaluation and monitoring study [28], fourteen programs of ten NSFs were funded to be implemented more broadly by sports clubs in the Netherlands over a three-year implementation period. Examples include a six-week training program for adult novice runners and an adjusted form of weekly hockey for seniors played with soft balls and soft sticks.

For significant public health impact, it is important that successful HEPA programs are widely adopted, implemented and continued as ongoing practice. In this regard, the importance of evaluating the context in which programs are implemented has been identified as critical [29-33]. The primary provider of sport in the Netherlands and in many other countries (e.g. Australia, Finland, Norway) is the sports club. Any HEPA sporting program to be implemented must be interpreted and implemented by the representatives of the sports club, which are mainly volunteers and whose main focus is on providing sports activities and organizing sports competitions [32, 33]. Nonetheless, sports clubs are aware of the healthy outcomes of sport and sometimes use this as legitimacy for their activities [33].

To date, little research has focused on understanding the organized sports implementation context, including factors facilitating and impeding implementation of health programs or activities [29-31]. A few studies have been conducted in Australia concerning the development of healthy and welcoming environments (HWEs) in sports clubs $[14-16,19]$. Important factors facilitating the implementation of HWEs, both for the funded State Sporting Associations and implementing sports clubs, were the availability of funding; guidance and support (e.g. training, advice, materials); understanding of benefits (i.e. increased participation at sports clubs); a positive attitude towards the HWE concept; and support of key individuals within the organization. The barriers to implementation were mainly the inverse of the facilitators. Other important barriers were State Sporting Associations' limited capacity and power to influence activities at the club level; limited 
capacity of volunteer-based sports clubs; no clear outlining of expectations and responsibilities; unrealistic time-frames for implementation; and structural impediments (e.g. a lack of facilities, costs). Furthermore, the Finnish 'Health Promoting Sports Club' guidelines provide fourteen consecutive steps for local youth sports clubs to enhance health promotion as part of their activities [23]. The guidelines are divided into policy development actions and activities a club needs to perform before the club actors (e.g. coaches) can implement health promotion as part of their daily practice, like "prioritize the most relevant health promotion aims" (policy development) and "educate coaches and other club officials" (practice development). For each guideline, the rationale and practical examples are provided.

The aforementioned studies have a relatively broad focus when it comes to health promotion. Less is known about the implementation of HEPA programs per se. The promotion of HEPA is more closely related to the core business of sporting organizations (i.e. the provision of sports activities) than other health promotion actions and may, therefore, result in different implementation successes or challenges. There is one Australian study that focused on partnership and capacity-building strategies associated with successful implementation of cross-sectoral (e.g. sports, recreation, health) sports and recreation programs [13]. The investigated programs had a strong emphasis on participation in physical activity that would benefit people who were not currently active and on low incomes. The findings showed that engagement of key stakeholders, formalization of the partnership agreement and capacity (diversity of skills and resources within the partnership) to develop and implement sports and recreation programs facilitated program implementation. In addition, addressing the development of partnerships, implementing a phased approach to program development and implementation was suggested to assist the sports and recreation sector build capacity to participate in partnership approaches to health promotion. The researchers focused on cross-sectoral HEPA programs and addressed only a particular aspect of the implementation process (i.e. partnership and capacity-building strategies). Therefore, to gain a broader understanding of the implementation of HEPA programs in the organized sports setting, this study focused on HEPA programs initiated by sporting organizations and the implementation process as a whole. Specifically, the main factors influencing implementation of the fourteen NAPSE sporting programs, initiated by NSFs and implemented by sports clubs in the Netherlands, were studied. The study results will support sports practitioners and policy makers with developing and implementing HEPA programs in this setting. The findings of this study are of international interest, particularly in countries where the organized sports sector is used as a setting to promote HEPA. 


\section{METHODS}

\section{Sample}

This study focused on the fourteen NAPSE sporting programs and the ten funded NSFs, i.e. the program coordinators who were designated to facilitate implementation of these programs in local sports clubs in the Netherlands. The programs varied with regard to targeted age group, content and duration. A description of the programs can be found in Table 5.1. The NAPSE sporting programs were implemented by different sports clubs over a three-year implementation period (June 2008-June 2011). Sizes of the NSFs, as well as program aims and the extent to which NSFs were successful in achieving these aims, varied widely. The actual reach of the programs ranged from 9 ( $45 \%$ of aim reached) to 680 (159\%) participating locations (a sports club could implement the program in different locations) and 85 (43\%) to 273,896 (304\%) participants (see Table 5.2).

\section{Design}

This research was part of a larger study in which both a process and effectiveness evaluation of the programs were conducted [34]. It consisted of a qualitative component to explore factors facilitating and impeding implementation of the individual sporting programs followed by a quantitative component to identify a generic set of factors (i.e. the most important factors across all sporting programs) influencing implementation. The qualitative component results informed the quantitative component. When performing the study, ethical guidelines were followed (i.e. with regard to avoiding undue intrusion, avoiding adverse consequences, confidentiality, enabling participation, informed consent and data protection) [35]. Before the start of the implementation phase, a group meeting was held with the program coordinators of the NSFs to explain in plain language the purpose of the research, the methods, demands, potential risks and possible outcomes of the research. In addition, it was explained that monitoring implementation progress was part of the NAPSE funding agreement, but that NSFs were not judged on the basis of the program or research results (i.e. the NSFs had a best-efforts obligation with regard to implementing the programs). Written informed consent for participation in the study was obtained from the NSFs when they applied for the funding. According to Dutch legislation, approval by a medical ethics committee was not obligatory, as participants were not subjected to procedures, nor were they required to follow rules of behavior. The privacy regulations of the study were approved by the Dutch Data Protection Authority. For reporting of results, the RATS guidelines were used as a guidance [36]. 
Table 5.1 Description Dutch NAPSE sporting programs

\begin{tabular}{|c|c|c|c|}
\hline NSF & $\begin{array}{l}\text { Sporting } \\
\text { program }\end{array}$ & $\begin{array}{l}\text { Target } \\
\text { group }\end{array}$ & Description \\
\hline Athletics & Start to Run & Adults & $\begin{array}{l}\text { 6-week training program for novice runners aimed at running } \\
3 \mathrm{~km} \text { continuously. The program is offered by athletics clubs } \\
\text { and running stores. }\end{array}$ \\
\hline Judo & $\begin{array}{l}\text { Judo in } \\
\text { school }\end{array}$ & $\begin{array}{l}\text { Children, } \\
\text { adolescents }\end{array}$ & $\begin{array}{l}\text { During a few weeks judo lessons in school provided by a } \\
\text { qualified judo trainer. }\end{array}$ \\
\hline Walking & $\begin{array}{l}\text { Through } \\
4 \text { Days } \\
\text { Marches }\end{array}$ & Adults & $\begin{array}{l}\text { 6-month training program for the Four Days Marches } \\
\text { of Nijmegen. Participants can take part in the program } \\
\text { individually or at a walking club. }\end{array}$ \\
\hline Walking & $\begin{array}{l}\text { Working by } \\
\text { Walking }\end{array}$ & Adults & $\begin{array}{l}\text { Walking program of at least } 16 \text { weeks aimed at improving } \\
\text { health parameters. The program is provided by qualified } \\
\text { walking trainers. }\end{array}$ \\
\hline Gymnastics & $\begin{array}{l}\text { Trendy } \\
\text { Weeks for } \\
\text { Masters }\end{array}$ & $\begin{array}{l}\text { Older adults } \\
(45+)\end{array}$ & $\begin{array}{l}\text { During 8-12 weeks gymnastic classes with a specific theme } \\
\text { (e.g. Move on music) at a gymnastics club. }\end{array}$ \\
\hline Hockey & Fit Hockey & $\begin{array}{l}\text { Older adults } \\
(50+)\end{array}$ & $\begin{array}{l}\text { Hockey played in a team with soft sticks and soft balls; } \\
\text { training opportunities are provided continuously at the } \\
\text { hockey club. }\end{array}$ \\
\hline Swimming & $\begin{array}{l}\text { My } \\
\text { Swimming } \\
\text { Coach }\end{array}$ & Adults & $\begin{array}{l}\text { A membership of the NSF, including access to an online } \\
\text { swimming coach and opportunities to participate in swim } \\
\text { clinics and events. }\end{array}$ \\
\hline Bridge & $\begin{array}{l}\text { Thinking and } \\
\text { Doing }\end{array}$ & $\begin{array}{l}\text { Older adults } \\
(55+)\end{array}$ & $\begin{array}{l}\text { A project of two years in which bridge is used to create } \\
\text { communities of older people. After a year physical activities } \\
\text { are offered. }\end{array}$ \\
\hline $\begin{array}{l}\text { Sportive } \\
\text { cycling }\end{array}$ & Cycle-Fit & Adults & $\begin{array}{l}\text { 6-week training program for novice cyclers (speed cycling, } \\
\text { mountain biking). The program is offered by (sportive) } \\
\text { cycling clubs and cycling stores. }\end{array}$ \\
\hline $\begin{array}{l}\text { Sportive } \\
\text { cycling }\end{array}$ & $\begin{array}{l}\text { Cycle \& } \\
\text { Enjoy Nature }\end{array}$ & $\begin{array}{l}\text { Older adults } \\
(45+)\end{array}$ & $\begin{array}{l}\text { Regular recreational cycling activities with a focus on } \\
\text { relaxing and enjoying nature at a cycling club; or an individual } \\
\text { introduction package including a cycling magazine, a training } \\
\text { manual, a map with cycling routes and a calendar with } \\
\text { cycling events. }\end{array}$ \\
\hline Triathlon & $\begin{array}{l}\text { Trio- } \\
\text { Triathlon }\end{array}$ & Adults & $\begin{array}{l}\text { Organization of Trio-Triathlon (the three sports of a triathlon } \\
\text { are performed by three different individuals) events. }\end{array}$ \\
\hline Volleyball & $\begin{array}{l}\text { Beach } \\
\text { volleyball }\end{array}$ & $\begin{array}{l}\text { Children, } \\
\text { adolescents, } \\
\text { adults }\end{array}$ & $\begin{array}{l}\text { Organization of different beach volleyball activities (e.g. } \\
\text { clinics, tournaments, workshops) at schools, (beach) } \\
\text { volleyball clubs, companies and (beach) volleyball events. }\end{array}$ \\
\hline Volleyball & $\begin{array}{l}\text { Cool Moves } \\
\text { Volley }\end{array}$ & Children & $\begin{array}{l}\text { A volleyball approach adapted to the abilities and needs of } \\
\text { kids. Training opportunities are provided continuously at } \\
\text { volleyball clubs; clinics are provided in schools. }\end{array}$ \\
\hline Volleyball & $\begin{array}{l}\text { Ultimate } \\
\text { Volley } \\
\text { Xperience }\end{array}$ & Adolescents & $\begin{array}{l}\text { A volleyball event in a Caribbean atmosphere. The event is } \\
\text { held at a special location and includes music and spectacular } \\
\text { side-events. }\end{array}$ \\
\hline
\end{tabular}




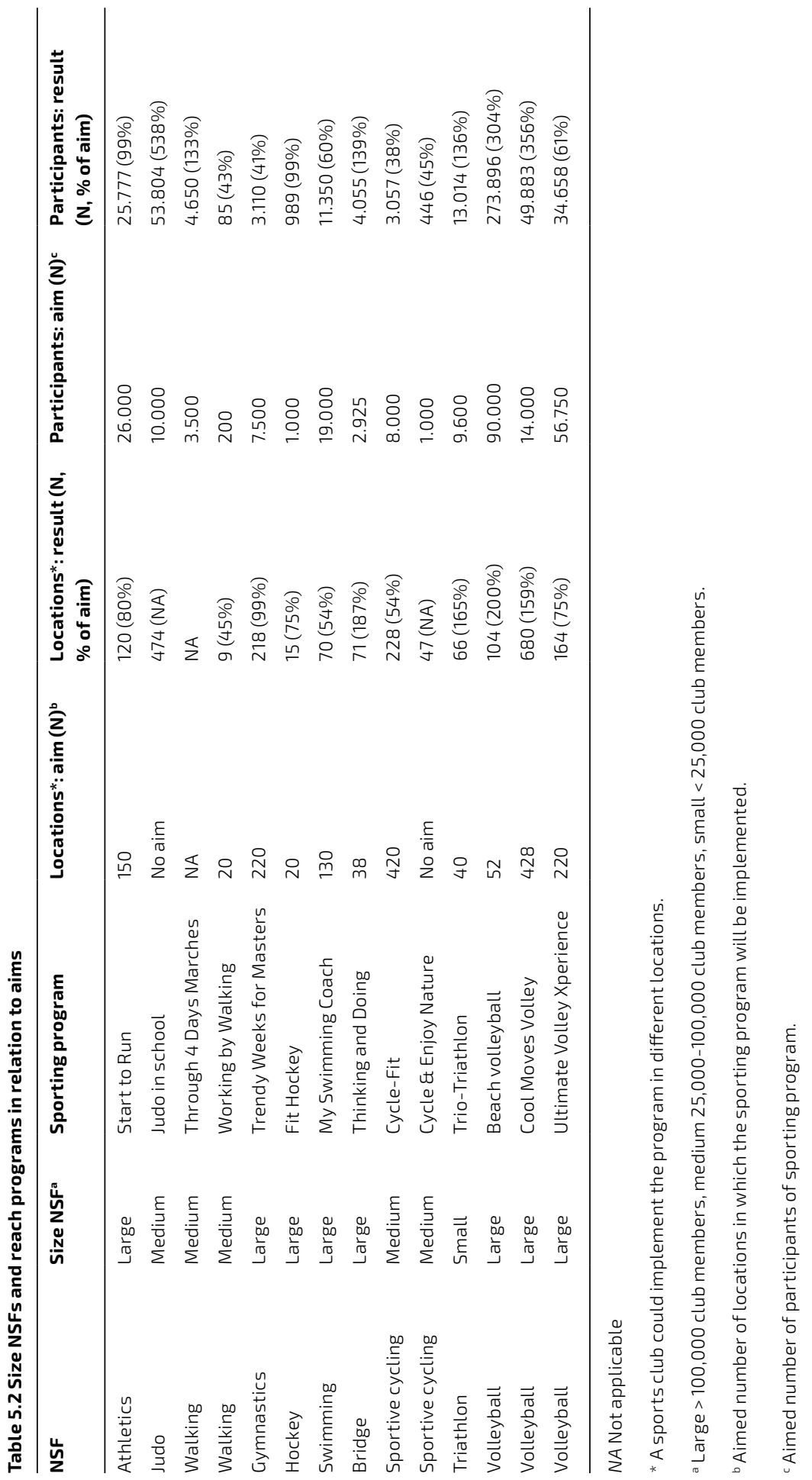




\section{Procedures}

\section{Qualitative part}

\section{Face-to-face interviews}

Face-to-face interviews were conducted with the program coordinators of the NSFs ( $n=12$; one program coordinator per NAPSE sporting program; two program coordinators were responsible for two programs). Overall, fourteen (i.e. one interview per program) semistructured interviews of 60-90 minutes duration were conducted yearly (in 2009, 2010 and 2011) during the three-year implementation period by the primary researcher (LO). The same program coordinators participated in the interviews, except for five sporting programs. For these programs, there was a change in program coordinator during the implementation period. The interview questions focused on implementation progress in the past year and factors that respondents believed have facilitated and/or hindered implementation. Also, other topics were considered, like the number of participants, obtained results, developed products, collaboration with other parties, the follow-up activities offered and continuation of the program after cessation of funding. The latter topics, however, were asked in light of the general process evaluation. In this research, they were only used as background information. The interview questions were partly based on interview questions used during the pilot study [28] and further developed by an expert panel consisting of the two researchers (LO and CV) and representatives of the Netherlands Olympic Committee and Netherlands Sports Federation (NOC*NSF), the Dutch Ministry of Health, Welfare and Sport, the Netherlands Institute for Sport and Physical Activity and four NSFs. The interviews were recorded with a digital voice recorder and transcribed later on. A transcript summarizing the main findings was sent for review and revision to the interviewees.

\section{Extraction and categorizing of factors}

For each sporting program, facilitating and impeding factors were extracted from the interview transcripts and summarized. Subsequently, a list of facilitating and impeding factors for all sporting programs was created. For this purpose, cross case analyses [37] were performed with the individual sporting programs representing the cases. Factors were compared between sporting programs to investigate commonalities: Comparable factors between sporting programs were summarized and added as a single factor. For instance, multiple program coordinators indicated that it was important to visit sports clubs personally when asking for participation. This was summarized as the facilitating factor: 'approaching sports clubs personally'. Unique factors were added as a single factor to the list. Finally, thematic analyses [38] were performed to categorize the factors according to themes. Extraction of factors, cross-case and thematic analyses were performed manually by the primary researcher (LO) using Microsoft Word 2010 (Microsoft Corporation, Redmond, United States). To enhance rigor, all analyses were checked by a second researcher (CV). Differences between researchers were discussed. This resulted in only minor adjustments. 


\section{Meeting with program coordinators}

To verify the obtained factors and categorizing according to themes or, in this case, phases, the results were presented and discussed at a meeting with the program coordinators $(n=8$, the others were unable to attend). In a general discussion which was led by the primary researcher (LO), consensus was reached about the phases. In addition, the program coordinators were asked whether they agreed on the identified factors and whether any important factors were missing. For this purpose, they circulated along paper boards. On each board, a phase with its accompanying factors was presented. Program coordinators could add or remove factors. This led to the addition of 16 new facilitating factors and three new impeding factors. These factors are presented in bold in appendix 5.1: Overview of all factors and their ranking scores. No factors were removed. Subsequently, a final overview of factors categorized by phases was made by the researcher (LO).

\section{Quantitative part}

\section{Ranking of factors}

To identify the most important facilitating and impeding factors across all sporting programs, the final overview was sent to the program coordinators $(n=12)$ by email. The program coordinators were asked to rank the factors in an attached ranking form, whereby ranking was done by phase and for facilitating and impeding factors separately. The most important (facilitating or impeding) factor was assigned ranking 1, the second most important factor was assigned ranking 2, etc. As the number of factors varied by phase, the number of assigned rankings also varied. Completed ranking forms $(n=12)$ were returned by email.

\section{Calculating mean ranking scores and composing the top three of factors}

The mean ranking score for each factor was calculated (i.e. sum of ranks divided by number of program coordinators $(n=12)$ ) by the researcher (LO) using Stata statistical software version 10.1 (Stata Corporation, College Station, Texas). Then, the factors were placed in order of importance, with the lower mean ranking scores corresponding to more important factors. Subsequently, the top three facilitating and impeding factors were composed per phase. In case there were three or less than three factors, all factors are presented. 


\section{RESULTS}

\section{Phases and final overview of factors}

Based on thematic analyses and the meeting with the program coordinators of the NSFs, factors were categorized according to six phases through which all programs proceeded in a consecutive manner:

1) Program development: factors that influenced implementation, but had to be dealt with during program development, i.e. the phase proceeding implementation;

2) Organizational (pre)conditions: factors that influenced implementation at the level of the NSF;

3) Recruiting local sports clubs: factors that affected the recruitment of local sports clubs;

4) Recruiting participants: factors that facilitated or impeded recruitment of participants for the program;

5) Local implementation: factors that were important during local implementation, i.e. at the level of the sports club;

6) Securing continuation of the program: factors that had to be considered during implementation and influenced continuation of the program after implementation, both at the level of the NSF and sports clubs.

The final overview of factors, comprising the six phases, contained a total of 56 facilitating and 29 impeding factors (see Appendix 5.1: Overview of all factors and their ranking scores). The number of facilitating factors varied by phase from 7 to 12 , the number of impeding factors varied by implementation phase from 2 to 7 . In each phase, there were more facilitating than impeding factors.

\section{Ranking results}

Based on the ranking of factors according to importance, the top three facilitating and impeding factors per phase were identified. These results are presented in Tables 5.3 and 5.4 for facilitating and impeding factors respectively. Comparing both tables, it is apparent that the impeding factors were mainly the inverse of the facilitating factors. Furthermore, the range of rankings shows that there were some differences in ranking by the program coordinators. Under the headings of the six phases, the factors will be explained in more detail and illustrated with examples provided by the program coordinators in the interviews. Since the impeding factors were often the inverse of the facilitators, they are not always explained separately. In the additional file, all factors and their ranking scores are presented (see Appendix 5.1: Overview of all factors and their ranking scores). 
Table 5.3 The top three facilitating factors per phase based on ranking by NAPSE program coordinators $(n=12)$

\begin{tabular}{|c|c|c|c|}
\hline $\begin{array}{l}\text { Phase (total } \\
\text { number of } \\
\text { factors in phase) }\end{array}$ & Top three factors & $\begin{array}{l}\text { Mean } \\
\text { ranking } \\
\text { score }^{a}\end{array}$ & $\begin{array}{l}\text { Range } \\
\text { assigned } \\
\text { rankings }^{\mathrm{b}}\end{array}$ \\
\hline \multirow{3}{*}{$\begin{array}{l}\text { 1. Program } \\
\text { development } \\
(n=12)\end{array}$} & $\begin{array}{l}\text { - The program matches the target group's needs, wishes } \\
\text { and possibilities }\end{array}$ & 1.1 & $1-2$ \\
\hline & - The program is easy to implement locally & 3.8 & $2-7$ \\
\hline & - Low threshold for participation of inactive people & 3.9 & $1-7$ \\
\hline \multirow{3}{*}{$\begin{array}{l}\text { 2. Organizational } \\
\text { (pre)conditions } \\
(n=10)\end{array}$} & - Having a 'dedicated' program coordinator & 2.9 & $1-8$ \\
\hline & - Sufficient time (in man-hours) to coordinate the program & 3.1 & $1-6$ \\
\hline & . Internal support for the program & 3.9 & $1-9$ \\
\hline \multirow{3}{*}{$\begin{array}{l}\text { 3. Recruiting local } \\
\text { sports clubs } \\
(n=10)\end{array}$} & $\begin{array}{l}\text { - Providing a complete (readily usable) package to } \\
\text { sports clubs }\end{array}$ & 3.8 & $1-7$ \\
\hline & - Approaching sports clubs personally & 4.3 & $1-10$ \\
\hline & - Support for the program by sports clubs & 4.7 & $1-10$ \\
\hline \multirow{3}{*}{$\begin{array}{l}\text { 4. Recruiting } \\
\text { participants } \\
(\mathrm{n}=9)\end{array}$} & - Support for the program by the target group & 3.3 & $1-6$ \\
\hline & $\begin{array}{l}\text { A good promotion/marketing strategy nationally } \\
\text { and locally }\end{array}$ & 3.4 & $1-8$ \\
\hline & $\begin{array}{l}\text { The sports activities are organized in close proximity } \\
\text { to the target group }\end{array}$ & 3.6 & $1-6$ \\
\hline \multirow{3}{*}{$\begin{array}{l}\text { 5. Local } \\
\text { implementation } \\
(\mathrm{n}=8)\end{array}$} & $\begin{array}{l}\text { Enthusiastic people within sports clubs delivering (high-) } \\
\text { quality performances }\end{array}$ & 2.9 & $1-7$ \\
\hline & $\begin{array}{l}\text { - Sports clubs are (personally) supported by the NSF } \\
\text { when implementing the program locally }\end{array}$ & 3.8 & $1-7$ \\
\hline & $\begin{array}{l}\text { - Availability of follow-up sports activities locally that } \\
\text { match participants' needs, wishes and possibilities }\end{array}$ & 3.8 & $1-8$ \\
\hline \multirow{3}{*}{$\begin{array}{l}\text { 6. Securing } \\
\text { continuation } \\
\text { of the program } \\
(n=7)\end{array}$} & . The program is part of the NSF's long-term policy & 2.6 & $1-5$ \\
\hline & $\begin{array}{l}\text { The NSF has sufficient financial resources available to } \\
\text { continue the program/secure the program for the future }\end{array}$ & 2.7 & $1-6$ \\
\hline & . The program is part of the sports club's long-term policy & 3.0 & $1-6$ \\
\hline
\end{tabular}

a For each factor: Sum of rankings divided by the number of program coordinators $(n=12)$.

${ }^{\mathrm{b}}$ Lowest and highest ranking of factor. 
Table 5.4 The top three impeding factors per phase based on ranking by NAPSE program coordinators ( $n=12)$

\begin{tabular}{|c|c|c|c|}
\hline $\begin{array}{l}\text { Phase (total } \\
\text { number of } \\
\text { factors in phase) }\end{array}$ & Top three factors & $\begin{array}{l}\text { Mean } \\
\text { ranking } \\
\text { score }^{a}\end{array}$ & $\begin{array}{l}\text { Range } \\
\text { assigned } \\
\text { rankings }\end{array}$ \\
\hline \multirow{3}{*}{$\begin{array}{l}\text { 1. Program } \\
\text { development } \\
(n=6)\end{array}$} & $\begin{array}{l}\text { The program does not match the target group's needs, } \\
\text { wishes and/or possibilities }\end{array}$ & 1.8 & $1-6$ \\
\hline & - The (implementation of the) program (locally) is costly & 3.2 & $1-5$ \\
\hline & $\begin{array}{l}\text { - The program does not match the needs, wishes and/or } \\
\text { possibilities of sports clubs }\end{array}$ & 3.3 & $1-5$ \\
\hline \multirow{3}{*}{$\begin{array}{l}\text { 2. Organizational } \\
\text { (pre)conditions } \\
(n=3)\end{array}$} & $\begin{array}{l}\text { - Insufficient finances to coordinate and implement } \\
\text { the program }\end{array}$ & 1.4 & $1-2$ \\
\hline & - No or insufficient support for the program internally & 1.9 & $1-3$ \\
\hline & - Internal organizational changes & 2.7 & $1-3$ \\
\hline \multirow{3}{*}{$\begin{array}{l}\text { 3. Recruiting local } \\
\text { sports clubs } \\
(n=6)\end{array}$} & - No or insufficient qualified trainers locally & 2.2 & $1-4$ \\
\hline & - No or insufficient support for the program by sports clubs & 2.4 & $1-6$ \\
\hline & - Unavailability of additional (local) funding possibilities & 3.6 & $1-6$ \\
\hline \multirow{3}{*}{$\begin{array}{l}\text { 4. Recruiting } \\
\text { participants } \\
(n=7)\end{array}$} & $\begin{array}{l}\text { - The target group is unfamiliar with the program or } \\
\text { the sport }\end{array}$ & 3.0 & $1-5$ \\
\hline & $\begin{array}{l}\text { No or insufficient support for the program by the } \\
\text { target group }\end{array}$ & 3.3 & $1-7$ \\
\hline & - The program does not reach/engage inactive people & 3.4 & $1-5$ \\
\hline \multirow{3}{*}{$\begin{array}{l}\text { 5. Local } \\
\text { implementation } \\
\qquad(n=5)\end{array}$} & $\begin{array}{l}\text { - No enthusiastic and/or incompetent people within } \\
\text { sports clubs }\end{array}$ & 1.5 & $1-4$ \\
\hline & $\begin{array}{l}\text { - No clear division of roles, tasks and responsibilities } \\
\text { between the NSF and sports clubs }\end{array}$ & 3.0 & $1-5$ \\
\hline & $\begin{array}{l}\text { - No (appropriate) follow-up sports activities for } \\
\text { participants locally }\end{array}$ & 3.2 & $1-5$ \\
\hline \multirow{2}{*}{$\begin{array}{l}\text { 6. Securing } \\
\text { continuation } \\
\text { of the program } \\
(n=2)\end{array}$} & $\begin{array}{l}\text { The NSF has insufficient financial resources available to } \\
\text { continue the program/secure the program for the future }\end{array}$ & 1.4 & $1-2$ \\
\hline & $\begin{array}{l}\text { - Sports clubs have insufficient financial resources available } \\
\text { to continue the program locally/secure the program for } \\
\text { the future }\end{array}$ & 1.6 & $1-2$ \\
\hline
\end{tabular}

a For each factor: Sum of rankings divided by the number of program coordinators $(n=12)$.

b Lowest and highest ranking of factor. 


\section{Program development}

It was reported that, when developing a program, it is important to consider the needs, wishes and possibilities of the target group. Both the content of the program (e.g. sport, intensity of activity) as well as organizational aspects (e.g. day and time of activities) have to be tailored to the target group.

The NAPSE sporting programs were aimed at inactive people. For this particular target group, the threshold for participation had to be low. This meant that people with no previous training experiences or specific sport skills could participate and sports activities were offered in a non-threatening manner to non-sport participants. The NSFs lowered barriers for participation by using graded training programs (i.e. starting with small amounts of physical activity and gradually increasing intensity over time), simplified sport techniques and/or rules and easy to use (soft and non-threatening) sport materials.

Furthermore, it was important to consider the needs, wishes and possibilities of local sports clubs, because they were the ones actually implementing the programs. The main focus of sports clubs was to provide sports competition and they generally relied on volunteers. Implementation was facilitated when the program was easy to implement locally, i.e. the program required little in terms of materials, manpower and time. In contrast, high implementation costs (i.e. a costly program) were perceived as a barrier to local implementation. For example, intensive personal guidance of participants, expensive program materials, (regular) transportation of sports equipment and the need to rent a specific (sports) accommodation contributed to high implementation costs.

\section{Organizational (pre)conditions}

A major facilitator of implementation at the level of the NSF was having a 'dedicated' program coordinator, i.e. someone who was committed to the program and believed in it. Additionally, it was important that this person had sufficient time to coordinate the program. Preferably, he or she was only working on the program and was not being distracted by other projects or activities.

Another key factor to successful implementation at the level of the NSF was having support for the program within the NSF's organization, of both individuals that were involved in the program as well as individuals that were not directly involved (e.g. staff members and other NSF departments). High level management and administrative commitment and support was especially needed in cases where the program required large organizational or structural changes. For example, for one sporting program a new type of membership was introduced, whereby individual sports participants became a direct member of the NSF. In absence of support, it took longer to get programs running and, in some cases, this led to delayed implementation.

Other main factors at the level of the NSF impeding implementation were insufficient finances for coordination/implementation and internal organizational changes. The NAPSE programs were all funded programs. For the implementation of two programs additional co-financing of municipalities was taken into account, so that the programs could be implemented in more locations than was possible with the NAPSE funding alone. Many 
municipalities have a budget to stimulate sports participation. However, municipalities were not always willing or able (i.e. there was no budget or the budget was already spent) to provide financial resources, which hindered the implementation of the programs in certain locations. Next to that, the NSFs agreed that, in general, insufficient finances are an important barrier to implementation of these kind of sporting programs. Examples of (unfavorable) organizational changes that took place were staff turnover, policy changes and a reorganization of the NSF. Particularly, a change of program coordinator resulted in slowed implementation of planned activities within the programs. This was due to the time required for the NSF to employ a new program coordinator and for the new program coordinator to become oriented with the program and sports clubs.

\section{Recruiting local sports clubs}

Local sports clubs were more willing to participate when they valued the program and supported it. The opposite, was a great barrier to recruiting sports clubs. Most NSFs experienced (some) resistance from their sports clubs, especially when the programs were first introduced. The NSFs described the sports clubs as being traditional: Their primary focus was on running their sports competitions and regular training programs. Providing physical activity opportunities for inactive people was something else and beyond their core business. However, during the three-year implementation period, resistance often ceased because sports clubs became familiar with the program and/or were positively affected by other sports clubs implementing the program. Sports clubs were introduced to the successes of other sports clubs through the NSF website, the NSF (online) newsletter, adverts in local newspapers and (meetings with) trainers of other sports clubs. Also, different sports clubs provided demonstrations of the sporting programs (e.g. during large sports events) and implementation successes were spread by partner organizations of the NSF and implementing sports clubs.

Nonetheless, to convince sports clubs to participate a more personal approach was required. Preferably, the NSF visited the club personally to explain the program and ask for participation. Furthermore, a complete (readily usable) package with all necessary materials (e.g. trainer manual, sport materials, promotional materials) enhanced participation of sports clubs, because this saved them a lot of time during local implementation.

A main factor impeding participation of sports clubs was having no or insufficient qualified trainers. Finding volunteers with the appropriate skills (i.e. volunteers that were able to work with non-sport participants) was an issue for many sports clubs. Most NSFs developed and organized special trainer courses to grow their trainer database.

For implementation of the programs, it was sometimes required that sports clubs invested their own financial resources (e.g. to produce promotional materials, pay trainers or buy sports equipment). However, sports clubs did not always have enough internal financial resources and they depended on external financial resources to participate. Unavailability of (local) funding possibilities, therefore, impeded the recruitment of sports clubs as well. 


\section{Recruiting participants}

As with the recruitment of sports clubs, recruitment of participants was facilitated when (potential) participants valued the program and supported it. In addition, a good promotion and marketing strategy, both nationally and locally, was needed. According to the NSFs, promoting the program at a national level was necessary to get people familiar with the program. For the actual recruitment of participants, however, local marketing was more important. The NSFs marketed their programs via national press, the internet, television and partner organizations. Local marketing was done by sports clubs through the distribution of posters, flyers and leaflets. Also, adverts were placed in local newspapers, demonstrations were given and participants were recruited by word of mouth. On the other hand, when the target group was unfamiliar with the program or the sport in general, recruitment was impeded. Some sports, for example, had the image of being tough (e.g. hockey, sports of a triathlon) or only to be played by certain (sub)groups (e.g. hockey).

Organizing the sports activities in close proximity to the target group was another factor facilitating recruitment. In this way, travel distance was no barrier to participation. Providing the program in many different locations in the Netherlands was one way that some NSFs dealt with this. Others organized the sports activities in places where the target group gathered; for example, activities for children were organized in elementary schools.

Finally, the NAPSE sporting programs were all aimed at increasing physical activity levels of inactive people. However, some NSFs stated that it was very difficult to attract large numbers of inactive people to their sports activities. Most participants were already a little or very physically active. A NSF summarized this as not having the right people and channels to reach this target group.

\section{Local implementation}

For the program to be successfully implemented by a local sports club, it was important to have people (e.g. a trainer) within the club who were enthusiastic about the program and skilled in running the program. The NSFs stated that, when the program was of high-quality (i.e. participants had good experiences due to trainer capabilities), participants gladly came back to the club to participate in (additional) sports activities.

(Personal) support of sports clubs by the NSF was another factor positively influencing local implementation. During the implementation period, the NSFs supported sports clubs in different ways, for example, by providing them with personal guidance, financial resources, advice and (promotional) materials. In this way, local barriers were overcome and sports clubs spent less time on decision making and developing new products.

A main factor hindering implementation locally was an unclear division of roles, tasks and responsibilities between the NSF and sports clubs. For the NSF, this resulted in doing more supportive work than initially planned; and for the sport club, this led to a slowing down of planned activities.

Finally, to stimulate continuous participation in physical activity and to recruit new members for the sports club, it was important to have follow-up activities at the sports club 
that matched participants' needs, wishes and possibilities. Follow-up activities consisted, for example, of a few additional introductory training sessions for free or at low costs at the club. Sports clubs also offered membership options at a reduced rate with continuation of activities in an appropriate beginners' group. In cases where there were no suitable follow-up activities at the sports club, it was difficult to capture participants' interest for the sport and they were often lost to club membership.

\section{Securing continuation of the program}

Including the program in both the NSF's and sports club's long-term policy was reported to enhance continuation of the program. This ensured integration of the program in the organization and available time and resources to run the program. With regard to resources, having sufficient financial resources was reported as a separate facilitating factor. At the same time, a lack of financial resources was seen as a great barrier to sustaining a program, both for the NSF as well as the sports clubs. Of the fourteen NAPSE sporting programs, ten were reported to be continued after the funding period. Programs that were self-sustaining after the implementation period spent funds to develop the program infrastructure, such as educating trainers and providing equipment and resources. These programs could be financed from internal financial resources and/or membership/participation fees. Other programs still relied on external financial resources following cessation of funding. In these cases, the program infrastructure was not fully developed and program costs (e.g. costs related to use of accommodations or facilities, sports equipment, payment of trainers, promotion and recruitment strategies) could not be covered by internal financial resources or membership/participation fees. At the time of the last interview, some NSFs were still struggling with finding sponsors or funding opportunities. Others already found a sponsor for their programs for the next year, like a health insurance company and an international bank.

\section{Summary of results}

Given the ecological perspective of the settings-based approach [9-12], an ecological model is used to summarize the results (see Figure 5.1). The organized sports setting and the different levels of influence - policy, NSF and sports clubs (organizational and environmental level) and non-sport participants (personal level) - are presented on the left. The factors are presented on the right in the form of a checklist, which can be used as guidance when developing and implementing HEPA programs in the organized sports setting. The arrows indicate the influence of the different ecological levels on the implementation process. Behind each factor, the exact level of influence is indicated (NSF, SC, P). For instance, at the non-sport participants and sports club level, program development must consider how the program can be tailored to the target group (inactive people) and sports clubs; and at the non-sport participants level, recruitment must consider both national and local promotion strategies. Furthermore, the results show that the major factors influencing implementation of HEPA programs by the organized sports setting do not act on the policy level (e.g. regulations for facilities, safety laws). Therefore, the arrow representing this influence is dashed. 


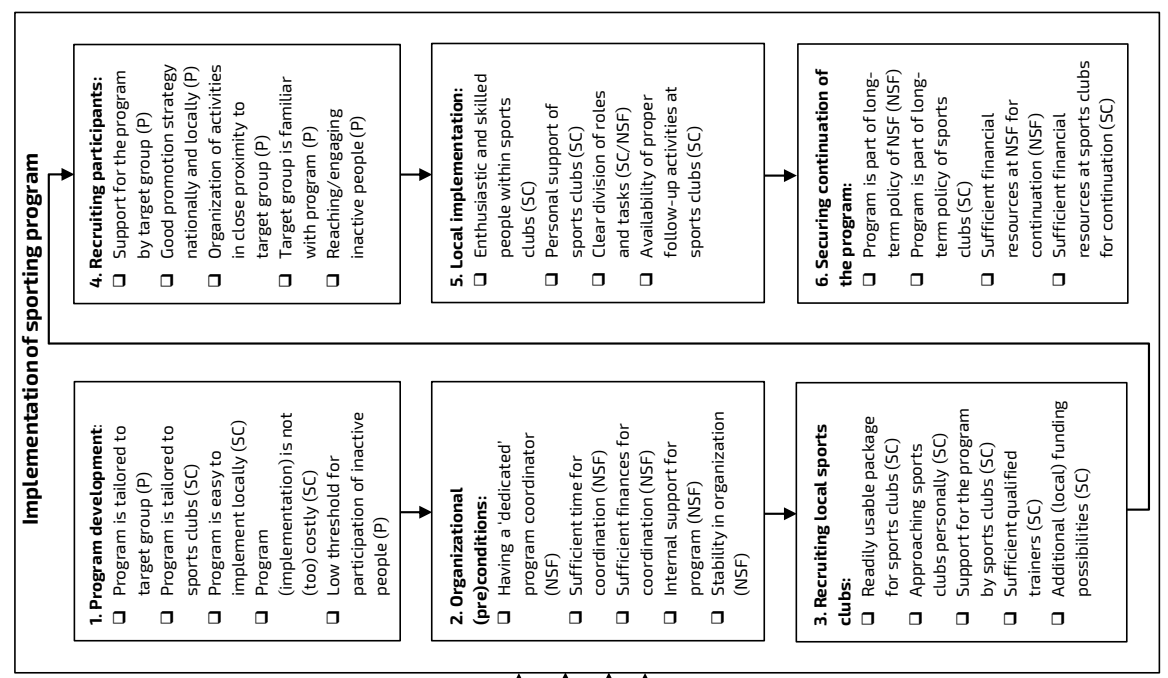

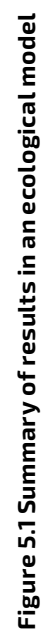

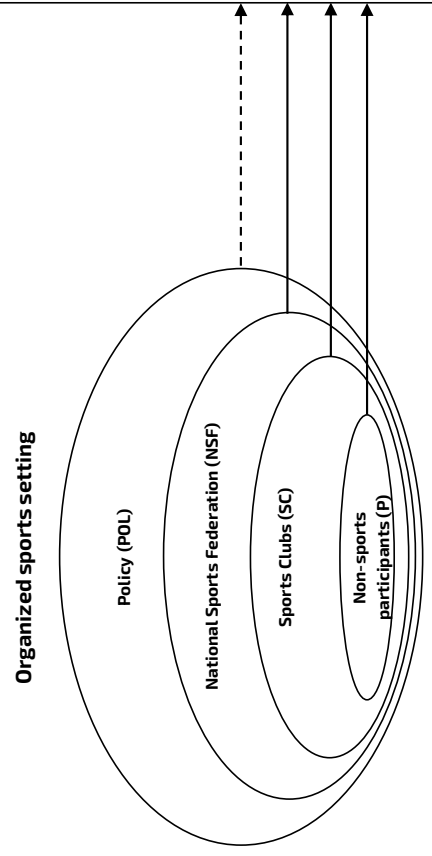




\section{DISCUSSION}

A new setting of interest in the promotion of health, including health-enhancing physical activity (HEPA), is the organized sports sector [13-23]. In this study, the main factors facilitating and impeding implementation of sporting programs, aimed at inactive population groups, were identified (see Tables 5.3-5.4 and Figure 5.1). The results showed that different factors acted during the different phases of the implementation process. When comparing factors across phases, several key learnings are evident. These will be discussed here in a broader context.

First, program design is an important influencer of implementation. HEPA sporting programs must be tailored to the needs, wishes and possibilities of both inactive populations groups as well as the implementing sports clubs. This could be achieved by engaging and actively involving these parties in the program development and implementation process [39]. Consequently, support for and implementation of the program will be enhanced. In addition, there are different formative research strategies (e.g. interviews, observations, focus groups) that can be used before a program is developed or implemented to obtain detailed information about the target group and implementers of the program [40]. In this study, the focus was on implementation and not on program development. Therefore, it is not known how the programs were developed and whether non-sport participants and sports clubs were involved in program design. However, all programs were pilot tested before advancing to broader implementation [28], which suggests that needs of both participants and sports clubs have been addressed. Satisfaction of participants with the programs was measured during the effectiveness evaluation of the programs [34]. The results showed that a majority (87\%-99\%) of participants of the sporting programs enjoyed participation and liked the sports activities offered. The average rating of the programs varied between 7.6 and 8.4 (scale $0-10$; 0 being very poor and 10 being excellent), which indicates that the sporting programs were suitable for their participants.

However, the actual target group, i.e. inactive people, was not always reached, at least not in great numbers. It seems that the organized sports sector is not yet 'a setting of everyday life' for this target group. The results of the effectiveness evaluation confirm this [34]. The percentage of inactive people varied from $0 \%$ to $15 \%$ per sporting program. In addition, for seven sporting programs enough data were available to assess effectiveness on increasing levels of HEPA. Three sporting programs showed significant increases in physical activity levels of participants six months after the start of the programs and in comparison with a control group. For two of these programs, this was accompanied by a significant increase in the percentage of participants meeting levels of HEPA ( $+26 \%$ and $+12 \%$ compared to baseline). For the remaining four sporting programs, no significant changes in levels of physical activity of participants were observed. Therefore, to engage more inactive people into organized sports activities, sporting organizations should focus on proper recruitment methods and channels to reach this target group. In this regard, they 
may consider engaging in partnerships with primary health care, community health or other relevant organizations to get closer to this target group [41].

Another important finding was that successful implementation was largely dependent upon enthusiastic people within sporting organizations (e.g. program coordinator, trainer at a sports club) that were willing to invest time in coordinating/running the program. These people needed to possess the right skills, especially the local trainers, to provide highquality training programs. This ensured participants returned to the club for (additional) sports activities.

For continued participation in sport of (initially) inactive people, however, suitable follow-up activities were required at the sports club. This was also advocated in a study which investigated structural links between sports participation programs conducted in schools and participation in community-based sports clubs [42]. The school-based sporting programs were seen as ineffective in promoting sustained sports participation and club membership due to a lack of formal strategies linking program participants with sports clubs. Repeated or additional experiences in the sport at the sports club was one of the strategies suggested to encourage engagement of participants in a local sports club. In addition, it was recommended that sporting organizations tailor their school-based programs using recognized health promotion planning principles (including taking into account the needs of participants and sports clubs) rather than continuing their current 'one-size-fits-all' approach.

Furthermore, within the NAPSE, the NSFs received the funding, but the sports clubs were the ones actually implementing the HEPA programs. (Financial) resources of the mainly voluntary-based sports clubs were often limited. In addition, their primary focus was on running their sports competitions and regular training programs. Therefore, it was not self-evident that sports clubs implemented the HEPA programs in addition to their regular sports activities. Similar conclusions were drawn in a study which investigated the work of sports clubs as seen by representatives of sports clubs [33]. Sports clubs do what is familiar to them and respond to their local environment [32]. In the current study, it was also seen that sports clubs' support for the programs increased when they became familiar with the programs and were introduced to successes of other sports clubs implementing the programs. These latter sports clubs can be seen as the 'early adopters' in the diffusion of innovations theory [43] and can thus be used to recruit other sports clubs. Nonetheless, to convince sports clubs to actually participate a more personal approach was required. Moreover, the support that NSFs offered to sports clubs (i.e. providing sports clubs with personal guidance, financial resources, advice and (promotional) materials) was essential and facilitated implementation at the sports club level. At the same time, this highlights the need to allocate (financial) resources directly to the implementing sports club and it should be considered in funding arrangements in which the implementing sports club is not the receiver of the funding.

Finally, for population health gains, all programs for promoting HEPA through sport will need to be sustained over a long period of time [17]. Of the fourteen NAPSE programs, ten were reported to be continued after the funding period. A lack of financial resources was 
seen as a great barrier to sustaining a program, both for the NSFs as well as the sports clubs. The sustainability of health promotion programs within sport and recreation organizations also relied heavily on continued funding [44]. Hence, it is important that program funds are spent to develop the program infrastructure so that the program is self-sustaining and can be financed from internal financial resources and/or membership/participation fees. It should be noted that it is unknown whether the NAPSE programs will actually be sustained in the absence of ongoing funding. This was also a limitation of the study concerning the sustainability of health promotion programs within sport and recreation organizations [44]. Thus, further research is required to examine factors influencing the long-term sustainability of HEPA programs in the organized sports setting.

The findings of this study add to those found in the study regarding partnership and capacity-building strategies associated with successful implementation of cross-sectoral sport and recreation programs [13]. In addition, the identified factors are comparable to those found in the studies concerning the implementation of HWEs [14-16, 19] and the factors acting on the sports club level support the 'Health Promoting Sports Club' guidelines [23]. For instance, the guideline "determine the current state of will to practice health promotion in your club" is a prerequisite for the identified facilitating factor "support for the program by sports clubs" and the guideline "educate coaches and other club officials" is the solution to the impeding factor "no or insufficient qualified trainers locally". This implies there are generic factors, independent of the health program or activity being implemented, influencing implementation in the organized sports setting. Nonetheless, some factors are specific to the implementation of HEPA programs, such as the factor "low threshold for participation of inactive people (program development)".

In contrast to the organized sports setting, a lot of research is available concerning the implementation of promotion and prevention programs in other settings, like schools and the health care setting [e.g. 45-46]. Surprisingly, the identified factors in this study reflect some of the major facilitators (and barriers) to program implementation in these settings, such as the availability of funding, skill proficiency (of providers) (vs. trainers with the appropriate skills), compatibility of the innovation (vs. a program that matches the needs, wishes and possibilities of sports clubs), the existence of a program champion (vs. enthusiastic people within sporting organizations) and provision of training and technical assistance (vs. providing (personal) support to sports clubs) [45]. Nevertheless, some caution in interpreting this findings is needed. The practical realization of factors may, for example, be quite different between programs or settings (e.g. training volunteers in sports clubs to provide HEPA programs vs. training health professionals in providing substance abuse prevention programs). Therefore, the context in which programs are implemented remains important [29-31].

Overall, the findings of this study can assist sports practitioners and policy makers with developing and implementing HEPA programs in the organized sports setting. Figure 5.1, in which the results are summarized, can be used as guidance to tailor programs and implementation strategies to this setting. Also, the practical examples provided in the results section may be of value for realization of factors. Moreover, the results can be 
used to guide funding guidelines (e.g. allocating (a part of the) financial resources directly to implementing sports clubs and using funds for developing program infrastructure). Considering the main facilitating and impeding factors during the development and implementation process will concurrently facilitate successful implementation [29-31].

This study was designed to contribute to the understanding of the implementation of HEPA programs in the organized sports setting. A strength of the study was that the implementation process was studied longitudinally. Interviews were conducted yearly during the three-year implementation period. In this way, the (time-)specific features of the implementation process were better captured and recall bias was reduced. Moreover, the (partly) qualitative nature of the study (i.e. semi-structured interviews, meeting) revealed detailed information about the implementation process. A disadvantage of self-report might be the introduction of social desirability biases. However, given the fact that the program coordinators of the NSFs reported both the facilitators and barriers to implementation, it appears there was limited social desirability bias. In addition, it is believed that the different evaluation rounds ensured the reliability of this study.

With regard to quantitative ranking of factors, the mean ranking score was calculated from an ordinal ranking scale. It is not certain whether the difference in ranking between one and two is the same as that, for example, between three and four on a ordinal ranking scale. Moreover, when the mean ranking score of factor $A$ is two and four of factor $B$, this does not necessarily mean that factor A was twice as important as factor B. In addition, there were some differences in ranking of factors between program coordinators. This could be due to differences in programs (e.g. content, size) and/or NSFs (e.g. size, organizational structure), making some factors more or less relevant. However, the sum of ranks and the mode of ranks (results not presented in this article) did not yield a different ordering of factors. Therefore, it is believed that the mean ranking score was appropriate to identify the top three facilitating and impeding factors in this study.

Furthermore, in this study, the focus was on the perceptions of the program coordinators of the NSFs, because they were the ones designated to facilitate implementation of the programs in local sports clubs. Information was not directly obtained from representatives of the sports clubs, i.e. the actual implementers of the programs. This could be seen as a limitation of the study. However, the program coordinators worked in close collaboration with the sports clubs and were, therefore, well-informed about the implementation process locally. Nonetheless, in future research it would be interesting to evaluate directly at the sports club level. 


\section{CONCLUSIONS}

Considering both the strengths and limitations, this study does add to knowledge base concerning the implementation of sporting programs, aimed at inactive people, in the organized sports setting. The main factors facilitating and impeding implementation were identified. The results of this study can be used by sports practitioners and policy makers when developing and implementing HEPA programs in this setting. Moreover, the results can be used to guide funding guidelines. In future research, it would be interesting to evaluate implementation directly at the sports club level and to study factors influencing the longterm sustainability of HEPA programs. This will further contribute to the understanding of the implementation context of the organized sports setting, and will, consequently, improve the implementation and sustainability of HEPA programs in this setting. 


\section{REFERENCES}

1. Haskell WL, Lee IM, Pate RR, Powell KE, Blair SN, Franklin BA, Macera CA, Heath GW, Thompson PD, Bauman A. Physical activity and public health: updated recommendation for adults from the American College of Sports Medicine and the American Heart Association. Med Sci Sports Exerc. 2007;39:1423-1434.

2. Ströhle A. Physical activity, exercise, depression and anxiety disorders. J Neural Transm. 2009;116:777-784.

3. Warburton DER, Nicol CW, Bredin SSD. Health benefits of physical activity: the evidence. CMAJ. 2006;174(6):801-809.

4. Bernaards C. TNO monitor physical activity and health: physical activity in the Netherlands 2000-2010 (report in Dutch). Leiden: TNO Healthy Living; 2011.

5. World Health Organization (WHO). Global status report on noncommunicable diseases 2010. Geneva: WHO; 2011.

6. World Health Organization (WHO). Review of physical activity promotion policy development and legislation in European Union Member States. Copenhagen: WHO; 2010.

7. Whitelaw S, Baxendale A, Bryce C, MacHardy L, Young I, Witney E. 'Settings' based health promotion: a review. Health Promot Int. 2001;16(4):339-353.

8. World Health Organization (WHO). Ottawa Charter for Health Promotion. Geneva: WHO; 1986.

9. Dooris M. Healthy settings: challenges to generating evidence of effectiveness. Health Promot Int. 2006;21(1):55-65.

10. Dooris M. Holistic and sustainable health improvement: the contribution of the settings-based approach to health promotion. Perspect Public Health. 2009;129(1):29-36.

11. McLeroy KR, Bibeau D, Steckler A, Glanz K. An ecological perspective on health promotion programs. Health Educ Q. 1988;15(4):351-377.

12. Sallis JF, Owen N, Fisher EB: Ecological models of health behavior. In: Glanz K, Rimer BK, Viswanath $\mathrm{K}$, editors. Health behavior and health education: theory, research and practice. San Francisco: Jossey-Bass; 2008. p.465-485.

13. Casey MM, Payne WR, Eime RM. Partnership and capacity-building strategies in community sports and recreation programs. Manag Leis. 2009;14(3):167-176.

14. Casey MM, Payne WR, Eime RM. Organisational readiness and capacity building strategies of sporting organisations to promote health. Sport Manag Rev. 2012;15:109-124.

15. Crisp BR, Swerissen H. Critical processes for creating health-promoting sporting environments in Australia. Health Promot Int. 2003;18(2):145-152.

16. Dobbinson SJ, Hayman JA, Livingston PM. Prevalence of health promotion policies in sports clubs in Victoria, Australia. Health Promot Int. 2006;21(2):121-129.

17. Donaldson A, Finch CF. Sport as a setting for promoting health. Br J Sports Med. 2012;46:4-5.

18. Dutch Ministry of Health, Welfare and Sport. Time for sport: exercise, participate, perform. The Hague: Dutch Ministry of Health, Welfare and Sport; 2005.

19. Eime RM, Payne WR, Harvey JT. Making sporting clubs healthy and welcoming environments: a strategy to increase participation. J Sci Med Sport. 2008;11(2):146-154. 
20. European Commission: Communication from the commission to the European parliament, the council, the European economic and social committee and the committee of the regions: developing the European Dimension in Sport. Brussels: European Commission; 2011.

21. Holman CD, Donovan RJ, Corti B, Jalleh G, Frizzell SK, Carroll AM. Banning tobacco sponsorship: replacing tobacco with health messages and creating health-promoting environments. Tob Control. 1997;6:115-121.

22. Kokko S, Kannas L, Villberg J. The health promoting sports club in Finland--a challenge for the settings-based approach. Health Promot Int. 2006;21(3):219-229.

23. Kokko 5 . Guidelines for youth sports clubs to develop, implement, and assess health promotion within its activities. Health Promot Pract. 2014;15(3):373-382.

24. NOC*NSF. Membership NOC*NSF 2010 (report in Dutch). Arnhem: NOC*NSF; 2011.

25. Eime RM, Young JA, Harvey JT, Charity MJ, Payne WR. A systematic review of the psychological and social benefits of participation in sport for adults: informing development of a conceptual model of health through sport. Int J Behav Nutr Phys Act. 2013;10:135.

26. Eime RM, Harvey JT, Brown WJ, Payne WR. Does sports club participation contribute to healthrelated quality of life? Med Sci Sports Exerc. 2010;42:1022-1028.

27. Fuller CW, Junge A, Dorasami C, DeCelles J, Dvorak J. '11 for Health', a football-based health education programme for children: a two-cohort study in Mauritius and Zimbabwe. Br J Sports Med. 2011;45:612-618.

28. Pisters MF, Veenhof, C. Evaluation of the pilot phase of the National Action Plan for Sport and Exercise: the sports setting (report in Dutch). Utrecht: NIVEL; 2008.

29. Finch C. A new framework for research leading to sports injury prevention. J Sci Med Sport. 2006;9:3-9.

30. Finch CF, Donaldson A. A sports setting matrix for understanding the implementation context for community sport. Br J Sports Med. 2010;44:973-978.

31. Finch CF. No longer lost in translation: the art and science of sports injury prevention implementation research. Br J Sports Med. 2011;45:1253-1257.

32. Skille EA. Understanding sport clubs as sport policy implementers: a theoretical framework for the analysis of the implementation of central sport policy through local and voluntary sport organizations. Int Rev Sociol Sport. 2008;43(2):181-200.

33. Skille EA. Competitiveness and health: the work of sport clubs as seen by sport clubs representatives - a Norwegian case study. Int Rev Sociol Sport. 2010;45(1):73-85.

34. Ooms L, Veenhof C. Evaluation of the implementation phase of the National Action Plan for Sport and Exercise, the sports setting: results process and effectiveness evaluation (report in Dutch). Utrecht: NIVEL; 2011.

35. Webster S, Lewis J, Brown A. Ethical considerations in qualitative research. In: Ritchie J, Lewis J, McNaughton Nicholls C, Ormston R, editors. Qualitative research practice: a guide for social science students and researchers. London: SAGE Publications, Ltd; 2014. p.77-110.

36. Clark JP. How to peer review a qualitative manuscript. In: Godlee F, Jefferson T, editors. Peer review in health sciences. 2nd ed. London: BMJ Books; 2003. p.219-235.

37. Patton MQ. Qualitative analysis and interpretation. In: Qualitative research \& evaluation methods. Thousand Oaks, California: SAGE Publications, Inc; 2015. p.520-651. 
38. Boyatzis RE. Transforming qualitative information: thematic analysis and code development. Thousand Oaks, California: SAGE Publications, Inc; 1998.

39. Donaldson A, Finch CF. Planning for implementation and translation: seek first to understand the end-users' perspectives. Br J Sports Med. 2012;46(5):306-307.

40. Gittelsohn J, Steckler A, Johnson CC, Pratt C, Grieser M, Pickrel J, Stone EJ, Conway T, Coombs D, Staten LK. Formative research in school and community-based health programs and studies: "state of the art" and the TAAG approach. Health Educ Behav. 2006;33:25-39.

41. Casey MM, Payne WR, Brown SJ, Eime RM. Engaging community sport and recreation organisations in population health interventions: factors affecting the formation, implementation, and institutionalisation of partnership efforts. Ann Leis Res. 2009;12(2):129147.

42. Eime RM, Payne WR. Linking participants in school-based sport programs to community clubs. J Sci Med Sport. 2009;12:293-299.

43. Haider M, Kreps GL. Forty years of diffusion of innovations: utility and value in public health. J Health Commun. 2004;9(51):3-11.

44. Casey MM, Payne WR, Eime RM, Brown SJ. Sustaining health promotion programs within sport and recreation organisations. J Sci Med Sport. 2009;12:113-118.

45. Durlak JA, DuPre EP. Implementation matters: a review of research on the influence of implementation on program outcomes and the factors affecting implementation. Am J Community Psychol. 2008;41: 327-350.

46. Meyers DC, Durlak JA, Wandersman A. The quality implementation framework: a synthesis of critical steps in the implementation process. Am J Community Psychol. 2012;50: 462-480. 


\section{APPENDIX 5.1}

\section{Overview of all factors and their ranking scores ${ }^{1}$}

The factors presented in bold were added during the meeting with the NSF program coordinators.

Table A5.1.1 Phase 1 Program development: facilitating factors $(n=12)$

\begin{tabular}{lll}
\hline Facilitating factor & $\begin{array}{l}\text { Mean } \\
\text { ranking } \\
\text { score }\end{array}$ & $\begin{array}{l}\text { Range } \\
\text { assigned } \\
\text { rankings }\end{array}$ \\
\hline $\begin{array}{l}\text { - The program matches the target group's needs, wishes and possibilities } \\
\text { - The program is easy to implement locally }\end{array}$ & 1.1 & $1-2$ \\
- Low threshold for participation of inactive people & 3.8 & $2-7$ \\
- The program matches the needs, wishes and possibilities of sports clubs & 5.2 & $1-7$ \\
- The program matches the NSF's policy & 5.5 & $2-11$ \\
- The program is fully developed; it is of good quality and ready to be & 6.8 & $2-11$ \\
implemented & $4-10$ \\
The NSF uses existing knowledge and experiences when developing \\
the program
\end{tabular}

1 Mean ranking score: For each factor: Sum of rankings divided by the number of program coordinators $(n=12) ;$ Range assigned rankings: Lowest and highest ranking of factor. 
Table A5.1.2 Phase 1 Program development: impeding factors ( $n=6)$

\begin{tabular}{|c|c|c|}
\hline Impeding factor & $\begin{array}{l}\text { Mean } \\
\text { ranking } \\
\text { score }\end{array}$ & $\begin{array}{l}\text { Range } \\
\text { assigned } \\
\text { rankings }\end{array}$ \\
\hline $\begin{array}{l}\text { - The program does not match the target group's needs, wishes and/or } \\
\text { possibilities }\end{array}$ & 1.8 & $1-6$ \\
\hline - The (implementation of the) program (locally) is costly & 3.2 & $1-5$ \\
\hline $\begin{array}{l}\text { - The program does not match the needs, wishes and/or possibilities of } \\
\text { sports clubs }\end{array}$ & 3.3 & $1-5$ \\
\hline - The program is not easy to implement locally & 3.8 & $2-6$ \\
\hline $\begin{array}{l}\text { The program (or parts of the program) is (are) not fully developed; } \\
\text { it is not ready to be implemented }\end{array}$ & 4.0 & $2-6$ \\
\hline $\begin{array}{l}\text { The program consists of one (training) session or a one day event; in this } \\
\text { way it is more difficult to capture participants' interest for the sport/a } \\
\text { sports club membership }\end{array}$ & 4.8 & $1-6$ \\
\hline
\end{tabular}

Table A5.1.3 Phase 2 Organizational (pre)conditions: facilitating factors $(n=10)$

\begin{tabular}{lll}
\hline Facilitating factor & $\begin{array}{l}\text { Mean } \\
\text { ranking } \\
\text { score }\end{array}$ & $\begin{array}{l}\text { Range } \\
\text { assigned } \\
\text { rankings }\end{array}$ \\
\hline - Having a 'dedicated' program coordinator & 2.9 & $1-8$ \\
- Sufficient time (in man-hours) to coordinate the program & 3.1 & $1-6$ \\
- Internal support for the program & 3.9 & $1-9$ \\
- Sufficient finances to coordinate and implement the program & 4.1 & $1-9$ \\
- Agood organizational structure for the program internally; tasks and & 5.6 & $2-9$ \\
responsibilities are properly assigned and clearly defined & & $2-10$ \\
- External support for the program & 5.8 & $4-9$ \\
- Availability of trainer education and certification courses & 6.9 & $4-10$ \\
- Good internal communication of the program & 7.4 & $4-10$ \\
- Availability of implementation materials & 7.5 & $3-10$ \\
\hline
\end{tabular}

Table A5.1.4 Phase 2 Organizational (pre)conditions: impeding factors $(n=3)$

\begin{tabular}{lll}
\hline Impeding factor & $\begin{array}{l}\text { Mean } \\
\text { ranking } \\
\text { score }\end{array}$ & $\begin{array}{l}\text { Range } \\
\text { assigned } \\
\text { rankings }\end{array}$ \\
\hline - Insufficient finances to coordinate and implement the program & 1.4 & $1-2$ \\
- No or insufficient support for the program internally & 1.9 & $1-3$ \\
- Internal organizational changes & 2.7 & $1-3$ \\
\hline
\end{tabular}


Table A5.1.5 Phase 3 Recruiting local sports clubs: facilitating factors $(n=10)$

\begin{tabular}{|c|c|c|}
\hline Facilitating factor & Mean & Range \\
\hline - Providing a complete (readily usable) package to sports clubs & 3.8 & $1-7$ \\
\hline - Approaching sports clubs personally & 4.3 & $1-10$ \\
\hline - Support for the program by sports clubs & 4.7 & $1-10$ \\
\hline - A good promotion/marketing strategy & 4.8 & $1-8$ \\
\hline - Providing financial support to sports clubs & 4.8 & $1-10$ \\
\hline $\begin{array}{l}\text { Using a segmentation-based approach for recruiting sports clubs, } \\
\text { based on expectations of successfulness }\end{array}$ & 5.3 & $1-9$ \\
\hline - Sufficient qualified trainers locally & 5.3 & $1-10$ \\
\hline $\begin{array}{l}\text { - Evidence of effectiveness and/or benefits of the program can be } \\
\text { provided to sports clubs }\end{array}$ & 6.5 & 2-10 \\
\hline $\begin{array}{l}\text { - Collaboration with others to promote the program and/or recruit sports } \\
\text { clubs }\end{array}$ & 7.4 & $4-10$ \\
\hline - Absence of competing programs/sports & 7.9 & $3-10$ \\
\hline
\end{tabular}

Table A5.1.6 Phase 3 Recruiting local sports clubs: impeding factors $(n=6)$

\begin{tabular}{lll}
\hline Impeding factor & $\begin{array}{l}\text { Mean } \\
\text { ranking } \\
\text { score }\end{array}$ & $\begin{array}{l}\text { Range } \\
\text { assigned } \\
\text { rankings }\end{array}$ \\
\hline - No or insufficient qualified trainers locally & 2.2 & $1-4$ \\
- No or insufficient support for the program by sports clubs & 2.4 & $1-6$ \\
- Unavailability of additional (local) funding possibilities & 3.6 & $1-6$ \\
- No (proper) sports accommodation, location and/or facilities locally & 3.9 & $1-6$ \\
- No collaboration with others to promote the program and/or recruit & 4.2 & $2-6$ \\
sports clubs & & $1-6$ \\
\hline
\end{tabular}


Table A5.1.7 Phase 4 Recruiting participants: facilitating factors $(n=9)$

\begin{tabular}{|c|c|c|}
\hline Facilitating factor & $\begin{array}{l}\text { Mean } \\
\text { ranking } \\
\text { score }\end{array}$ & $\begin{array}{l}\text { Range } \\
\text { assigned } \\
\text { rankings }\end{array}$ \\
\hline - Support for the program by the target group & 3.3 & $1-6$ \\
\hline - A good promotion/marketing strategy nationally and locally & 3.4 & $1-8$ \\
\hline - The sports activities are organized in close proximity to the target group & 3.6 & $1-6$ \\
\hline - Sports clubs collaborate with other (local) parties to recruit participants & 4.1 & $1-9$ \\
\hline $\begin{array}{l}\text { - Support of local promotion/marketing strategies by the NSF through } \\
\text { provision of promotional materials and/or financial incentives }\end{array}$ & 4.1 & $2-8$ \\
\hline - The NSF collaborates with others to recruit participants & 5.1 & $2-8$ \\
\hline - The program reaches/engages inactive people & 6.2 & $2-9$ \\
\hline $\begin{array}{l}\text { - Provision of sports equipment by the NSF or sports clubs at no (borrowing } \\
\text { equipment) or low (hiring equipment) costs to facilitate participation }\end{array}$ & 7.3 & $3-9$ \\
\hline - Absence of competing programs or sports & 7.9 & $5-9$ \\
\hline
\end{tabular}

Table A5.1.8 Phase 4 Recruiting participants: impeding factors $(n=7)$

\begin{tabular}{lll}
\hline Impeding factor & $\begin{array}{l}\text { Mean } \\
\text { ranking } \\
\text { score }\end{array}$ & $\begin{array}{l}\text { Range } \\
\text { assigned } \\
\text { rankings }\end{array}$ \\
\hline - The target group is unfamiliar with the program or the sport & 3.0 & $1-5$ \\
- No or insufficient support for the program by the target group & 3.3 & $1-7$ \\
- The program does not reach/engage inactive people & 3.4 & $1-5$ \\
- The sports activities are not organized in close proximity to the & 3.7 & $1-6$ \\
target group & & $1-7$ \\
- Promotional/marketing materials and/or channels are not appropriate & 4.2 & $2-7$ \\
to the target group & & $1-7$ \\
\hline
\end{tabular}


Table A5.1.9 Phase 5 Local implementation: facilitating factors $(n=8)$

\begin{tabular}{|c|c|c|}
\hline Facilitating factor & $\begin{array}{l}\text { Mean } \\
\text { ranking } \\
\text { score }\end{array}$ & $\begin{array}{l}\text { Range } \\
\text { assigned } \\
\text { rankings }\end{array}$ \\
\hline $\begin{array}{l}\text { - Enthusiastic people within sports clubs delivering (high-)quality } \\
\text { performances }\end{array}$ & 2.9 & $1-7$ \\
\hline $\begin{array}{l}\text { Sports clubs are (personally) supported by the NSF when implementing } \\
\text { the program locally }\end{array}$ & 3.8 & $1-7$ \\
\hline $\begin{array}{l}\text { - Availability of follow-up sports activities locally that match participants' } \\
\text { needs, wishes and possibilities }\end{array}$ & 3.8 & $1-8$ \\
\hline - Personal/good communication between the NSF and sports clubs & 4.0 & $1-8$ \\
\hline $\begin{array}{l}\text { - Enthusiastic participants; they stimulate both the sports clubs (to } \\
\text { continue their efforts) as well as other participants }\end{array}$ & 4.2 & $1-8$ \\
\hline $\begin{array}{l}\text { A good organizational structure for the program locally; tasks and } \\
\text { responsibilities are properly assigned and clearly defined }\end{array}$ & 4.8 & $1-7$ \\
\hline $\begin{array}{l}\text { - Opportunities for sports clubs (provided by the NSF) to exchange } \\
\text { knowledge and experiences }\end{array}$ & 5.9 & $2-8$ \\
\hline $\begin{array}{l}\text { Sports clubs collaborate with other (local) parties to run the } \\
\text { program locally }\end{array}$ & 6.7 & $2-8$ \\
\hline
\end{tabular}

Table A5.1.10 Phase 5 Local implementation: impeding factors $(n=5)$

\begin{tabular}{lll}
\hline Impeding factor & $\begin{array}{l}\text { Mean } \\
\text { ranking } \\
\text { score }\end{array}$ & $\begin{array}{l}\text { Range } \\
\text { assigned } \\
\text { rankings }\end{array}$ \\
\hline - No enthusiastic and/or incompetent people within sports clubs & 1.5 & $1-4$ \\
- No clear division of roles, tasks and responsibilities between the NSF & 3.0 & $1-5$ \\
and sports clubs & 3.2 & $1-5$ \\
- No (appropriate) follow-up sports activities for participants locally & 3.3 & $2-5$ \\
- Insufficient personal contact between the NSF and sports clubs & 4.0 & $1-5$ \\
\hline
\end{tabular}


Table A5.1.11 Phase 6 Securing continuation of the program: facilitating factors $(n=7)$

\begin{tabular}{|c|c|c|}
\hline Facilitating factor & $\begin{array}{l}\text { Mean } \\
\text { ranking } \\
\text { score }\end{array}$ & $\begin{array}{l}\text { Range } \\
\text { assigned } \\
\text { rankings }\end{array}$ \\
\hline . The program is part of the NSF's long-term policy & 2.6 & $1-5$ \\
\hline $\begin{array}{l}\text { The NSF has sufficient financial resources available to continue } \\
\text { the program/secure the program for the future }\end{array}$ & 2.7 & $1-6$ \\
\hline . The program is part of the sports club's long-term policy & 3.0 & $1-6$ \\
\hline $\begin{array}{l}\text { Sports clubs have sufficient financial resources available to } \\
\text { continue the program locally/secure the program for the future }\end{array}$ & 3.8 & $1-7$ \\
\hline $\begin{array}{l}\text { Evaluation of the program (and/or the implementation process) } \\
\text { to identify necessary adjustments }\end{array}$ & 4.8 & $1-7$ \\
\hline $\begin{array}{l}\text { The NSF collaborates with others to continue the program/ } \\
\text { secure the program for the future }\end{array}$ & 5.5 & $2-7$ \\
\hline $\begin{array}{l}\text { Sports clubs collaborate with others to continue the program/ } \\
\text { secure the program for the future }\end{array}$ & 5.7 & $2-7$ \\
\hline
\end{tabular}

Table A5.1.12 Phase 6 Securing continuation of the program: impeding factors $(n=2)$

\begin{tabular}{lll}
\hline Impeding factor & $\begin{array}{l}\text { Mean } \\
\text { ranking } \\
\text { score }\end{array}$ & $\begin{array}{l}\text { Range } \\
\text { assigned } \\
\text { rankings }\end{array}$ \\
\hline $\begin{array}{l}\text { The NSF has insufficient financial resources available to continue } \\
\text { the program/secure the program for the future }\end{array}$ & 1.4 & $1-2$ \\
$\begin{array}{l}\text { Sports clubs have insufficient financial resources available to } \\
\text { continue the program locally/secure the program for the future }\end{array}$ & 1.6 & $1-2$ \\
\hline
\end{tabular}



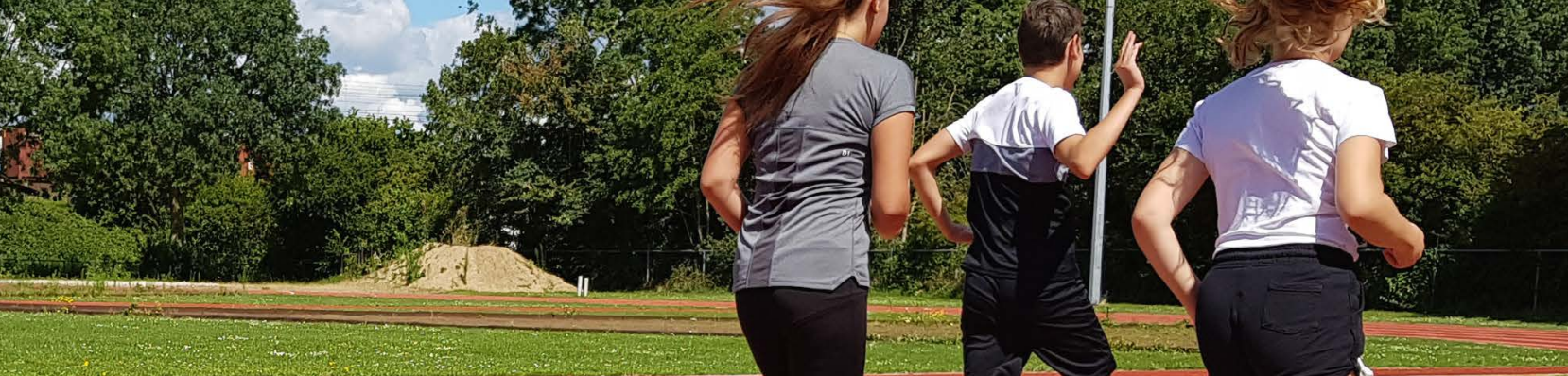


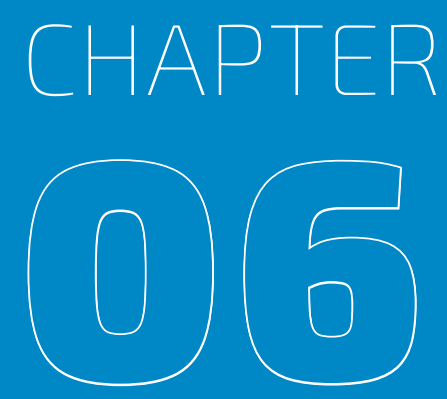

\section{Sporting programs aimed at inactive population groups in the Netherlands: factors influencing their long-term sustainability in the organized sports setting}

Published as: Ooms L, van Kruijsbergen M, Collard D, Leemrijse C, Veenhof C. Sporting programs aimed at inactive population groups in the Netherlands: factors influencing their long-term sustainability in the organized sports setting. BMC Sports Science, Medicine and Rehabilitation. 2019;11:33. 


\section{ABSTRACT}

Background: The organized sports sector has received increased interest as a setting to stimulate physical activity among inactive target groups. To include many inactive people and to obtain population health benefits, it is important that effective sporting programs are sustained (i.e. continuation of program activities) over a long period of time. This study identified the factors influencing the long-term sustainability of these kind of sporting programs located within local sports clubs in the Netherlands.

Methods: Fourteen Dutch sporting programs aimed at increasing physical activity levels of inactive population groups and funded within the National Action Plan for Sport and Exercise (NAPSE) were the focus of this study. The programs were developed by ten Dutch National Sports Federations (NSFs) and implemented by different sports clubs in the Netherlands within a three-year funded implementation period (2008-2011). This research consisted of semi-structured face-to-face interviews with the program coordinators of the NSFs $(n=14)$ and semi-structured telephone interviews with representatives of sports clubs that provided the programs ( $n=17$ continued the program, $n=11$ discontinued the program) six and a half years after the funding period ended (November 2017-March 2018). A sustainability framework with five pre-specified main themes (i.e. program design, implementation, trainer/coach, organizational setting, broader community environment) guided data collection and (deductive) thematic analysis.

Results: Ten of the fourteen NAPSE funded sporting programs were sustained at the level of the NSFs. Most factors facilitating (+) and impeding (-) the long-term sustainability of the programs were common to both NSFs and sports clubs, like program adaptation (+) and a lack of program financing (-). Program evaluation (+) and high program costs (-) were specific factors mentioned by NSFs, while factors related to human resources (e.g. lack of volunteers (-)) or the sports club nature (e.g. social aspect in program design (+)) applied to sports clubs. The factors were summarized in the form of a checklist.

Conclusions: Key factors influencing the long-term sustainability of the sporting programs were identified. The results can be used to develop strategies to promote long-term sustainability of these kind of programs and inform funding guidelines in countries with a similar organized sports infrastructure. 


\section{BACKGROUND}

Participation in regular physical activity has positive effects on physical, mental and social health, both for children and adults [1-4]. Nonetheless, 53\% of the Dutch population of 4 years and older is not sufficiently active to receive these benefits [5]. People who are insufficiently active are at increased risk for chronic diseases and mortality, especially those who are completely inactive $[4,6]$. There is therefore a need for initiatives to promote physical activity among inactive target groups. In this regard, a settings-based approach to health promotion has been advocated by the World Health Organization [7]. A setting is the place or social context in which people engage in daily activities in which policy, environmental, organizational, interpersonal and personal factors interact to affect health and well-being. The settings-based approach has an ecological perspective and highlights the importance of the whole system of the setting, rather than just individual responsibility, when stimulating healthy behaviors [8-10].

Next to settings such as schools and workplaces, the organized sports sector has received increased interest by policy makers, health professionals and sport practitioners as a setting to stimulate physical activity among inactive target groups [11-16]. Sports clubs have great potential to reach many people due to their wide reach into community and the social and informal nature of participation $[15,17]$. Furthermore, participation in sport at a sports club can contribute significantly to physical activity levels for health benefits [18]. Therefore, attracting inactive target groups to sports clubs seems a promising strategy to increase population levels of physical activity. However, increasing participation in sport by these inactive target groups may impose challenges as well considering the high rate of drop out among novice sport participants, the increased risk of injuries with high-intensity and competitive sports and the fact that some people do not like to participate in sport at all [19-22].

Notwithstanding these challenges, different countries have been investing resources in the organized sports sector to promote physical activity among inactive target groups. In Australia, for instance, State Sporting Organizations were funded to implement health promotion policies and practices in their associated sports clubs to create healthy and welcoming environments $[12,14]$. Also, the development of cross-sectoral (including partnerships between health organizations, local governments and sports clubs) sporting programs for people who are not being active and who are on low incomes was stimulated $[11,23]$. Considering the low levels of physical activity in the Dutch population, the Dutch Ministry of Health, Welfare and Sport initiated the National Action Plan for Sport and Exercise (NAPSE). The main aim of this program was: more people are sufficiently active and less people are inactive. In the program, it was stated that: "the range of sports and physical activities that are offered must be geared more towards encouraging inactive people and those who do not or rarely participate in sport or exercise." [24] Therefore, ten National Sports Federations (NSFs) received financial resources to develop sporting 
programs adapted to the needs and abilities of inactive people [16]. These activities had to be incorporated within the regular activities of their associated sports clubs. A total of fourteen sporting programs were developed and implemented within a three-year funded implementation period (2008-2011). Most sporting programs were offered by sports clubs one ore multiple times a year during a limited time period (e.g. weeks/months) and were aimed at teaching inactive people the basics of the sport in an easy and gradual manner. Afterwards, they were encouraged to continue the sport in a beginner's group at the sports club. An example is the six-week cycling program Start2Bike in which adults learn the basics of mountain biking or road cycling. Other sporting programs were provided by sports clubs on a continuous (i.e. weekly) basis and used simplified sport techniques and/or rules and easy to use (soft and non-threatening) sport materials to lower barriers for participation. An example is Fit Hockey, which is weekly hockey for seniors played on a small field with soft sticks and soft balls. There is evidence that these sporting programs are effective in attracting insufficiently active people and increasing their physical activity levels, but it seems a challenge to reach large numbers of the least active ones [25-27]. To include many inactive people and to obtain population health benefits, it is important that effective programs are sustained (i.e. the sports clubs' sustainable offer of the program) over a long period of time [13]. However, many effective health promotion programs are discontinued after initial funding ends. Although a lack of financial resources after the funding period often plays a role, there may be other reasons for discontinuing programs, such as a lack of human capacity, an organization's competing demands, an unfavorable economic environment and lack of political or community support for the program [28-31].

Different frameworks have been created to support the development of sustainable health promotion programs in health care, school and community settings [28, 30-34]. There is limited research, however, concerning the sustainability of health promotion programs implemented in the organized sports setting. One study examined factors influencing the sustainability of a funded health promotion program within sport and recreation organizations [23]. Sustainability of the health program was, for example, facilitated when the program aligned with the core values and activities of the sport organization, supportive partnerships were available and training opportunities were provided to staff. Conversely, a lack of funding opportunities was an important factor impeding sustainability of the health program. Another study, investigating the implementation period of the aforementioned NAPSE sporting programs, also found that a lack of financial resources after the funding period hindered continuation of programs, while integration of the program in the sport organization's long-term policy facilitated program sustainability [16]. Both studies were performed directly after the funding period ended and it is not known whether programs were actually sustained over time. Furthermore, research questions were not directly examined at the level of sports clubs, but only representatives of regional and national sport organizations (i.e. Regional Sports Assemblies and NSFs) were questioned. The focus of sports clubs is mainly on providing sport activities and running competitions and they mostly rely on volunteers. Consequently, they may experience other challenges than (sport) organizations that rely on professionals or paid staff in sustaining programs that require 
them to work beyond their core business, such as lack of time, human resources and skills (e.g. networking skills or skills to recruit or guide inactive people) $[11,16]$. Therefore, the aim of this study was to examine factors influencing the long-term sustainability of the fourteen Dutch NAPSE sporting programs, considering both the perspectives of the NSFs and sports clubs, to identify similarities and differences between these two groups.

\section{METHODS}

\section{Definitions and framework}

In the scientific literature there is little consensus on the definition of sustainability [29, $31,34]$. In this study, sustainability is defined as the continuation of a program or program activities within an organization after an initial funding period [23,31]. There is also no consensus about how long programs or activities should be continued after an initial funding period to be called 'sustained', but a period of at least two years is frequently mentioned [29, 34]. In the current study, the focus is on factors influencing the long-term sustainability of programs, which is often conceptualized in the literature as program continuation six years after full implementation [35]. Due to practical reasons, the current study was performed six and a half years after the funding period ended.

The sustainability framework of Shediac-Rizkallah \& Bone (1998) guided data collection and (deductive) thematic analysis [31]. This theoretical framework suggests that potential factors influencing sustainability of health promotion programs can be grouped in four main themes: 1) program design factors; 2 ) implementation factors; 3) factors within the organizational setting (in this study, the organizational setting of the NSF and sports club) and 4) factors in the broader community environment. This theoretical framework was complemented with other (more recent) sustainability studies [16, 23, 28-30, 32-34, 3638]. This was done by organizing the identified factors from these studies under the four main themes by two researchers (LO, MK). However, two studies also revealed different factors related to the actual user or implementer of a program $[29,32]$. In this study, this corresponded with the trainer or coach of the sports club. Therefore, these factors were included in our framework under a new and fifth main theme of factors, namely 'trainer/ coach' (see also Appendix 6.1: Theoretical framework of factors). 


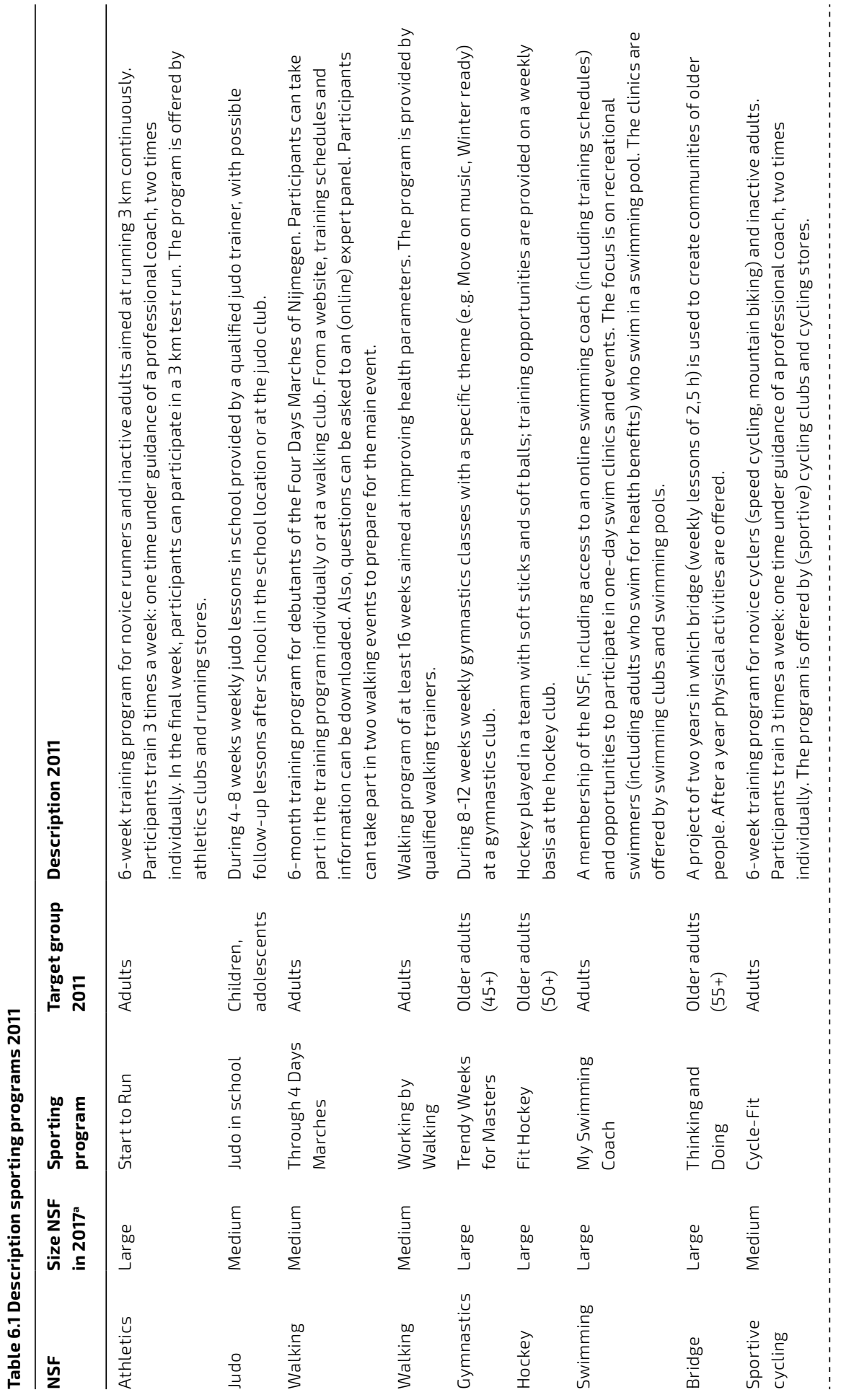




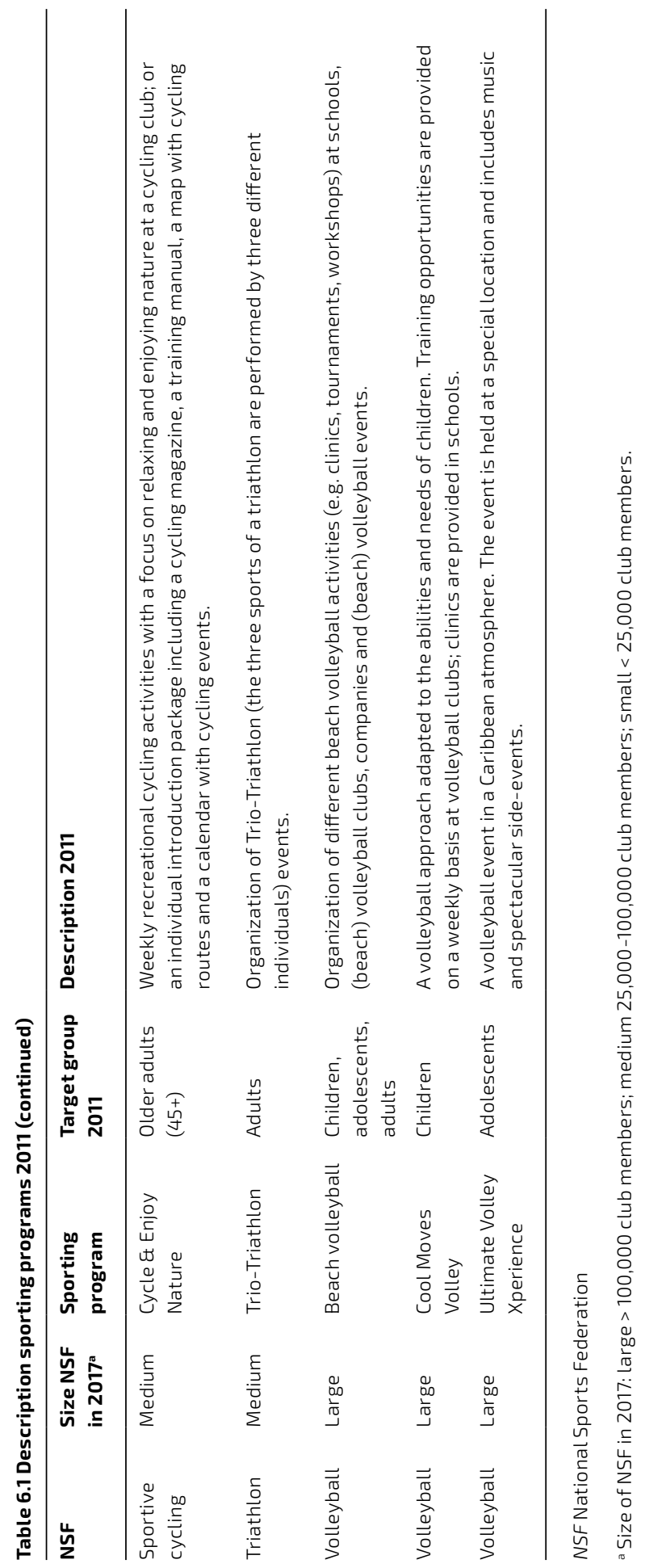




\section{Sample}

This study included the 14 NAPSE sporting programs that were developed by ten Dutch NSFs and implemented by different sports clubs in the Netherlands (period June 2008-June 2011). For more information about the funded implementation period, we refer to a previous article [16]. The programs varied with regard to sport type, content, duration and target group. A description of the original programs can be found in Table 6.1.

The program coordinators of the NSFs $(n=14)$, who also participated in the research concerning the implementation period [16], were invited to participate in this study by email. In case a program coordinator did not respond, a general email was sent to the NSF to get in contact with the former or current program coordinator or a representative of the NSF that was well-informed about the sporting program. In addition, the participating NSFs were asked to provide the email addresses of four sports clubs that started the program between 2008-2011: 1) two sports clubs that continued the program and; 2) two sports clubs that discontinued the program. In case a sports club agreed to participate, the NSF provided the email address of the sports club (i.e. of the local coordinator or trainer of the program) to the researchers. Subsequently, the sports club was invited to participate in the research by email.

\section{Procedures}

A total of 14 semi-structured face-to-face interviews of 60-90 minutes duration were conducted with former $(n=6)$ and current $(n=8)$ program coordinators of the NSFs between November 2017 and March 2018. In addition, semi-structured telephone interviews were conducted with representatives of sports clubs. In case the NSF had stopped the program or no current program coordinator was present, it was more difficult to retrieve participating or non-participating sports clubs. In general, sports clubs that discontinued the program were harder to retrieve by the NSFs. Therefore, not all NSFs provided enough contact details of sports clubs and for two NAPSE sporting programs (a program that was continued by the NSF and a program that was discontinued by the NSF) no email addresses of sports clubs were provided. Consequently, a total of 28 semi-structured telephone interviews of 45-60 minutes duration were conducted with representatives of sports clubs ( $n=17$ continued the program, $n=11$ discontinued the program; see also Appendix 6.2: Number of interviews with sports clubs) between January 2018 and March 2018. The semi-structured interviews were performed by two researchers (LO, MK) independent of each other. The first researcher (LO) was experienced in performing semi-structured interviews. This researcher also performed the (yearly) semi-structured interviews with the program coordinators of the NSFs during the three-year funded implementation period [16]. The second researcher (MK) was instructed by the first researcher (LO) on how to conduct the interviews. Furthermore, the first two interviews were conducted by both researchers so that interviewing was 
done in a comparable manner. All interviews were recorded with a digital voice recorder and transcribed verbatim.

A set of predetermined open-ended questions, which were framed on the five prespecified main themes of the sustainability framework, was used with the opportunity for the interviewer to explore particular themes or responses further. In addition, background information about the respondent, NSF/sports club and sporting program were obtained. An example of an interview guide can be found in Appendix 6.3: Interview guide sports clubs continued.

The representatives of the NSFs and sports clubs were informed about the background and aims of the study through email (written) and before the start of the interview (verbally). In addition, they were informed that participation was voluntary, all collected information would be kept strictly confidential and only anonymized data would be published. All respondents provided informed consent for their participation as well as consent for their interviews to be recorded and transcribed verbatim. Participants were not exposed to procedures, nor were they obligated to follow certain behavioral rules. Therefore, in accordance with the Dutch Medical Research Involving Human Subjects Act (WMO), medical ethics committee's approval was not necessary for conducting this study [39]. Study privacy procedures followed General Data Protection Regulations [40]. For reporting of results, the RATS (Relevancy, Appropriateness, Transparency, Soundness) guidelines were used as a guidance [41].

\section{Data analysis}

MAXQDA version 10.0 software was used for data analysis. Data analysis was performed by the researchers (LO, MK) that were also involved in data collection. Thematic analysis was performed to examine the perspectives of the NSFs and sports cubs regarding key factors influencing the long-term sustainability of the sporting programs, highlighting the similarities and differences between the views of these two groups. For this purpose, a codebook was developed by the researchers ( $L O, M K$ ) based on the aforementioned sustainability framework including the five main themes of factors (see Appendix 6.1: Theoretical framework of factors). Subsequently, the following steps were taken to enhance trustworthiness of the thematic analysis as recommended by Nowell et al. (2017) [42]: First, all interview transcripts were read once by one researcher (LO) to become familiar with the data. Second, the transcripts were coded systematically by this researcher (LO), starting first with coding of the transcripts of the NSFs followed by coding of the transcripts of the sports clubs. A transcript was read again and coded using the codebook. When new subthemes emerged, new codes were inductively added. An example of a new subtheme was 'social aspect' - namely the social opportunities provided during the program and the social relationships acquired by participating in the sporting program. This was an important reason for (previously) inactive participants to attend and keep attending (according to trainers) and for trainers of sports clubs to continue program activities. By combining both a 
deductive and inductive coding approach, knowledge of previous literature and theory could be used, while simultaneously extending this knowledge with new (sub)themes derived from the raw data [43]. After initial coding, the codes (subthemes) were sorted into the five possible main themes by researcher $L O$. To assure quality of the coding process, a second researcher (MK) cross-checked coding of a random selection of the transcripts (19\% of transcripts). In addition, the second researcher (MK) checked all derived subthemes and sorting of these subthemes in the five main themes. In case of disagreement, the results were discussed between both researchers. When no consensus could be reached, a third researcher was available (DC). However, the latter was not necessary because in all cases consensus could be reached and the discussions between the two researchers (LO, MK) only led to minor adjustments in subthemes and sorting of subthemes in main themes. After that, the coding of all transcripts was once again checked by the first researcher (LO) in the same way and order as described previously. The results of the NSFs and sports clubs were compared (by researcher LO) to identify the key (sub)themes or factors important for the long-term sustainability of a sporting program aimed at inactive people in the organized sports setting and to summarize similarities and differences between the two groups (i.e. NSFs and sports clubs). For this purpose, we compared the two groups with respect to the meaning and interpretation of (sub)themes, the frequency and prominence of (sub)themes (number of respondents mentioning a theme), and specific examples provided to support or explain a particular (sub)theme. Finally, the findings were shared and discussed with the whole research team ( $L O, M K, D C, C L, C V)$ for feedback and comment. However, this did not result in any changes in coding or (sub)themes per group.

\section{RESULTS}

Respondent characteristics are presented in Table 6.2. Although there were some changes in (local) coordinators after the funding period, most representatives of NSFs and sports clubs were involved in the sporting program for multiple years. Representatives of sports clubs were mainly the trainers that provided the program to participants. Furthermore, a diverse sample of sports clubs was represented, including sports clubs of different sizes and from all regions in the Netherlands (see also Table 6.2). Sports clubs that discontinued programs had provided the programs for an average of three years (range 1-8 years; not in Table). 
Table 6.2 Descriptive characteristics of interviewees

\begin{tabular}{|c|c|c|}
\hline NSFs $(n=14)$ & $\begin{array}{l}\text { Program continued } \\
(n=10)\end{array}$ & $\begin{array}{l}\text { Program stopped } \\
(n=4)\end{array}$ \\
\hline \multicolumn{3}{|l|}{ Gender (n, \%) } \\
\hline Female & $4(40)$ & $1(25)$ \\
\hline Male & $6(60)$ & $3(75)$ \\
\hline Age, mean + range (years) & $43(25-59)$ & $50(35-59)$ \\
\hline Number of years employed with the NSF, mean + range (years) & $14\left(1 /{ }_{3}-36\right)$ & $13(10-18)$ \\
\hline Number of years involved in program, mean + range (years) & $4(1 / 4-9)$ & $4(2-9)$ \\
\hline \multicolumn{3}{|l|}{ Function within NSF (n, \%) } \\
\hline Current program coordinator & $8(80)$ & $0(0)$ \\
\hline Former program coordinator & $2(20)$ & $4(100)$ \\
\hline \multicolumn{3}{|l|}{ Size NSF (n, \%) } \\
\hline Medium (25.000-100.000 club members) & $3(30)$ & $3(75)$ \\
\hline Large (> 100.000 club members) & $7(70)$ & $1(25)$ \\
\hline Sports clubs $(n=28)$ & $\begin{array}{l}\text { Program continued } \\
(n=17)\end{array}$ & $\begin{array}{l}\text { Program stopped } \\
(n=11)\end{array}$ \\
\hline \multicolumn{3}{|l|}{ Gender (n, \%) } \\
\hline Female & $7(41)$ & $5(45)$ \\
\hline Male & $10(59)$ & $6(55)$ \\
\hline Age, mean + range (years) & $56(36-78)$ & $59(27-79)$ \\
\hline Number of years employed with the sports club, mean + range (years) & $11(1 / 6-25)$ & $24(5-52)$ \\
\hline Number of years involved in program, mean + range (years) & $8(2-15)$ & $3(1-8)$ \\
\hline \multicolumn{3}{|l|}{ Function within sports club (n, \%) } \\
\hline Trainer/coach & $12(71)$ & $8(73)$ \\
\hline Board member & $4(24)$ & $0(0)$ \\
\hline Chairperson & $2(12)$ & $2(18)$ \\
\hline Secretary & 1(6) & $2(18)$ \\
\hline Other & $0(0)$ & $2(18)$ \\
\hline \multicolumn{3}{|l|}{ Size sports club (n, \%) } \\
\hline Small ( $\leq 100$ club members) & $3(18)$ & $1(9)$ \\
\hline Medium (101-300 club members) & $7(41)$ & $6(55)$ \\
\hline Large ( $\geq 301$ club members) & $6(35)$ & $2(18)$ \\
\hline Unknown & $1(6)$ & $2(18)$ \\
\hline \multicolumn{3}{|l|}{ Region in the Netherlands ( $\mathrm{n}, \%)$} \\
\hline North & $4(24)$ & $1(9)$ \\
\hline East & $6(35)$ & $2(18)$ \\
\hline West & $4(24)$ & $4(36)$ \\
\hline South & $3(18)$ & $4(36)$ \\
\hline
\end{tabular}

NSFs National Sports Federations

${ }^{a}$ An interviewee could have multiple functions within the sports club. 
Table 6.3 describes continuation of and changes made to the sporting programs after the funding period by the NSFs. Six and a half years after the funding period ended, ten of the fourteen NAPSE funded sporting programs were sustained at the level of the NSFs, but one program without direct involvement of sports clubs. Previously, people could participate in this program on an individual basis or at a sports club, but the NSF only continued the individual training option. Many sports clubs, however, still provided their own training programs for inactive people or people novice to the sport. For eight of the sustained programs, a NSF program coordinator was present and nine NSFs still provided support (e.g. materials, advice) to their associated sports clubs to run the programs. During the years, some changes were made in target group ( $n=6$ programs) and/or content ( $n=9$ programs) of the programs. The other four NAPSE funded sporting programs were directly stopped at the level of the NSF after the funding period. However, one program was still offered by sports clubs without involvement of the NSF. For another program, coordination of the NSF was not necessary anymore, because sports clubs (and event organizations) could run the program on their own.

The sustained programs varied widely with regard to the number of activities offered per year, their actual reach and the number of participants becoming a member of a sports club/the NSF (see Table 6.4). When there was no NSF program coordinator or a program was completely stopped at the level of the NSF (but not at the level of sports clubs), this information was often unknown. 


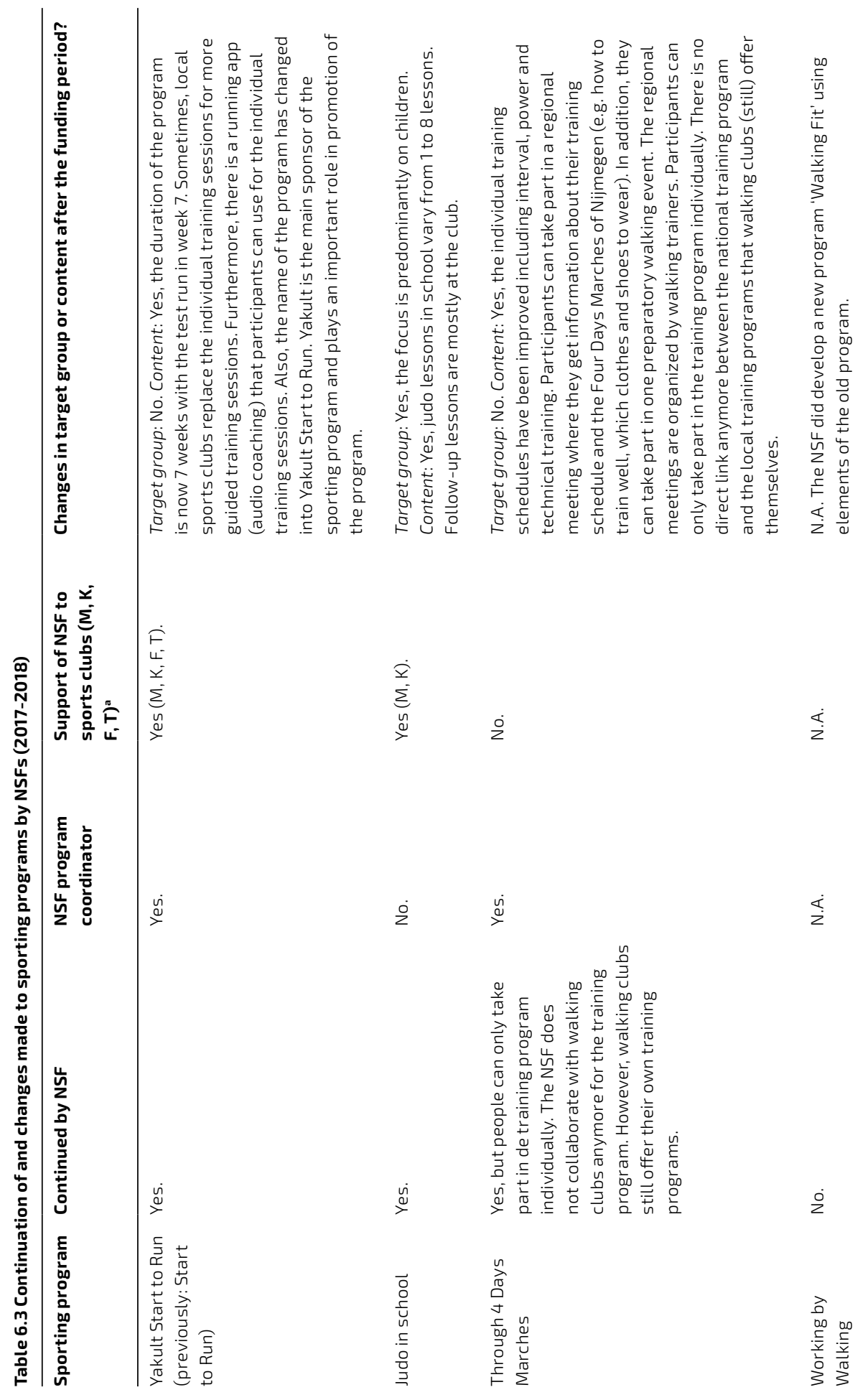




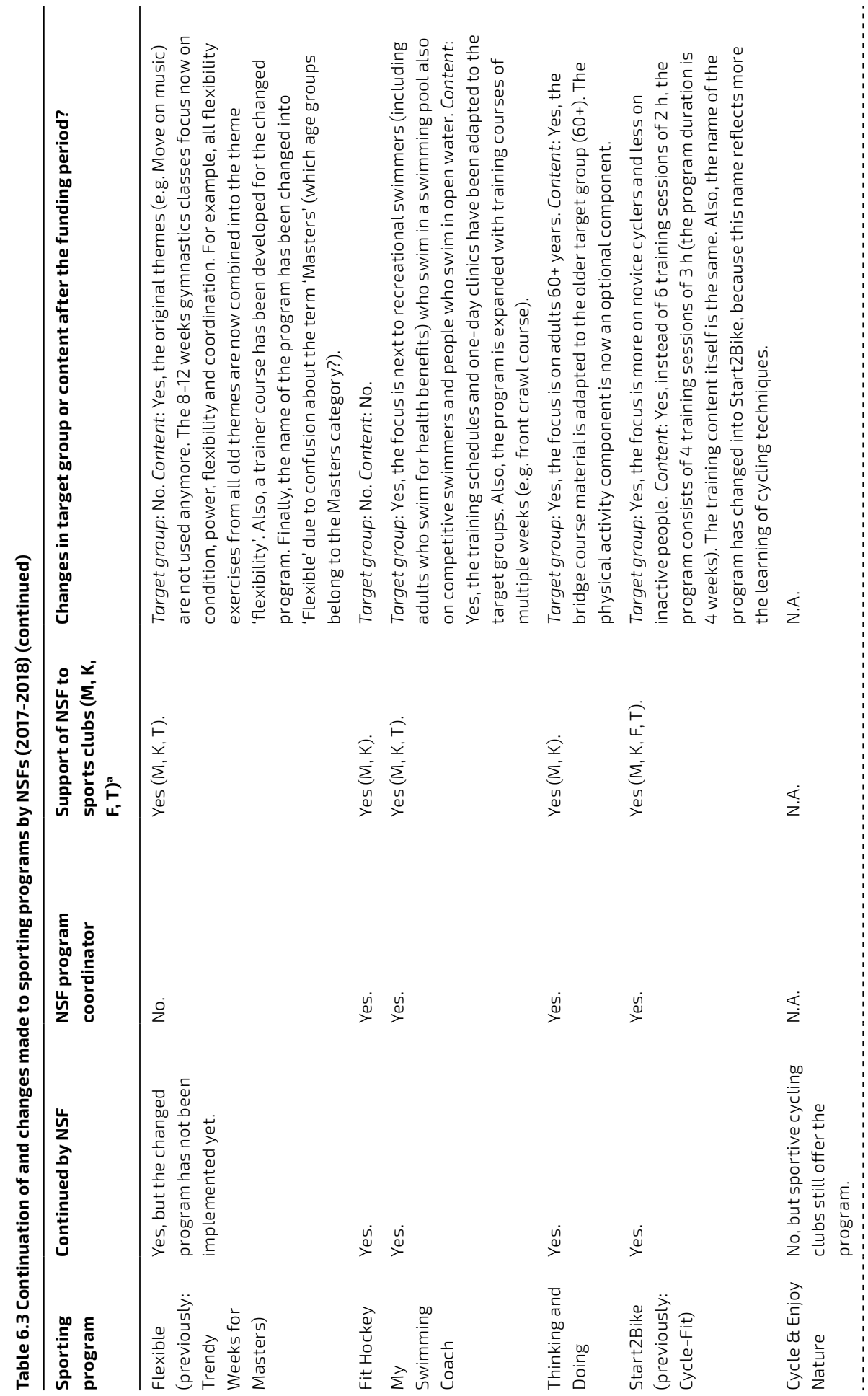




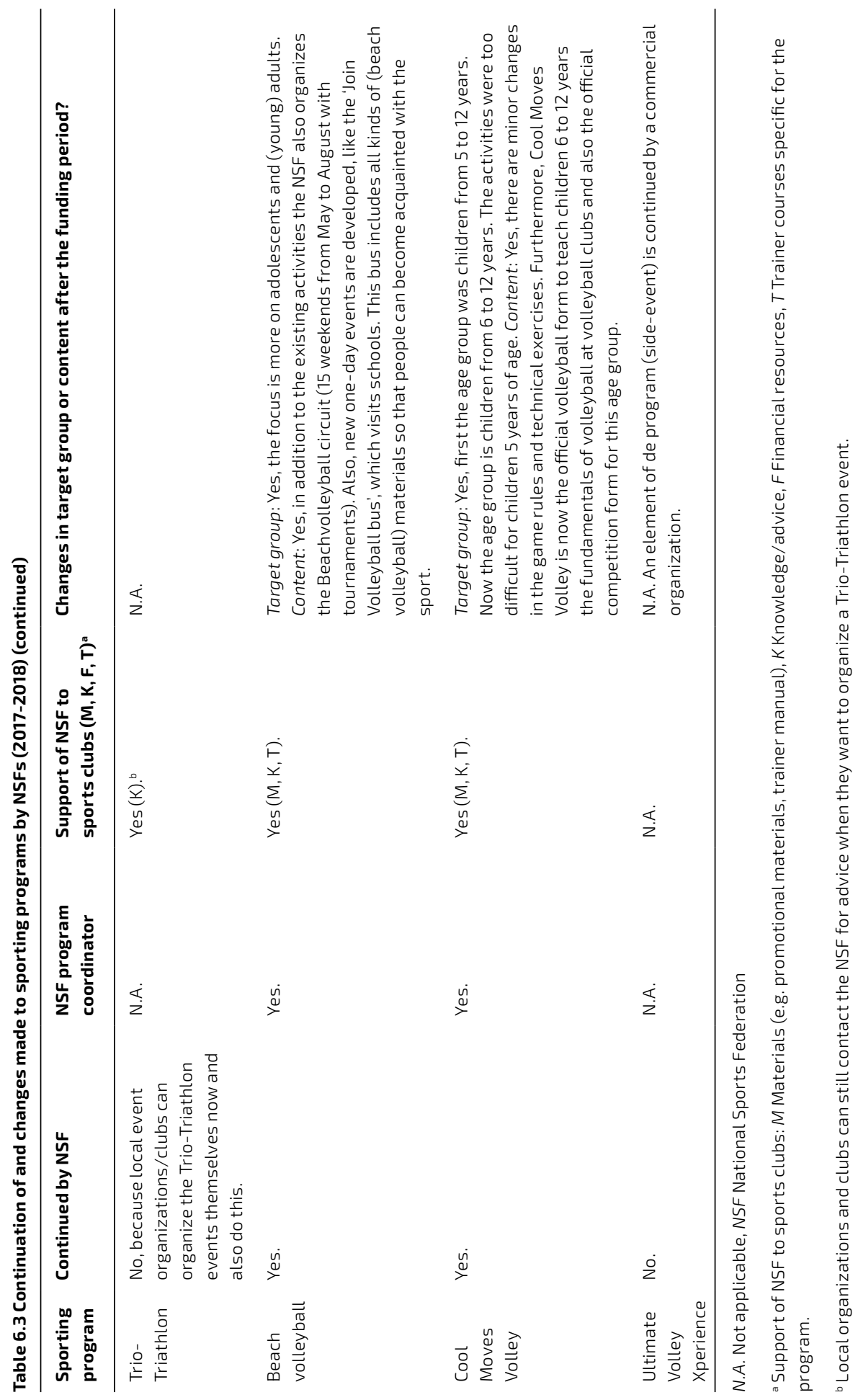




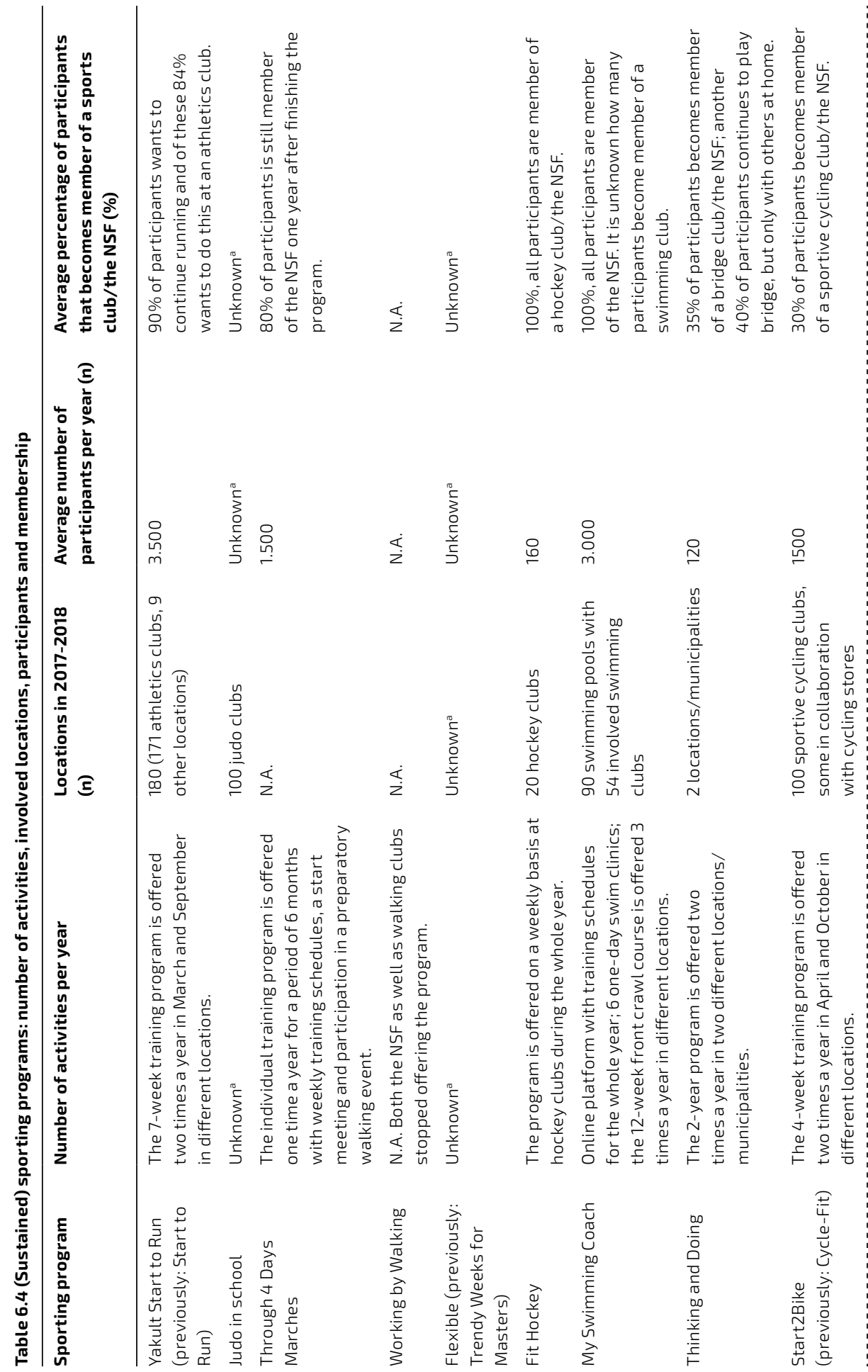




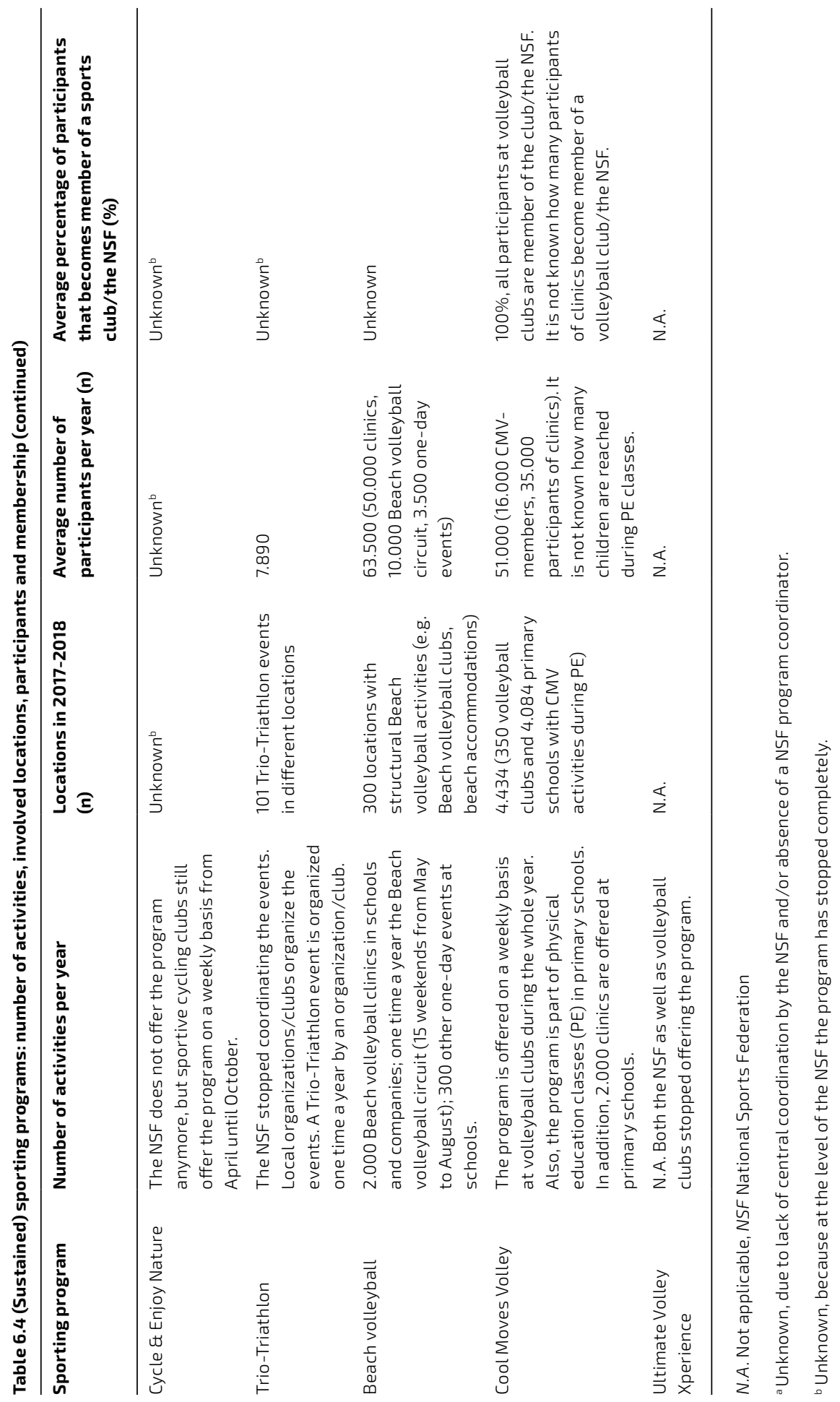




\section{Key factors influencing the long-term sustainability of sporting programs aimed at inactive population groups}

In Table 6.5, the key facilitating (+) and impeding factors (-) influencing the long-term sustainability of the sporting programs are presented per main theme. Inductively added factors are presented in bold. Most factors were mentioned by both NSFs and sports clubs ( $n=17$, e.g. Program design: program adaptation (+)). However, some factors were more important to NSFs ( $\mathrm{n}=5$, e.g. Implementation: program evaluation (+)) or sports clubs $(n=9$, e.g. Program design: social aspect $(+))$. The results are described in more detail below under the five main themes - program design, implementation, trainer/coach, organizational setting NSF/sports club and broader community environment. Since the impeding factors were often the inverse of the facilitating factors, they are not always explained separately. Factors common to both NSFs and sports clubs are described first (common factors), followed by description of factors specific to NSFs or sports clubs (specific factors).

\section{Program design}

\section{Common factors}

NSFs and sports clubs continued sporting programs because they aligned with the inactive target group's needs. For inactive people, the threshold to participate in sport in general or at a sports club in particular may often be too high. The sporting programs provided opportunities for this target group to become acquainted with the sport in an easy and appropriate manner without getting injuries. Afterwards, these people are experienced enough to continue the sport in a beginner's group at the club.

Program adaptation was another program design factor enhancing programs' long-term sustainability. During the years, sporting programs were adapted (i.e. with regard to content or organizational aspects) both by NSFs and sports clubs, to constantly meet the needs of the (previously) inactive target group and the sports clubs. Continuous sporting programs were, for instance, (gradually) adapted to the (previously inactive) participants becoming more physically active (e.g. creating a beginner's and more advanced group). Changes were also made to programs due to the availability of new knowledge or technologies (e.g. including more strength and flexibility exercises in training sessions to prevent injuries with inactive people, using a running app instead of a training schedule per email), new partnerships (e.g. changing program name in sponsor name) and sometimes decreased financial resources (e.g. providing less training sessions in schools). Mostly, only minor adaptations were made (see also Table 6.3):

"We changed the program from six training sessions of 2 hours to four training sessions of 3 hours, based on feedback of participants. First, they had to plan six weekends free, now only four weekends. And with 2 hour sessions, there was 


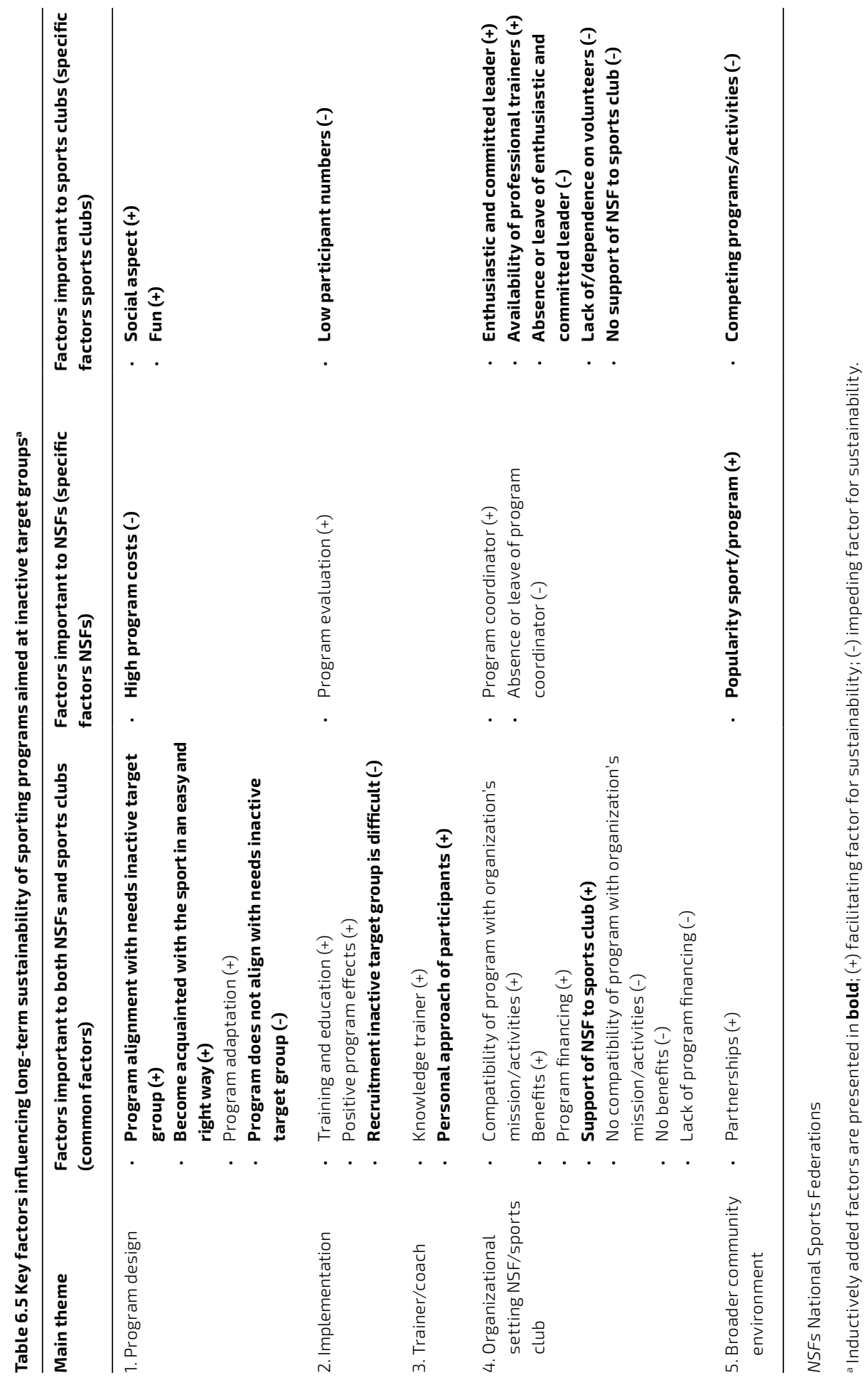


actually little time left to cycle, because you had to move to the starting location of the training and due to the time needed to startup the training. So now they have more time to cycle." (NSF, continued program)

\section{Specific factors}

(Trainers of) sports clubs continued sport activities due to their social and fun characteristics: The social opportunities provided during the program (e.g. drinking coffee/ tea before, during or after training, going to and participating in a sport event together), the acquired social relationships and having fun during participation were main reasons for (previously) inactive sport participants to attend and keep attending the programs (according to trainers) and also for trainers to stay motivated themselves.

High program costs (e.g. due to the use of expensive program materials, intensive guidance of participants or the need to rent a specific (sports) accommodation), which could not be financed from participant fees alone and for which external financial resources were needed, resulted in discontinuation of programs by NSFs.

\section{Implementation}

Key implementation factors influencing the long-term sustainability of programs are described below. It should be noted that these factors were not only important during the three-year funded implementation period but also thereafter.

\section{Common factors}

NSFs (e.g. national or regional trainer courses) and sports clubs (e.g. trainers transmitting knowledge and skills to other trainers) provided trainer courses specific for the sporting programs on a regular basis (i.e. once or multiple times a year). These were very important for sustaining the programs: they provided trainers of sports clubs with the necessary skills to guide the inactive target group and assured sufficient (professional) trainers were available.

Another implementation factor facilitating the long-term sustainability of programs was their effectiveness. When a program showed positive effects with participants, like participants learning the sport and becoming more physically active, NSFs and sports clubs were more likely to continue it. Also, partners and sponsors were more willing to contribute (and keep contributing) to effective programs:

"The schoolteachers think the sport lessons are very important. They see the positive effects of the lessons on the behavior of the children and how they interact with each other. So we keep continuing the lessons. We bought training suits together." (Sports club, continued program) 
The sporting programs were aimed at increasing participation in sport by inactive target groups. The NSFs promoted their programs via national press, the internet (including social media), television and partner organizations. The actual recruitment of participants was done locally by sports clubs through the distribution of posters, flyers and leaflets. Also, adverts were placed in local newspapers and on social media and participants were recruited by word of mouth. When sufficient participants were recruited, a large part was often already somewhat physically active at the start. In general, it was difficult to recruit large numbers of inactive people through these standard recruitment strategies and trainers of sports clubs did not always have the knowledge or resources to get in contact with the inactive target group. This also resulted in discontinuation of programs:

"The inactive and overweight target group was difficult to reach. We underestimated this. To get in contact with this target group you need more. You need other expertise and contacts next to a sport trainer." (NSF, discontinued program)

It should be noted, however, that some NSFs and sports clubs did manage to reach larger numbers of inactive people through collaboration with organizations or people that are close to this target group (e.g. organization for older adults, physiotherapist, general practitioner). These organizations or people promoted the sporting program to inactive people or referred inactive people to the programs (see also factors Broader community environment).

\section{Specific factors}

Program evaluation contributes to the long-term sustainability of programs according to NSFs. It was done by the NSFs to demonstrate program effectiveness and to ensure the program fitted with the target group and sports clubs. NSFs used different methods for evaluation, like (online) questionnaires, interviews and group meetings with participants and/or trainers:

"Every year, we evaluate with all 70 involved trainers. We ask for their opinions: the opportunities they see, the barriers they experience. What do they notice with the target group? They are close to the participants, so they are well-informed about their experiences. Also, participants receive an online questionnaire. Based on the results, we give feedback to the trainers, so that they can further develop themselves. We also use the results to improve the courses and clinics." (NSF, continued program)

For sports clubs, low participant numbers (also in relation to the difficulty to recruit large numbers of inactive people) was an important factor hindering sustainability of their sporting programs. 


\section{Trainer/coach}

\section{Common factors}

The sporting programs aimed to encourage (constantly new) inactive people to participate in sport. Both NSFs and sports clubs agreed that for their long-term sustainability it is very important that the appointed trainers have the knowledge and skills to guide this particular target group. This ensures that participants have positive sport experiences and gladly come back to the club to participate in (additional) sport activities. In this regard, a personal approach of participants is desired:

"The person in front of the group is very important. Participants want to have the feeling 'he (the trainer) sees me', 'he knows what I am doing'." (Sports club, continued program)

As mentioned previously, providing training and education opportunities to trainers is a way to realize this (see Implementation factors).

\section{Specific factors}

There were no trainer/coach factors specific to NSFs or sports clubs.

\section{Organizational setting NSF/sports club}

Most retrieved factors important for the long-term sustainability of programs were related to the organizational setting of the NSFs and sports clubs.

\section{Common factors}

Sustained programs aligned with the NSFs' and sports clubs' core values and activities:

"This program fits with the DNA of our organization. It's the DNA of our sport. There will always be a concept like this within our organization." (NSF, continued program)

Programs were also continued by NSFs and sports clubs due to the acquired benefits, such as more people becoming familiar with the sport or sports club, a better image of the sport, attracting new target groups, more participants, new club members and people who are willing to do club volunteer tasks. However, programs were stopped when they did not align with the organizations' core values and activities and program benefits were absent:

"We are not the right organization to do something with this target group. The program has no advantages for us. It even has no societal advantages." (NSF, discontinued program) 
Sustained programs secured their financial resources. For both NSFs and sports clubs this included internal financial resources, participant/membership fees and in some cases sponsorship fees. Financial resources were not only used to run the programs, but also to educate trainers, to promote the program, to buy (sport) materials and to further develop the program. On the other hand, a lack of program financing, sometimes in combination with high program costs (see Program design factors), was an important reason for NSFs and sports clubs to discontinue programs.

Most NSFs still supported sports clubs in different ways, for example, by providing them with knowledge and advice, (promotional) materials, financial resources and training and education opportunities (see also Table 6.3). Promoting the sporting programs nationally and supporting clubs with organizational aspects were other examples of NSF support to clubs. This saved sports clubs a lot of time and made it possible for them to focus mainly on the sport activities and guidance of participants. Both NSFs and sports clubs, therefore, agreed that the support that NSFs offered was of great value to sports clubs for continuing activities.

\section{Specific factors}

For some sports clubs, a lack of support of their NSF was a reason why they stopped offering programs:

"First, the NSF had three club advisors, but they left due to cut downs. After that, we were not approached anymore to implement the program. The club advisors always helped us. They made the connections with municipalities and schools. We implemented the program multiple times, but now we have stopped. I think because we are not approached anymore." (Sports club, discontinued program)

The remaining (specific) organizational factors influencing long-term sustainability were related to human resources. Having one or more persons in the organization responsible for coordinating the program within the organization facilitated the long-term sustainability of programs. On the level of the NSF, this was the employed NSF program coordinator, sometimes assisted by other NSF employees. This person focused, for instance, on (coordinating) national promotion of the program, recruitment and assistance of clubs and recruitment of partners. Sports clubs relied on one or more enthusiastic committed trainers or volunteers who were occupied with the recruitment of (other) trainers and participants and all kinds of other organizational aspects:

"I am the head trainer and I coordinate the program. There are eight assistanttrainers and two other educated trainers. I coordinate all actions and assign tasks to everyone. Every two months, we meet with all trainers to discuss everything, like problems encountered during implementation or problems with participants and so on. The trainers alternate during the training sessions. We do this with a lot of enthusiasm. We like to be in front of a group of participants and to share our enthusiasm for the sport." (Sports club, continued program) 
Programs were less sustainable when there was no national coordinator present. Also, continuation of programs was threatened when the national coordinator would leave. The same was true for sports clubs regarding their local coordinator. For sports clubs, it was even more difficult to find a (new) coordinator due to their reliance on and often a lack of volunteers:

"Well, I am doing this now for the third or fourth year. One day, I will look around to see whether someone could take over my task. When there is no one who wants to do this, this could impede continuation of the program. It is common in volunteering that people want to help and support, but it is sometimes difficult to find a real coordinator or leader." (Sports club, continued program)

With regard to human resources, sports clubs also mentioned the availability of (enough) professional trainers as an important factor for continuing activities at the sports club level. As described previously, professional trainers enhanced sport experiences of (inactive) participants and, in this way, contributed to continuation of programs (see also factors related to Implementation and Trainer/coach).

\section{Broader community environment}

Several factors in the broader community environment were reported that influenced the long-term sustainability of programs.

\section{Common factors}

Long-term partnerships were important for sustaining programs, both at the national and local level. NSFs collaborated, for instance, with (sport) event organizers, municipalities, sport stores and other commercial organizations (e.g. from food and drink industry). Local sports clubs collaborated amongst others with schools, municipalities, organizations for older people, sport stores, health professionals (e.g. a general practitioner, physiotherapist) and other sports clubs. Partners promoted the programs, supported in recruitment of inactive participants (e.g. referral of inactive people to program), provided financial, material or human resources and shared their expertise or facilities. Brand awareness, more participants (e.g. for sport events), attracting new customers (e.g. for sport stores) and contributing to more healthy or physically active people were examples of benefits for partner organizations. 


\section{Specific factors}

The popularity of a sport in general or of the sporting program in particular supported it's long-term sustainability according to the NSFs:

"Many people do the sport and the sport is still growing enormously. We encourage people to practice it with this program. We show people that practicing the sport in a safe and appropriate manner is important to us." (NSF, continued program)

On the other hand, competing programs or sport activities threatened continuation of sporting programs according to sports clubs:

"In our municipality, many children play soccer and handball. And there is hockey and they offer all kinds of other sports. Children have many options to choose from which leaves fewer children for our activities." (Sports club, continued program)

\section{Results in the ecological perspective}

Considering the ecological perspective of the settings-based approach to health promotion [8-10], an ecological model is used to summarize the results. The factors are presented in the form of a checklist, which can be used as guidance to enhance the long-term sustainability of sporting programs aimed at (previously) inactive target groups and implemented in the organized sports setting (see Figure 6.1). Figure 6.1 illustrates that the long-term sustainability of a program is a continuous process: it should be considered from the very beginning, i.e. during program development/design (arrow 1). Furthermore, continuous attention should be paid to sustainability during the implementation/continuation phases (arrow 2). Moreover, the long-term sustainability of a sporting program is influenced by all levels of the organized sports setting (arrow 3), either directly or indirectly through program development/design and program implementation/continuation factors (e.g. sport participant level). By taking into account the different factors that influence long-term sustainability, the sustainability process in turn influences program development/design, program implementation/continuation and the different levels of the organized sports setting. This is visualized by reciprocal arrows (arrows 1-3). 


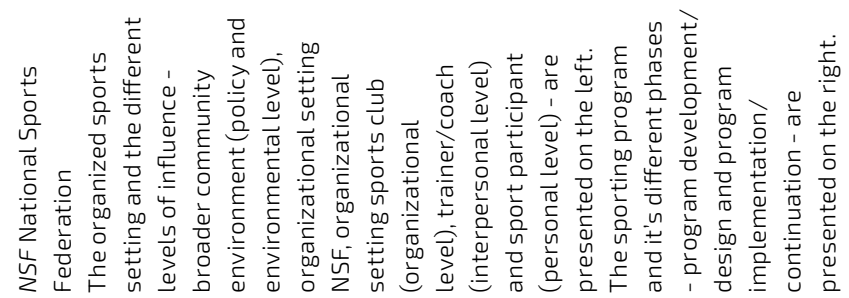
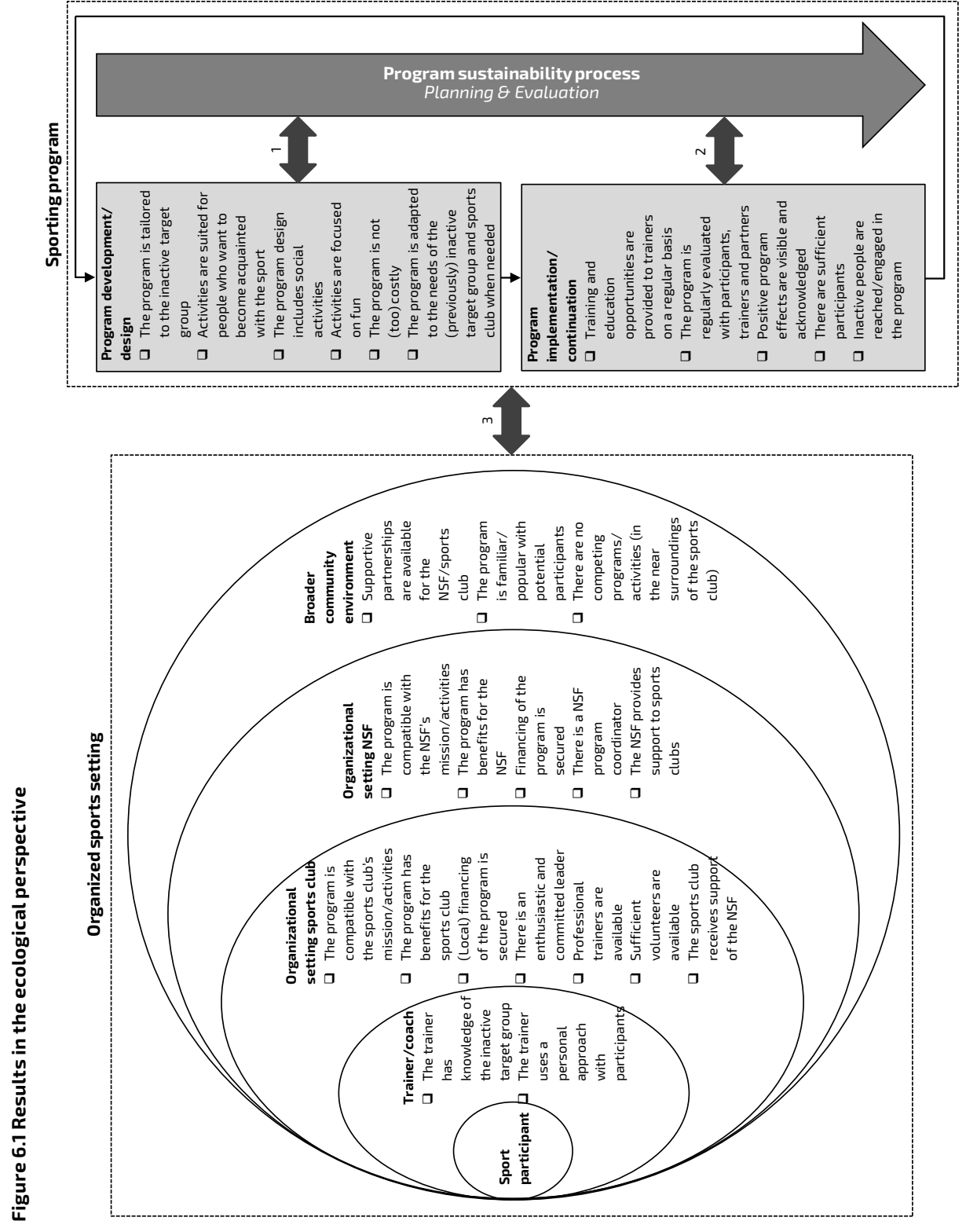


\section{DISCUSSION}

\section{General findings}

This study identified factors influencing the long-term sustainability of the fourteen Dutch NAPSE sporting programs aimed at inactive people, taking into account both the views of the NSFs and sports clubs. It is positive that ten of the fourteen NAPSE sporting programs were continued by the NSFs (and their associated sports clubs) six and half years after the funding period ended. Programs were sustained in different ways, for instance, with and without coordination or support of the NSF, continuing all or a part of the activities and with varying reach into the community.

Although financial resources were important for NSFs and sports clubs to sustain programs, there were many other common influencing factors, such as program adaptation and program effectiveness. However, there were also differences in influencing factors between NSFs and sports clubs, which were specific to the context of these organizations, i.e. a professional-led organization vs. a mostly voluntary-based organization (see also Table 6.5 and Comparison of factors with other studies).

Furthermore, the long-term sustainability of a sporting program is a continuous process, which starts at program development and continues through program implementation and continuation (after a funding period) phases. Therefore, early and active planning is needed to create the conditions that enhance the long-term sustainability of programs. This requires formulating sustainability objectives (e.g. what is to be sustained, how, by whom and when) and developing and implementing strategies specifically to enhance sustainability. In this regard, the checklist in Figure 6.1 can be helpful. Furthermore, monitoring and evaluating sustainability objectives and strategies through time and at all levels of the organized sports setting is important to make adjustments when necessary.

As mentioned previously, program adaptation was an important factor supporting longterm sustainability of programs according to NSFs and sports clubs. Changes to programs were made to align the program with the needs of the (previously) inactive target group and sports clubs, but changes were also made due to the availability of new knowledge or technologies, new partnerships and decreased financial resources. In the literature, program adaptation is also identified as an important factor for program sustainability and it was a pre-specified factor in our framework [29, 30, 34]. However, changing or removing essential components of programs could lead to non-desired outcomes $[34,44]$. Therefore, it is important to identify the core elements of the programs that are critical for the achievement of desired outcomes (i.e. increasing physical activity levels of inactive people) and to further study how program adaptation influences these outcomes.

Finally, the sporting programs were aimed at encouraging inactive people to participate in sport. However, it was difficult to recruit large numbers of inactive people using standard recruitment strategies (e.g. flyers, posters). Although activity levels of participants were 
based on views of the interviewees, they are in accordance with results of an effectiveness evaluation of the NAPSE sporting programs during the three-year implementation period. Based on these results, it appeared that 0 to $15 \%$ of participants of the programs was completely inactive at the start [45]. It is important to keep attracting inactive people by promoting the sporting programs in a fun and non-threatening manner, using promotion channels that are appropriate to the target group [25]. Some NSFs and sports clubs did manage to recruit larger numbers of inactive people by collaborating with organizations (e.g. organizations for older people) or people (e.g. a general practitioner, physiotherapist) that are close to this target group. However, trainers of sports clubs often did not have the knowledge or resources to get in contact with inactive people. By sharing knowledge and good practices between NSFs and sports clubs and by educating trainers of sports clubs on how to recruit and engage inactive people (in collaboration with others), participant numbers can be increased. This will contribute to the long-term sustainability of these kind of programs.

\section{Comparison of factors with other studies}

To our knowledge, this is the first study that examined factors influencing the long-term sustainability of sporting programs aimed at inactive target groups and implemented in the organized sports setting. Some of the retrieved sustainability factors that were common to both NSFs and sports clubs are comparable to those found in the study concerning the implementation period of the NAPSE programs [16] and the research about the sustainability of a health promotion program within sport and recreation organizations [23]. For example, alignment of the program with the sport organization's mission and activities, the availability of financial resources, the provision of training and education opportunities and supportive partnerships. Presumably, these are the basic factors or conditions for continuation of sporting programs, both in the short and longer term and independent of the implementing (sport) organization. The same is true when comparing the common factors with our theoretical framework, which was based on sustainability research of health promotion programs in a diverse range of settings (e.g. healthcare setting, schools, communities) [16, 23, 28-34, 36-38]. This implies there are generic factors influencing the long-term sustainability of a health promotion program independent of the setting in which it is implemented. However, this study also identified new factors (i.e. the inductively added factors), especially those that were related to the specific aim of the NAPSE programs (e.g. program alignment with needs inactive target group) and the (organizational) setting of sports clubs (e.g. dependence on volunteers). The latter also resulted in different influencing factors between NSFs and sports clubs. Sports clubs are largely run by volunteers and the sports clubs setting is, therefore, quite different from the more professional led NSF setting and the other studied settings (e.g. health care setting, schools, communities). Securing human resources (e.g. availability of professional trainers, committed leader) is for sports clubs (as opposed to NSFs) one of their main challenges when continuing program activities 
over a long period of time. Furthermore, sports clubs ran into other practical issues, like competing activities in their neighborhood and low participant numbers. In addition, the social and fun aspects of participation are inherent to the sports club nature and are important aspects to include in program design. It is important that these factors specific to sports clubs are taken into account, in particular when the NSF is the developer of the program and receiver of the funding and sports clubs are responsible for implementation and continuation of activities. In this regard, the support that NSFs provided to sports clubs (e.g. the provision of training and education opportunities, knowledge and advice, (promotional) materials) facilitated long-term sustainability of programs at sports clubs. Furthermore, as discussed previously, educating trainers of sports club on how to recruit and engage inactive people (in collaboration with others) can be helpful as well in sustaining these kind of programs. In general, this highlights again that it is important to take into account the particular (implementation) context of a program when considering its longterm sustainability $[46,47]$.

\section{Practical implications}

Overall, the results of this study can be useful to policy makers, sport practitioners and health professionals in countries with a similar organized sports infrastructure. The results can aid them in the development of strategies to promote long-term sustainability of health promotion programs in general and physical activity promotion programs in particular located within the organized sports setting. As mentioned previously, the checklist in Figure 6.1 can be used as guidance for this purpose. The checklist can also be helpful in formulating funding guidelines by funding bodies, so that program developers and implementers pay greater attention to the long-term sustainability of their program from the start and integrate sustainability goals and evaluation of these goals in their plans. Program developers and implementers should, for example, elaborate on how they will consider the needs of the inactive target group and how they are going to secure financial resources for the program after the funding period. In this way, the long-term sustainability of these kind of programs will be enhanced.

\section{Strengths and limitations of the study}

Factors influencing long-term sustainability were assessed six and a half years after the funding period ended and both the views of NSFs and sports clubs were examined. In addition, a diverse sample of sporting programs and sporting organizations were included in this study. These are strengths of this study. However, there are also some limitations. Considering the qualitative nature of the study and the Dutch context, it is not known whether the results are generalizable to sport organizations in other countries, particularly as the organizational structure and interplay between organizations may 
influence the findings. Sports clubs that discontinued programs were harder to find and were less represented in this study $(n=11)$ in comparison with sports clubs that continued programs $(n=17)$. Also, at the level of the NSF there were fewer programs stopped $(n=4)$ than continued $(n=10)$. This may have resulted in more insight into facilitating factors of long-term sustainability than impeding factors. Furthermore, thematic analysis is a proper method to examine views of NSFs and sports clubs regarding key factors influencing the long-term sustainability of their programs and highlighting similarities and differences between the views of these two groups [42]. However, thematic analysis does not focus on the relative importance of these key factors (e.g. are training and education opportunities more important for long-term sustainability than supportive partnerships?). Nonetheless, when considering all of the common and specific factors (see Table 6.5 and Figure 6.1), the likelihood of successfully continuing program activities is increased. Finally, we did not examine possible interactions between influencing factors. For instance, the availability of supportive partnerships (factor Broader community environment) could lead to the availability of more financial resources (factor Organizational setting NSF/sports club) or the recruitment of larger numbers of inactive people (Implementation/continuation factor). In future studies, the possible interaction between factors should be further explored.

\section{CONCLUSIONS}

Notwithstanding these strengths and limitations, this study does add to the knowledge base concerning the long-term sustainability of sporting programs aimed at inactive people in the organized sports setting. The key factors facilitating and impeding the longterm sustainability of programs were identified, highlighting similarities and differences in these factors between NSFs and sports clubs. The results of this study can be used by policy makers, sport practitioners and health professionals in countries with a similar organized sports infrastructure in the development of strategies to promote long-term sustainability of these kind of sporting programs. Furthermore, the results can be used to guide funding guidelines. In future research, it is important to identify the core elements of programs that are critical for the achievement of desired outcomes and to further study how program adaptation influences these outcomes. Further research is needed to determine generalizability of the results to differing organized sports settings in other countries. Future research should also take into account possible interactions between influencing factors. This will further contribute to our understanding of how the long-term sustainability of physical activity promotion programs in particular and health promotion programs in general, can be improved in this setting. 


\section{REFERENCES}

1. Bailey R, Hillman C, Arent S, Petitpas A. Physical activity: an underestimated investment in human capital? J Phys Act Health. 2013;10(3):289-308.

2. Eime RM, Young JA, Harvey JT, Charity MJ, Payne WR. A systematic review of the psychological and social benefits of participation in sport for children and adolescents: informing development of a conceptual model of health through sport. Int J Behav Nutr Phys Act. 2013;10:98.

3. Eime RM, Young JA, Harvey JT, Charity MJ, Payne WR. A systematic review of the psychological and social benefits of participation in sport for adults: informing development of a conceptual model of health through sport. Int J Behav Nutr Phys Act. 2013;10:135.

4. Warburton DER, Nicol CW, Bredin SSD. Health benefits of physical activity: the evidence. CMAJ. 2006;174(6):801-809.

5. Statistics Netherlands (CBS), National Institute for Public Health and the Environment (RIVM). Health questionnaire/Lifestyle monitor 2014-2017. 2017. https://www.volksgezondheidenzorg. info/onderwerp/sport-en-bewegen/cijfers-context/huidige-situatie\#nodebeweegrichtlijnen. Accessed 13 February 2019.

6. Kyu HH, Bachman VF, Alexander LT, Mumford JE, Afshin A, Estep K, Veerman JL, Delwiche K, Iannarone ML, Moyer ML, Cercy K, Vos T, Murray CJL, Forouzanfar MH. Physical activity and risk of breast cancer, colon cancer, diabetes, ischemic heart disease, and inschemic stroke events: systemic review and dose-response meta-analysis for the Global Burden of Disease Study 2013. BMJ. 2016;354:i3857.

7. World Health Organization (WHO). Ottawa Charter for Health Promotion. Geneva: WHO; 1986.

8. Dooris M. Holistic and sustainable health improvement: the contribution of the settings-based approach to health promotion. Perspect Public Health. 2009;129(1):29-36.

9. Mcleroy KR, Bibeau D, Steckler A, Glanz K. An ecological perspective on health promotion programs. Health Educ Q. 1988;15(4):351-377.

10. Whitelaw S, Baxendale A, Bryce C, MacHardy L, Young I, Witney E. 'Settings' based health promotion: a review. Health Promot Int. 2001;16(4):339-353.

11. Casey MM, Payne WR, Eime RM. Partnership and capacity-building strategies in community sports and recreation programs. Manag Leis. 2009;14(3):167-176.

12. Casey MM, Payne WR, Eime RM. Organisational readiness and capacity building strategies of sporting organisations to promote health. Sport Manag Rev. 2012;15:109-124.

13. Donaldson A, Finch CF. Sport as a setting for promoting health. Br J Sports Med. 2012;46(1):4-5.

14. Eime RM, Payne WR, Harvey JT. Making sporting clubs healthy and welcoming environments: a strategy to increase participation. J Sci Med Sport. 2008;11(2):146-154.

15. Kokko S, Kannas L, Villberg J. The health promoting sports club in Finland--a challenge for the settings-based approach. Health Promot Int. 2006;21(3):219-229.

16. Ooms L, Veenhof C, Schipper-van Veldhoven N, de Bakker DH. Sporting programs for inactive population groups: factors influencing implementation in the organized sports setting. BMC Sports Sci Med Rehabil. 2015;7:12. 
17. Eime RM, Harvey JT, Brown WJ, Payne WR. Does sports club participation contribute to healthrelated quality of life? Med Sci Sports Exerc. 2010;42(5):1022-1028.

18. Eime RM, Harvey JT, Charity MJ, Casey MM, van Uffelen JGZ, Payne WR. The contribution of sport participation to overall health enhancing physical activity levels in Australia: a populationbased study. BMC Public Health. 2015;15:806.

19. Allender S, Cowburn G, Foster C. Understanding participation in sport and physical activity among children and adults: a review of qualitative studies. Health Educ Res. 2006;21(6):826835.

20. Fokkema T, Hartgens F, Kluitenberg B, Verhagen E, Backx FJG, van der Worp H, Bierma-Zeinstra SMA, Koes BW, van Middelkoop M. Reasons and predictors of discontinuation of running after a running program for novice runners. J Sci Med Sport. 2018;22(1):106-111.

21. Khan KM, Thompson AM, Blair SN, Sallis JF, Powell KE, Bull FC, Bauman AE. Sport and exercise as contributors to the health of nations. Lancet. 2012;380:59-64.

22. Ristolainen L, Toivo K, Parkkari J, Kokko S, Alanko L, Heinonen OJ, Korpelainen R, Savonen K, Selänne H, Vasankari T, Kannas L, Villberg J, Kujala UM. Acute and overuse injuries among sports club members and non-members: the Finnish Health Promoting Sports Club (FHPSC) study. BMC Musculoskelet Disord. 2019;20:32.

23. Casey MM, Payne WR, Eime RM, Brown SJ. Sustaining health promotion programs within sport and recreation organisations. J Sci Med Sport. 2009;12:113-118.

24. Dutch Ministry of Health, Welfare and Sport. Time for sport: exercise, participate, perform. The Hague: Dutch Ministry of Health, Welfare and Sport; 2005.

25. Ooms L, Leemrijse C, Collard D, Schipper-van Veldhoven N, Veenhof C. Characteristics of insufficiently active participants that benefit from health-enhancing physical activity (HEPA) promotion programs implemented in the sports club setting. BMC Public Health. 2018;18:685

26. Ooms L, Veenhof C, de Bakker DH. Effectiveness of Start to Run, a 6-week training program for novice runners, on increasing health-enhancing physical activity: a controlled study. BMC Public Health. 2013;13:697.

27. Ooms L, Veenhof C, de Bakker DH. The Start2Bike program is effective in increasing healthenhancing physical activity: a controlled study. BMC Public Health. 2017;17:606.

28. Bossert TJ. Can they get along without us? Sustainability of donor-supported health projects in Central America and Africa. Soc Sci Med. 1990;30(9):1015-1023.

29. Scheirer MA. Is sustainability possible? A review and commentary on empirical studies and program sustainability. Am J Eval. 2005;26(3):320-347.

30. Schell SF, Luke DA, Schooley MW, Elliot MB, Herbers SH, Mueller NB, Bunger AC. Public health program capacity for sustainability: a new framework. Implement Sci. 2013;8:15.

31. Shediac-Rizkallah MC, Bone LR. Planning for sustainability of community-based health programs: conceptual framework and future directions for research, practice and policy. Health Educ Res. 1998;13(1):87-108.

32. Fleuren MAH, Paulussen TGWM, van Dommelen P, van Buuren S. Towards a measurement instrument for determinants of innovations. Int J Qual Health Care. 2014;26(5):501-510.

33. Hawe P, King L, Noort M, Jordens C, Lloyd B. Indicators to help with capacity building in health promotion. North Sydney: NSW Health; 1999. 
34. Wiltsey Stirman S, Kimberly J, Cook N, Calloway A, Castro F, Charns M. The sustainability of new programs and innovations: a review of the emperical literature and recommendations for future research. Implement Sci. 2012;7:17.

35. Bond GR, Drake RE, McHugo GJ, Peterson AE, Jones AM, Williams J. Long-term sustainability of evidence-based practices in community mental health agencies. Adm Policy Ment Health Ment Health Serv Res. 2014;41(2):228-236.

36. Swerissen H, Crisp BR. The sustainibility of health promotion interventions for different levels of social organization. Health Promot Int. 2004;19(1):123-129.

37. Weisbrod RR, Pirie PL, Bracht NF. Impact of a community health promotion program on existing organizations: the Minnesota Heart Health Program. Soc Sci Med. 1992;34(6):639-648.

38. Whitley MA, Forneris T, Barker B. The reality of sustaining community-based sport and physical activity programs to enhance the development of underserved youth: challenges and potential strategies. Quest. 2015;67(4):409-423.

39. Dutch government. Medical Research Involving Human Subjects Act (WMO). https://wetten. overheid.nl/BWBR0009408/2019-04-02. Accessed 17 June 2019.

40. European Union. General Data Protection Regulation. https://autoriteitpersoonsgegevens.nl/ sites/default/files/atoms/files/gdpr.pdf. Accessed 17 June 2019.

41. Clark JP. How to peer review a qualitative manuscript. In: Godlee F, Jefferson T, editors. Peer review in health sciences. 2nd ed. London: BMJ Books; 2003. p.219-235.

42. Nowell LS, Morris JM, White DE, Moules NJ. Thematic analysis: striving to meet the trustworthiness criteria. Int I Qual Methods. 2017;16:1-13.

43. Fereday J, Muir-Cochrane E. Demonstrating rigor using thematic analysis: a hybrid approach of inductive and deductive coding and theme development. Int I Qual Methods. 2006;5(1):1-11.

44. Pluye P, Potvin L, Denis JL, Pelletier J. Program sustainaibility: focus on organziational routines. Health Promot Int. 2004;19(4):489-500.

45. Ooms L, Veenhof C. Evaluation of the implementation phase of the National Action Plan for Sport and Exercise, the sports setting: results process and effectiveness evaluation (report in Dutch). Utrecht: NIVEL; 2011.

46. Finch CF. No longer lost in translation: the art and science of sports injury prevention implementation research. Br J Sports Med. 2011;45:1253-1257.

47. Finch CF, Donaldson A. A sports setting matrix for understanding the implementation context for community sport. Br J Sports Med. 2010;44:973-978. 


\section{APPENDIX 6.1}

\section{Theoretical framework of factors}

Table A6.1.1 Program design factors

\begin{tabular}{|c|c|c|c|}
\hline $\begin{array}{l}\text { Factor } \\
\text { summarized } \\
\text { (subtheme) }\end{array}$ & $\begin{array}{l}\text { Name of factor in } \\
\text { literature }\end{array}$ & Description of factor in literature & References \\
\hline \multirow[t]{9}{*}{$\begin{array}{l}\text { Stakeholder } \\
\text { involvement }\end{array}$} & $\begin{array}{l}\text { Project negotiation } \\
\text { process }\end{array}$ & $\begin{array}{l}\text { Project approaches and goals are discussed } \\
\text { with recipient community members as equal } \\
\text { partners (addressing everyone's needs: } \\
\text { donors, community, technical experts). }\end{array}$ & $\begin{array}{l}\text { Shediac-Rizkallah } \\
\text { \& Bone, } 1998\end{array}$ \\
\hline & $\begin{array}{l}\text { Mutually } \\
\text { respectful } \\
\text { negotiating } \\
\text { process }\end{array}$ & $\begin{array}{l}\text { Project that is designed and approved in a } \\
\text { mutually respectful negotiating process } \\
\text { involving implementers and national } \\
\text { government. }\end{array}$ & Bossert, 1990 \\
\hline & $\begin{array}{l}\text { Stakeholders' } \\
\text { involvement in } \\
\text { program design }\end{array}$ & $\begin{array}{l}\text { Stakeholders are aware of the program and } \\
\text { are involved in its development. }\end{array}$ & Casey et al., 2009 \\
\hline & $\begin{array}{l}\text { Stakeholders' } \\
\text { involvement in } \\
\text { program design }\end{array}$ & $\begin{array}{l}\text { People with a stake in the program - funders, } \\
\text { administrators, consumers/beneficiaries, } \\
\text { other agencies - have been aware of the } \\
\text { program and/or involved in its development. }\end{array}$ & Hawe et al., 1999 \\
\hline & $\begin{array}{l}\text { Host } \\
\text { organization's } \\
\text { support to the } \\
\text { program in the } \\
\text { past }\end{array}$ & $\begin{array}{l}\text { The organization which you intend to host } \\
\text { the program in the future has been making } \\
\text { some real or in kind support to the program } \\
\text { in the past. }\end{array}$ & Hawe et al., 1999 \\
\hline & $\begin{array}{l}\text { Stakeholder } \\
\text { involvement/ } \\
\text { support }\end{array}$ & No description. & $\begin{array}{l}\text { Wiltsey Stirman } \\
\text { et al., } 2012\end{array}$ \\
\hline & $\begin{array}{l}\text { Shared decision } \\
\text { making among } \\
\text { stakeholders }\end{array}$ & No description. & $\begin{array}{l}\text { Wiltsey Stirman } \\
\text { et al., } 2012\end{array}$ \\
\hline & $\begin{array}{l}\text { Community } \\
\text { involvement in } \\
\text { development } \\
\text { program goals }\end{array}$ & $\begin{array}{l}\text { The community is engaged in the } \\
\text { development of program goals. }\end{array}$ & Schell et al., 2013 \\
\hline & $\begin{array}{l}\text { Community } \\
\text { involvement and } \\
\text { ownership }\end{array}$ & $\begin{array}{l}\text { Program is developed, implemented and } \\
\text { evaluated with widespread community } \\
\text { involvement and ownership. }\end{array}$ & $\begin{array}{l}\text { Whitley et al., } \\
2015\end{array}$ \\
\hline
\end{tabular}


Table A6.1.1 Program design factors (continued)

\begin{tabular}{|c|c|c|c|}
\hline $\begin{array}{l}\text { Factor } \\
\text { summarized } \\
\text { (subtheme) }\end{array}$ & $\begin{array}{l}\text { Name of factor in } \\
\text { literature }\end{array}$ & Description of factor in literature & References \\
\hline \multirow[t]{4}{*}{$\begin{array}{l}\text { Program } \\
\text { adaptation }\end{array}$} & $\begin{array}{l}\text { Ability to be } \\
\text { modified/ } \\
\text { modifications } \\
\text { made }\end{array}$ & The intervention or program can be modified. & $\begin{array}{l}\text { Wiltsey Stirman } \\
\text { et al., } 2012\end{array}$ \\
\hline & $\begin{array}{l}\text { Adaptation/ } \\
\text { alignment }\end{array}$ & $\begin{array}{l}\text { Adaptation of the intervention to improve fit/ } \\
\text { alignment between the innovation and the } \\
\text { setting. }\end{array}$ & $\begin{array}{l}\text { Wiltsey Stirman } \\
\text { et al., } 2012\end{array}$ \\
\hline & $\begin{array}{l}\text { Program } \\
\text { adaptation }\end{array}$ & $\begin{array}{l}\text { Actions are taken to adapt the program } \\
\text { to ensure its ongoing effectiveness: The } \\
\text { program periodically reviews the evidence } \\
\text { base; it adapts strategies as needed; it } \\
\text { adapts to new science; it proactively adapts } \\
\text { to changes in the environment; it makes } \\
\text { decisions about which components are } \\
\text { ineffective and should not continue. }\end{array}$ & Schell et al., 2013 \\
\hline & $\begin{array}{l}\text { Program } \\
\text { modifiable }\end{array}$ & A program can be modified over time. & Scheirer, 2005 \\
\hline Project type & Project type & $\begin{array}{l}\text { More resources are allocated to curative } \\
\text { than to preventive care. }\end{array}$ & $\begin{array}{l}\text { Shediac-Rizkallah } \\
\text { \& Bone, } 1998\end{array}$ \\
\hline Program fidelity & $\begin{array}{l}\text { Ability to maintain } \\
\text { fidelity/integrity }\end{array}$ & $\begin{array}{l}\text { Degree to which an intervention or program } \\
\text { is delivered as intended. }\end{array}$ & $\begin{array}{l}\text { Wiltsey Stirman } \\
\text { et al., } 2012\end{array}$ \\
\hline $\begin{array}{l}\text { Procedural } \\
\text { clarity }\end{array}$ & Procedural clarity & $\begin{array}{l}\text { The innovation clearly describes which } \\
\text { steps/activities should be performed and in } \\
\text { which order. }\end{array}$ & $\begin{array}{l}\text { Fleuren et al., } \\
2014\end{array}$ \\
\hline Correctness & Correctness & $\begin{array}{l}\text { The innovation is based on factually correct } \\
\text { knowledge. }\end{array}$ & $\begin{array}{l}\text { Fleuren et al., } \\
2014\end{array}$ \\
\hline Completeness & Completeness & $\begin{array}{l}\text { The innovation provides all the information } \\
\text { and materials needed to work with it } \\
\text { properly. }\end{array}$ & $\begin{array}{l}\text { Fleuren et al., } \\
2014\end{array}$ \\
\hline Complexity & Complexity & $\begin{array}{l}\text { The innovation is not too complex to } \\
\text { implement/use. }\end{array}$ & $\begin{array}{l}\text { Fleuren et al., } \\
2014\end{array}$ \\
\hline
\end{tabular}


Table A6.1.2 Implementation factors

\begin{tabular}{|c|c|c|c|}
\hline $\begin{array}{l}\text { Factor } \\
\text { summarized } \\
\text { (subtheme) }\end{array}$ & $\begin{array}{l}\text { Name of factor } \\
\text { in literature }\end{array}$ & Description of factor in literature & References \\
\hline \multirow[t]{7}{*}{$\begin{array}{l}\text { Program } \\
\text { evaluation }\end{array}$} & $\begin{array}{l}\text { Evaluation and } \\
\text { feedback }\end{array}$ & No description. & $\begin{array}{l}\text { Wiltsey Stirman } \\
\text { et al., } 2012\end{array}$ \\
\hline & $\begin{array}{l}\text { Program } \\
\text { evaluation }\end{array}$ & $\begin{array}{l}\text { The program has the capacity for quality } \\
\text { program evaluation. }\end{array}$ & Schell et al., 2013 \\
\hline & $\begin{array}{l}\text { Program } \\
\text { evaluation }\end{array}$ & $\begin{array}{l}\text { The program reports short-term and } \\
\text { intermediate outcomes. }\end{array}$ & Schell et al., 2013 \\
\hline & $\begin{array}{l}\text { Program } \\
\text { evaluation }\end{array}$ & $\begin{array}{l}\text { Evaluation results inform planning and } \\
\text { implementation. }\end{array}$ & Schell et al., 2013 \\
\hline & $\begin{array}{l}\text { Program } \\
\text { evaluation }\end{array}$ & $\begin{array}{l}\text { Program evaluation results are used to } \\
\text { demonstrate successes to funders and other } \\
\text { key stakeholders. }\end{array}$ & Schell et al., 2013 \\
\hline & $\begin{array}{l}\text { Program } \\
\text { evaluation }\end{array}$ & $\begin{array}{l}\text { The program provides strong evidence to the } \\
\text { public that the program works. }\end{array}$ & Schell et al., 2013 \\
\hline & $\begin{array}{l}\text { Monitoring and } \\
\text { evaluation }\end{array}$ & $\begin{array}{l}\text { This includes both monitoring (i.e. formative } \\
\text { evaluation), when programs are assessed } \\
\text { during development or early implementation } \\
\text { to determine ways in which the program can } \\
\text { be improved, as well as summative evaluation, } \\
\text { when programs are assessed in order to decide } \\
\text { whether a program should be continued, } \\
\text { expanded, modified, or ended. }\end{array}$ & $\begin{array}{l}\text { Whitley et al., } \\
2015\end{array}$ \\
\hline \multirow[t]{6}{*}{$\begin{array}{l}\text { Program } \\
\text { effectiveness }\end{array}$} & $\begin{array}{l}\text { Project } \\
\text { effectiveness }\end{array}$ & $\begin{array}{l}\text { Project has been shown to be effective } \\
\text { (perceived as effective, visible effects). }\end{array}$ & $\begin{array}{l}\text { Shediac-Rizkallah } \\
\text { \& Bone, } 1998\end{array}$ \\
\hline & $\begin{array}{l}\text { Perceived project } \\
\text { effectiveness }\end{array}$ & $\begin{array}{l}\text { Project that achieves its expected goals and } \\
\text { objectives with a relatively efficient use of } \\
\text { resources. }\end{array}$ & Bossert, 1990 \\
\hline & $\begin{array}{l}\text { Program } \\
\text { effectiveness }\end{array}$ & $\begin{array}{l}\text { The program has shown itself to be effective. } \\
\text { Effects are visible and acknowledged. }\end{array}$ & Hawe et al., 1999 \\
\hline & Visibility & $\begin{array}{l}\text { The outcomes (effects) of using the innovation } \\
\text { are clearly observable (for the user). }\end{array}$ & $\begin{array}{l}\text { Fleuren et al., } \\
2014\end{array}$ \\
\hline & $\begin{array}{l}\text { Effectiveness or } \\
\text { benefit }\end{array}$ & No description. & $\begin{array}{l}\text { Wiltsey Stirman } \\
\text { et al., } 2012\end{array}$ \\
\hline & $\begin{array}{l}\text { Program } \\
\text { effectiveness } \\
\text { (program } \\
\text { evaluation) }\end{array}$ & $\begin{array}{l}\text { The program provides strong evidence to the } \\
\text { public that the program works. }\end{array}$ & Schell et al., 2013 \\
\hline
\end{tabular}


Table A6.1.2 Implementation factors (continued)

\begin{tabular}{|c|c|c|c|}
\hline $\begin{array}{l}\text { Factor } \\
\text { summarized } \\
\text { (subtheme) }\end{array}$ & $\begin{array}{l}\text { Name of factor } \\
\text { in literature }\end{array}$ & Description of factor in literature & References \\
\hline \multirow[t]{6}{*}{$\begin{array}{l}\text { Training and } \\
\text { education }\end{array}$} & Training & $\begin{array}{l}\text { Training of professionals and para- } \\
\text { professionals. }\end{array}$ & $\begin{array}{l}\text { Shediac-Rizkallah } \\
\text { \& Bone, } 1998\end{array}$ \\
\hline & Training & $\begin{array}{l}\text { Project with strong training components, } \\
\text { including professional training and para- } \\
\text { professional training. }\end{array}$ & Bossert, 1990 \\
\hline & Training & $\begin{array}{l}\text { Formal and informal training of staff in the } \\
\text { program (i.e. training new skills in health } \\
\text { promotion and partnership development). }\end{array}$ & Casey et al., 2009 \\
\hline & Training & $\begin{array}{l}\text { The program has involved formal and/or } \\
\text { informal training of people whose skills and } \\
\text { interests are retained in the program or its } \\
\text { immediate environment. }\end{array}$ & Hawe et al., 1999 \\
\hline & $\begin{array}{l}\text { Training and } \\
\text { education }\end{array}$ & No description. & $\begin{array}{l}\text { Wiltsey Stirman } \\
\text { et al., } 2012\end{array}$ \\
\hline & $\begin{array}{l}\text { Knowledge } \\
\text { translation }\end{array}$ & $\begin{array}{l}\text { Partner training, technical assistance and } \\
\text { continuing education, with a focus on building } \\
\text { the capacity of all partners in community-based } \\
\text { programs, including leadership development. }\end{array}$ & $\begin{array}{l}\text { Whitley et al., } \\
2015\end{array}$ \\
\hline \multirow[t]{2}{*}{ Funding period } & Project duration & Long funding period. & $\begin{array}{l}\text { Shediac-Rizkallah } \\
\text { \& Bone, } 1998\end{array}$ \\
\hline & $\begin{array}{l}\text { Duration of } \\
\text { funding }\end{array}$ & Financial support over a long period of time. & $\begin{array}{l}\text { Swerissen \& } \\
\text { Crisp, } 2004\end{array}$ \\
\hline
\end{tabular}


Table A6.1.3 Factors on the level of the user/implementer (trainer/coach of sports club)

\begin{tabular}{|c|c|c|c|}
\hline $\begin{array}{l}\text { Factor } \\
\text { summarized } \\
\text { (subtheme) }\end{array}$ & $\begin{array}{l}\text { Name of factor } \\
\text { in literature }\end{array}$ & Description of factor in literature & References \\
\hline \multirow[t]{2}{*}{$\begin{array}{l}\text { Personal } \\
\text { benefits/ } \\
\text { drawbacks }\end{array}$} & $\begin{array}{l}\text { Personal } \\
\text { benefits/ } \\
\text { drawbacks }\end{array}$ & $\begin{array}{l}\text { The innovation has advantages for the user/ } \\
\text { implementer. }\end{array}$ & $\begin{array}{l}\text { Fleuren et } \\
\text { al., } 2014\end{array}$ \\
\hline & $\begin{array}{l}\text { Perceived } \\
\text { benefits }\end{array}$ & $\begin{array}{l}\text { Staff members or key stakeholders perceive benefits } \\
\text { to themselves and/or clients. }\end{array}$ & $\begin{array}{l}\text { Scheirer, } \\
2005\end{array}$ \\
\hline \multirow[t]{2}{*}{$\begin{array}{l}\text { Relevance for } \\
\text { client }\end{array}$} & $\begin{array}{l}\text { Relevance for } \\
\text { client }\end{array}$ & $\begin{array}{l}\text { The user believes the innovation is relevant for his/ } \\
\text { her client. }\end{array}$ & $\begin{array}{l}\text { Fleuren et } \\
\text { al., } 2014\end{array}$ \\
\hline & $\begin{array}{l}\text { Perceived } \\
\text { benefits }\end{array}$ & $\begin{array}{l}\text { Staff members or key stakeholders perceive benefits } \\
\text { to themselves and/or clients. }\end{array}$ & $\begin{array}{l}\text { Scheirer, } \\
2005\end{array}$ \\
\hline $\begin{array}{l}\text { Outcome } \\
\text { expectations }\end{array}$ & $\begin{array}{l}\text { Outcome } \\
\text { expectations }\end{array}$ & $\begin{array}{l}\text { The user thinks it is important to achieve the client } \\
\text { objectives as intended by the innovation and expects } \\
\text { that the innovation will actually achieve these } \\
\text { objectives. }\end{array}$ & $\begin{array}{l}\text { Fleuren et } \\
\text { al., } 2014\end{array}$ \\
\hline $\begin{array}{l}\text { Professional } \\
\text { obligation }\end{array}$ & $\begin{array}{l}\text { Professional } \\
\text { obligation }\end{array}$ & $\begin{array}{l}\text { The innovations fits in the tasks for which the user } \\
\text { feels responsible when doing his/her work. The user } \\
\text { feels it as his/her responsibility as a professional to } \\
\text { use the innovation. }\end{array}$ & $\begin{array}{l}\text { Fleuren et } \\
\text { al., } 2014\end{array}$ \\
\hline $\begin{array}{l}\text { Client } \\
\text { satisfaction }\end{array}$ & $\begin{array}{l}\text { Client } \\
\text { satisfaction }\end{array}$ & $\begin{array}{l}\text { The user thinks that his or her clients will (in general) } \\
\text { be satisfied with the innovation. }\end{array}$ & $\begin{array}{l}\text { Fleuren et } \\
\text { al., } 2014\end{array}$ \\
\hline $\begin{array}{l}\text { Client } \\
\text { cooperation }\end{array}$ & $\begin{array}{l}\text { Client } \\
\text { cooperation }\end{array}$ & $\begin{array}{l}\text { The user thinks that his or her clients will (in general) } \\
\text { cooperate when using the innovation. }\end{array}$ & $\begin{array}{l}\text { Fleuren et } \\
\text { al., } 2014\end{array}$ \\
\hline Social support & Social support & $\begin{array}{l}\text { The user expects or experiences support from } \\
\text { important social referents relating to the use of the } \\
\text { innovation (e.g. colleagues, other professionals they } \\
\text { work with, heads of department or management). }\end{array}$ & $\begin{array}{l}\text { Fleuren et } \\
\text { al., } 2014\end{array}$ \\
\hline $\begin{array}{l}\text { Descriptive } \\
\text { norm }\end{array}$ & Descriptive norm & $\begin{array}{l}\text { Colleagues' observed behavior: degree to which } \\
\text { other colleagues use the innovation. }\end{array}$ & $\begin{array}{l}\text { Fleuren et } \\
\text { al., } 2014\end{array}$ \\
\hline Subjective norm & Subjective norm & $\begin{array}{l}\text { The influence of important others on the use of the } \\
\text { innovation: the extent that they expect the user to } \\
\text { use the innovation and the extent to which the user } \\
\text { complies with their opinions. }\end{array}$ & $\begin{array}{l}\text { Fleuren et } \\
\text { al., } 2014\end{array}$ \\
\hline Self-efficacy & Self-efficacy & $\begin{array}{l}\text { The user believes he or she is able to implement the } \\
\text { activities involved in the innovation. }\end{array}$ & $\begin{array}{l}\text { Fleuren et } \\
\text { al., } 2014\end{array}$ \\
\hline Knowledge & Knowledge & $\begin{array}{l}\text { The user has the knowledge needed to use the } \\
\text { innovation. }\end{array}$ & $\begin{array}{l}\text { Fleuren et } \\
\text { al., } 2014\end{array}$ \\
\hline $\begin{array}{l}\text { Awareness of } \\
\text { content of the } \\
\text { innovation }\end{array}$ & $\begin{array}{l}\text { Awareness of } \\
\text { content of the } \\
\text { innovation }\end{array}$ & $\begin{array}{l}\text { The user has learnt about the content of the } \\
\text { innovation. }\end{array}$ & $\begin{array}{l}\text { Fleuren et } \\
\text { al., } 2014\end{array}$ \\
\hline
\end{tabular}


Table A6.1.4 Factors within the organizational setting (of NSF/sports club)

\begin{tabular}{|c|c|c|c|}
\hline $\begin{array}{l}\text { Factor } \\
\text { summarized } \\
\text { (subtheme) }\end{array}$ & $\begin{array}{l}\text { Name of factor } \\
\text { in literature }\end{array}$ & Description of factor in literature & References \\
\hline \multirow[t]{13}{*}{$\begin{array}{l}\text { Program } \\
\text { financing }\end{array}$} & Project financing & $\begin{array}{l}\text { Enough sources to fund the program (internal, external, } \\
\text { mixture). Community can afford the program. }\end{array}$ & $\begin{array}{l}\text { Shediac- } \\
\text { Rizkallah \& } \\
\text { Bone, } 1998\end{array}$ \\
\hline & Financing & $\begin{array}{l}\text { Availability of sources of funds for continuing project } \\
\text { activities after donor's funding for a project stops. }\end{array}$ & $\begin{array}{l}\text { Bossert, } \\
1990\end{array}$ \\
\hline & $\begin{array}{l}\text { Financial } \\
\text { resources } \\
\text { for needs } \\
\text { assessment }\end{array}$ & $\begin{array}{l}\text { Financial resources for community needs assessment to } \\
\text { ensure the program fits with the community and policy } \\
\text { environment. }\end{array}$ & $\begin{array}{l}\text { Casey et al., } \\
2009\end{array}$ \\
\hline & Financing & Ability to generate enough (new) financial resources. & $\begin{array}{l}\text { Casey et al., } \\
2009\end{array}$ \\
\hline & $\begin{array}{l}\text { Relationship } \\
\text { with funder }\end{array}$ & Good relationship with funder. & $\begin{array}{l}\text { Casey et al., } \\
2009\end{array}$ \\
\hline & Financing & $\begin{array}{l}\text { Prospects for the program to acquire or generate some } \\
\text { additional funds or resources for the future are good. }\end{array}$ & $\begin{array}{l}\text { Hawe et al., } \\
1999\end{array}$ \\
\hline & Financing & Enough financial resources. & $\begin{array}{l}\text { Swerissen \& } \\
\text { Crisp, } 2004\end{array}$ \\
\hline & $\begin{array}{l}\text { Financial } \\
\text { resources }\end{array}$ & $\begin{array}{l}\text { There are enough financial resources available to use } \\
\text { the innovation as intended. }\end{array}$ & $\begin{array}{l}\text { Fleuren et } \\
\text { al., } 2014\end{array}$ \\
\hline & Funding & No description. & $\begin{array}{l}\text { Wiltsey } \\
\text { Stirman et } \\
\text { al., } 2012\end{array}$ \\
\hline & Funding stability & $\begin{array}{l}\text { Establishing a consistent financial base for the program: } \\
\text { the program is funded through a variety of sources; } \\
\text { the program has a combination of stable and flexible } \\
\text { funding; the program has sustained funding. }\end{array}$ & $\begin{array}{l}\text { Schell et al., } \\
2013\end{array}$ \\
\hline & $\begin{array}{l}\text { Financial } \\
\text { resources }\end{array}$ & $\begin{array}{l}\text { The organization (National Sports Federation/sports } \\
\text { club) has sufficient financial resources available to } \\
\text { continue the program. }\end{array}$ & $\begin{array}{l}\text { Ooms et al., } \\
2015\end{array}$ \\
\hline & $\begin{array}{l}\text { Funding from } \\
\text { other sources }\end{array}$ & $\begin{array}{l}\text { Funding from other sources, particularly the availability } \\
\text { of a larger number of funding sources or the transfer of } \\
\text { support to local governmental sources. }\end{array}$ & $\begin{array}{l}\text { Scheirer, } \\
2005\end{array}$ \\
\hline & Securing funding & $\begin{array}{l}\text { Secure and maintain sustainable funding: diverse } \\
\text { funding sources, partnering with others for financial } \\
\text { resources taking into account their needs. }\end{array}$ & $\begin{array}{l}\text { Whitley et } \\
\text { al., } 2015\end{array}$ \\
\hline $\begin{array}{l}\text { Program } \\
\text { integration }\end{array}$ & $\begin{array}{l}\text { Integration } \\
\text { with existing } \\
\text { programs/ } \\
\text { services }\end{array}$ & $\begin{array}{l}\text { Program is integrated into the standard operating } \\
\text { practices of its host organization. The mission of the } \\
\text { program is compatible with the mission and activities of } \\
\text { its host organization. }\end{array}$ & $\begin{array}{l}\text { Shediac- } \\
\text { Rizkallah \& } \\
\text { Bone, } 1998\end{array}$ \\
\hline
\end{tabular}


Table A6.1.4 Factors within the organizational setting (of NSF/sports club) (continued)

\begin{tabular}{|c|c|c|c|}
\hline $\begin{array}{l}\text { Factor } \\
\text { summarized } \\
\text { (subtheme) }\end{array}$ & $\begin{array}{l}\text { Name of factor } \\
\text { in literature }\end{array}$ & Description of factor in literature & References \\
\hline \multirow{7}{*}{$\begin{array}{l}\text { Program } \\
\text { integration } \\
\text { (continued) }\end{array}$} & $\begin{array}{l}\text { Project } \\
\text { integration }\end{array}$ & $\begin{array}{l}\text { Project is integrated into the existing institutional } \\
\text { hierarchies. }\end{array}$ & $\begin{array}{l}\text { Bossert, } \\
1990\end{array}$ \\
\hline & $\begin{array}{l}\text { Complementary } \\
\text { to and } \\
\text { integration } \\
\text { in existing } \\
\text { programs }\end{array}$ & $\begin{array}{l}\text { Program complements other programs and is integrated } \\
\text { within existing programs. }\end{array}$ & $\begin{array}{l}\text { Casey et al., } \\
2009\end{array}$ \\
\hline & $\begin{array}{l}\text { Integration } \\
\text { in host } \\
\text { organization }\end{array}$ & $\begin{array}{l}\text { Part of the program's essential 'business' is integrated } \\
\text { into other aspects of the host organization, e.g. in policies, } \\
\text { practices, responsibilities, etc. That is, the program does } \\
\text { not simply exist as an entirely separate entity. }\end{array}$ & $\begin{array}{l}\text { Hawe et al., } \\
1999\end{array}$ \\
\hline & $\begin{array}{l}\text { Integration of } \\
\text { rules/policies }\end{array}$ & Integration of program into policies. & $\begin{array}{l}\text { Wiltsey } \\
\text { Stirman et } \\
\text { al., } 2012\end{array}$ \\
\hline & $\begin{array}{l}\text { Integration in } \\
\text { policies }\end{array}$ & $\begin{array}{l}\text { The program implements policies to help ensure } \\
\text { sustained funding. }\end{array}$ & $\begin{array}{l}\text { Schell et al., } \\
2013\end{array}$ \\
\hline & $\begin{array}{l}\text { Program } \\
\text { integration }\end{array}$ & $\begin{array}{l}\text { The program is well integrated into the operations of the } \\
\text { organization. }\end{array}$ & $\begin{array}{l}\text { Schell et al., } \\
2013\end{array}$ \\
\hline & $\begin{array}{l}\text { Integration in } \\
\text { policy }\end{array}$ & $\begin{array}{l}\text { The program is part of the organization's (National } \\
\text { Sports Federation/sports club) long-term policy. }\end{array}$ & $\begin{array}{l}\text { Ooms et al., } \\
2015\end{array}$ \\
\hline \multirow[t]{7}{*}{$\begin{array}{l}\text { Program } \\
\text { champion } \\
\text { (internal) }\end{array}$} & $\begin{array}{l}\text { Program } \\
\text { champion/ } \\
\text { leadership }\end{array}$ & $\begin{array}{l}\text { Influential individuals within the organization are } \\
\text { advocates of continuation of the program (or external } \\
\text { program champion). }\end{array}$ & $\begin{array}{l}\text { Shediac- } \\
\text { Rizkallah \& } \\
\text { Bone, } 1998\end{array}$ \\
\hline & $\begin{array}{l}\text { Program } \\
\text { champion }\end{array}$ & $\begin{array}{l}\text { Influential individuals within the organization that act } \\
\text { as advocates of continuation of the program. }\end{array}$ & $\begin{array}{l}\text { Casey et al., } \\
2009\end{array}$ \\
\hline & $\begin{array}{l}\text { Program } \\
\text { champion }\end{array}$ & $\begin{array}{l}\text { There is someone in authority or seniority, other than } \\
\text { the director of the program itself, who is an advocate } \\
\text { for the program at high levels in the organization. }\end{array}$ & $\begin{array}{l}\text { Hawe et al., } \\
1999\end{array}$ \\
\hline & $\begin{array}{l}\text { Champions } \\
\text { (internal) }\end{array}$ & No description. & $\begin{array}{l}\text { Wiltsey } \\
\text { Stirman et } \\
\text { al., } 2012\end{array}$ \\
\hline & $\begin{array}{l}\text { Program } \\
\text { champion }\end{array}$ & Champions exist who strongly support the program. & $\begin{array}{l}\text { Schell et al., } \\
2013\end{array}$ \\
\hline & $\begin{array}{l}\text { Program } \\
\text { champion with } \\
\text { ability to garner } \\
\text { resources }\end{array}$ & $\begin{array}{l}\text { The program has strong champions with the ability to } \\
\text { garner resources. }\end{array}$ & $\begin{array}{l}\text { Schell et al., } \\
2013\end{array}$ \\
\hline & $\begin{array}{l}\text { Program } \\
\text { champion }\end{array}$ & $\begin{array}{l}\text { A person who is strategically located to have access to } \\
\text { upper management and also has influence on, or control } \\
\text { over, day-to-day program operations. The champion } \\
\text { enthusiastically advocates for the needs of the program, } \\
\text { particularly to help secure resources for its continuation. }\end{array}$ & $\begin{array}{l}\text { Scheirer, } \\
2005\end{array}$ \\
\hline
\end{tabular}


Table A6.1.4 Factors within the organizational setting (of NSF/sports club) (continued)

\begin{tabular}{|c|c|c|c|}
\hline $\begin{array}{l}\text { Factor } \\
\text { summarized } \\
\text { (subtheme) }\end{array}$ & $\begin{array}{l}\text { Name of factor } \\
\text { in literature }\end{array}$ & Description of factor in literature & References \\
\hline \multirow[t]{6}{*}{$\begin{array}{l}\text { Program's } \\
\text { compatibility } \\
\text { with organiza- } \\
\text { tion's mission } \\
\text { and activities }\end{array}$} & $\begin{array}{l}\text { Health } \\
\text { promotion fits } \\
\text { organization's } \\
\text { mission }\end{array}$ & $\begin{array}{l}\text { The organization's needs and interests fit the goals of } \\
\text { the intervention study. }\end{array}$ & $\begin{array}{l}\text { Weisbrod et } \\
\text { al., } 1992\end{array}$ \\
\hline & $\begin{array}{l}\text { Compatibility } \\
\text { of the program } \\
\text { with the core } \\
\text { values and focus } \\
\text { areas of the } \\
\text { organization }\end{array}$ & $\begin{array}{l}\text { Program aligns with organizational values and } \\
\text { focus areas, such as capacity building, partnership } \\
\text { development and participation in physical activity. }\end{array}$ & $\begin{array}{l}\text { Casey et al., } \\
2009\end{array}$ \\
\hline & $\begin{array}{l}\text { Program mission } \\
\text { is compatible } \\
\text { with mission and } \\
\text { activities of host } \\
\text { organization }\end{array}$ & $\begin{array}{l}\text { The mission of the program is compatible with the } \\
\text { mission and activities of the intended host organization. }\end{array}$ & $\begin{array}{l}\text { Hawe et al., } \\
1999\end{array}$ \\
\hline & Compatibility & $\begin{array}{l}\text { The innovation is compatible with the values and } \\
\text { working method in place. }\end{array}$ & $\begin{array}{l}\text { Fleuren et } \\
\text { al., } 2014\end{array}$ \\
\hline & Fit & $\begin{array}{l}\text { The fit of the program or intervention with the system } \\
\text { or organization. }\end{array}$ & $\begin{array}{l}\text { Wiltsey } \\
\text { Stirman et } \\
\text { al., } 2012\end{array}$ \\
\hline & Fit & $\begin{array}{l}\text { The program fits with its organization's existing } \\
\text { mission and standard operating procedures. }\end{array}$ & $\begin{array}{l}\text { Scheirer, } \\
2005\end{array}$ \\
\hline \multirow[t]{5}{*}{$\begin{array}{l}\text { Organizational } \\
\text { strength }\end{array}$} & $\begin{array}{l}\text { Institutional } \\
\text { strength }\end{array}$ & $\begin{array}{l}\text { Mature (developed, stable, resourceful) organization } \\
\text { that is implementing the program (host organization). }\end{array}$ & $\begin{array}{l}\text { Shediac- } \\
\text { Rizkallah \& } \\
\text { Bone, } 1998\end{array}$ \\
\hline & $\begin{array}{l}\text { Institutional } \\
\text { strength }\end{array}$ & $\begin{array}{l}\text { Strong well-integrated implementing institutions with } \\
\text { goal structures that are consistent with the project } \\
\text { goals, that have strong leadership and relatively high } \\
\text { skill levels. }\end{array}$ & $\begin{array}{l}\text { Bossert, } \\
1990\end{array}$ \\
\hline & $\begin{array}{l}\text { Organization } \\
\text { with mature } \\
\text { subsystems }\end{array}$ & $\begin{array}{l}\text { Mature organization that is implementing the program, } \\
\text { having independent resources and staff. Working } \\
\text { through existing larger organizations. }\end{array}$ & $\begin{array}{l}\text { Weisbrod et } \\
\text { al., } 1992\end{array}$ \\
\hline & $\begin{array}{l}\text { Mature host } \\
\text { organization }\end{array}$ & $\begin{array}{l}\text { The organization that you intend to host the program in } \\
\text { de future is mature (developed, stable, resourceful). It } \\
\text { is likely to provide a strong organizational base for the } \\
\text { program. }\end{array}$ & $\begin{array}{l}\text { Hawe et al., } \\
1999\end{array}$ \\
\hline & $\begin{array}{l}\text { Supportive } \\
\text { organizational } \\
\text { systems }\end{array}$ & $\begin{array}{l}\text { Organizational systems are in place to support the } \\
\text { various program needs. }\end{array}$ & $\begin{array}{l}\text { Schell et al., } \\
2013\end{array}$ \\
\hline
\end{tabular}


Table A6.1.4 Factors within the organizational setting (of NSF/sports club) (continued)

\begin{tabular}{|c|c|c|c|}
\hline $\begin{array}{l}\text { Factor } \\
\text { summarized } \\
\text { (subtheme) }\end{array}$ & $\begin{array}{l}\text { Name of factor } \\
\text { in literature }\end{array}$ & Description of factor in literature & References \\
\hline \multirow[t]{4}{*}{$\begin{array}{l}\text { Internal } \\
\text { support }\end{array}$} & $\begin{array}{l}\text { Support for the } \\
\text { program within } \\
\text { the organization }\end{array}$ & $\begin{array}{l}\text { The program is well supported in the organization. That } \\
\text { is, it is not under threat and there are few rivals in the } \\
\text { organization who could benefit from the closure of the } \\
\text { program. }\end{array}$ & $\begin{array}{l}\text { Hawe et al., } \\
1999\end{array}$ \\
\hline & $\begin{array}{l}\text { Leadership } \\
\text { support within } \\
\text { the larger } \\
\text { organization }\end{array}$ & $\begin{array}{l}\text { The program has leadership support from within the } \\
\text { larger organization. }\end{array}$ & $\begin{array}{l}\text { Schell et al., } \\
2013\end{array}$ \\
\hline & $\begin{array}{l}\text { Formal } \\
\text { ratification by } \\
\text { management }\end{array}$ & $\begin{array}{l}\text { The management has set up formal arrangements in } \\
\text { the organization relating to the use of the innovation (in } \\
\text { policy plans, work plans, etc.). }\end{array}$ & $\begin{array}{l}\text { Fleuren et } \\
\text { al., } 2014\end{array}$ \\
\hline & Ongoing support & No description. & $\begin{array}{l}\text { Wiltsey } \\
\text { Stirman et } \\
\text { al., } 2012\end{array}$ \\
\hline \multirow[t]{3}{*}{ Leadership } & Leadership & No description. & $\begin{array}{l}\text { Wiltsey } \\
\text { Stirman et } \\
\text { al., } 2012\end{array}$ \\
\hline & Leadership & $\begin{array}{l}\text { Leadership effectively articulates the vision of the } \\
\text { program to external partners. }\end{array}$ & $\begin{array}{l}\text { Schell et al., } \\
2013\end{array}$ \\
\hline & Leadership & $\begin{array}{l}\text { Leadership effectively manages staff and other } \\
\text { resources. }\end{array}$ & $\begin{array}{l}\text { Schell et al., } \\
2013\end{array}$ \\
\hline \multirow[t]{3}{*}{ Staff capacity } & Staff capacity & $\begin{array}{l}\text { There are enough people in the organization to use the } \\
\text { innovation as intended. }\end{array}$ & $\begin{array}{l}\text { Fleuren et } \\
\text { al., } 2014\end{array}$ \\
\hline & $\begin{array}{l}\text { Workforce } \\
\text { (staffing, } \\
\text { attributes) }\end{array}$ & $\begin{array}{l}\text { Stability and attributes of workforce, such as their } \\
\text { skills and attitudes. }\end{array}$ & $\begin{array}{l}\text { Wiltsey } \\
\text { Stirman et } \\
\text { al., } 2012\end{array}$ \\
\hline & Adequate staff & $\begin{array}{l}\text { The program has adequate staff to complete the } \\
\text { program goals. }\end{array}$ & $\begin{array}{l}\text { Schell et al., } \\
2013\end{array}$ \\
\hline \multirow[t]{3}{*}{$\begin{array}{l}\text { Retention of } \\
\text { program staff }\end{array}$} & $\begin{array}{l}\text { Retention of } \\
\text { program staff }\end{array}$ & Program staff is retained in the program. & $\begin{array}{l}\text { Casey et al., } \\
2009\end{array}$ \\
\hline & $\begin{array}{l}\text { Retention of } \\
\text { program staff }\end{array}$ & $\begin{array}{l}\text { The program has involved formal and/or informal } \\
\text { training of people whose skills and interests are } \\
\text { retained in the program or its immediate environment. }\end{array}$ & $\begin{array}{l}\text { Hawe et al., } \\
1999\end{array}$ \\
\hline & $\begin{array}{l}\text { Replacement } \\
\text { when staff leave }\end{array}$ & $\begin{array}{l}\text { In the organization, there are arrangements in place } \\
\text { so that staff who use the innovation and leave the } \\
\text { organization are replaced in good time by employees } \\
\text { who are/will be adequately prepared to take over. }\end{array}$ & $\begin{array}{l}\text { Fleuren et } \\
\text { al., } 2014\end{array}$ \\
\hline
\end{tabular}


Table A6.1.4 Factors within the organizational setting (of NSF/sports club) (continued)

\begin{tabular}{|c|c|c|c|}
\hline $\begin{array}{l}\text { Factor } \\
\text { summarized } \\
\text { (subtheme) }\end{array}$ & $\begin{array}{l}\text { Name of factor } \\
\text { in literature }\end{array}$ & Description of factor in literature & References \\
\hline \multirow[t]{2}{*}{$\begin{array}{l}\text { Material } \\
\text { resources and } \\
\text { facilities }\end{array}$} & Resources & No description. & $\begin{array}{l}\text { Wiltsey } \\
\text { Stirman et } \\
\text { al., } 2012\end{array}$ \\
\hline & $\begin{array}{l}\text { Material } \\
\text { resources and } \\
\text { facilities }\end{array}$ & $\begin{array}{l}\text { Presence of materials and other resources or facilities } \\
\text { necessary for the use of the innovation as intended } \\
\text { (such as equipment, material and space). }\end{array}$ & $\begin{array}{l}\text { Fleuren et } \\
\text { al., } 2014\end{array}$ \\
\hline \multirow[t]{2}{*}{$\begin{array}{l}\text { Organizational } \\
\text { change }\end{array}$} & $\begin{array}{l}\text { System/policy } \\
\text { change }\end{array}$ & No description. & $\begin{array}{l}\text { Wiltsey } \\
\text { Stirman et } \\
\text { al., } 2012\end{array}$ \\
\hline & $\begin{array}{l}\text { Unsettled } \\
\text { organization }\end{array}$ & $\begin{array}{l}\text { There are other changes in progress (organizational or } \\
\text { otherwise) that represent obstacles to the process of } \\
\text { implementing the innovation, such as re-organizations, } \\
\text { mergers, cuts, staffing changes or the simultaneous } \\
\text { implementation of different innovations. }\end{array}$ & $\begin{array}{l}\text { Fleuren et } \\
\text { al., } 2014\end{array}$ \\
\hline \multirow[t]{2}{*}{$\begin{array}{l}\text { Strategic } \\
\text { planning }\end{array}$} & Planning & No description. & $\begin{array}{l}\text { Wiltsey } \\
\text { Stirman et } \\
\text { al., } 2012\end{array}$ \\
\hline & $\begin{array}{l}\text { Strategic } \\
\text { planning }\end{array}$ & $\begin{array}{l}\text { Processes are used that guide the program's direction, } \\
\text { goals and strategies: The program plans for future } \\
\text { resource needs, has a long-term financial plan and } \\
\text { has a sustainability plan. The program's goals are } \\
\text { understood by all stakeholders and the program clearly } \\
\text { outlines roles and responsibilities for all stakeholders. }\end{array}$ & $\begin{array}{l}\text { Schell et al., } \\
2013\end{array}$ \\
\hline \multirow[t]{2}{*}{$\begin{array}{l}\text { (Perceived) } \\
\text { benefits }\end{array}$} & $\begin{array}{l}\text { Personal } \\
\text { benefits/ } \\
\text { drawbacks }\end{array}$ & $\begin{array}{l}\text { The innovation has advantages for the user/ } \\
\text { implementer. }\end{array}$ & $\begin{array}{l}\text { Fleuren et } \\
\text { al., } 2014\end{array}$ \\
\hline & $\begin{array}{l}\text { Perceived } \\
\text { benefits }\end{array}$ & $\begin{array}{l}\text { Staff members or key stakeholders perceive benefits to } \\
\text { themselves and/or clients. }\end{array}$ & $\begin{array}{l}\text { Scheirer, } \\
2005\end{array}$ \\
\hline Coordinator & Coordinator & $\begin{array}{l}\text { Presence of one or two persons responsible for } \\
\text { coordinating the implementation of the innovation in } \\
\text { the organization. }\end{array}$ & $\begin{array}{l}\text { Fleuren et } \\
\text { al., } 2014\end{array}$ \\
\hline Time available & Time available & $\begin{array}{l}\text { There is enough time available to use the innovation in } \\
\text { day-to-day (work) activities. }\end{array}$ & $\begin{array}{l}\text { Fleuren et } \\
\text { al., } 2014\end{array}$ \\
\hline $\begin{array}{l}\text { Information } \\
\text { accessible } \\
\text { about use of } \\
\text { innovation }\end{array}$ & $\begin{array}{l}\text { Information } \\
\text { accessible about } \\
\text { use of innovation }\end{array}$ & $\begin{array}{l}\text { It is easy to find information in the organization about } \\
\text { using the innovation as intended. }\end{array}$ & $\begin{array}{l}\text { Fleuren et } \\
\text { al., } 2014\end{array}$ \\
\hline
\end{tabular}


Table A6.1.4 Factors within the organizational setting (of NSF/sports club) (continued)

\begin{tabular}{llll}
\hline $\begin{array}{l}\text { Factor } \\
\text { summarized } \\
\text { (subtheme) }\end{array}$ & $\begin{array}{l}\text { Name of factor } \\
\text { in literature }\end{array}$ & Description of factor in literature & References \\
\hline $\begin{array}{l}\text { Performance } \\
\text { feedback }\end{array}$ & $\begin{array}{l}\text { Performance } \\
\text { feedback }\end{array}$ & $\begin{array}{l}\text { In the organization, feedback is regularly provided } \\
\text { (to the user/implementer) about progress with the } \\
\text { implementation of the innovation. }\end{array}$ & $\begin{array}{l}\text { Fleuren et } \\
\text { al., 2014 }\end{array}$ \\
\hline $\begin{array}{l}\text { Organizational } \\
\text { culture }\end{array}$ & $\begin{array}{l}\text { Organizational } \\
\text { culture }\end{array}$ & No description. & Wiltsey \\
\hline $\begin{array}{l}\text { Organizational } \\
\text { climate }\end{array}$ & $\begin{array}{l}\text { Organizational } \\
\text { climate }\end{array}$ & No description. & Stirman et \\
& & & al., 2012 \\
\hline $\begin{array}{l}\text { Setting } \\
\text { characteristics } \\
\text { (structure, } \\
\text { policies) }\end{array}$ & $\begin{array}{l}\text { Setting } \\
\text { (structure, } \\
\text { policies) }\end{array}$ & No description. & Wiltsey \\
\hline $\begin{array}{l}\text { History of } \\
\text { innovations }\end{array}$ & $\begin{array}{l}\text { History of } \\
\text { innovations }\end{array}$ & $\begin{array}{l}\text { The intended host organization has a history of } \\
\text { innovation or developing new responses to situations in } \\
\text { its environment. }\end{array}$ & Stirman et \\
& & & al., 2012 \\
\hline
\end{tabular}


Table A6.1.5 Factors in the broader community environment

\begin{tabular}{|c|c|c|c|}
\hline $\begin{array}{l}\text { Factor } \\
\text { summarized } \\
\text { (subtheme) }\end{array}$ & $\begin{array}{l}\text { Name of factor } \\
\text { in literature }\end{array}$ & Description of factor in literature & References \\
\hline \multirow[t]{6}{*}{ Partnerships } & $\begin{array}{l}\text { Supportive } \\
\text { partnerships }\end{array}$ & $\begin{array}{l}\text { Network of organizations that advocates for the } \\
\text { program. }\end{array}$ & $\begin{array}{l}\text { Casey et al., } \\
2009\end{array}$ \\
\hline & $\begin{array}{l}\text { Supportive } \\
\text { partnerships }\end{array}$ & $\begin{array}{l}\text { People in the community, or other agencies and } \\
\text { organizations, will advocate for and maintain a } \\
\text { demand for the existence of the program should } \\
\text { it be threatened. }\end{array}$ & $\begin{array}{l}\text { Hawe et al., } \\
1999\end{array}$ \\
\hline & $\begin{array}{l}\text { Supportive } \\
\text { partnerships }\end{array}$ & $\begin{array}{l}\text { Organizations that are similar to the intended } \\
\text { host organization have taken steps of supporting } \\
\text { programs somewhat like your program. }\end{array}$ & $\begin{array}{l}\text { Hawe et al., } \\
1999\end{array}$ \\
\hline & $\begin{array}{l}\text { Collaboration/ } \\
\text { partnership }\end{array}$ & No description. & $\begin{array}{l}\text { Wiltsey Stirman } \\
\text { et al., } 2012\end{array}$ \\
\hline & Partnerships & $\begin{array}{l}\text { Cultivating connections between the program } \\
\text { and its stakeholders. }\end{array}$ & $\begin{array}{l}\text { Schell et al., } \\
2013\end{array}$ \\
\hline & Partnerships & $\begin{array}{l}\text { Creating and maintaining strong, trusting } \\
\text { relationships with community partners: A variety } \\
\text { of partnerships built on mutual trust, which are } \\
\text { formalized, with community members involved } \\
\text { from the start. }\end{array}$ & $\begin{array}{l}\text { Whitley et al., } \\
2015\end{array}$ \\
\hline \multirow[t]{6}{*}{ External support } & $\begin{array}{l}\text { Ongoing } \\
\text { support }\end{array}$ & No description. & $\begin{array}{l}\text { Wiltsey Stirman } \\
\text { et al., } 2012\end{array}$ \\
\hline & Public support & The program has strong public support. & $\begin{array}{l}\text { Schell et al., } \\
2013\end{array}$ \\
\hline & $\begin{array}{l}\text { Community } \\
\text { involvement/ } \\
\text { support }\end{array}$ & No description. & $\begin{array}{l}\text { Wiltsey Stirman } \\
\text { et al., } 2012\end{array}$ \\
\hline & $\begin{array}{l}\text { Commitment } \\
\text { community to } \\
\text { the program }\end{array}$ & $\begin{array}{l}\text { Community members are passionately } \\
\text { committed to the program. }\end{array}$ & $\begin{array}{l}\text { Schell et al., } \\
2013\end{array}$ \\
\hline & $\begin{array}{l}\text { National } \\
\text { commitment }\end{array}$ & No description. & Bossert, 1990 \\
\hline & $\begin{array}{l}\text { Stakeholders } \\
\text { in other } \\
\text { organizations } \\
\text { provide support }\end{array}$ & $\begin{array}{l}\text { Support from other organizations in the } \\
\text { environment, for example, for in-kind resources } \\
\text { such as expert advice in fund-raising, for political } \\
\text { support, or to help mobilize clients to advocate } \\
\text { for new funding. }\end{array}$ & Scheirer, 2005 \\
\hline \multirow[t]{3}{*}{$\begin{array}{l}\text { Community } \\
\text { participation }\end{array}$} & $\begin{array}{l}\text { Community } \\
\text { participation }\end{array}$ & $\begin{array}{l}\text { Involvement of the community in the program } \\
\text { (collective attack, ownership, community } \\
\text { capacity). }\end{array}$ & $\begin{array}{l}\text { Shediac- } \\
\text { Rizkallah \& } \\
\text { Bone, } 1998\end{array}$ \\
\hline & $\begin{array}{l}\text { Community } \\
\text { participation }\end{array}$ & $\begin{array}{l}\text { Involvement of the community in health care } \\
\text { projects. }\end{array}$ & Bossert, 1990 \\
\hline & $\begin{array}{l}\text { Community } \\
\text { involvement/ } \\
\text { support }\end{array}$ & No description. & $\begin{array}{l}\text { Wiltsey Stirman } \\
\text { et al., } 2012\end{array}$ \\
\hline
\end{tabular}


Table A6.1.5 Factors in the broader community environment (continued)

\begin{tabular}{|c|c|c|c|}
\hline $\begin{array}{l}\text { Factor } \\
\text { summarized } \\
\text { (subtheme) }\end{array}$ & $\begin{array}{l}\text { Name of factor } \\
\text { in literature }\end{array}$ & Description of factor in literature & References \\
\hline \multirow{2}{*}{$\begin{array}{l}\text { Community } \\
\text { participation } \\
\text { (continued) }\end{array}$} & $\begin{array}{l}\text { Community } \\
\text { participation }\end{array}$ & $\begin{array}{l}\text { Diverse community organizations are invested in } \\
\text { the success of the program. }\end{array}$ & $\begin{array}{l}\text { Schell et al., } \\
2013\end{array}$ \\
\hline & $\begin{array}{l}\text { Community } \\
\text { involvement } \\
\text { and ownership }\end{array}$ & $\begin{array}{l}\text { Program is developed, implemented and } \\
\text { evaluated with widespread community } \\
\text { involvement and ownership. }\end{array}$ & $\begin{array}{l}\text { Whitley et al., } \\
2015\end{array}$ \\
\hline \multirow[t]{4}{*}{$\begin{array}{l}\text { Program } \\
\text { champion } \\
\text { (external) }\end{array}$} & $\begin{array}{l}\text { Stakeholder } \\
\text { involvement/ } \\
\text { support }\end{array}$ & No description. & $\begin{array}{l}\text { Wiltsey Stirman } \\
\text { et al., } 2012\end{array}$ \\
\hline & $\begin{array}{l}\text { Leadership } \\
\text { support from } \\
\text { outside of the } \\
\text { organization }\end{array}$ & $\begin{array}{l}\text { The program has leadership support from } \\
\text { outside of the organization. }\end{array}$ & $\begin{array}{l}\text { Schell et al., } \\
2013\end{array}$ \\
\hline & $\begin{array}{l}\text { Involvement } \\
\text { community } \\
\text { leaders }\end{array}$ & $\begin{array}{l}\text { Community leaders are involved with the } \\
\text { program. }\end{array}$ & $\begin{array}{l}\text { Schell et al., } \\
2013\end{array}$ \\
\hline & $\begin{array}{l}\text { Champions } \\
\text { (external) }\end{array}$ & No description. & $\begin{array}{l}\text { Wiltsey Stirman } \\
\text { et al., } 2012\end{array}$ \\
\hline \multirow[t]{4}{*}{ Policy factors } & $\begin{array}{l}\text { Socioeconomic } \\
\text { and political } \\
\text { considerations }\end{array}$ & $\begin{array}{l}\text { Favorable socioeconomic and political } \\
\text { environment. }\end{array}$ & $\begin{array}{l}\text { Shediac- } \\
\text { Rizkallah \& } \\
\text { Bone, } 1998\end{array}$ \\
\hline & Political factors & $\begin{array}{l}\text { Strong governmental institutions, good political } \\
\text { infrastructure, stable regime (Africa). }\end{array}$ & Bossert, 1990 \\
\hline & $\begin{array}{l}\text { Alignment with } \\
\text { policy }\end{array}$ & $\begin{array}{l}\text { There is a favorable external environment for } \\
\text { the program, that is, the values and mission fit } \\
\text { well with community opinion, and the policy } \\
\text { environment. }\end{array}$ & $\begin{array}{l}\text { Hawe et al., } \\
1999\end{array}$ \\
\hline & $\begin{array}{l}\text { Legislation and } \\
\text { regulations }\end{array}$ & $\begin{array}{l}\text { The innovation fits within existing legislation } \\
\text { and regulations established by the competent } \\
\text { authorities (e.g. financial structures, substantive } \\
\text { law and supervision from the Dutch Health Care } \\
\text { Inspectorate or the Dutch Care Authority). }\end{array}$ & $\begin{array}{l}\text { Fleuren et al., } \\
2014\end{array}$ \\
\hline \multirow[t]{3}{*}{ Economic factors } & $\begin{array}{l}\text { Socioeconomic } \\
\text { and political } \\
\text { considerations }\end{array}$ & $\begin{array}{l}\text { Favorable socioeconomic and political } \\
\text { environment. }\end{array}$ & $\begin{array}{l}\text { Shediac- } \\
\text { Rizkallah \& } \\
\text { Bone, } 1998\end{array}$ \\
\hline & $\begin{array}{l}\text { Economic } \\
\text { factors }\end{array}$ & Economic growth, strong economies (Africa). & Bossert, 1990 \\
\hline & $\begin{array}{l}\text { Supportive } \\
\text { state economic } \\
\text { climate }\end{array}$ & $\begin{array}{l}\text { The program exists in a supportive state } \\
\text { economic climate. }\end{array}$ & $\begin{array}{l}\text { Schell et al., } \\
2013\end{array}$ \\
\hline
\end{tabular}


Table A6.1.5 Factors in the broader community environment (continued)

\begin{tabular}{|c|c|c|c|}
\hline $\begin{array}{l}\text { Factor } \\
\text { summarized } \\
\text { (subtheme) }\end{array}$ & $\begin{array}{l}\text { Name of factor } \\
\text { in literature }\end{array}$ & Description of factor in literature & References \\
\hline \multirow{3}{*}{$\begin{array}{l}\text { Program } \\
\text { alignment with } \\
\text { community } \\
\text { opinion }\end{array}$} & $\begin{array}{l}\text { Alignment with } \\
\text { community } \\
\text { opinion }\end{array}$ & Program aligns with community opinion (needs). & $\begin{array}{l}\text { Casey et al., } \\
2009\end{array}$ \\
\hline & $\begin{array}{l}\text { Alignment with } \\
\text { community } \\
\text { opinion }\end{array}$ & $\begin{array}{l}\text { There is a favorable external environment for } \\
\text { the program, that is, the values and mission fit } \\
\text { well with community opinion, and the policy } \\
\text { environment. }\end{array}$ & $\begin{array}{l}\text { Hawe et al., } \\
1999\end{array}$ \\
\hline & $\begin{array}{l}\text { Meaningful } \\
\text { objectives }\end{array}$ & $\begin{array}{l}\text { Program objectives meet the needs and interests } \\
\text { of the community and the individuals. }\end{array}$ & $\begin{array}{l}\text { Whitley et al., } \\
2015\end{array}$ \\
\hline \multirow[t]{2}{*}{$\begin{array}{l}\text { Communication } \\
\text { (external) }\end{array}$} & $\begin{array}{l}\text { Communication } \\
\text { with community } \\
\text { leaders }\end{array}$ & $\begin{array}{l}\text { The program communicates with community } \\
\text { leaders. }\end{array}$ & $\begin{array}{l}\text { Schell et al., } \\
2013\end{array}$ \\
\hline & Communications & $\begin{array}{l}\text { Strategic communication with stakeholders and } \\
\text { the public about the program. }\end{array}$ & $\begin{array}{l}\text { Schell et al., } \\
2013\end{array}$ \\
\hline $\begin{array}{l}\text { (Perceived) } \\
\text { benefits } \\
\text { stakeholders }\end{array}$ & $\begin{array}{l}\text { Perceived } \\
\text { benefits }\end{array}$ & $\begin{array}{l}\text { Staff members or key stakeholders perceive } \\
\text { benefits to themselves and/or clients. }\end{array}$ & Scheirer, 2005 \\
\hline $\begin{array}{l}\text { Socio-cultural } \\
\text { factors }\end{array}$ & $\begin{array}{l}\text { Socio-cultural } \\
\text { factors }\end{array}$ & No description. & Bossert, 1990 \\
\hline Natural disasters & $\begin{array}{l}\text { Natural } \\
\text { disasters }\end{array}$ & No description. & Bossert, 1990 \\
\hline Private sector & Private sector & No description. & Bossert, 1990 \\
\hline $\begin{array}{l}\text { Donor } \\
\text { coordination }\end{array}$ & $\begin{array}{l}\text { Donor } \\
\text { coordination }\end{array}$ & No description. & Bossert, 1990 \\
\hline
\end{tabular}




\section{APPENDIX 6.2}

\section{Number of interviews with sports clubs}

Table A6.2.1 Number of telephone interviews with representatives of sports clubs

\begin{tabular}{lll}
\hline NAPSE sporting program & $\begin{array}{l}\text { Included sports clubs that } \\
\text { continued the sporting } \\
\text { program (n) }\end{array}$ & $\begin{array}{l}\text { Included sports clubs that } \\
\text { discontinued the sporting } \\
\text { program (n) }\end{array}$ \\
\hline Start to Run (Yakult Start to Run*) & 1 & 2 \\
Judo in School & 1 & 2 \\
Through 4 Days Marches & 1 & 2 \\
Working by Walking & 0 & 1 \\
Trendy Weeks for Masters (Flexible*) & 2 & 1 \\
Fit Hockey & 2 & 0 \\
My Swimming Coach & 0 & 0 \\
Thinking and Doing & 2 & 2 \\
Cycle-Fit (Start2Bike*) & 2 & 1 \\
Cycle \& Enjoy Nature & 2 & 0 \\
Trio-Triathlon & 1 & 0 \\
Beach Volleyball & 1 & 0 \\
Cool Moves Volley & 2 & 0 \\
Ultimate Volley Xperience & 0 & 0 \\
Total & 17 & 11 \\
\hline
\end{tabular}

NAPSE National Action Plan for Sport and Exercise

*Current name sporting program. 


\section{APPENDIX 6.3}

\section{Interview guide sports clubs continued}

\section{Interview guide: sports clubs that continued the sporting program}

Date of interview:

Method of interview (face-to-face/telephone interview):

Sporting program:

Sports club:

Number of members of sports club:

\section{Background information respondent:}

Name:

Function within sports club:

Number of years employed with the sports club:

Involved in the sporting program since (year):

Gender:

Age:

\section{Implementation/progress program:}

When did the sports club start providing <<name sporting program $>>$ ?

What happened with <<name sporting program $>>$ in the years thereafter (important moments/changes)?

What are the most important reasons for the sports club to continue offering $<<$ name sporting program $>>$ ?

\section{Program design:}

How does the sports club provide <<name sporting program>> (type of activities, duration and frequency of training sessions, group size, etc.)? Did (the content of) the sporting program change since the start?

- If yes, what has changed, when and why?

- If no, why not?

What is the current target group of <<name sporting program $>>$ ?

- <<name sporting program >> was part of the National Action Plan for Sport and Exercise (NAPSE). Within the NAPSE, the focus was on inactive target groups. Are inactive people still (part of) the target group? Please explain why they are or are not (part of) the target group (anymore).

- Are you able to reach/include inactive people with <<name sporting program >>?

- If yes, how do you reach/include inactive people?

- If no, why not? 
How often does the sports club provide the activities per year?

How many participants are there (on average) per activity per year?

- How many participants become (on average) member of the sports club due to participation in $<<$ name sporting program $>>$ ?

\section{Organizational setting sports club:}

How is <<name sporting program>> organized/run within the sports club (who is involved, what are their roles and tasks)? Did the organization of the sporting program change during the years? If yes, how and why?

- Does the National Sports Federation still provide support to the sports club to run $<<$ name sporting program $>>$ ?

- If yes, how?

- If no, why not?

- Does the sporting program fit with the sports club's tasks and aims? If yes/no, please explain.

- Is there (sufficient) support for the sporting program within the sports club? If yes/no, please explain.

. Is the sporting program part of the sports club's long-term policy?

- Is implementation of <<name sporting program >> by the sports club financially secured (e.g. with sponsorship, participant fees)? If yes/no, please explain.

\section{Trainer/coach:}

Did the sports club recruit new trainers and/or are trainers (within the club) educated to run $<<$ name sporting program $>>$ ? And if yes, are they still available to the club?

- Are there sufficient (educated) trainers?

Are there possibilities to educate new trainers and/or are there extra training options (refreshment courses) for current trainers?

\section{Broader community environment:}

Did the sports club collaborate with other people/organizations to run $<<$ name sporting program >>?

- If yes, with whom and how?

- Does the sports club still collaborate with these people/organizations?

- Are partnerships for <<name sporting program>> stopped? If yes, with whom and why?

- Is there (sufficient) support for the sporting program outside the sports club (e.g. with the target group, in the community, with partners)? If yes/no, please explain.

\section{Results/effects of sporting program:}

What are the most important results of <<name sporting program >> for the sports club? Is <<name sporting program >> of added value to the sports club in comparison with already existing/regular activities? 
What are the most important results/effects of <<name sporting program $>>$ with participants? Do they enjoy participating in the program?

. Do participants of <<name sporting program >> keep participating in the sport (inside/ outside the club)? And how do you encourage this?

\section{Facilitating and impeding factors for continuation of the sporting program:}

When considering all that is previously discussed:

- What are the most important factors that facilitated/supported continuation of <<name sporting program >> by your sports club?

- Are there any factors that impeded continuation of $<<$ name sporting program $>>$ by your sports club?

\section{Future of sporting program:}

Does your sports club intend to provide <<name sporting program >> in the future?

- If yes, how?

- If no, why not? Is the sporting program replaced by other activities?

Are there any challenges/barriers for your sports club to continue the sporting program in the future?

\section{Remaining remarks:}

Do you have anything to add to this interview? For example, something that is important for (continuance of) <<name sporting program >>, but what we did not discuss before. 


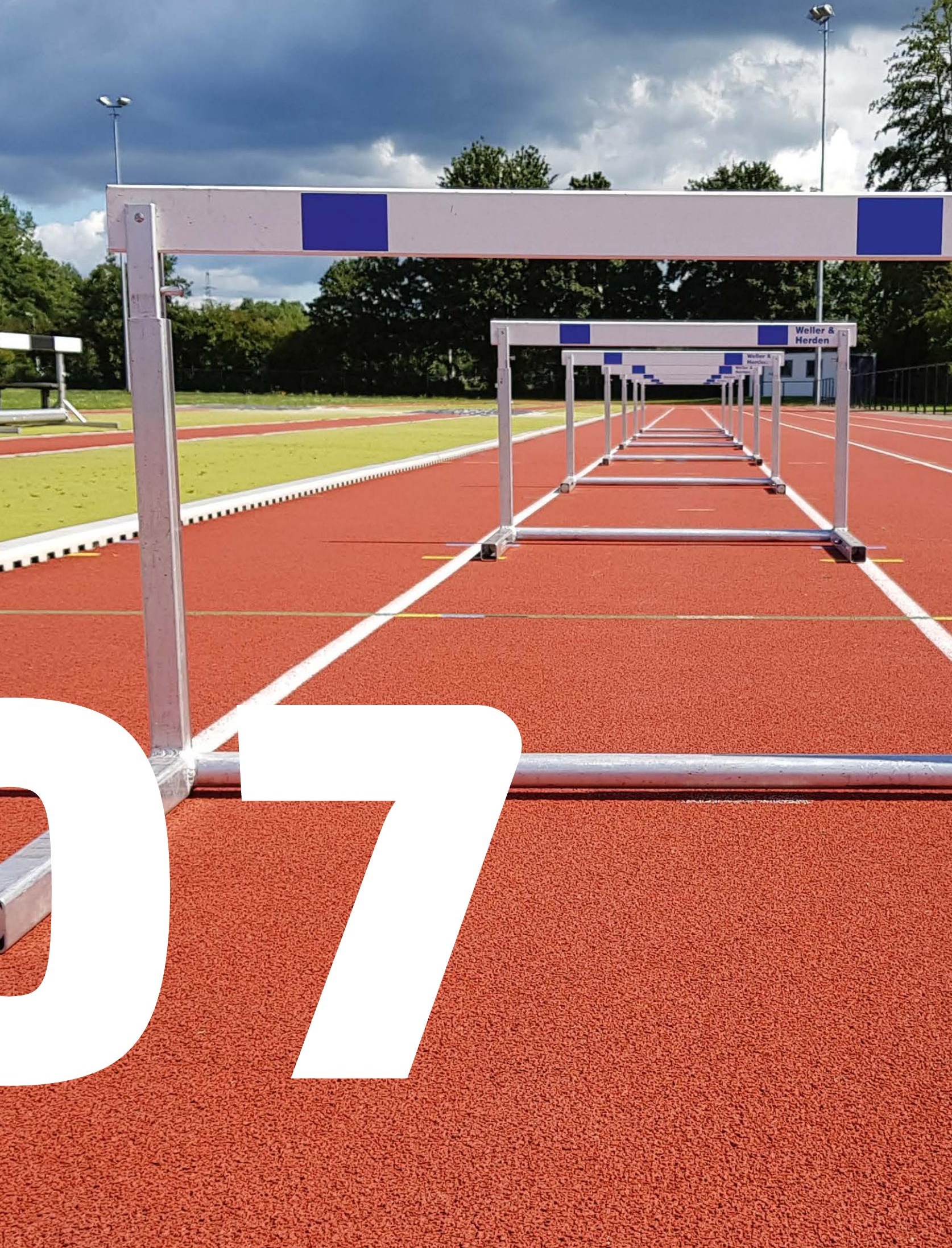



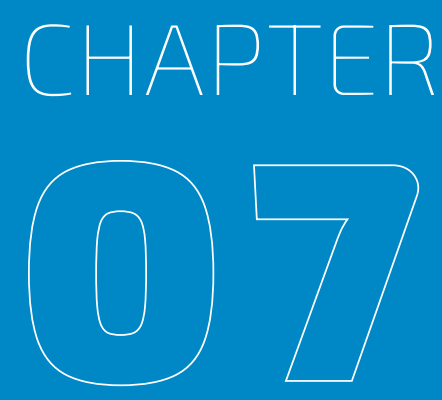

General discussion 
Physical inactivity increases the risk for chronic diseases and mortality, and is a problem faced by countries worldwide [1-7]. Strategies to promote physical activity among inactive target groups are therefore necessary. In this regard, a settings-based approach towards physical activity promotion has been encouraged $[8,9]$.

The main focus of this thesis was to understand if and how the organized sports setting can successfully contribute to increasing physical activity levels of inactive people. Fourteen Dutch sporting programs aimed at increasing sport participation among inactive population groups were studied during the three-year funded implementation period and six and half years thereafter. These programs were developed by ten National Sports Federations (NSFs) as part of the National Action Plan for Sport and Exercise (NAPSE) and implemented by sports clubs in the Netherlands. The research in this thesis focused on the effectiveness of two programs within the NAPSE (i.e. Start to Run and Start2Bike) and characteristics of insufficiently active participants who benefited the most from these programs (i.e. from Start to Run, Start2Bike and Through 4 Days Marches) in terms of increasing healthenhancing physical activity. Furthermore, factors influencing the implementation and longterm sustainability of all NAPSE programs were examined. In this final chapter, the main findings are put into perspective and discussed. This chapter also addresses methodological considerations, practical implications and suggestions for future research.

\section{Short- and long-term effectiveness}

Chapters 2 and 3 showed that a six-week sporting program provided by a sports club can be effective in stimulating health-enhancing physical activity in both the short- and longterm. However, this conclusion is based only on the effectiveness evaluations of two NAPSE sporting programs (Start to Run and Start2Bike). Physical activity levels of participants in all NAPSE sporting program were monitored during the first year of the implementation period. The research results have been described in a publicly accessible report [10]. However, there were several research limitations in the monitoring of most NAPSE sporting programs, such as a low number of participants/respondents (4 programs), unavailability of a suited control group (3 programs) and inability to determine the response when paper questionnaires were distributed by trainers (2 programs). Furthermore, two NAPSE sporting programs consisted of one-day sporting events. It was unlikely that these programs would result in long-term changes in physical activity behavior of participants. Therefore, the physical activity data collected for these NAPSE sporting programs were not suitable for an effectiveness evaluation or more in-depth analyses, with the exception of the six-month Through 4 Days Marches program. This program showed positive effects on physical activity behavior of participants six months after starting the program (see also chapter 4).

Two recently published international studies support our results that physical activity promotion programs, a few weeks in duration and provided by sports clubs, may be used to increase physical activity levels of inactive people in the short-term [11, 12]. However, for the long-term effects, the results in the literature are not convincing. In England, 33 
pilot projects designed to support inactive people in increasing physical activity resulted in increased sport participation by the target group after three months. However, long-term effects of these projects were not yet measured at the time of publication [11]. In Austria, inactive adults who attended a residential stay in a health resort, received a coupon for twelve, free (weekly) sessions of a supervised exercise program in a sports club in their home region. Although physical activity levels of participants increased four months after baseline, this increase was not maintained nine months after the last free training session [12]. Thus, while sporting programs that are few weeks in duration may be used to increase physical activity levels of inactive people in the sports clubs setting, this does not guarantee that these increases are maintained in the long term. Therefore, suitable follow-up activities should be provided at the sports club (see next paragraph).

\section{Characteristics of effective sporting programs}

The three effective NAPSE sporting programs Start to Run, Start2Bike and Through 4 Days Marches, share some common program design characteristics: a very low threshold for participation; the use of graded training programs with feasible sports; guidance of participants by educated trainers; low participation costs; and follow-up activities in a beginner group at the sports club. These program characteristics may be important to inactive people in starting and continuing sport participation. Furthermore, these characteristics may help participants overcome some of the personal barriers that they may experience when engaging in sport, such as high participation costs and a lack of past sport experiences [13-16]. In addition, the research results in chapter 4 showed that these programs (i.e. Start to Run, Start2Bike and Through 4 Days Marches) were more effective in increasing physical activity when participants received familial support with regard to their sport participation. Lack of familial support, sometimes in combination with cultural norms and barriers, is an important barrier for inactive people towards sport participation [14, 15]. Therefore, adding familial support strategies as a component of these kind of sporting programs can be effective in stimulating sport participation. The sports club can be an ideal setting to involve family members as active (e.g. as a sporting buddy) or passive (e.g. as a volunteer) participants. However, more research is needed to determine which familial support strategies are most beneficial to increase participant's sport participation in this setting.

To promote physical activity, it is important to understand what prevents people from being active so that programs can be tailored to the needs, wishes and possibilities of the inactive target group (see chapters 5 and 6 ). This could be achieved by giving inactive people a role in the development and implementation of programs, which may lead to more support for the program by the target group $[17,18]$. This in turn could help in recruiting this target group (see next paragraph). It should be noted that in the past few years, both nationally and internationally, policy makers and professionals working in the sports and health sectors, have become more aware of the importance of including the target group in program design [e.g. 9, 19-21]. 


\section{Recruiting inactive people}

Although the NAPSE sporting programs succeeded in reaching insufficiently active people, it was difficult to recruit large numbers of people who were completely inactive using generic recruitment strategies (e.g. poster, flyers, social media) (see chapters 5 and 6). Also, other research has shown that it is difficult to attract inactive people to sport activities using these recruitment methods $[11,20]$. Therefore, targeted recruitment strategies are necessary to reach inactive people (see chapter 6). Targeted recruitment strategies were successful in recruiting inactive people in similar sporting programs in the Netherlands, as well as in other countries. Sports clubs collaborated, for instance, with health professionals, health resorts and welfare organizations, to recruit inactive people for their sport activities $[11,12,20,22]$. However, collaborations between the sport, health and welfare sectors are not self-evident. Our results showed that trainers of sports clubs did not always have the knowledge or resources to get in contact with the inactive target group (see chapters 5 and 6). Other research shows that sports clubs may be unaware of some relevant parties, such as intermediaries, who are key persons within the community that have strong contact with certain inactive population groups [20,22]. Therefore, in order to recruit and engage inactive people, it is important to educate trainers about relevant people or organizations within a community and support trainers in making connections. Simultaneously, primary care health professionals are not always aware of the sport and physical activity opportunities available, or do not know whether these opportunities are suitable for their inactive patients [23-25]. In this regard, creating opportunities for sports clubs to meet with other clubs and organizations in the community and exchange knowledge and best practices, can be helpful [18].

In addition to proper recruitment channels, attention should be paid to the way sport activities are promoted. Unfamiliarity with the NAPSE sporting programs and the perception of some sports prevented inactive people from participating in these programs (see chapter 5). These individual barriers to sport are also found in the literature [11, 13-16]. In contrast to these barriers, the research results showed that the fun and social aspects of programs were very important motives for (previously) inactive people to attend and keep attending programs (see chapter 6 ). By reframing the message of 'sport' by focusing on fun and social aspects of participation, 'sport' may be more appealing to inactive people.

Organizing the sport activities in close proximity to the target group was another facilitating factor in the recruitment of inactive people (see chapter 5). Lack of time and lack of (financial resources for) transport are important barriers for inactive people to attend sport activities that are organized far from their homes [13-15, 26]. By organizing sport activities in their neighborhood, these barriers can be minimized.

Although the aforementioned strategies can enhance recruitment of inactive people, this will not guarantee that they will actually participate in sport. Many inactive people face more complex problems that go beyond sport and physical activity participation, such as a combination of unemployment, financial debts, health problems and cultural issues [11, $14,15]$. To reach these inactive people and find a proper solution to their physical inactivity, 
more collaboration between the organized sports setting and other settings is necessary (see paragraph broader approach to combat physical inactivity).

\section{Planning for successful implementation and long-term sustainability}

The results of the studies in chapters 5 and 6 showed that both the implementation and the long-term sustainability of a program is influenced by many factors during the different program phases (i.e. program development, implementation and continuation) and at the different levels of the setting (i.e. the policy, NSF, sports club and participant level). This highlights the need for multi-strategy, ecological approaches to promote physical activity among inactive people in the organized sports setting. Moreover, many of the influencing factors have to be considered before the program is developed. As mentioned previously, it is important to explore the needs of the inactive target group, but also those of the sports clubs providing the program, so that the program meets the needs of the target group and reflects an understanding of the local delivery context. In addition, making connections with relevant stakeholders in the community to reach and recruit inactive people, as well as considering financial options during and after the funding period, are other examples of necessary actions that should be completed prior to program development. In this regard, using a sustainable business model when addressing broader issues, such as physical inactivity, is seen as important by sporting organizations, but remains a challenge, especially for the traditional, volunteer-run sports clubs [27].

In general, the implementation and long-term sustainability of a program can be seen as a continuous (cyclic) process, wherein the program and implemented strategies must continuously adapt to changing needs of both the target group and the sports clubs, as well as to the environmental conditions. In this sense, regularly monitoring and evaluating a program and implemented strategies is necessary (see chapter 6). Thus, enough time should be reserved for program planning and development, as well as program implementation and evaluation.

\section{Implementation strategies and support for sports clubs}

The present study found several factors relevant to implementation, such as support for the program by sports clubs and the target group, and to the long-term sustainability of a program, such as the availability of supportive partnerships. These factors are comparable to those found in previous research on health promotion programs in the organized sports setting [28-34]. Although much is already known about factors influencing program implementation, the impeding factors found in our research were also observed in more recently implemented sporting programs for inactive target groups [20, 22, 27]. Concurrently, a recent systematic review that aimed to determine the effectiveness of 
strategies to improve the implementation of policies, practices or programs in sporting organizations targeting different health risk behaviors, found only three relevant studies, none of which examined physical inactivity [35]. This suggests that the translation of evidence-based, relevant factors into effective implementation strategies, is lacking. In this regard, the checklists developed in chapters 5 and 6 could be used as a starting point to formulate goals and develop strategies to deal with influencing factors.

Furthermore, our results showed that local sports clubs cannot implement these programs on their own (see chapters 5 and 6). Trainers at local sports clubs need support with regard to recruiting and guiding the inactive target group, as well as with other implementation matters. The NSF should support sports clubs in the form of training and education opportunities and the provision of different implementation materials (e.g. trainer manual, materials for promotion and evaluation), both during and after the implementation period. In addition, the NSF should advise sports clubs on how to create a sustainable business model when providing sport activities for inactive target groups. Finally, the NSF should help sports clubs to make connections with relevant partners in the community and create opportunities to share best practices with other sports clubs.

\section{Settings-based approach}

The Dutch NAPSE program was initiated from a settings-based approach [36]. However, it was initially a top-down approach with the NAPSE sport policy being translated by NSFs into sporting programs for inactive groups and sports clubs implementing these programs. The primary focus was on changes at the personal level, namely increasing physical activity levels of inactive people. A settings-based approach to health promotion requires changes, and thus strategies, at all levels of the setting (i.e. policy, NSF, sports clubs, participants). It starts when people within each level participate to make these changes, requiring bottom-up approaches, such as active participation in the planning, development and implementation of programs [37-42].

A recent systematic mapping review concerning health promotion interventions in sports clubs found that the settings-based approach was not yet applied to sports clubs with interventions targeting only one level of the socio-ecological model, mainly the personal level. However, it was also stated that interventions focusing on the personal level can be a first step to achieve a settings-based approach and that intervention success can convince others, such as trainers, local organizations and potential participants, to participate [43]. The same was observed in the NAPSE sporting programs. During the implementation period, for example, sports clubs were hesitant to implement the sporting programs at first, but resistance ceased when they became familiar with the programs and saw the successes of other sports clubs that had implemented the programs (see chapter 5). Gradually, the different levels of the organized sports setting became more actively involved, leading to, among other things, the education of trainers, the integration of the sporting programs into the policy and activities of NSFs and sports clubs, collaborations with other organizations 
and more participants. Also, the monitoring and evaluation of processes and effects became important, especially for NSFs (see chapters 5 and 6). Nonetheless, when a settings-based approach was applied from the start, involving people from all levels of the setting, many of the impeding factors (see chapters 5 and 6 ) could have been avoided.

\section{Broader approach to combat physical inactivity}

The research results in this thesis show that the organized sports sector can be used as a setting to increase the physical activity levels of some inactive people. However, for other inactive people, participation in organized sports is not the best solution to their inactivity. Settings-based approaches acknowledge that people live their lives in different settings, and that initiatives in one setting prioritize networking with and establishing links to initiatives in other settings [37-39, 41]. NSFs and sports clubs, therefore, cannot solve the problem of physical inactivity in the Dutch population on their own. Solutions to complex health (behavior) problems, such as physical inactivity, require collaborations between settings, such as in a whole system approach. A whole system approach includes both the participation of the target group and a broad-range of stakeholders to understand the root of the problem of physical inactivity and to support the identification and testing of solutions. This is a long-term endeavor, often delivered through incremental steps, and in collaboration with many partners [37-39, 41]. A whole system approach could, therefore, lead to different solutions (in other settings) for people to be more physically active. Examples include initial guidance from a physical therapist to minimize fear of movement and injury; promotion of physical activity during daily activities, such as gardening or cycling to the store instead of taking the car; changes in the physical environment to stimulate active transportation in the community; or a combination of solutions in different settings. Some NSFs and sports clubs, who participated in the NAPSE program, have already made good progress by collaborating with relevant stakeholders in the community. Furthermore, in general, policy makers and professionals working in the sports and health sectors, have become more aware of the need for multisectoral partnerships to increase population levels of physical activity [e.g. 9, 19-21]. However, more work needs to be done, by NSFs, sports clubs and actors in other settings, to combat physical inactivity through a whole system approach.

\section{Methodological considerations}

Several research designs were used in this thesis. The strengths and limitations of each research design have been described in the previous chapters. This section will focus on the overall research project.

First, our research focused on the possible role of the organized sports setting in the promotion of physical activity among inactive target groups. For this purpose, sporting 
programs for inactive people that were developed by Dutch NSFs and implemented by Dutch sports clubs were studied during the three-year implementation period and six and a half years thereafter. Consequently, this research reflects activities in the real-world sport setting and research results are directly applicable to practice.

Second, in our studies and in previous research regarding the pilot [44] and implementation phase [10], the perspectives of inactive people were only minimally included. Also, no research was conducted on the people who chose not to participate in or did not complete the NAPSE sporting programs. Questioning inactive people about their motivations, barriers and preferences regarding (participation in) these kind of sporting programs, could help tailor programs to their needs. This in turn could enhance the effectiveness of these programs.

Third, the main physical activity outcome measures in chapters 2-4 were based on the Dutch physical activity norms that were used prior to 2017. It is likely that with the 2017 Dutch physical activity guidelines, more participants would have been classified as insufficiently active. For example, according to the original Dutch physical activity norms, 32\% of Dutch adults were insufficiently active in 2008 [45], but according to the new guidelines, this percentage was 57\% [5]. Had the NAPSE sporting programs followed the 2017 guidelines, they would have had a larger target group. However, this should be interpreted with caution, because the qualitative research results (see chapters 5 and 6) showed that a majority of participants of the sporting programs were already somewhat physically active and that few inactive people participated. Furthermore, the new physical activity guidelines also recommend to participate in muscle and bone strengthening and balance activities and to avoid long periods sitting down [46]. So, in addition to the measurement of aerobic physical activity, future research should also include measurements of muscle and bone strengthening activities and sedentary behavior.

Finally, this research was conducted entirely in the Dutch context and it is unknown if the results are generalizable to other countries with a different sports infrastructure.

\section{Implications for policy and practice}

It can be concluded that the organized sports setting has potential to increase the physical activity levels of inactive population groups. However, for the success of these programs, it is important that additional conditions are met. Therefore, the following recommendations are provided for policy and practice:

\section{Recommendations for national and local policy makers}

1. Continue to use sport and physical activity policy to stimulate and support the promotion of physical activity among inactive population groups in the organized sports setting.

2. Use bottom-up approaches by including the target group, sports clubs and other relevant local stakeholders, in developing sport and physical activity promotion policy. 
3. Stimulate collaboration between the organized sports sector and other sectors (e.g. health, welfare, work) to combat physical inactivity.

4. Make sure that funding arrangements are long enough in duration and that financial resources are allocated towards planning, developing, implementing and evaluating (sustainable) sporting programs and activities in the organized sports setting.

5. Support sports clubs with implementation and evaluation of sport activities for inactive target groups by providing supporting implementation and evaluation materials, and opportunities for knowledge sharing.

\section{Recommendations for NSFs and sports clubs}

For these recommendations, it is assumed that the NSF develops the sporting program and that sports clubs implement the program. In the current Dutch sport policy, the focus is more on the local context [47]. Therefore, it is possible that a sports club could develop a program. In that case, recommendations 1-5 for NSFs would apply to sports clubs as well.

\section{Recommendations for NSFs}

1. Take enough time to learn about the inactive target group and involve inactive people in program design, so that a sporting program is tailored to the inactive target group's needs.

2. Involve trainers from the sports clubs in program design so that a sporting program is tailored to the local implementation context.

3. Collaborate with organizations or people in the community that are connected to the inactive target group, to reach and recruit inactive people.

4. Reserve enough time for program planning and development, taking into account the different (known) facilitating and impeding factors.

5. Regularly monitor and evaluate the implementation process at the organizational level as well as the effects at the individual level, i.e. the inactive target group.

6. Support sports clubs in implementing and evaluating the sporting program by providing training and educational opportunities, opportunities for knowledge sharing and the provision of supporting implementation materials, such as a trainer manual and materials for promotion and evaluation.

\section{Recommendations for sports clubs}

1. Use proper recruitment methods and channels to attract inactive people.

2. Collaborate with organizations or people in the community that are connected to the inactive target group, to reach and recruit inactive people. 
The current Dutch sport policy, which consists of the development of local and regional sports agreements ${ }^{2}$, and the employment of neighborhood sport coaches ${ }^{3}$, provides different opportunities for local sports clubs to collaborate with relevant stakeholders in the community to enhance physical activity levels among inactive population groups [21, 47, 48].

\section{Future research}

Our research has led to new knowledge regarding the role of the organized sports setting in the promotion of physical activity among inactive target groups. However, there are also (new) questions that need to be answered. Therefore, based on the findings in this thesis, several recommendations for future research can be made.

First, when developing sporting programs for inactive target groups, research should start with learning about the inactive target group and inactive people's needs for support to participate in organized sports. In addition, future research should include non-adopters and inactive people that drop out of programs, as this will provide valuable information for the improvement of programs and activities for this target group.

Second, it was shown that familial support, with regard to the participant's sport participation, enhanced the effectiveness of the sporting programs. The concept of familial social support should be evaluated with inactive people in a qualitative manner to better understand the meaning of familial support and what strategies could be helpful in stimulating familial support. Subsequently, different familial support strategies could be developed and tested in sports clubs to see which ones are most effective in stimulating sport participation.

Third, there is a lack of knowledge about which implementation strategies are effective in improving the implementation of programs and activities for inactive people in the organized sports setting. In future research, the retrieved factors influencing the

2 Within a local or regional sports agreement, municipalities, local sport and physical activity providers and other local organizations, collaborate to make plans to stimulate sport and physical activity participation in the municipality. The Dutch government provides funding for implementation of the local or regional sports agreement, which is dependent on the number of inhabitants of the municipality. The Dutch government will provide 30 million euros over the period of 2019-2021 to achieve the goals set in the local and regional sports agreements.

3 Neighborhood sport coaches are responsible for stimulating sport and physical activity in the community by facilitating connections between the organized sports setting and other settings. Neighborhood sport coaches receive $40 \%$ of their funding from the state and $60 \%$ from the municipality or other local organizations. The Dutch government will provide 73.3 million euros per year to employ neighborhood sport coaches (and cultural coaches) over the period of 2019 2022. Neighborhood sport coaches are active in 344 of the 355 municipalities in the Netherlands. 
implementation and long-term sustainability of the NAPSE sporting programs should be translated into implementation strategies that can be tested in sport organizations.

Fourth, due to the introduction of the new Dutch physical activity guidelines in the Netherlands in 2017, future studies regarding the effectiveness of programs and activities on increasing health-enhancing physical activity should use these guidelines as basis for outcome measures. With regard to measuring physical activity levels, new technologies are available such as smart watches, wrist-band sensors that track physical activity and apps on smart-phones and tablets. Since many people already possess one or more of these devices, their use in sport and physical activity promotion research should be further explored $[49,50]$. 


\section{REFERENCES}

1. 2018 Physical Activity Guidelines Advisory Committee. 2018 Physical Activity Guidelines Advisory Committee Scientific Report. Washington, DC: U.S. Department of Health and Human Services; 2018.

2. De Souto Barreto P, Cesari M, Andrieu S, Vellas B, Rolland Y. Physical activity and incident chronic diseases: a longitudinal oberservational study in 16 European countries. Am J Prev Med. 2017;52(3):373-378.

3. Guthold R, Stevens GA, Riley LM, Bull FC. Worldwide trends in insufficient physical activity from 2001 to 2016: a pooled analysis of 358 population-based surveys with 1.9 million participants. Lancet Glob Health. 2018;6(10):e1077-1086.

4. Kyu HH, Bachman VF, Alexander LT, Mumford JE, Afshin A, Estep K, Veerman JL, Delwiche K, Lannarone ML, Moyer ML, Cercy K, Vos T, Murray CJL, Forouzanfar MH. Physical activity and risk of breast cancer, colon cancer, diabetes, ischemic heart disease, and inschemic stroke events: systemic review and dose-response meta-analysis for the Global Burden of Disease Study 2013. BMJ. 2016;354:i3857.

5. Statistics Netherlands (CBS), National Institute for Public Health and the Environment (RIVM), Trimbos-institute. Standardized trend of meeting physical activity guidelines 2001-2017. https://www.volksgezondheidenzorg.info/onderwerp/bewegen/cijfers-context/trends. Accessed 27 April 2020.

6. Warburton DER, Nicol CW, Bredin SSD. Health benefits of physical activity: the evidence. CMAJ. 2006;174(6):801-809.

7. World Health Organization (WHO). Global recommendations on physical activity for health. Geneva: WHO; 2010.

8. World Health Organization (WHO). Ottawa Charter for Health Promotion. Geneva: WHO; 1986.

9. World Health Organization (WHO). Global action plan on physical activity 2018-2030: more active people for a healthier world. Geneva: WHO; 2018.

10. Ooms L, Veenhof C. Evaluation of the implementation phase of the National Action Plan for Sport and Exercise, the sports setting: results process and effectiveness evaluation (report in Dutch). Utrecht: NIVEL; 2011.

11. Cavill N, Adams E, Gardner S, Ruane S. Tackling inactivity: What we know: key insights from our Get Healthy Get Active pilots. Londen: Sport England; 2016.

12. Titze S, Schebesch-Ruf W, Lackinger C, Großschädl L, Strehn A, Dorner TE, Niebauer J. Short- and long-term effectiveness of a physical activity intervention with coordinated action between the health care sector and local sports clubs. A pragmatic trial in Austrian adults. Int J Environ Res Public Health. 2019;16:2362.

13. Allender S, Cowburn G, Foster C. Understanding participation in sport and physical activity among children and adults: a review of qualitative studies. Health Educ Res. 2006;21(6):826835. 
14. Deelen I, Özgül P, Lagendijk E. What moves vulnerable groups in neighborhoods in Utrecht? Qualitative research about the motives and barriers to participate in sport and physical activity (report in Dutch). Amsterdam: DSP-group; 2018.

15. Hoogendoorn MP, de Hollander EL. Barriers and motivators to sport and physical activity participation among underrepresented groups (report in Dutch). Bilthoven: National Institute for Public Health and the Environment (RIVM); 2016.

16. Zwolinsky S, McKenna J, Pringle A. How can the health system benefit from increasing participation in sport, exercise and physical activty. In: Conrad D, White A, editors. Sports-based health interventions: case studies from around the world. New York: Springer; 2016. p.29-52.

17. Donaldson A, Finch CF. Planning for implementation and translation: seek first to understand the end-users' perspectives. Br J Sports Med. 2012;46(5):306-307.

18. Mansfield L, Kay T, Anokye N, Fox-Rushby J. A qualitative investigation of the role of sport coaches in designing and delivering a complex community sport intervention for increasing physical activity and improving health. BMC Public Health. 2018;18:1196.

19. Dutch Ministry of Health, Welfare and Sport. The National Prevention Agreement: a healthier Netherlands. The Hague: Dutch Ministry of Health, Welfare and Sport; 2018.

20. Ooms L, Dellas V, Gutter K, Heijnen E, van Lindert C. Sustainability of Sport Impulse projects rounds 2015-2017 (report in Dutch). Utrecht: Mulier Institute; 2020.

21. van Stam W, van Lindert C, Brandsema A. Progress report Monitor Sport and Physical Activity in the Neighborhood 2018 (report in Dutch). Utrecht: Mulier Institute; 2018.

22. Dellas V, Gutter K, Heijnen H, Ooms L, van Lindert C. Evaluation of the JILIB and KSG Sport Impulse projects round 2018: in-depth interviews with local actors, participating children and their parents (report in Dutch). Utrecht: Mulier Institute; 2020.

23. Leemrijse CJ, de Bakker DH, Ooms L, Veenhof C. Collaboration of general practitioners and exercise providers in promotion of physical activity: a written survey among general practitioners. BMC Fam Pract. 2015;16:96.

24. Leenaars KEF, Florisson AME, Smit E, Wagemakers A, Molleman GRM, Koelen MA. The connection between the primary care and the physical activity sector: professionals' perceptions. BMC Public Health. 2016;16:1001.

25. Leenaars KEF, Smit E, Wagemakers A, Molleman GRM, Koelen MA. The role of the care sport connector in the Netherlands. Health Promot Int. 2018;33(3):422-435.

26. Hoare E, Stavreski B, Jennings GL, Kingwell BA. Exploring motivation and barriers to physical activity among active and inactive Australian adults. Sports. 2017;5(3):47.

27. Staley K, Donaldson A, Randle E, Nicholson M, O'Halloran P, Nelson R, Cameron M. Challenges for sport organisations developing and delivering non-traditional social sport products for insufficiently active populations. Aust NZ J Public Health. 2019;43(4):373-381

28. Casey MM, Payne WR, Brown SJ, Eime RM. Engaging community sport and recreation organisations in population health interventions: factors affecting the formation, implementation, and institutionalisation of partnership efforts. Ann Leis Res. 2009;12(2):129147.

29. Casey MM, Payne WR, Eime RM. Partnership and capacity-building strategies in community sports and recreation programs. Manag Leis. 2009;14(3):167-176. 
30. Casey MM, Payne WR, Eime RM. Organisational readiness and capacity building strategies of sporting organisations to promote health. Sport Manag Rev. 2012;15:109-124.

31. Crisp BR, Swerissen H. Critical processes for creating health-promoting sporting environments in Australia. Health Promot Int. 2003;18(2):145-152.

32. Dobbinson SJ, Hayman JA, Livingston PM. Prevalence of health promotion policies in sports clubs in Victoria, Australia. Health Promot Int. 2006;21(2):121-129.

33. Eime RM, Payne WR, Harvey JT. Making sporting clubs healthy and welcoming environments: a strategy to increase participation. J Sci Med Sport. 2008;11(2):146-154.

34. Koski P, Matarma T, Pedisic Z, Kokko S, Lane A, Hartmann H, Geidne S, Hämäläinen T, Nykänen U, Rakovac M, Livson M, Savola J. Sports Club for Health (SCforH): updated guidelines for healthenhancing sports activities in a club setting. Helsinki: Finnish Olympic Committee; 2017.

35. McFadyen T, Chai LK, Wyse R, Kingsland M, Yoong SL, Clinton-McHarg T, Bauman A, Wiggers J, Rissel C, Williams CM, Wolfenden L. Strategies to improve the implementation of policies, practices or programmes in sporting organisations targeting poor diet, physical inactivity, obesity, risky alcohol use or tobacco use: a systematic review. BMJ Open. 2018;8:e019151.

36. Dutch Ministry of Health, Welfare and Sport. Time for sport: exercise, participate, perform. The Hague: Dutch Ministry of Health, Welfare and Sport; 2005.

37. Dooris M. Joining up settings for health: a valuable instrument for strategic partnerships? Crit Public Health. 2004;14(1):49-61.

38. Dooris M. Healthy settings: challenges to generating evidence of effectiveness. Health Promot Int. 2006;21(1):55-65.

39. Dooris M. Holistic and sustainable health improvement: the contribution of the settings-based approach to health promotion. Perspect Public Health. 2009;129(1):29-36.

40. Kokko S. Sports clubs as settings for health promotion: fundamentals and an overview to research. Scan J Public Health. 2014;42(Suppl.15):60-65.

41. Kokko S, Green LW, Kanas L. A review of settings-based health promotion with applications to sports clubs. Health Promot Int. 2013;29(3):494-509.

42. Whitelaw S, Baxendale A, Bryce C, MacHardy L, Young I, Witney E. 'Settings' based health promotion: a review. Health Promot Int. 2001;16(4):339-353.

43. Geidne S, Kokko S, Lane A, Ooms L, Vuillemin A, Seghers J, Koski P, Kudlacek M, Johnson S, van Hoye A. Health promotion interventions in sports clubs: can we talk about a setting-based approach? A systematic mapping review. Health Educ Behav. 2019;46(4):592-601.

44. Pisters MF, Veenhof, C. Evaluation of the pilot phase of the National Action Plan for Sport and Exercise: the sports setting (report in Dutch). Utrecht: NIVEL; 2008.

45. Bernaards CM. TNO monitor physical activity and health: physical activity in the Netherlands 2000-2013 (report in Dutch). Leiden: TNO Healthy Living; 2014.

46. Weggemans RM, Backx FJG, Borghouts L, Chinapaw M, Hopman MTE, Koster A, Kremers S, van Loon LJC, May A, Mosterd A, van der Ploeg HP, Takken T, Visser M, Wendel-Vos GC, de Geus EJC, Committee Dutch Physical Activity Guidelines 2017. The 2017 Dutch physical activity guidelines. Int J Behav Nutr Phys Act. 2018;15:58.

47. Dutch Ministry of Health, Welfare and Sport. National Sports Agreement: sport unites the Netherlands (report in Dutch). The Hague: Dutch Ministry of Health, Welfare and Sport; 2018. 
48. Pulles I, van Stam W, Heijnen E, van Lindert C. Monitor Broad Regulation Combination functions 2019 (report in Dutch). Utrecht: Mulier Institute; 2019.

49. Bort-Roig J, Gilson ND, Puig-Ribera A, Contreras RS, Trost SG. Measuring and influencing physical activity with smartphone technology: a systematic review. Sports Med. 2014;44:671-686.

50. Seifert A, Schlomann A, Rietz C, Schelling HR. The use of mobile devices for physical activity tracking in older adults' everyday life. Digit Health. 2017;3:1-12. 


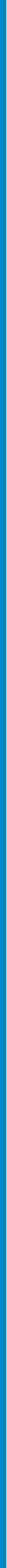




\section{Summary}

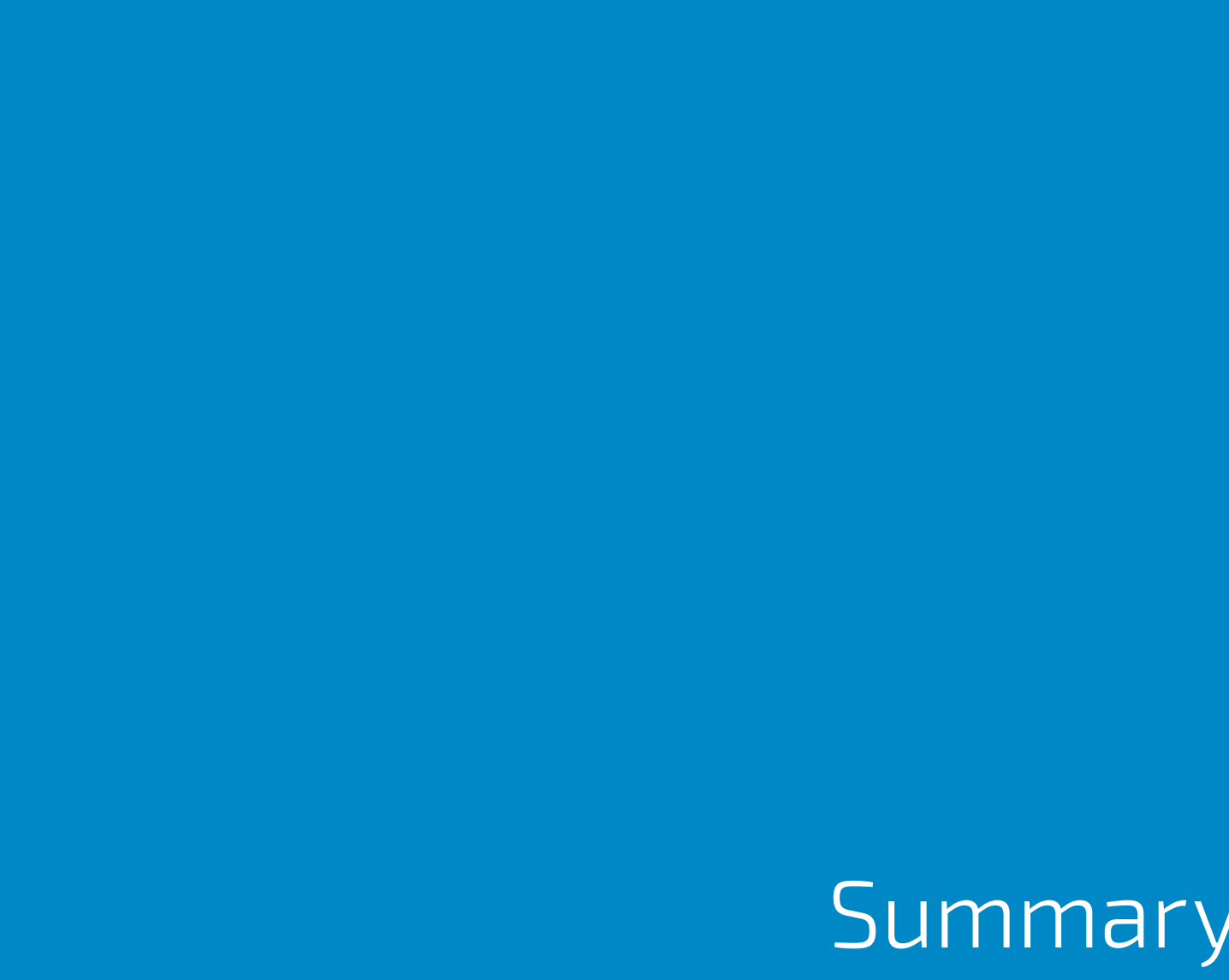


Physical inactivity increases the risk for chronic diseases and mortality, and is a problem faced by countries worldwide. Strategies to promote physical activity among inactive target groups are therefore necessary. In this regard, a settings-based approach towards physical activity promotion has been encouraged. The organized sports setting, in particular sports clubs, is seen as a promising setting to increase physical activity among inactive groups within a population (chapter 1). The main focus of this thesis was to understand if and how the organized sports setting can successfully contribute to increasing physical activity levels among inactive people. Fourteen Dutch sporting programs aimed at increasing sport participation in inactive population groups, were studied during the three-year funded implementation period and six and half years thereafter. These programs were developed by ten National Sports Federations (NSFs) as part of the National Action Plan for Sport and Exercise (NAPSE) and implemented by sports clubs in the Netherlands (period 2008-2011). The research in this thesis focused on the effectiveness of two programs within the NAPSE and characteristics of insufficiently active participants who benefited the most from these programs in terms of increasing health-enhancing physical activity. Furthermore, factors influencing the implementation and long-term sustainability of all NAPSE programs were examined. Both quantitative and qualitative research methods were used.

\section{Effectiveness}

The effectiveness of the six-week Start to Run (chapter $\mathbf{2}$ ) and six-week Start2Bike program (chapter 3) for increasing health-enhancing physical activity levels were each investigated in two separate controlled studies. Self-reported physical activity levels of program participants were assessed at baseline, six weeks post-baseline (i.e. immediately after completing the programs) and six months post-baseline (i.e. 4.5 months after finishing the programs). Changes in physical activity levels six months after baseline (Start to Run $\mathrm{n}=100$; Start2Bike $\mathrm{n}=79$ ) were compared with a matched control group. The percentage of Start to Run and Start2Bike participants that participated in physical activity at healthenhancing levels increased significantly, both six weeks and six months after baseline. In addition, the increases in physical activity six months post-baseline were significantly greater in comparison with a control group (no changes in physical activity behavior were observed in either control group). This was because program participants spent more time in vigorous-intensity activities and sport activities. It was concluded that a short sporting program, six weeks in duration and provided by a sports club, can be effective in stimulating health-enhancing physical activity in both the short- and long-term.

\section{Characteristics of insufficiently active participants}

The characteristics of insufficiently active participants that benefit from health-enhancing physical activity promotion programs implemented in sports clubs are presented in chapter 
4. Physical activity data from participants in three NAPSE sporting programs, Start to Run, Start2Bike and Through 4 Days Marches ( $n=458)$, were used for more in-depth analyses. Insufficiently active participants were more likely to reach health-enhancing physical activity levels six months after starting the program when they received support from family members with regard to their sport participation and were already engaging in moderate-intensity physical activity at baseline. The results showed that these sporting programs can be used to increase health-enhancing physical activity levels of insufficiently active people but that it remains challenging to reach the least active people. Furthermore, strategies that promote familial support, such as including family members as sporting buddies or involving them in other club activities (e.g. social activities, volunteering), could enhance the effectiveness of the programs.

\section{Factors influencing implementation}

The factors that influenced the implementation of the fourteen NAPSE sporting programs during the three-year funded implementation period are presented in chapter 5. A mixed methods study was performed at the level of the NSF program coordinators to identify the most important influencing factors. The qualitative research component consisted of yearly face-to-face interviews with the program coordinators (i.e. fourteen interviews each year, $\mathrm{n}=12$ ) and a group meeting with the program coordinators $(\mathrm{n}=8)$. In the quantitative research component, program coordinators $(n=12)$ ranked factors by level of importance. The results showed that different factors are relevant during six identified (implementation) phases: 1) program development, 2) organizational (pre)conditions, 3) recruiting local sports clubs, 4) recruiting participants, 5) local implementation and 6) securing continuation of the program. When comparing factors across phases, several key learnings points for implementation were evident. Successful implementation relied, for example, on proper program design and enthusiastic individuals within the sporting organizations. In addition, skilled local trainers, high-quality programming and the presence of suitable follow-up activities stimulated continued participation. However, it was difficult to recruit large numbers of inactive people to the sporting programs and not all sports clubs were willing to offer the NAPSE sporting programs. To engage more inactive people, sporting organizations should focus on proper recruitment methods and channels to reach this target group. In this regard, they may consider partnering with primary health care, community health or other relevant organizations to get closer to this target group. Participation of sports clubs improved when NSFs used a personal approach and provided support to sports clubs during implementation. Finally, program funds should be spent on developing the program infrastructure so that the program is self-sustaining after the funded implementation period ends. 


\section{Factors influencing long-term sustainability}

The factors influencing the long-term sustainability of the fourteen NAPSE sporting programs are presented in chapter $\mathbf{6}$. A qualitative study was performed at the level of the NSFs and sports clubs to identify the most important influencing factors. The research consisted of semi-structured face-to-face interviews with the NSF program coordinators $(n=14)$ and semi-structured telephone interviews with representatives of sports clubs that had provided the programs ( $n=17$ continued the program, $n=11$ discontinued the program) six and a half years after the funding period ended. Factors were categorized and described under five pre-specified main themes: 1) program design, 2) implementation, 3) trainer/ coach, 4) organizational setting NSF/sports club and 5) broader community environment. The results showed that ten of the fourteen NAPSE sporting programs were sustained at the level of the NSFs (and their associated sports clubs) six and a half years after the funded implementation period ended. Although financial resources were important for NSFs and sports clubs to sustain the programs, there were many other common influencing factors, such as program adaptation (i.e. adapting the program to the (changing) needs of (previously) inactive participants and sports clubs) and program effectiveness (i.e. positive effects of the program on participants). However, there were also differences in reported influencing factors between NSFs and sports clubs, which were specific to the (organizational) context of these organizations, i.e. a professional-led organization vs. a mostly voluntary-based organization. For example, securing personnel (e.g. availability of professional trainers, committed leader) was one of the main challenges faced by sports clubs in continuing program activities over a long period of time. NSFs did not have this issue. Since sports clubs are responsible for program implementation and continuation, it is important that NSFs, which develop the programs and receive funding, take factors specific to sports clubs into account. Overall, the long-term sustainability of a sporting program is a continuous process which needs to be considered during all program phases (i.e. program development, implementation and continuation). Therefore, early and active planning is needed to create the conditions that enhance the long-term sustainability of programs. Finally, to keep recruiting inactive people to the sporting programs, NSFs and sports clubs should collaborate (more) with organizations or people that are close to the inactive target group.

Chapter 7 discusses the results, conclusions and implications of our research. The research conducted in this thesis shows that the organized sports sector can be used as a setting to increase physical activity levels of some inactive people. However, physical inactivity is a complex health behavior problem that NSFs and sports clubs cannot solve on their own. A solution requires collaborations between settings, like in a whole system approach. A whole system approach includes participation of the target group and a broad range of stakeholders to both understand the root of the problem of physical inactivity, and to support the identification and testing of solutions. Some NSFs and sports clubs that participated in the NAPSE program have already made good progress by collaborating 
with relevant stakeholders in the community. Furthermore, in general, policy makers and professionals working in the sports and health sectors, have become more aware of the need for multisectoral partnerships to increase population levels of physical activity. However, more work needs to be done by NSFs, sports clubs and actors in other settings, to combat physical inactivity through a whole system approach.

To support NSFs and sports clubs in realizing this, national and local policy makers are advised to use bottom-up approaches in developing sport and physical activity promotion policy and to stimulate (more) collaboration between the organized sports sector and other sectors (e.g. health, welfare, work) to combat physical inactivity. NSFs, as the program developers, are advised to take enough time to learn about the inactive target group and involve these people in program design. Both NSFs and sports clubs are recommended to collaborate more with organizations or people in the community that are connected to the inactive target group, to reach and recruit inactive people.

When developing sporting programs for inactive target groups, research should start with learning about the inactive target group and inactive people's needs for support to participate in organized sports. A further examination of the concept of familial social support and the translation of the retrieved factors influencing the implementation and long-term sustainability of the NAPSE sporting programs into implementation strategies, are other suggestions for future research. 


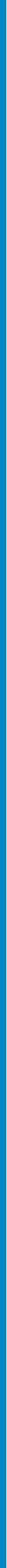


Hoofdstuk 1 beschrijft de aanleiding van het onderzoek. Te weinig bewegen is een wereldwijd probleem. Lichamelijke inactiviteit verhoogt het risico op het krijgen van allerlei chronische ziekten en vroegtijdig overlijden. Daarom is er behoefte aan strategieën om meer bewegen onder inactieve doelgroepen te stimuleren. Om dit te bereiken, kiest men steeds vaker voor een setting-gerichte aanpak. De georganiseerde sportsector, en met name sportverenigingen, wordt als een kansrijke omgeving gezien om bewegen onder inactieve groepen in de bevolking te stimuleren. Het hoofddoel van dit proefschrift was te onderzoeken of en hoe sportbonden en sportverenigingen succesvol kunnen bijdragen aan het in beweging brengen van inactieve mensen. Hiervoor zijn veertien Nederlandse sportprogramma's, die als doel hadden om de sportparticipatie onder inactieve mensen te verhogen, onderzocht. Deze programma's zijn ontwikkeld door tien sportbonden in het kader van het Nationaal Actieplan Sport en Bewegen (NASB) en uitgevoerd door verschillende sportverenigingen in Nederland (periode 2008-2011). Het onderzoek in dit proefschrift richtte zich op de effecten van deelname aan twee NASB-sportprogramma's op het beweeggedrag van deelnemers en de kenmerken van deelnemers die meer zijn gaan bewegen. Daarnaast is gekeken naar de factoren die van invloed zijn op de implementatie en borging van de sportprogramma's. Het onderzoek vond plaats tijdens de gesubsidieerde implementatiefase van drie jaar en zes en half jaar na beëindiging van de subsidie. Voor het onderzoek zijn zowel kwantitatieve als kwalitatieve onderzoeksmethoden gebruikt.

\section{Effectiviteit}

In twee aparte gecontroleerde studies zijn de effecten van de zes weken durende sportprogramma's Start to Run (hoofdstuk 2) en Start2Bike (hoofdstuk 3) onderzocht. Deelnemers vulden drie keer een vragenlijst over hun beweeggedrag in: bij aanvang van het programma, direct na afloop van het programma en zes maanden na aanvang. Het beweeggedrag van de deelnemers (Start to Run $n=100$; Start2Bike $n=79$ ) is vergeleken met het beweeggedrag van een controlegroep. De controlegroep bestond uit deelnemers die vergelijkbaar waren met de deelnemers aan de sportprogramma's voor wat betreft leeftijd en geslacht. Deelnemers van de controlegroep vulden een vragenlijst over hun beweeggedrag in bij aanvang van het onderzoek en zes maanden later. Na zes weken en na zes maanden voldeden meer Start to Run en Start2Bike deelnemers aan de Nederlandse beweegnormen dan bij aanvang van de sportprogramma's. De toename in beweeggedrag van deelnemers was na zes maanden groter dan in de controle groep, die in zes maanden niet meer of minder ging bewegen. De resultaten laten zien dat een kortdurend sportprogramma van zes weken bij een sportvereniging, positieve korte- en lange-termijn effecten op het beweeggedrag van deelnemers kan hebben. 


\section{Kenmerken van deelnemers}

Hoofdstuk $\mathbf{4}$ beschrijft de kenmerken van de deelnemers die meer zijn gaan bewegen. Gegevens over de achtergrondkenmerken en het beweeggedrag van deelnemers van de sportprogramma's Start to Run, Start2Bike en Via Vierdaagse $(n=458)$, zijn gebruikt voor verdiepende analyses. De kans dat deelnemers zes maanden na de start van het sportprogramma meer bewegen, is groter wanneer zij door hun familie bij het sporten worden gesteund en bij aanvang van het sportprogramma al matig lichamelijk actief zijn. De sportprogramma's kunnen dus worden ingezet om lichaamsbeweging te stimuleren. Wel blijkt het lastig om de minst actieven te bereiken. Strategieën die sociale steun van familie voor het sporten bevorderen, zoals het mee laten sporten van familieleden of het betrekken van familieleden bij andere verenigingsactiviteiten (bijv. sociale activiteiten, vrijwilligerstaken), kunnen de effectiviteit van de sportprogramma's vergroten.

\section{Factoren die de implementatie beïnvloeden}

Hoofdstuk 5 geeft inzicht in de factoren die de implementatie van de veertien NASBsportprogramma's hebben beïnvloed. Hiervoor zijn verschillende onderzoeksmethoden gebruikt waarbij de programmaleiders van de sportbonden ( $n=12$; twee programmaleiders waren ieder verantwoordelijk voor twee sportprogramma's) aangaven welke factoren zij het meest belangrijk vonden. De resultaten laten zien dat verschillende factoren een rol spelen tijdens de verschillende fases van het implementatieproces. Om dergelijke sportprogramma's succesvol te implementeren is het bijvoorbeeld belangrijk dat goed is nagedacht over de inhoud van het sportprogramma en dat enthousiaste trekkers binnen sportbonden en sportverenigingen aanwezig zijn. Sportverenigingen zijn niet altijd bereid om dergelijke sportprogramma's aan te bieden, maar doen eerder mee wanneer zij hiervoor persoonlijk worden benaderd door de sportbond en de sportbond hen ondersteunt bij de uitvoering ervan. Verder bleek het lastig om grote aantallen inactieve mensen naar de sportactiviteiten te trekken. Het is belangrijk dat sportbonden en sportverenigingen de juiste wervingsstrategieën en -kanalen gebruiken om meer inactieven te werven. Zij kunnen bijvoorbeeld met de eerstelijnsgezondheidszorg, andere relevante organisaties of personen in de wijk samenwerken om met de doelgroep in contact te komen. De kans dat (voorheen) inactieve deelnemers blijven sporten, is groter wanneer de trainer vaardig is in het begeleiden van inactieve mensen en geschikte vervolgactiviteiten voor deelnemers binnen de sportvereniging aanwezig zijn. Tot slot is het belangrijk dat de financiële middelen voor implementatie worden gebruikt om een goede basisinfrastructuur voor het sportprogramma te creëren, zodat het sportprogramma na de subsidieperiode zelfstandig kan worden voortgezet. 


\section{Factoren die de lange-termijn borging beïnvloeden}

Hoofdstuk 6 geeft inzicht in de factoren die de borging van de veertien NASBsportprogramma's op de lange termijn beïnvloeden. Hiervoor zijn interviews afgenomen met de programmaleiders van de sportbonden $(n=14)$ en vertegenwoordigers van sportverenigingen die de NASB-sportprogramma's hebben aangeboden $(n=28)$. De interviews vonden zes en een half jaar na beëindiging van de subsidieperiode plaats. Uit de resultaten blijkt dat tien van de veertien NASB-sportprogramma's nog steeds door de sportbonden en de daarbij aangesloten sportverenigingen worden aangeboden. Veel factoren die de lange-termijn borging beïnvloeden, zijn zowel door sportbonden als sportverenigingen genoemd. Voldoende financiële middelen voor de uitvoering en de mogelijkheid om het programma aan veranderde behoeften van de (voorheen) inactieve doelgroep aan te passen, zijn voorbeelden van overeenkomstige bevorderende factoren. Ook wanneer het sportprogramma tot positieve effecten bij deelnemers leidt, is dat voor zowel sportbond als sportvereniging een stimulans om het sportprogramma te blijven aanbieden. $\mathrm{Er}$ is echter ook een aantal beïnvloedende factoren dat specifiek door sportbonden of sportverenigingen is benoemd. Deze factoren hebben vooral te maken met de verschillen in de organisatie van sportbond en sportvereniging, waarbij de sportbond gebruik maakt van betaalde professionele krachten en de sportvereniging vooral afhankelijk is van de inzet van vrijwilligers. Sportverenigingen hebben bijvoorbeeld moeite om opgeleide trainers en enthousiaste trekkers voor een langere periode vast te houden. Dit probleem speelt minder bij sportbonden. Sportbonden moeten rekening houden met de beïnvloedende factoren die sportverenigingen hebben benoemd. Dit geldt vooral wanneer de sportbond de subsidie ontvangt en het sportprogramma ontwikkelt, maar sportverenigingen verantwoordelijk zijn voor de uitvoering en het borgen ervan. Het borgen van een sportprogramma op de lange termijn is een continu proces dat tijdens alle programmafasen (programma ontwikkeling, implementatie en borging) aandacht verdient. Daarom is het belangrijk om al voor de ontwikkeling van het programma te beginnen met het maken van programmaplannen en het creëren van de randvoorwaarden voor het borgen van het sportprogramma op de lange termijn. Tot slot is het belangrijk dat sportbonden en sportverenigingen meer samenwerken met organisaties en personen die in nauw contact met de inactieve doelgroep staan om meer inactieve deelnemers voor de sportprogramma's te werven.

In hoofdstuk 7 worden de resultaten, conclusies en implicaties van het onderzoek in dit proefschrift besproken. De onderzoekresultaten laten zien dat de georganiseerde sportsector een bijdrage kan leveren aan het in beweging brengen van sommige inactieve mensen. Lichamelijke inactiviteit is echter een complex gezondheidsprobleem dat afhankelijk is van vele factoren. Sportbonden en sportverenigingen kunnen dit probleem niet alleen oplossen. Hiervoor is meer samenwerking tussen verschillende sectoren nodig, zoals bij een complete systeembenadering. Bij een systeembenadering worden de doelgroep en een groot aantal stakeholders uit verschillende sectoren betrokken om de oorzaken van lichamelijke inactiviteit te begrijpen en verschillende oplossingen te bedenken en testen. 
Sommige NASB-sportbonden en -sportverenigingen hebben reeds goede stappen gezet door samen te werken met relevante stakeholders in hun omgeving. In het algemeen zijn beleidsmakers en professionals uit de sport- en gezondheidssector zich meer bewust van het belang van multisectorale samenwerking om bewegen in de bevolking te stimuleren. $\mathrm{Er}$ moet echter nog meer gedaan worden door sportbonden, sportverenigingen en personen en organisaties uit andere sectoren om dit daadwerkelijk te kunnen realiseren.

Om sportbonden en sportverenigingen hierbij te ondersteunen, is een aantal aanbevelingen gedaan. Nationale en lokale beleidsmakers worden geadviseerd om inactieve mensen, sportverenigingen en andere relevante lokale partijen bij de ontwikkeling van sport- en beweegstimuleringsbeleid te betrekken en meer samenwerking tussen de georganiseerde sportsector en andere sectoren (bijv. gezondheidszorg, welzijn, werk) te stimuleren om lichamelijke inactiviteit in de bevolking te verminderen. Sportbonden moeten als programmaontwikkelaars genoeg tijd nemen om de inactieve doelgroep te leren kennen en de doelgroep bij de ontwikkeling van het programma betrekken. Sportbonden en sportverenigingen worden geadviseerd om meer samen te werken met organisaties of personen die in nauw contact met de inactieve doelgroep staan om inactieve mensen te bereiken en werven.

Ook in toekomstig onderzoek is het belangrijk om meer inzicht te krijgen in de motivaties, belemmeringen en ondersteuningsbehoeften van inactieve mensen als het gaat om deelname aan georganiseerde sporten. Daarnaast is het van belang om in vervolgonderzoek meer inzicht te krijgen in de betekenis van sociale steun van familie voor het deelnemen aan sport omdat dit een van de factoren is die de sport- en beweegdeelname van inactieve mensen beïnvloedt. De vertaling van de factoren die de implementatie en de borging op de lange termijn van de NASB-sportprogramma's beïnvloeden naar effectieve implementatiestrategieën is een andere suggestie voor vervolgonderzoek. 


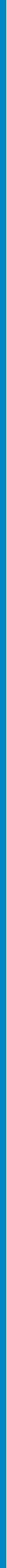


Mijn promotietraject is goed te vergelijken met een 'hurdle race'. Je moet goed trainen om alle hordes te kunnen nemen. Ik heb veel geleerd tijdens het doen van alle onderzoeken en het schrijven van wetenschappelijke artikels. Soms waren er tegenslagen, zoals wanneer een artikel voor de zoveelste keer was afgewezen. Er waren momenten dat ik wilde stoppen, maar opgeven hoort niet bij een topsportersmentaliteit. Met het schrijven van dit dankwoord neem ik de een-na-laatste horde en is de finish bijna in zicht. De laatste horde is de verdediging van het proefschrift. Dit was allemaal niet mogelijk geweest zonder de steun en het vertrouwen van mensen uit mijn omgeving. Zij hebben mij direct of indirect geholpen met het schrijven van dit proefschrift. Deze laatste pagina's wil ik graag gebruiken om deze mensen persoonlijk te bedanken.

Allereerst wil ik de sportbonden, sportverenigingen en deelnemers aan de NASBsportprogramma's bedanken voor hun deelname aan het onderzoek. Ik denk met plezier terug aan de gesprekken die ik heb gevoerd met mensen die met zoveel enthousiasme over hun sport vertelden. Ook wil ik NOC*NSF bedanken voor het financieel ondersteunen van dit onderzoek. In het bijzonder dank ik Nicolette Schipper-van Veldhoven en Hein Veerman van NOC*NSF voor het meedenken in en het faciliteren van het onderzoek. Nicolette, ook bedankt voor jouw rol als lid van de beoordelingscommissie.

Graag had ik vervolgens Dinny de Bakker, mijn promotor, willen bedanken voor zijn vertrouwen in mij en de vrijheid die hij me gaf bij het doen van het onderzoek. Helaas is Dinny eind 2016, na een korte ziekteperiode, overleden.

Cindy Veenhof, jij hebt de taken van Dinny als promotor overgenomen, zodat ik toch mijn promotietraject heb kunnen afmaken. Eigenlijk had ik nooit het doel om promotieonderzoek te gaan doen. Eerlijk gezegd leek het mij niks. Dat veranderde toen ik al mijn NIVEL-collega's zag promoveren en jij mij vroeg of ik dat misschien ook zou willen. Het lijkt nog helemaal niet zo lang geleden dat we brainstormden over de globale inhoud van mijn proefschrift. Ik wil jou bedanken voor het vertrouwen in mij en de goede begeleiding. Jouw advies "als je iets minder jouw best doet, dan is het nog steeds heel goed", neem ik altijd mee. Al is dat soms best lastig voor iemand die alles perfect wil doen.

Chantal Leemrijse, mijn copromotor. Mede door jou ben ik het sportonderzoek ingerold, toen jij samen met Cindy mij een kans gaf om bij het NIVEL te werken. Jouw frisse blik en uitgebreide feedback (inclusief het weghalen van alle onnodige haakjes in de tekst; sorry voor de haakjes), af en toe gecombineerd met wat humor, hebben ervoor gezorgd dat ik de eindstreep op een goede manier en met een glimlach heb gehaald. Bedankt daarvoor.

Dorine Collard, mijn copromotor en collega bij het Mulier Instituut. Jij sloot eigenlijk als laatste aan bij mijn promotieteam. Bedankt voor jouw bijdrage als lid van mijn promotieteam en de extra tijd die je daarnaast nam om met mij te sparren wanneer ik vastliep. Hierdoor heb ik het laatste deel van mijn promotietraject in een stroomversnelling kunnen doorlopen. 
Mijn oud-collega's van het NIVEL, die op de één of andere manier een bijdrage aan dit proefschrift hebben geleverd. In het bijzonder wil ik Marina van Geelkerken bedanken, die al een hele tijd van haar welverdiende pensioen geniet. Jij speelde een belangrijke rol bij de organisatie van het onderzoek. Verder dank ik de statistici Lucas van der Hoek en Peter Spreeuwenberg voor hun adviezen met betrekking tot het analyseren van de kwantitatieve data (hoofdstukken 2-4). Ook wil ik de directie en het management van het NIVEL bedanken voor hun vertrouwen en de geboden mogelijkheden om mijzelf te ontwikkelen.

Mijn collega's bij het Mulier Instituut. Bedankt voor jullie belangstelling voor mijn promotieonderzoek en de fijne werksfeer. Agnes Elling en Mirjam Stuij, bedankt voor jullie adviezen met betrekking tot het verzamelen, verwerken en analyseren van kwalitatieve data voor mijn laatste artikel (hoofdstuk 6). Ook alle stagiaires die mee hebben geholpen met het transcriberen van de interviews voor mijn laatste artikel, bedankt. Mette van Kruijsbergen, het was erg fijn dat jij zo gestructureerd en nauwkeurig jouw deel van het onderzoek (in hoofdstuk 6) hebt uitgevoerd. Ik wens jou veel succes met jouw eigen promotieonderzoek naar de effectiviteit van blended en onbegeleide online MindfulnessBased Cognitive Therapy (MBCT) voor mensen met kanker. Maxine de Jonge, bedankt dat jij als 'native speaker' mijn Engels in de algemene inleiding, algemene discussie en mijn CV hebt gecontroleerd en waar nodig gecorrigeerd. Marije Lüschen, heel erg fijn dat jij hetzelfde wilde doen bij de Nederlandse teksten in mijn proefschrift. Ook dank ik de directie van het Mulier Instituut voor het vertrouwen in mij en het faciliteren van mijn promotieonderzoek.

De overige leden van de leescommissie, prof. dr. F.J.G. Backx, prof. dr. M. van Bottenburg, prof. dr. P.P. Groenewegen en prof. dr. ir. A.J. Schuit. Bedankt voor de tijd die jullie hebben vrijgemaakt om dit proefschrift te beoordelen.

Lieve familie en vrienden. Promoveren kost veel tijd. Daardoor had ik soms minder tijd voor jullie. Ook was ik niet altijd de vrolijkste wanneer iets tegenzat.

Mijn sportmaatjes bij het hardlopen en (kick)boksen. Bedankt voor de gezellige momenten en de nodige ontspanning.

Kenneth Macnack, al 26 jaar mijn (kick)bokstrainer. Wij hebben samen al heel wat 'hurdle races' gehad in de (kick)bokssport en daarbuiten. Jij hebt mij in al die jaren gesteund of ik nu wilde kickboksen, boksen of hardlopen. Ook gaf je mij alle ruimte om mijn studie te doen en te promoveren naast mijn sport. Ik dank jou en jouw lieve partner Patsy Lobato de Mesquita voor al jullie tijd en liefde die jullie mij in al die jaren hebben gegeven.

Mijn lieve schoonfamilie, familie Beking. Wat is het fijn dat jullie voor mij, Guus en de kinderen zo vaak klaar staan. Hierdoor had ik ook meerdere malen mijn handen vrij om aan dit proefschrift te werken. 
Mijn lieve ouders John en Marjo Ooms. Mam en pap, jullie zijn er altijd voor mij. Als het mee zit, maar ook als het tegenzit. Wat fijn is het dat jullie zo dichtbij wonen en ik regelmatig langs kan komen voor een kopje thee en wat ontspanning. Zonder jullie zou ik niet zover zijn gekomen. Bedankt voor al jullie liefde en alles wat jullie voor mij hebben gedaan!

Mijn lieve zusjes Kristy en Carly Ooms. Samen lachen, samen huilen. Ze noemen ons ook wel de drie musketiers: "Eén voor allen, allen voor één." Dat zegt al genoeg.

De kinderen. Thymen, Jasmijn en mijn nichtje Alicia. Geduldig zijn is soms best lastig. Dat geldt niet alleen voor jullie maar ook voor mijzelf. Ik geniet van alle momenten met jullie. Gelukkig heb ik nu weer meer tijd om leuke dingen met jullie te ondernemen.

Als laatste wil ik mijn partner en (trainings)maatje Guus Beking bedanken. Lieve Guus, wat ben ik blij met jou aan mijn zijde. Bedankt voor al jouw liefde, geduld, steun, adviezen en vertrouwen in mij. Door jouw enthousiasme, relativeringsvermogen en humor is het leven zoveel makkelijker en leuker. Ik geniet van alle momenten dat we samen zijn. Ik kijk uit naar alle leuke dingen die we samen (en met de kinderen) nog gaan ondernemen. 
Linda Ooms was born on April $5^{\text {th }}, 1983$, in Warnsveld, the Netherlands. After completing secondary school in 2001, she started studying Biomedical Sciences at the Radboud University in Nijmegen. She chose to specialize in Human Movement Sciences, because she wanted to work in the sports field. After graduating in 2007, she started working as a researcher at the Netherlands Institute for Health Services Research (NIVEL). At NIVEL, she conducted different research projects in the field of sport, physical activity and health. In addition, she started her doctoral study on the role of the organized sports setting in physical activity promotion among inactive people. After leaving NIVEL in 2014, she worked as a monitoring and research advisor at Onbeperkt Sportief, a foundation dedicated to stimulating sport and physical activity participation among people with disabilities, which would later become part of the Knowledge Center for Sport and Physical Activity (20152016). She continued to work on her doctoral study in her free time.

Since 2017, she is working as a researcher at the Mulier Institute. She conducts different research projects in her specialization 'sport, physical activity and health' with a specific focus on the theoretical groundwork and evaluation of sport and physical activity interventions. At the Mulier Institute, she also conducted research for her final article for her doctorate study.

Linda combined her study and work with elite-level kickboxing. In 2007, she became world champion in her weight division. Later, she switched from kickboxing to boxing and started running. In 2018, she received a silver medal in the Masters 800-meter track event during the Dutch national track and field championships. She currently competes in boxing and participates in different running contests. In addition, she started swimming and cycling to participate in a triathlon event in the future. She likes to motivate others to participate in sport and is a running and kickboxing coach as well. Together with her partner Guus Beking, she guides athletes, performs running analyses and organizes sport events for Top Motion Gelderland and Top Motion Running Lab. 


\section{List of publications}

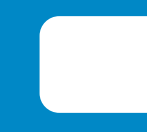


Ooms L, van den Dool R, Elling A. Factsheet Psychische gezondheid, bewegen en sport: de rol van bewegen en sport voor mensen met (ernstige) psychische klachten. Utrecht: Mulier Instituut; 2020.

Dellas V, Gutter K, Heijnen E, Ooms L, van Lindert C. Evaluatie JILIB- en KSGSportimpulsprojecten ronde 2018: verdiepende interviews met uitvoerende professionals, deelnemende kinderen en hun ouders. Utrecht: Mulier Instituut; 2020.

Ooms L, Dellas V, Gutter K, Heijnen E, van Lindert C. Borging Sportimpulsprojecten rondes 2015-2017. Utrecht: Mulier Instituut; 2020.

Heijnen E, Ooms L. Gemeente Neder-Betuwe: monitoring- en evaluatieresultaten 2015-2019. Utrecht: Mulier Instituut; 2020.

Ooms L, van Kruijsbergen M, Collard D, Leemrijse C, Veenhof C. Sporting programs aimed at inactive population groups in the Netherlands: factors influencing their long-term sustainability in the organized sports setting. BMC Sports Sci Med Rehabil. 2019;11:33.

Geidne S, Kokko S, Lane A, Ooms L, Vuillemin A, Seghers J, Koski P, Kudlacek M, Johnson S, van Hoye, $A$. Health promotion interventions in sports clubs: can we talk about a settingbased approach? A systematic mapping review. Health Educ Behav. 2019;46(4):592-601.

Brandsema A, Ooms L. Evaluatie 'Bewegen en meedoen in Ooij': "plezier en ontmoeten is het cement tussen onze onderdelen." Utrecht: Mulier Instituut; 2018.

Ooms L, Dellas V, van Lindert C. Bekendheid en inzet van erkende sport- en beweeginterventies: een verdiepend onderzoek onder (potentiële) gebruikers. Utrecht: Mulier Instituut; 2018.

Ooms L, van Stam W, Preller L, Hiemstra A. Monitoring en evaluatie inzet buurtsportcoach (presentatiesheets). Utrecht/Ede: Mulier Instituut/Kenniscentrum Sport; 2018.

Dellas V, Ooms L. Procesevaluatie Denken en Doen: de waardering en ervaring van de docenten en deelnemers met de bridge-interventie van de Nederlandse Bridge Bond. Utrecht: Mulier Instituut; 2018.

Ooms L, Dellas V, van Lindert C. Borging Sportimpulsprojecten ronde 2014. Utrecht: Mulier Instituut; 2018.

Ooms L, Leemrijse C, Collard D, Schipper-van Veldhoven N, Veenhof C. Characteristics of insufficiently active participants that benefit from health-enhancing physical activity (HEPA) promotion programs implemented in the sports club setting. BMC Public Health. 2018;18:685. 
Ooms L. Literatuuronderzoek bewegen door kinderen met overgewicht. Utrecht: Mulier Instituut; 2017.

Nieuwenhuis-Leijenhorst M, Steenbergen J, Scholten V, Ooms, L. Sportimpuls, meting 2017: verdiepingsonderzoek naar de lokale uitvoering en opbrengsten van de Sportimpuls projecten. Ede/Utrecht: Kennispraktijk/Mulier Instituut; 2017.

Ooms L, Scholten V, van Lindert C. Borging Sportimpulsprojecten rondes 2012 en 2013. Utrecht: Mulier Instituut; 2017.

Ooms L, Veenhof C, de Bakker DH. The Start2Bike program is effective in increasing healthenhancing physical activity: a controlled study. BMC Public Health. 2017;17:606.

Ooms L, Hiemstra A, Kalkman I. Factsheet Succesvol sportaanbod voor 50-plussers binnen de sportvereniging: werkzame elementen. Ede: Kenniscentrum Sport; 2016.

Ooms L. Sportmatch inwoners met een beperking: provincie Noord-Brabant. Bunnik: Onbeperkt Sportief; 2015.

Ooms, L. Sportmatch inwoners met een beperking: provincie Gelderland. Bunnik: Onbeperkt Sportief; 2015.

Leemrijse CJ, de Bakker DH, Ooms L, Veenhof C. Collaboration of general practitioners and exercise providers in promotion of physical activity: a written survey among general practitioners. BMC Fam Pract. 2015;16:96.

Ooms L, Veenhof C, Schipper-van Veldhoven N, de Bakker DH. Sporting programs for inactive population groups: factors influencing implementation in the organized sports setting. BMC Sports Sci Med Rehabil. 2015;7:12.

Ooms L, Veenhof C, Leemrijse C. Evaluatie programma Effectief Actief. Utrecht: NIVEL; 2015.

Ooms L, Veenhof C, de Bakker DH. Effectiveness of Start to Run, a 6-week training program for novice runners, on increasing health-enhancing physical activity: a controlled study. BMC Public Health. 2013;13:697.

Ooms L, Veenhof C. Evaluatie Pilotfase concepten Sport en Bewegen in de Buurt 2011-2012: resultaten procesevaluatie en monitorstudie. Utrecht: NIVEL; 2013.

Ooms L, Veenhof C. Procesevaluatie van de methodiek sCOOLsport. Utrecht: NIVEL; 2012. 
Ooms L, Veenhof C. Aanvullende NASB sportprojecten: inzicht in kenmerken deelnemers en veranderingen in beweeggedrag. Utrecht: NIVEL; 2012.

Ooms L, Veenhof C. Evaluatie van de implementatiefase van het Nationaal Actieplan Sport en Bewegen, setting sport: resultaten proces- en effectevaluatie. Utrecht: NIVEL; 2011.

Leemrijse CJ, Ooms L, Veenhof C. Evaluatie van kansrijke programma's om lichaamsbeweging in de bevolking te bevorderen: fase 3. Utrecht: NIVEL; 2011.

Ooms L, Veenhof C. Vaker op de fiets met Fiets-Fit! Factsheet Paramedische zorg, Sport bewegen en gezondheid. Utrecht: NIVEL; 2010.

Ooms L, Veenhof C. Meer bewegen met Start to Run. Factsheet Paramedische zorg, Sport bewegen en gezondheid. Utrecht: NIVEL; 2010.

Leemrijse CJ, Ooms L, Veenhof C. Denken en Doen zet ouderen samen in beweging. Factsheet Paramedische zorg, Sport bewegen en gezondheid. Utrecht: NIVEL; 2010.

Leemrijse CJ, Ooms L, Veenhof C. Evaluatie van kansrijke beweegprogramma's om lichaamsbeweging in de bevolking te bevorderen: fase 2. Utrecht: NIVEL; 2009.

Zuidgeest M, Ooms L, van Boheemen C, Vervloet M, van Dijk L. Evaluatie van het programma Farmaco Keten Ontwikkeling. Utrecht: NIVEL; 2009.

Ooms L, Veenhof C. Evaluatie van kansrijke interventies om lichaamsbeweging in de bevolking te bevorderen. Utrecht: NIVEL; 2008. 

